

\section{Editorial Board}

\section{Editor in Chief}

Mark Zilberman, MSc, Shiny World Corporation, Toronto, Canada

\section{Scientific Editorial Board}

Viktor Andrushhenko, PhD, Professor, Academician of the Academy of Pedagogical Sciences of Ukraine, President of the Association of Rectors of pedagogical universities in Europe

John Hodge, MSc, retired, USA

Petr Makuhin, PhD, Associate Professor, Philosophy and Social Communications faculty of Omsk State Technical University, Russia

Miroslav Pardy, PhD, Associate Professor, Department of Physical Electronics, Masaryk University, Brno, Czech Republic

Lyudmila Pet'ko, Executive Editor, PhD, Associate Professor, National Pedagogical Dragomanov University, Kiev, Ukraine

\section{IntellectualArchive, Volume 9, Number 2}

\begin{tabular}{|c|c|}
\hline $\begin{array}{l}\text { Publisher } \\
\text { Address }\end{array}$ & $\begin{array}{l}\text { Shiny World Corp. } \\
9200 \text { Dufferin Street } \\
\text { P.O. Box } 20097 \\
\text { Concord, Ontario } \\
\text { L4K 0C0 } \\
\text { Canada }\end{array}$ \\
\hline $\begin{array}{l}\text { E-mail } \\
\text { Web Site } \\
\text { Series } \\
\text { Frequency } \\
\text { Month } \\
\text { ISSN } \\
\text { DOI } \\
\text { Trademark }\end{array}$ & $\begin{array}{l}\text { support@IntellectualArchive.com } \\
\text { www.IntellectualArchive.com } \\
\text { Journal } \\
\text { Every } 3 \text { months } \\
\text { April - June } 2020 \\
1929-4700 \\
10.32370 / I A 2020 \text { 06 } \\
\text { IntEllectualArchiveTM }\end{array}$ \\
\hline
\end{tabular}

(C) 2020 Shiny World Corp. All Rights Reserved. No reproduction allowed without permission. Copyright and moral rights of all articles belong to the individual authors. 


\section{Intellectual Archive}

Volume 9

Number 2

April/June 2020

Table of Contents

COVID-19

\section{Zilberman}

J.C. Hodge

M. Pardy

\section{N. Pavlovska, V. Atamanchuk, M. Kulyk, H. Strilets, O. Kofanova Y. Komarynska, N. Pavlovska, E. Svoboda, A. Symchuk, O. Kofanova}

G. Negai

L. Ostrolutska

D. Bybyk

V. Budak, S. Zaskaleta, O. Oleksyuk
Adding a Water-Repellent Barrier to Low-Cost or Home-Made Masks and Respirators Using Aerosols

Physics

Nature of Beginning

The Zitterbewegung of Planets and Moon in the String Gravity

\section{Law}

Hologram Forensics on Forgery in Civil and Criminal Proceedings

Historiography of the Armed Terrorism Prevention in the Criminal Legislation of Ukraine

\section{Architecture}

The Notion of Tolerance of the Architectural Form

\section{Social Work}

Public Movements in Formation of Rehabilitation Services for Youth and Children with Disability: Advantages and Risks

Organizational and Pedagogical Conditions of Future Social Workers' Professional Training for Social Leadership

\section{Education}

System of Spiritual Values of Modern Youth: the European Dimension 66 


\section{Table of Contents (continued)}

D. Nefyodov

T. Tutova

A. Boiko

N. Slyusarenko,

M. Soter

D. Khrapach,

H. Krasylnykova

O. Kan

A. Liubas

V. Kuzmenko,

G. Chukh

Zhang Jiangan

B. Demchyna, I. Kunanets
The Use of Local Lore Materials at Lessons of History of Ukraine in Secondary

General Education Institutions

Future Primary Teacher's Model Preparation for Collaboration with Heterogeneous Groups of Students

Innovative Processes in Modernization of Non-Formal Education: Focus on

Creative Self-Expression of Primary Schoolchildren

The Webquest as a Means of Improving the Efficiency of Students' Foreign

Language Training of Ukrainian Technical Institutions of Higher Education

(Beginning of the 21 st Century)

Content and Structure of Bachelor's Training within the Dual Education System:

Ukrainian and German Experience

Learning and Teaching Support Materials for Training Philology Students in Ukrainian Universities from 1850 to 1917

Content of Building Intercultural Competence in Future Specialists of Combat and Operational Support

Content Transformation of Improvement of Qualification of the Teachers of Philological Disciplines in the Kherson Region (1944-1958)

The Methods on Forming the Worldview Culture of Future Music Teachers in the Process of Piano Learning

\section{Engineering}

Commissioning of Sole Micropiles with Foundation Slabs into Compatible

Construction During the Foundation Strengthening of an Existing Building

Manuscript Guidelines

172

\section{Toronto, April/June 2020}


DOI: 10.32370/IA_2020_06_1

\title{
Adding a Water-Repellent Barrier to Low-Cost or Home-Made Masks and Respirators Using Aerosols
}

\author{
Mark Zilberman, M.Sc., \\ Shiny World Corporation (Canada)
}

\begin{abstract}
In connection with the COVID-19 pandemic in the spring of 2020, an unprecedented situation has developed with masks and respirators protecting respiratory organs. The purpose of the mask (respirator) is to protect the person from drops of liquid that the COVID-19 carrier spreads around themselves when coughing/sneezing. Unfortunately, low-cost, non-professional and home-made masks and respirators let in a significant amount of droplets. An ideal solution would be to treat a cheap or even a makeshift mask or respirator to make it water-repellent (like a rubber respirator), but to still allow the wearer of the mask the ability to breathe and talk freely. Fortunately, this dilemma was long and successfully solved by manufacturers of products to protect clothes and furniture from spills and liquids.

This article describes experiments that tested the "Tana ${ }^{\circledR}$ Style $16 \AA$ Protector" aerosol manufactured by JOHNSON \& SON, INC for the installation of a water-repellent barrier on household water-permeable respirators and cotton fabric. The methodology and photographs of the passage of a jet of water through a household mask and cotton fabric are given before and after "Tana ${ }^{\circledR}$ Style $16 \AA$ Protector" aerosol treatment. Aerosols have been shown to be highly effective for installing a water-repellent barrier on water-permeable respirators and cotton fabric. It is understood that other countries may have similar aerosols under different names. The breathing through a waterrepellent barrier, as well as possible long-term effects, are discussed.
\end{abstract}

Keywords: COVID-19, pandemic, mask, respirator, aerosol, waterproof, water-repellent

In connection with the COVID-19 pandemic in the spring of 2020, an unprecedented situation has developed with masks that protect the respiratory system from a coughing and sneezing. The shortage, and lack of professional masks and respirators, led to the production of home-made and/or unprofessional masks that did not pass any testing. The general approach is "a home-made mask is better than none".

From the point of view of doctors, the goal of the mask (respirator) is to protect people from drops of liquid that the COVID-19 carrier spreads around itself when coughing or sneezing.

From the point of view of an individual wearing a mask (respirator), the goal of the mask (respirator) is to protect the wearer from the drops of liquid that other people circulate around them.

Both of these goals are achieved only if the mask (respirator) does not pass liquid droplets of small size. Unfortunately, regular professional and especially non-professional masks (respirators) pass a certain amount of liquid. Only high-quality professional respirators made of rubber or plastic truly shield fluid droplets. However, they are expensive (more than \$100), they are much more difficult to manufacture, they are few, and accordingly they were quickly sold out and ceased to be available to ordinary customers.

Therefore, the ideal solution would be to treat a cheap or even home-made mask to make it waterrepellent (to function like a rubber respirator), but at the same time to allow the wearer of the mask to breathe and talk freely. It would seem that this indescribable task was long and successfully 
solved by manufacturers of products that protect clothing and furniture from spills and liquids. Companies such as "3M" [1], "S.C. JOHNSON \& SON, INC "[2] and others have long produced aerosols, which, after settling on the fabric, make it water-repellent and, at the same time, let air through. These two companies are popular in the USA and Canada. It is understood that other countries may have similar aerosols under different names.

The author of the article did the experiments presented in this article to test the effectiveness of these products on cheap water-permeable respirators and cotton fabric.

\section{Un-treated materials}

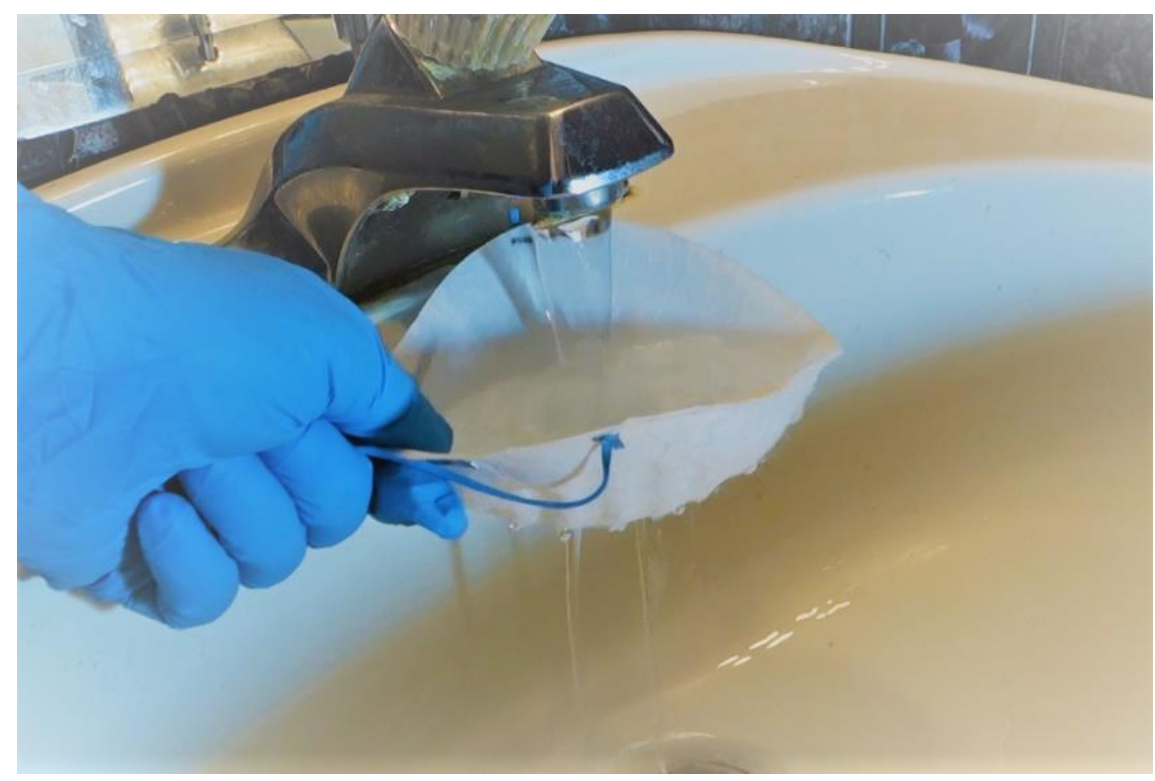

\section{Photo (1)}

Photo (1) illustrates the passage of water through an un-treated household respirator.

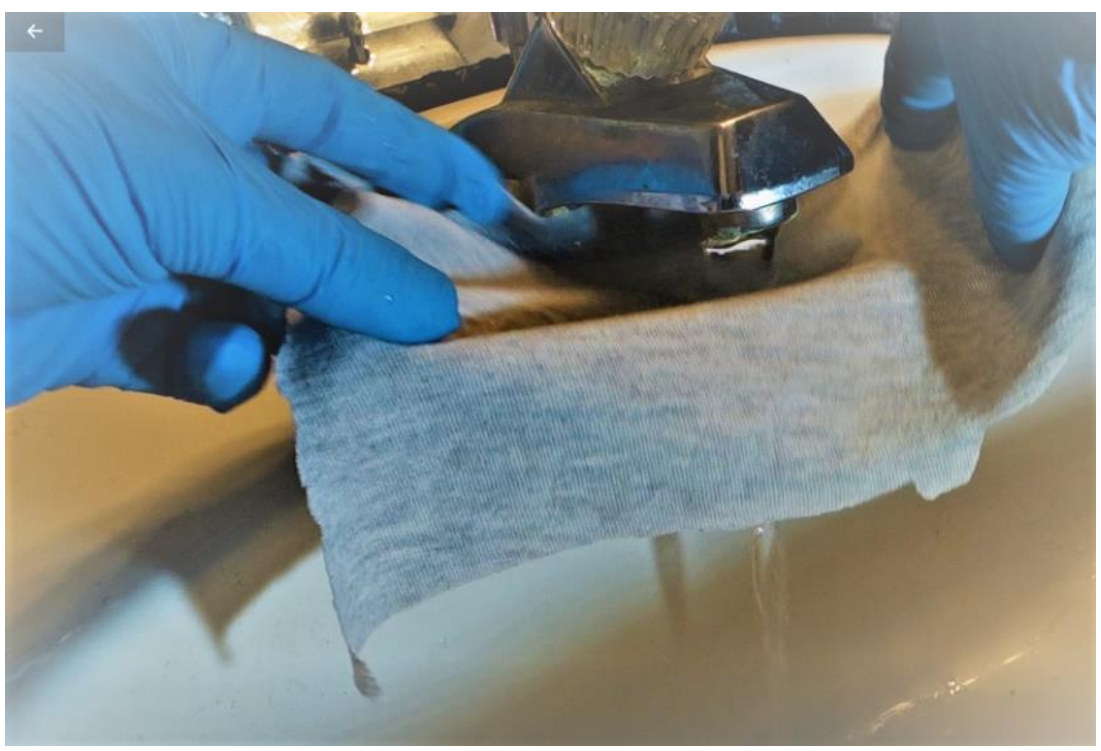

Photo (2) 
Photo (2) illustrates the passage of water through un-treated cotton fabric.

It can be seen that fabric as well as cheap household respirator let water pass through easily.

\section{Treatment}

As a treating agent, the spray "Tana ${ }^{\circledR}$ Style $16 \circledR$ Protector" manufactured by JOHNSON \& SON, INC. was used. The outer surface of the household moisture-permeable respirator (as well as the cotton fabric) was treated from an aerosol can for 10 seconds from a distance of 20-25 centimeters (as recommended by the "Tana ${ }^{\circledR}$ Style 16® Protector"). After that, the material was dried for 15 minutes and then treated with "Tana ${ }^{\circledR}$ Style $16 \AA$ Protector" one more time.

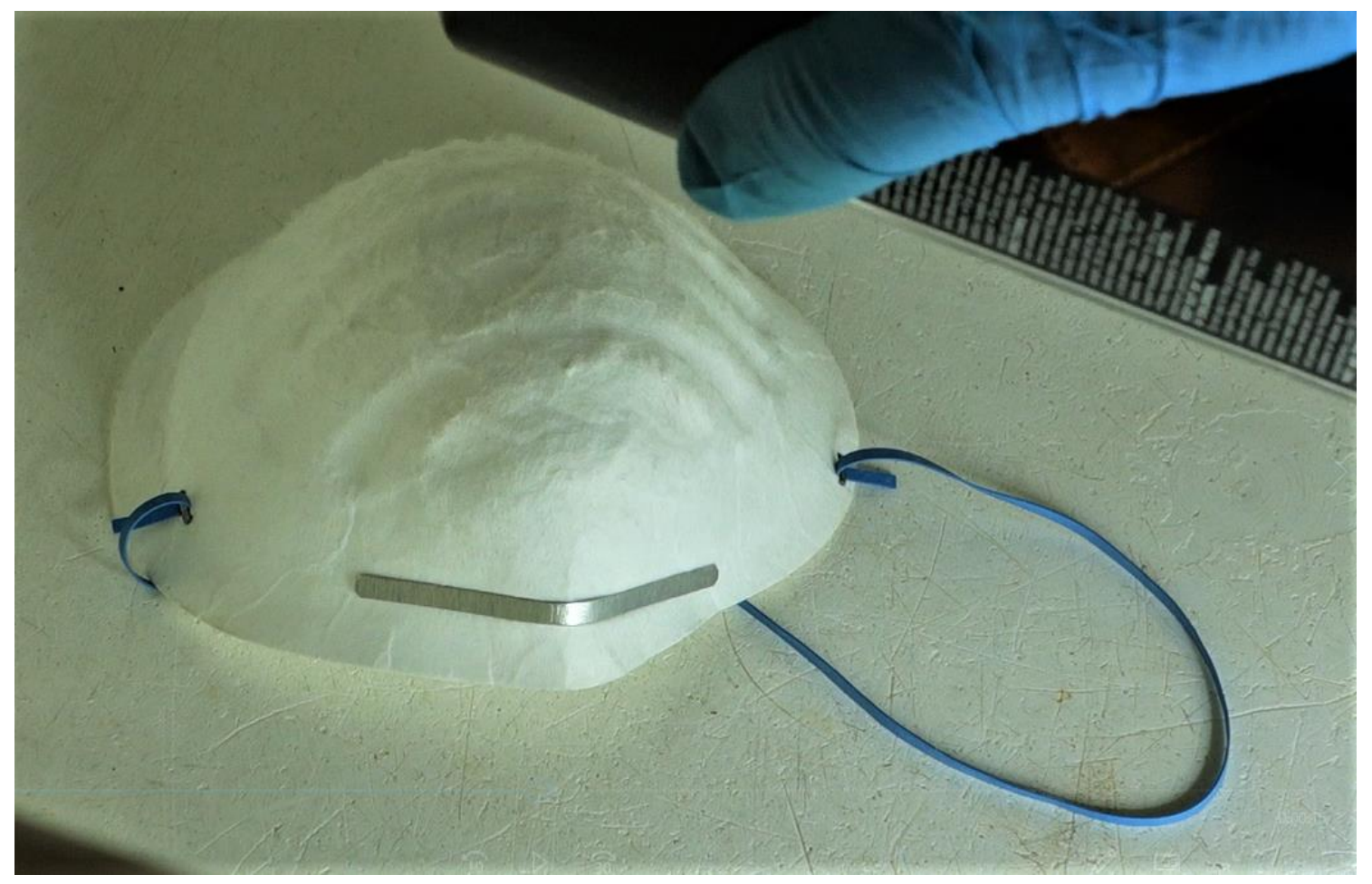

\section{Photo (3)}

Photo (3) illustrates the treatment of a household liquid-permeable respirator using a "Tana ${ }^{\circledR}$ Style 16® Protector" aerosol can.

\section{Result of treatment}

Photos (4) and (5) illustrate the absence of water passing through a treated household waterpermeable respirator. Despite the fact that only the external side of the respirator was treated, water stopped passing through it. 


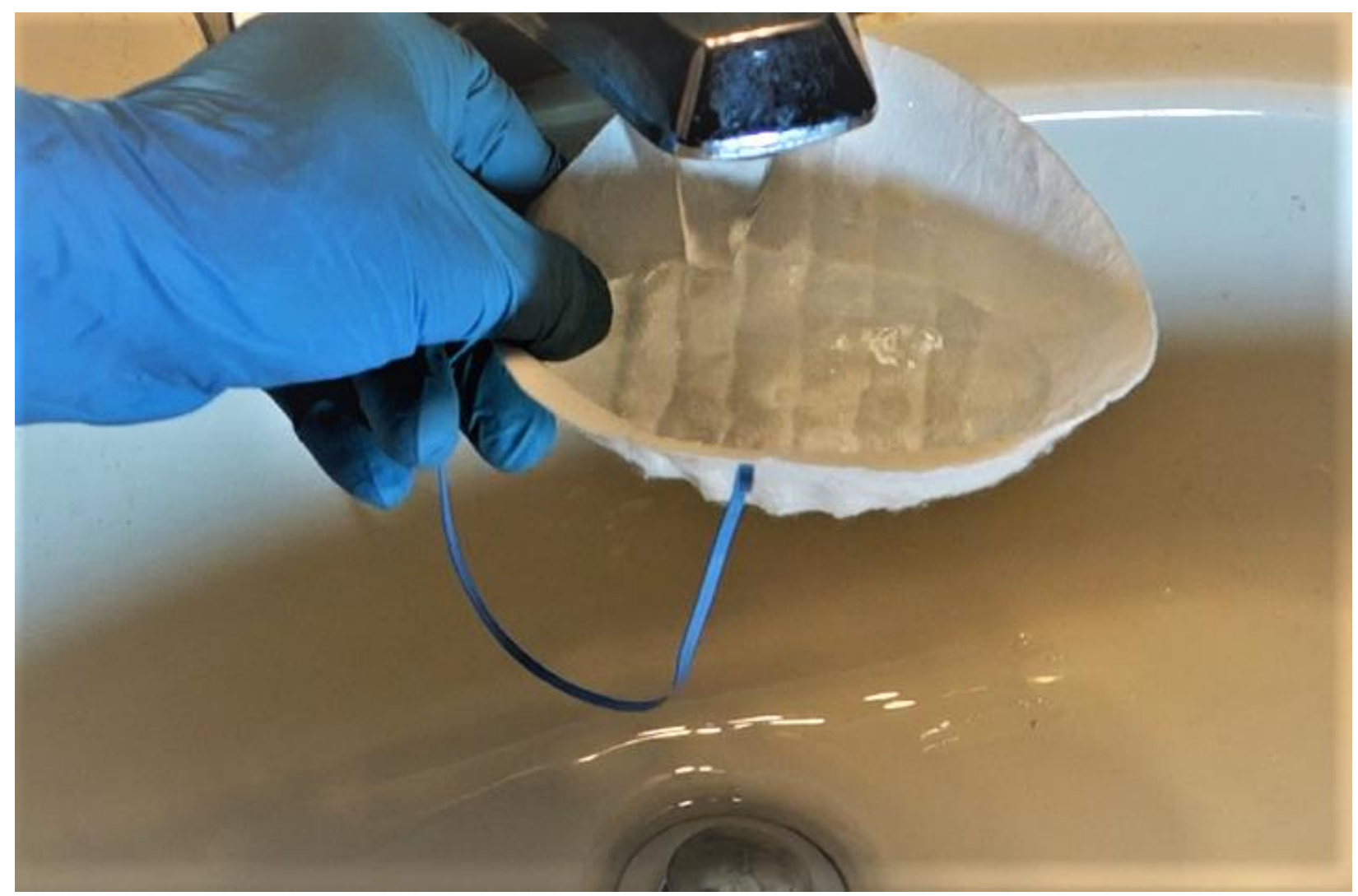

Photo (4)

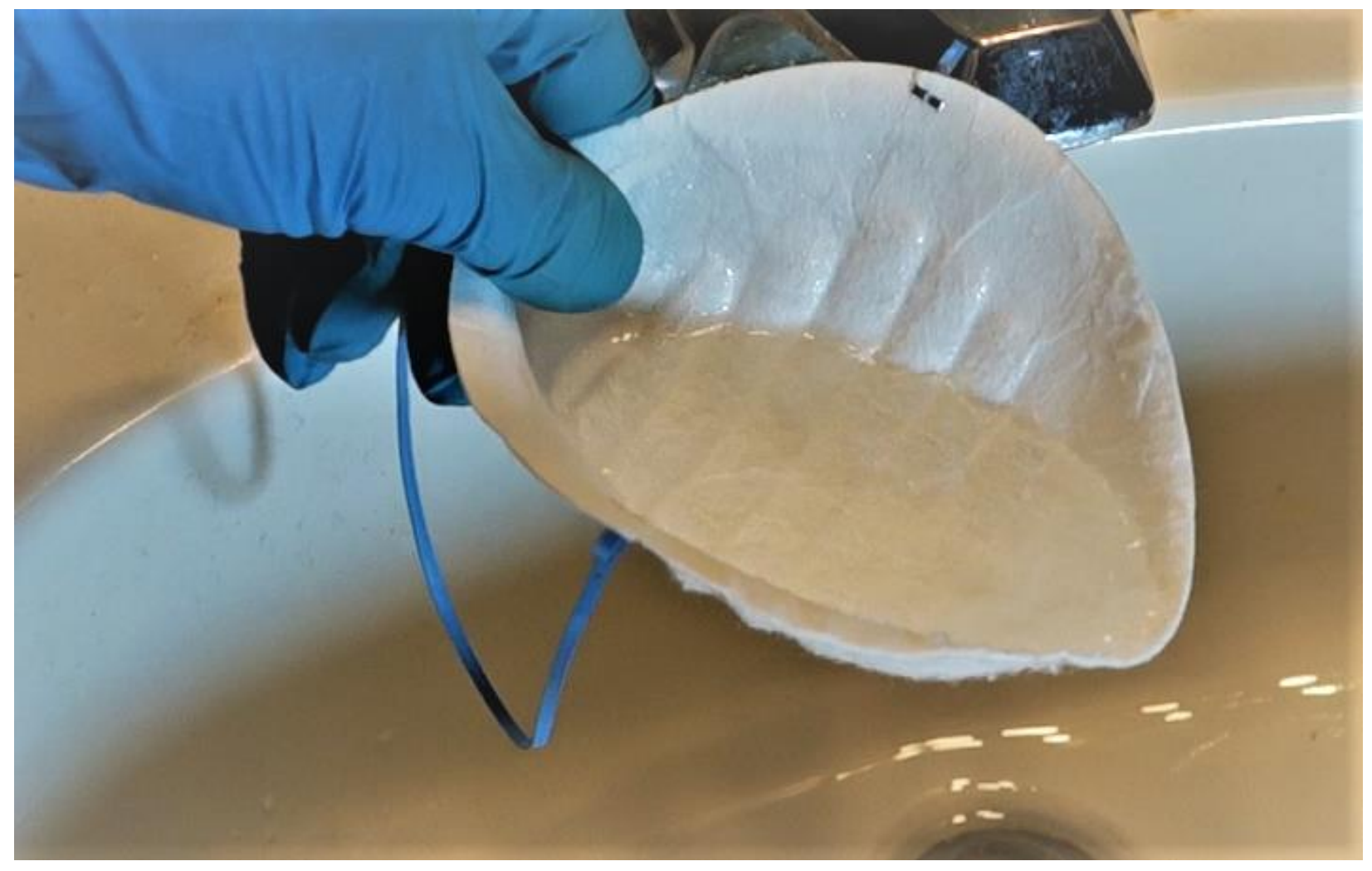

Photo (5) 
The same result was tested on treated cotton fabric. Photos (6) and (7) illustrate the absence of water passing through the treated cotton fabric.

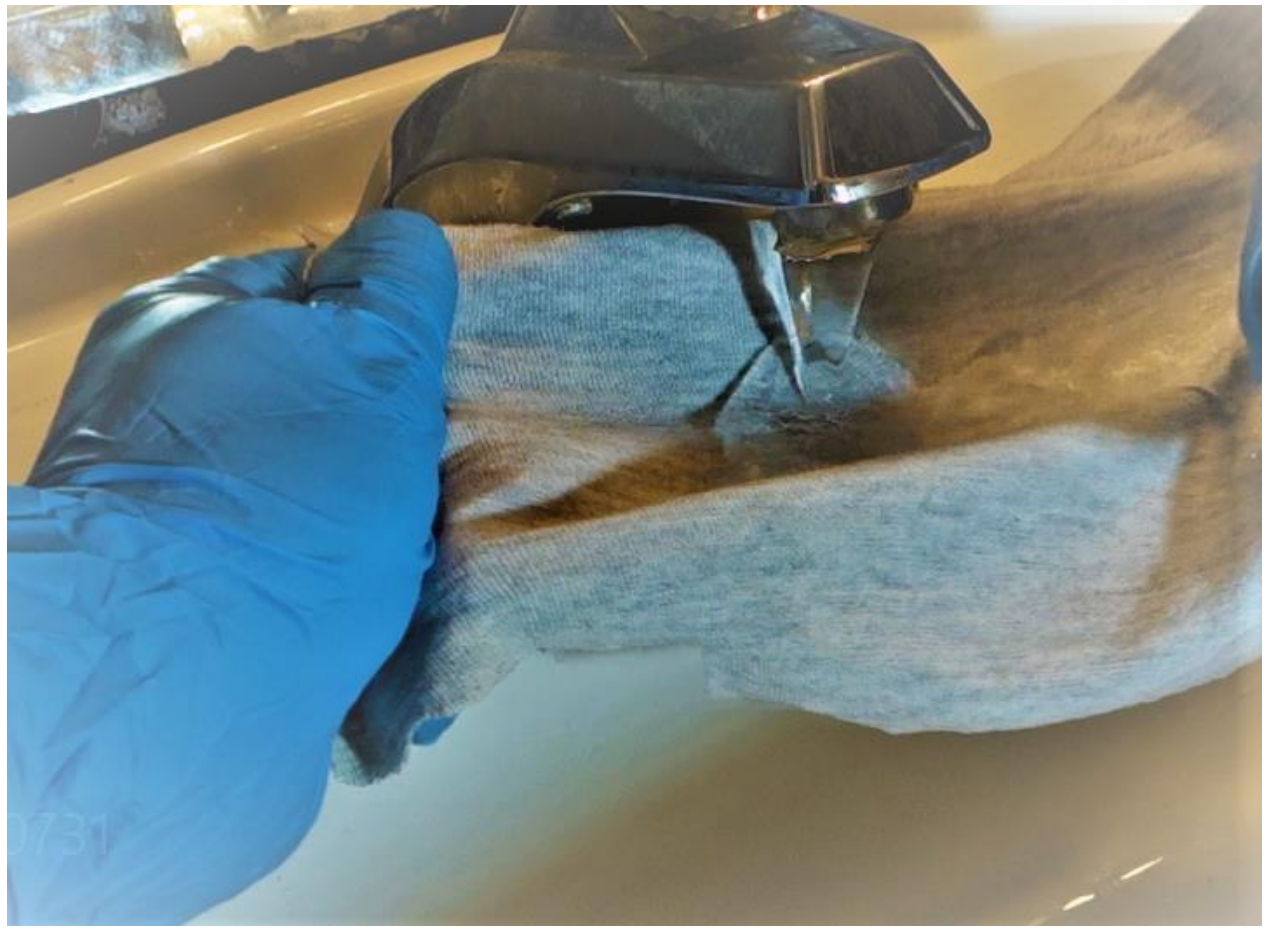

Photo (6)

In the photograph (7) it is seen how water spills over the edge of the fabric but does not pass through the fabric itself.

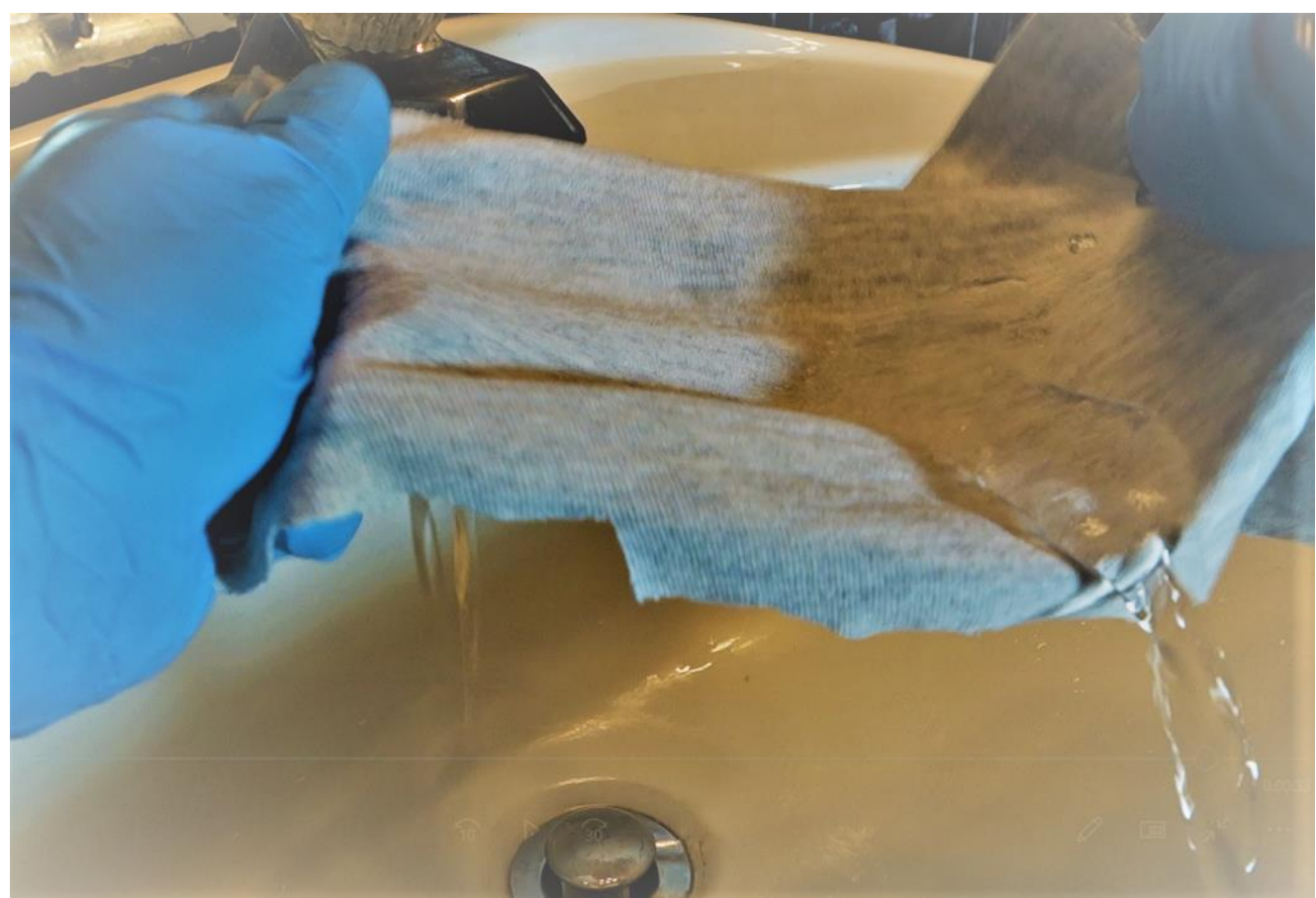

Photo (7) 


\section{Discussion}

1. The purpose of treatment of the mask (respirator) is not protection against the COVID-19 virus. Since air passes through the material both before and after processing, the virus can also pass through it. But it will only pass if it "hangs" in the air as an aerosol. And in this case, its concentration is small and at the moment there is no evidence that the aerosol infection of COVID19 can lead to illness.

The aim of the treatment is to significantly improve the protection of cheap / homemade masks and respirators from the penetration of drops of cough or saliva, which can carry COVID-19 in a pathogenic concentration.

2. Does the treated material have enough air to breathe? To answer this question, the author spent several hours in a treated respirator indoors and outdoors. No problems with a lack of air were noted. The author also did not note condensation of moisture contained in the exhaled air on the inner surface of the treated respirator. It seems that moisture came out with the air, and at the same time did not settle on the walls of the respirator.

3. After processing, the material retains the smell of the "Tana ${ }^{\circledR}$ Style 16 ${ }^{\circledR}$ Protector" aerosol for approximately one day. It is not recommended to use a treated respirator / mask before this time, so that the "Tana ${ }^{\circledR}$ Style 16® Protector" aerosol molecules do not enter the lungs.

4. At the moment, there is no data on the long-term effect of breathing through the treated tissue. However, no one can guarantee that breathing through aerosol-treated material is harmless. Potentially, it can lead to diseases of the respiratory tract and / or lungs. Research of the long-term effects must be done by the health professionals and is out of the author's competency. However, choosing between the potential unexplored danger and the actual significant protection of homemade masks from the penetration of liquid droplets - everyone makes the choice himself.

\section{Conclusion}

After reading the article, the idea of adding a water-repellent barrier on cheap or home-made masks and respirators by spraying them with aerosols that protect clothing and furniture from spills and liquids seems self-evident. Therefore, it would be appropriate to quote the parable of the Egg of Columbus [3]

An egg of Columbus or Columbus' egg (Italian: uovo di Colombo ['wo'vo di ko 'lombo]) refers to an idea or discovery that seems simple or easy after the fact. The expression refers to an apocryphal story, dating from at least the 15th century, in which it is said that Christopher Columbus, having been told that finding a new trade route was inevitable and no great accomplishment, challenges his critics to make an egg stand on its tip. After his challengers give up, Columbus does it himself by tapping the egg on the table to flatten its tip.

The story is often alluded to when discussing creativity. ... It also shows that anything can be done by anyone with the right set of skills; however, not everyone knows how to do it.

\section{References}

1. https://www.scotchgard.com/3M/en_CA/scotchgard-ca/how-to-use-fabric-upholsteryprotector/ 
2. https://www.tana.com/en-ca/products/tana-style-16-protector

3. https://en.wikipedia.org/wiki/Egg_of_Columbus 


\title{
Nature of beginning
}

\author{
J.C. Hodge ${ }^{1 *}$ \\ ${ }^{1}$ Retired, 477 Mincey Rd., Franklin, NC, 28734
}

\begin{abstract}
The Big Bang's model of the beginning of our universe is inconsistent with all other forms of beginning in the universe. The Scalar Theory of Everything (STOE) posits the general principles of all the components of the universe also apply to the universe as a whole. Therefore, the universe began as a single source, grew, and multiplied.
\end{abstract}

keywords: STOE, Theory of Everything, QSSC

\section{Introduction}

The Scalar Theory of Everything (STOE) posits the general principles of all the components of the universe also apply to the universe as a whole. This principle was used to relate the fine-tuning of parameters in the universe and the CMB temperature of the universe (Hodge 2006).

The major difference between the standard Big Bang cosmology (BB) model and the Quasi-Steady State Cosmology (QSSC) model is that matter creation of a "C-field" occurs continuously in the center of galaxies (Sources) with energy conservation. The resulting ejection increases the volume of the universe such that the Perfect Cosmological Principle (the universe looks the same in density and time) applies. The QSSC is a Machian theory. The basic observations that are currently interpreted as supporting the BB can be interpreted as supporting the QSSC, also (Hoyle et al. 2000, p. 321). The QSSC suggests no initial singularity. The creation field controls the expansion of the universe such that the density remains approximately constant with periods of expansion and contractions. The physical control mechanism is unexplained. Although debated, the QSSC has a better model than BB for QSOs [data from Arp (1998)], for the large scale structure of the universe, and for the abundance of light elements.

Both the BB and QSSC have many unexplained cosmological anomalies and neither suggests correspondence with the world of Quantum Mechanics (the double slit experiment). The STOE is a model that starts with the QSSC, that adds Sink galaxies, and that suggests two components of the stuff of the universe emerge into the universe.

*E-mail: jchodge@frontier.com 


\section{REFERENCES}

Arp (1998) suggested Seyfert galaxies are Quasar factories and were much closer than redshift values indicated. That is, QSOs are daughter galaxies and are growing to become new galaxies.

This paper suggests the nature of beginning of life, of planets, of suns, and of galaxies is also the nature of the beginning of the universe.

The physics observations of life include a beginning and an end. The life of a bacterial cell begins with cell division. The half-cell then gathers material from the environment to become a full-cell which then reproduces to form more cells.

Multi-cellular beings begin by half-cells uniting to form a single cell of the new being. The new cell then gathers material from the environment to become a new being which then reproduces to form more, similar beings.

Hydrogen in the outer regions of a spiral galaxy combine to form stars which then move inward. Planets start from small chunks of matter that combine with other asteroids.

The QSSC and the STOE suggest the universe began as a single source of the components of the universe and grew by the matter forming around the source to form the spiral galaxy. The number of sources reproduced by a method suggested by Halton Arp (1998). The STOE suggest some of the matter escapes the spiral galaxy and condenses to form sinks of elliptical galaxies in galaxy clusters. Thus, the difference between spiral and elliptical galaxies is explained (Binney, J. \& Merrifield, M. 1998).

The STOE suggest this pattern of starting small and growing is repeated for the universe as a whole. Therefore, the concept of starting big and then running down of the Big Bang universe model is incorrect.

\section{References}

Arp, H., 1998, Seeing Red: redshifts, cosmology and academic science, (ISBN 0-9683689-0-5, Apeiron, Montreal, Canada)

Binney, J. \& Merrifield, M., 1998, Galactic Astronomy, (ISBN 0-691-00402-1, Princeton Univ. Press, Princeton, NJ, USA).

Hoyle, F., Burbidge, G., \& Narklikar, J.V., 2000, A different approach to cosmology, (ISBN 9781469987361, Cambridge Univ. Press, Cambridge).

Narklikar, J.V. et al. 2015. Mon. Not. Astron. Soc. Physics Letters A 250, 1.

Hodge, J.C., 2006, Scalar potential model of the CMB radiation temperature, arXiv:astro-ph/0603140.

Hodge, J.C., 2018, STOE replaces relativity and quantum mechanics, (ISBN 978-613-9-91465-4, available through Amazon.com). 


\title{
The Zitterbewegung of planets and Moon in the string gravity
}

\author{
Miroslav Pardy \\ Department of Physical Electronics \\ and \\ Laboratory of Plasma physics \\ Masaryk University \\ Kotlářská 2, 61137 Brno, Czech Republic \\ e-mail:pamir@physics.muni.cz
}

May 3, 2020

\begin{abstract}
The string model of gravitational force was proposed by author 40 years ago (Pardy, 1980; 1996). In this model the string forms the mediation of the gravitational interaction between two gravitating bodies. It reproduces the Newtonian results in the first-order approximation and it predicts in the higher-oder approximations the existence of oscillations of the massive bodies interacting by the string. In case of the Moon it can be easily verified by NASA laser measurements.
\end{abstract}

PACS numbers: 03.20, 03.40, 02.30.J

\section{Introduction}

It is well known from the history of physics that the problem of action-at-a-distance was for the first time seriously considered by Newton, in his letter to Bentley (Bentley, 1692; 1838), which is cited in "Principia Mathematica" (Newton, 1966) and analysed in the Stanford Encyclopedia of Philosophy (2006).

Instead of resolution of this problem Newton suggested the phenomenological theory of the gravitational force, where there exists no answer concerning the dynamics, or, the mechanism of action-at-a-distance. Newton himself was awared that it necessary exists some mediation of interaction between two bodies at the different points in space because he has written (Newton. 1966): "It is inconceivable, that inanimate brute matter, should without the mediation of something else which is not material, operate upon and affect other matter without mutual contact .. ". In other words, the crucial notion in the Newton speculation is the mediation between two bodies. Now, we can say that Newton considered the string model of gravity because string model of gravity is the natural result of Newton scientific intuition.

The problem of mediation of the gravitational force between two bodies 1 and 2 can be analysed by the way which forms the serious motivations for reconsidering the problem od action-at-a-distance. If we trasmit body 1 with mass $m$ from one point to other during very short time interval, then the gravitational force acting to the second body 2 with 
mass $M$ necessary changes. However, in case that the second body is far from the first one, then much time elapses before it receives the gravitational input. The question is, where is the gravitational perturbation when the first body after short motion is yet in rest and the second one has no information on the motion on the first body?. It is evident the gravitational input is between body 1 and 2 on the line or string connecting body 1 with the body 2 . The string is the Newton medium which transmits the gravitational force from one body to the other one.

It is well known that Newtonian theory is successful in its domain of validity, and general relativity is successful in accounting for the discrepancies between observed gravitational data and the Newtonian theory, as well as in resolving its problem of compatibility with special relativity. Nevertheless, Newton theory does not involve the string tension which is logical necessary as we have seen.

By analogy with the mechanical situation we will suppose the model where the atractive force between two bodies is transmitted as tension in the fictitious string connecting the one body with the another one. Then, the theoretical problem is to show that such model works and gives not only the old results but new results which cannot be derived from the original Newton law.

We will consider the string, the left end of which is fixed at the beginning of the coordinate system and mass $m$ is fixed on the right end of the string. The motion of the system string and the body with mass $m$ is the fundamental problem of the equations of the mathematical physics in case that the tension is linearly dependent on elongation (Tikhonov et al., 1977). We will show that it is possible to represent the Newton gravitational law by the string with the nonlinear tension in the string. Because of the strong nonlinearity of the problem the motion of the string and the body can be solved only approximately. In the following text, we will give the aproximative solution of the classical two-body problem and then we obtaine the string solution of this problem.

\section{The classical two-body problem}

Let us consider two bodies 1 and 2 with masses $M$ and $m$, where $M \gg m$. The body 1 is supposed to be fixed at the origin of the coordinate system and the body 2 is for the simplicity moving in the interval

$$
(R-\delta, R+\delta)
$$

where $\delta \ll R$, which corresponds to the motion of planets of our Sun system. The Newton law

$$
F=-\kappa \frac{M m}{r^{2}}
$$

can be obviously expressed in the interval (1) approximatelly as

$$
F \approx a \eta+b ; \quad(-\delta, \delta) \ni \eta
$$

where

$$
a=\frac{2 \kappa M m}{R^{3}}, \quad b=-\frac{\kappa M m}{R^{2}} .
$$


The motion of body 2 in the gravitational potential of body 1 is described by equation (Landau et al., 1965)

$$
m \ddot{r}=-\kappa \frac{M m}{r^{2}}+\frac{J^{2}}{m r^{3}},
$$

where $J$ is the angular momentum of body 2 . In the inerval $(-\delta, \delta)$ we can write

$$
r(t)=R+\eta(t)
$$

and using approximation

$$
\frac{1}{(R+\eta)^{2}} \approx \frac{1}{R^{2}}\left(1-\frac{2 \eta}{R}\right), \quad \frac{1}{(R+\eta)^{3}} \approx \frac{1}{R^{3}}\left(1-\frac{3 \eta}{R}\right)
$$

we get after insertion of eq. (6) into eq. (5):

$$
\ddot{\eta}+\omega^{2} \eta=\lambda
$$

where

$$
\begin{gathered}
\omega^{2}=\frac{3 J^{2}}{m^{2} R^{4}}-\frac{2 \kappa M}{R^{3}} \\
\lambda=\frac{J^{2}}{m^{2} R^{3}}-\frac{\kappa M}{R^{2}} .
\end{gathered}
$$

For the circle motion we have $J=m \omega R^{2}, r=R$ and from eqs. (9) and (10) it follows:

$$
\omega=R^{-3 / 2}(\kappa M)^{1 / 2} ; \quad \lambda=0 .
$$

It is easy to see that the solution of eq. (8) is of the form:

$$
\eta(t)=\Lambda \cos (\omega t+\vartheta)+\frac{\lambda}{\omega^{2}}
$$

where $\Lambda$ and $\vartheta$ are constants involving the initial conditions of motion of the body 2 .

So far we have supposed no dynamics of mediation of the interaction between body 1 and 2. However, only the model involving the mechanism of mediation of interaction can describe logically consistent reality and explain the Newton puzzle. Let us try to elaborate the consistent and realistic model which describes the mechanism of mediation.

\section{The string mediation of interaction}

In this section we will solve the motion of a body 2 at the end of the string on the assumption that the tension in the string is nonlinear and it generates the Newton law in the statical regime. We will give the rigorous mathematical formulation of such problem named the Newton-Pardy string mediation of interaction. While for the Hook tension the problem has solution by the Fourier method, in case of the nonlinear tension it is not possible to use this method.

There is no evidence about solution of this Newton-Pardy string problem in the textbooks of mathematical physics, or, in the mathematical journals. So, it seems, we solve this problem for the first time. 
Let be given the string, the left end of which is fixed at beginning and the right end is at point $l$ at the state of equilibrium. The deflection of the string element $d l$ at point $x$ and time $t$ let be $u(x, t)$ where $x \in(0, l)$ and

$$
\eta(t)=u(l, t), \quad \eta(0)=u(l, 0) .
$$

Then, the motion of body 2 is described by the motion of the right end-point of the string, when the left point is constantly fixed at the origin.

The differential equation of motion of string elements can be derived by the following way: We suppose that the force acting on the element $d l$ of the string is given by the law:

$$
T(x, t)=-E S\left(\frac{\partial u}{\partial x}\right)^{-2},
$$

where $E$ is the modulus of elasticity, $S$ is the cross section of the string. We easily derive that

$$
T(x+d x)-T(x)=2 E S\left(u_{x}\right)^{-3} u_{x x} d x .
$$

The mass $d m$ of the element $d l$ is $\varrho E S d x$, where $\varrho$ is the mass density of the string matter and the dynamical equilibrium gives

$$
\varrho S d x u_{t t}=2 E S u_{x x}\left(u_{x}\right)^{-3} d x .
$$

Putting

$$
\varrho=\varrho_{0} \frac{2}{\left(u_{x}\right)^{3}} ; \quad \varrho_{o}=\text { const } .
$$

we get

$$
\frac{1}{c^{2}} u_{t t}-u_{x x}=0 ; \quad c=\left(\frac{E}{\varrho_{0}}\right)^{1 / 2} .
$$

The last procedure was performed evidently in order to get the wave equation.

Now, let us look for the correspondence between the string tension and the Newton law. Putting $u_{t t}=0$ we get the stationary case with the solution

$$
u(x, t)=\alpha x+\beta .
$$

Because $u(0, t) \equiv 0$, we get $\beta=0$. Then $u_{x}(x, t)=\alpha$ is not dependent on $x$ and according to the definition of the tension the force is constant along the length of the string which is the same result as in the case with the Hook law.

For sufficiently big elongation we have $u(l) \gg l$ and the elongation at point $l$ is the distance of the right end of the string from the origin and it means that the force acting on the right end of the string is proportional to the minus square of the distance of the right end of the string as in the Newton gravitational law. So, we have demonstrated that the Newton gravitational force can be realized by the string, while the Newton original force involves no mediation between two bodies. Now, we can repeat the formulation of the problem dscribed in the previous section in such a way that we will use the dynamical equation (18) instead of eq. (5). So, let us approach the solution of the problem of the motion of body on the end of the string where the tension of the string is defined by equation (14). 
From (19) we have:

$$
\alpha=\frac{u(l, t)}{l} .
$$

Thus,

$$
T(l, t)=-\frac{E S l^{2}}{u^{2}(l, t)}=-\kappa \frac{m M}{u^{2}(l, t)},
$$

which gives the relation between the string constants and the gravitating parameters

$$
E S l^{2}=\kappa m M .
$$

The complete solution of eq. (18) includes the initial and boundary conditions. The simplest nontrivial initial conditions can be chosen with regard to the character of the problem and they are:

$$
u(x, 0)=\frac{R}{l} x, \quad u_{t}(x, 0)=0 .
$$

The boundary conditions are given with respect to the dynamical equation (5):

$$
u(0, t)=0, \quad m u_{t t}(l, t)=T(l, t)+\frac{J^{2}}{m u^{3}(l, t)} .
$$

The solution of the wave equation with the strongly nonlinear boundary conditions is evidently beyond the possibility of the present mathematical physics. Nor the Fourier method, nor the d'Alembert one can be used in solution of our problem. So we are forced to find only the approximation of this problem. For this goal we write:

$$
u(x, t)=\frac{R}{l} x+v(x, t),
$$

from which follows

$$
u_{x}(x, t)=\frac{R}{l}+v_{x}, \quad u(l, t)=R+v
$$

and we suppose that $v \ll R$. In such a way the intial conditions are:

$$
v(x, 0)=0, \quad v_{t}(x, 0)=0 .
$$

The approximative formulae are given in the following form:

$$
\begin{gathered}
\frac{1}{u_{x}^{2}(x, t)} \approx \frac{l^{2}}{R^{2}}-\frac{2 v_{x} l^{3}}{R^{3}}, \\
\frac{1}{u^{3}(x, t)} \approx \frac{1}{R^{3}}-\frac{3 v}{R^{4}} .
\end{gathered}
$$

So, we get the new problem of mathematical physics: the wave equation

$$
v_{t t}=c^{2} v_{x x}
$$

with the initial conditions

$$
v(x, 0)=0 ; \quad v_{t}(x, 0)=0
$$


and with the boundary conditions

$$
v(0, t)=0 ; \quad m v_{t t}(l, t)=a+b v_{x}(l, t)+d v(l, t),
$$

where we have put

$$
a=-\kappa \frac{M m}{R^{2}}+\frac{J^{2}}{m R^{3}} ; \quad b=\frac{2 \kappa M m}{R^{3}} l ; \quad d=-\frac{3 J^{2}}{m R^{4}} .
$$

The equation (30) with the initial and boundary conditions (31) and (32) represents one of the standard problems of the mathematical physics and can be easily solved using the Laplace transform (Arfken, 1967):

$$
\hat{L} u(x, t) \stackrel{d}{=} \int_{0}^{\infty} e^{-p t} u(x, t) d t \stackrel{d}{=} u(x, p) .
$$

Using (30) we get with $\hat{L} v(x, t) \stackrel{d}{=} \varphi(x, p)$ :

$$
\begin{gathered}
\hat{L} v_{t t}(x, t)=p^{2} \varphi(x, p)-p v(x, 0)-v_{t}(x, 0)=p^{2} \varphi(x, p) \\
\hat{L} v_{x x}(x, t)=\varphi_{x x}(x, p) ; \quad \hat{L} a=\frac{a}{p} ; \quad \hat{L} v(0, t)=\varphi(0, p)=0 .
\end{gathered}
$$

After elementary mathematical operations we get the differential equation for $\varphi$ in the form:

$$
\varphi_{x x}(x, p)-k^{2} \varphi(x, p)=0 ; \quad k=p / c .
$$

with the boundary condition in eq. (36).

We are looking for the the solution of eq. (37) in the form

$$
\varphi(x, p)=c_{1} \cosh k x+c_{2} \sinh k x .
$$

We get from the boundary conditions in eq. (36) $c_{1}=0$ and

$$
c_{2}=\frac{a}{p} \frac{1}{\left(m p^{2}-d\right) \sinh k l-b k \cosh k l} .
$$

The corresponding $\varphi(x, p)$ is of the form:

$$
\varphi(x, p)=\frac{a}{p} \frac{\sinh k x}{\left(m p^{2}-d\right) \sinh k l-b k \cosh k l}
$$

The corresponding function $v(x, t)$ follows from the theory of the Laplace transform as the mathematical formula:

$$
\begin{gathered}
v(x, t)=\frac{1}{2 \pi i} \oint e^{p t} \varphi(x, p) d p=\sum_{p=p_{n}} r e s e^{p t} \varphi(x, p)= \\
\sum_{p=p_{n}} \operatorname{reses}^{p t} \frac{\sinh k x}{p} \frac{\sin }{\left(m p^{2}-d\right) \sinh k l-b k \cosh k l},
\end{gathered}
$$

where $p_{n}$ are poles of the function $\varphi(x, p)$ and they are evidently given by equation

$$
\left[\left(m p^{2}-d\right) \sinh k l-b k \cosh k l\right]=0,
$$


which is equivalent with $k \rightarrow i k$ to

$$
\tan k l=\frac{-b k}{m c^{2} k^{2}+d} .
$$

In case of $k \ll 1$ we have two solutions: $p_{0}=0$ and

$$
p_{1 / 2}= \pm\left(\frac{3 J^{2}}{m^{2} R^{4}}-\frac{2 \kappa M}{R^{3}}\right)^{1 / 2}
$$

which is in agreement with eq. (9) obtained by the approximation of classical Kepler problem. Further we have got the oscillations with frequences $p_{n}$ in the higher order approximation:

$$
p_{n} \rightarrow \frac{n \pi}{l}, \quad n \gg 1
$$

At present time it is still question, how to detect these oscillations, or, if it is possible to use the experimental procedures of Braginskii et al. (1977) for the detection. The analogous situation was in quantum physics, where the zero frequences of vacuum was considered as meaningless till it was shown by Casimir that they give the atractive force between two conductive plates. It is not excluded that the Zitterbewegung of cellestial bodies will be confirmed by NASA laser experiments.

\section{Discussion}

The basic heuristical idea of this article was the string realization of the gravitational force between two bodies.

In order to realize this idea we introduced the string of the length $l$ with the nonlinear tension which generates in the statical situation the Newton law at the distances much greater then is the fundamental length of the string. We have solved this problem only approximately because at present time the exact solution is beyond possibilities of mathematics.

While the string with the Hook tension has the equilibrium state, our string is in the dynamical state.

The difficulties with the action-at-distance as is an indication of the limitation of the Newtonian theory. The general relativity solves the problem as the metric theory of the gravitational interaction. General relativity is the geometry theory of space time and as such it is the physical model based on the Riemann and Gauss ideas. In General relativity, there is the fundamental notion, the metric tensor, while in the Newton theory the basic building stone is force. In our theory, which is the dynamical version of the Hook theory of string is the basic notion the tension of the string.

The string is between any two masses and it means that universe is occupied by strings, vacuum and by bodies and particles. Our planet is for instance connected by strings with all stars in universe.

Our problem was never defined to our knowledge in the mathematical or physical textbooks, monographies or scientific journals. Thus, our approach is original.

The proposed model can be also related in the modified form to the problem of the radial motion of quarks bound by a string and used to calculate the excited states of such system. The original solution was considered by Bardeen et al. (1976; 1976) Chodos et al. (1974) and by Frampton (1975). The new analysis of such problem was performed by 
Nesterenko (1990) and author (Pardy, 2016). So, there are open way in particle physics to follow our approach. It is not excluded that the Zitterbewegung of moon will be confirmed by NASA laser systems (NASA first!).

\section{References}

Arfken, G. Mathematical Methods for Physicists (Academic Press, New York and London, 1967).

Bardeen, W. Bars, A. I., Hanson, A. J. and Peccei, R. D. (1976). Quantum Poincare' covariance of the two-dimensional string, Phys. Rev. D 13, 2364.; ibid. 14, 2193.

Bentley, R. Works of Richard Bentley, Vol. 3, pp. 210-211,; Letter of Newton to Bentley, Trinity College, Jan 17, 1692-1693.

Braginsky, V. B., Caves, C. M. and Thorne, K. S. (1977). Laboratory experiments to test relativistic gravity, Phys. Rev. D 15, 2047.

Chodos, A. and Thorn, C. B. (1974). Making the massless string massive, Nucl. Phys. 72,509 .

Frampton, P. (1975). String approaches to hadron structure, Phys. Rev. D 12, 538.

Landau, L. D. and Lifschitz, E. M. Mechanics (Nauka, Moscow, 1965). (in Russian).

Newton, I. Principia Mathematica (University of California Press, Berkeley and Loss Angeles, 1966). p. 634.

Nesterenko, V. V. (1990). On the radial motion of quarks bound by a string, Z. Phys. C - Particles and Fields 47, 111.

Pardy, M. (1980). The string model of action at a distance, University of J. E. Purkynje (UJEP), Unpublished.

Pardy, M. (1996). The string model of gravity, arXiv:gr-qc/9602007v1, 5 Feb. 1996.

Pardy, (2016). The excited mesons due to laser pulse, Intellectual Archive, 2016-09-26, ID 1764.

Tikhonov, A. N. and Samarskii, A. A. The Equations of Mathematical Physics (Nauka, Moscow, 1977). (in Russsian).

Stanford Encyclopedia of Philosophy, (2006), Newton's Philosophy. 


\title{
Hologram Forensics on Forgery in Civil and Criminal Proceedings
}

\author{
Pavlovska Nataliia \\ PhD of Juridical Sciences, Associate Professor, Professor of Department \\ of Civil Law and Process of the National Academy of Internal Affairs, Kiev, \\ Ukraine ORCID ID 0000-0003-3311-0364 wwwpav@gmail.com

\begin{abstract}
Atamanchuk Volodymyr
PhD of Juridical Sciences, Chief of Department of Forensic Support and Forensic Expertise of the National Academy of Internal Affairs, Kiev, Ukraine ORCID ID 0000-0002-1464-7871 atamanchykvlad@ukr.net
\end{abstract}

\section{Kulyk Maryna}

PhD of Juridical Sciences, Associate Professor of Forensic Support and Forensic Expertise of the National Academy of Internal Affairs, Kiev, Ukraine ORCID ID 0000-0003-1373-6749 coolss777@ukr.net

\section{Strilets Halyna}

PhD of Judicial Sciences, Associate Professor of the Departament of Law of Prydunai Branch of Private Jointstock Company «Higher Educational Institution of Interregional Academy of Personnel Management», Izmail, Ukraine

ORCID ID 0000-0002-1067-0820 galinastrelets2018@gmail.com

\section{Kofanova Olena}

PhD of Juridical Sciences, Associate Professor of Forensic Support and Forensic Expertise of the National Academy of Internal Affairs, Kiev, Ukraine ORCID ID 0000-0002-0919-7570 kofanova_alena@ukr.net

\begin{abstract}
In expert practice, the issues of identifying holograms, establishing and comparing the protective properties of HSEs (holographic security elements) are often resolved.

Hologram examination consists of three stages.

The first stage involves visual control, during the second stage the microstructure is examined, while optical parameters are measured at the third stage. At each stage, the actual HSE data are identified, which together provide an answer to the questions raised. The study of holographic comparison methods is effective both for the study of a large number of objects and for diffraction of objects similar in their structure.
\end{abstract}

Keywords: determine the type of hologram, identify security level of the hologram, expertise of copyright objects and related rights, articles, specifications, datasheet. 
Introduction Identification, classification, and diagnostic tasks are resolved in the process of studying holograms.

Identification of holograms establishes:

- compliance of the hologram with its description - specifications, datasheet;

- holograms are replicated from the matrix supplied or from another matrix;

- compliance of the provided photo templates and layouts of the logo elements reproduced by the hologram;

- matching the original primary hologram to the rainbow hologram;

- compliance of the provided software with the synthesizing program.

Classification studies:

- determine the type of hologram;

- identify security level of the hologram.

The diagnostic study of holograms involves identification of the hologram production scheme. In our opinion, the hologram forensics should consist of several stages. First of all, a visual rapid test of the hologram shall be performed. Then the hologram type is established and the sequence of examinations depending on the possible method of forgery is determined [1].

A hologram is examined by comparing it with a reference sample. In this case the attention should be paid to:

- matching of the color scheme of the test hologram and the reference sample at the same illumination angles;

- presence of the holographic 'noise';

- accuracy of the logo recovery;

- type of the HSE attachment to the protected object (self-adhesive, hot stamping); 
- the number of image planes (mostly two or three planes, more of them are rarely used, because of the limitations on the depth and sharpness of the rainbow hologram);

- image depth (e.g. a $15 \times 15 \mathrm{~mm}$ hologram has a depth of 3 to $5 \mathrm{~mm}$ );

- presence of defects in the holographic image that may occur during the holographic copying of the original.

In addition, lesions, tears, cracks in the hologram are not allowed. Attention is also paid to the thickness of the hologram, the accuracy of its placement on the protected object, the structure of the material it is made of [2].

After that, the parameters are studied using laboratory methods. The following parameters are identified together with the reference sample: number of angles of the hologram (e.g., a complex hologram generally contains from 20 to 200 views, their number depends on the protected object, size of holographic images, color separations, materials used for recording; the playback quality of the microtext, nanotext and small parts of the image; HSE's diffraction grating modulus consists of a set of reflection gratings. The grating modulus spectrum determines how effectively the reflected light is decomposed into the spectrum. If viewed through a microscope with a magnification of 300 times, the holographic image will have the appearance of dark and light stripes. The diffraction grating modulus is the total width of the light and dark strips of the HSE; the width and relative position of the slits for a multifrequency rainbow hologram; the distance from the image of the slits to the hologram when the wave front is set to the specified curvature.

If encoded or hidden information is used in a hologram, it is decoded, identified, and analyzed to match the sample [3].

If necessary, additional studies of the hologram can be carried out, such as material control (glue/adhesives are selected so that the destruction of the hologram - complete or partial - occurs when peeling, heating and solvents are used; this renders it impossible to reuse or copy the HSE, optical study of the diffraction structure of the hologram. The study of holographic security marks by means of laboratory methods is conducted using standard optical devices (microscopes, photometers, spectrometers, etc.), special laser equipment, which identifies a complex image of the HSE and reads the latent image. A complex and latent 
image can not only be visually observed but also entered into a computer for further comparison with the reference sample. In this case, the image is examined on such crucial parameters as resolution, presence of three-dimensional images (for example, flat twodimensional image only, simultaneous coincidence of the foreground and background of 2D and 3D images, a fully three-dimensional image), the presence of color gamut, presence of mobility, available ink numbering on the surface of the hologram or laser numbering in the hologram, as well as a number of other parameters [4].

The requirement for the stability of the HSE's protective properties is recognized as the possibility of changing the appearance of the mark for at least one characteristic feature in case of unauthorized violation of its operating conditions. For example, when separating a security mark from a plastic card, it becomes completely or partially destroyed, exhibiting a decrease in resolution, violation of the color gamut, microtexts or micro-optical details in the image of the mark, non-reflection of the latent image, which is detected by a magnifying glass, microscope, laser device used for identifying holograms, and so on.

The stability of the protective properties of the HSE is ensured by the technology of manufacturing the mark in the form of a self-adhesive label. Hot stamping method, which in both cases ensures the destruction of the mark when trying to separate it [5].

In our opinion, in order to establish the authenticity of the hologram, it is advisable to put the following questions to the expert:

- whether a tag on the provided object is a holographic security mark; if so, what type (type) of HSE belongs to (hologram, kinegram, pixelgram etc);

- whether the test holographic sample meets the established standard;

- method of attaching the HSE to the protected object;

- whether the holographic security mark was exposed to unauthorized influence; if so, in what way;

- if a tag on the provided object is not a holographic security mark, then how is it made, what means were used to produce it;

- whether the equipment provided for the study was used to make the tag? 
For hologram forensics special laboratories have been created in the country's expert institutions. Research methods are developed and the possibilities of procedural permissibility of using lasers in court proceedings are considered. Familiarization with the practice of such laboratories has shown that they mainly conduct research on holograms that protect individual products from forgery and are used as seals for office equipment. Such research is conducted annually in the expert laboratories of the Security Service of Ukraine, dedicated expert institutions of the Ministry of justice in Ukraine [6].

Holographic security systems are based on the discoveries and achievements of modern optics and materials science. A hologram is a complex microstructure that comprises the visual perception of three-dimensionality of an image. Holographic information is recorded during the laser interference shooting. This technology makes it possible to obtain holographic elements with bright and high-quality images. Volume, iridescent color play, a large number of optical effects determines its significance.

Holographic protective elements combine the principle and action regardless of the retention method: these are relief microstructures with a size of about one micron and a depth of relief in the fraction of a micron. Light falling on such structures, as a result of diffraction and interference, splits into a spectrum forming a rainbow effect. In this case, the colour and shape of the image changes when the hologram is tilted or rotated [7].

Types of holograms:

- 3D holograms reproduce a three-dimensional image of a real object. To record them, you need a real object or its model at a scale of 1:1. Such holograms fully convey the brightness and three-dimensionality of objects however, their resistance to optical copying is not very high. 3D holograms are widely used to protect trade marks and enhance their image;

- A 2D hologram consists of several flat images that are visually located one after the other and deliver a three-dimensional effect. This type of hologram is protected from optical copying by introducing special graphic elements and optical effects into the structure of the GSE, so this type of hologram is used to protect goods, documents, and accountable forms;

- Dot-matrix - do not require the presence of the object and its model. The image delivers high brightness, contrast, and clarity that distinguishes it from other types. The 
presence of optical effects that are not available for other technologies makes holograms significant;

- combined holograms involve combining several technologies in one hologram.

The most effective protection can be achieved when additional security elements (holographic security elements) are included in the GSE [8].

- microtexts are texts embedded in a hologram with a font size of less than $0.1 \mathrm{~mm}$. Such text is invisible to the naked eye, and can only be read with a magnifying glass or microscope;

- guilloche and benday screens. The pattern consists of a complex interweaving of fine lines.

This pattern can be background, embedded in any element of the image, or superimposed on any part of the hologram [9]:

- latent image is not visible to the naked eye and is not perceived separately with a microscope;

- end-to-end numbering. Each holographic element has an individual number, made in marking ink that does not wash off, on a thermal transfer printer or by laser engraving;

- fractal structures. If you look at a fractal pattern under a microscope, you can see that it consists of a large number of small lines, which in turn consist of smaller ones. A simple example of a fractal structure is a snowflake;

- selective demetallization. The reflective metallized layer is removed from the specified sections of the holograms. In this way, a hologram may comprise a transparent image or inscription.

Hologramming methods [10].

Conclusions A self-adhesive label (application) is a holographic element that is applied to any object as a regular stick-on label, but when you try to remove it from the object, it is destroyed. Labels can be applied manually or using special tools. 
Hot stamping foil. Hot stamping foil consists of a polyester base on which a layer of protective varnish is applied, a metallized layer with a holographic pattern, an adhesive layer after pressing such HSE on the document, a thin (5 to 10 microns) layer of metallized varnish bearing holographic pattern is retained. Such a security element cannot be separated from the base and transferred to another document without compromising its integrity.

Lamination film. The holographic pattern is located on a transparent film that can be used for laminating documents. Conventional laminators can be used to apply such a film.

Holograms are used to:

- protect payment cards, letterhead papers against forgery;

- protect manufacturers' trademarks;

- certify the authenticity of products;

- control access to premises and facilities;

- give a bright look to advertising products.

\section{References}

1. Avdieieva H.K., 2006. Forensic examination of counterfeit audiovisual products (based on criminal case files). Monograph, ed. Professor V. Yu. Shepitko. Kharkiv: Pravo, available at http://dspace.nlu.edu.ua/bitstream/123456789/648/1/AvdeevaMono.pdf

2. The Law of Ukraine "On Distribution of Copies of Audiovisual Works, Phonograms, Videograms, Computer Software, Databases", available at https://zakon.rada.gov.ua/laws/show/1587-14

3. Lelotko Yu. I. The official web portal of the Verkhovna Rada of Ukraine. Available at http://elar.naiau.kiev.ua/jspui/bitstream/123456789/9057/1/\%D0\%A1\%D0\%A3\%D0 $\% 94 \%$ D0\%9E\%D0\%92\%D0\%9E$\% \mathrm{D} 0 \% 95 \% \mathrm{D} 0 \% 9 \mathrm{~A} \% \mathrm{D} 0 \% \mathrm{~A} 1 \% \mathrm{D} 0 \% 9 \mathrm{~F} \% \mathrm{D} 0 \% 95 \% \mathrm{D} 0 \% \mathrm{~A} 0 \% \mathrm{D} 0 \% \mathrm{~A} 2 \% \mathrm{D} 0 \% 9 \mathrm{D} \% \mathrm{D} 0$ \%90_p218-220.pdf

4. The Order No. 591 of the Ministry of Internal Affairs of Ukraine dated 17/07/2017. The official web portal of the Verkhovna Rada of Ukraine. Available at https://zakon.rada.gov.ua/laws/show/z1024-17 
5. The draft Law of Ukraine "On Amendments to Certain Legislative Acts of Ukraine", registration No. 2565 of 10/12/2019. The official web portal of the Verkhovna Rada of Ukraine. Available at http://w1.c1.rada.gov.ua/pls/zweb2/webproc4_1?pf3511=67591

6. Chvankin V.A. Osobennosti otdel'nyh kriminalisticheskih issledovanij produkcii, obladajushhej priznakami kontrafaktnosti : posob. [Features of individual forensic studies of products with signs of counterfeiting: handbook.] / V.A. Chvankin, A.L. Poskreblo. - Minsk, 2005.

7. Chvankin V.A. Praktichni aspekti kriminalistichnih doslidzhen' produkciï z oznakami kontrafaktnosti : metod.rek. [Practical aspects of forensic research of products with signs of counterfeiting: method. recomm.] / V.A. Chvankin, A.V. Kofanov. - K. : KIJ, 2008.

8. Chvankin V.A. Metodika tehniko-kriminalisticheskogo issledovanija poligraficheskogo oformlenija i jelementov zashhity magnitnyh i opticheskih nositelej informacii, soderzhashhih ob\#ekty intellektual'noj sobstvennosti, $v$ celjah ustanovlenija tehnicheskih priznakov kontrafaktnosti [Methodology of technical and forensic research of printing design and protection elements of magnetic and optical information carriers containing intellectual property objects, in order to establish technical signs of counterfeiting] / V.A. Chvankin // Kriminalisticheskoe obespechenie rassledovanija i raskrytija prestuplenij: nauch. tezisy, vystup. $i$ soobshh, Kyiv, 30 apr. 2010 . / Kyiv. nac. un-t vnutr. del Ukrainy. - K.: KIJ, 2010. - P. 150-155.

9. Practical Aspects of Appointment of Judicial Expertise in the Field of Intellectual Property (Expertise of Copyright Objects and Related Rights, Articles, Computer Programs and Databases). URL: https://doi.org/10.32370/IA_2019_09_12

10. Forensic Examination of Packaging with Indications of Counterfeiting Present on Optical Media in Civil and Criminal Proceedings. URL: https://doi.org/10.32370/IA_2020_01_9

\section{Translation of the References \#6-8 to the original language}

6. Чванкин В.А. Особенности отдельных криминалистических исследований продукции, обладающей признаками контрафактности : пособ. / В.А. Чванкин, А.Л. Поскребло. - Минск, 2005.

7. Чванкін В.А. Практичні аспекти криміналістичних досліджень продукції $з$ ознаками контрафактності : метод.рек. / В.А. Чванкін, А.В. Кофанов. - К. : КИЙ, 2008.

8. Чванкин В.А. Методика технико-криминалистического исследования 
полиграфического оформления и элементов защиты магнитных и оптических носителей информации, содержащих объекты интеллектуальной собственности, в целях установления технических признаков контрафактности / В.А. Чванкин // Криминалистическое обеспечение расследования и раскрытия преступлений: науч. тезисы, выступ. и сообщ, Киев, 30 апр. 2010 г. / Киев. нац. ун-т внутр. дел Украины. - К.: КИЙ, 2010. C. $150-155$. 


\title{
Historiography of the Armed Terrorism Prevention in the Criminal Legislation of Ukraine
}

\author{
Komarynska Yuliia \\ PhD of Juridical Sciences, Associate Professor, Professor of \\ Department of Criminology and Forensic Medicine of the National Academy \\ of Internal Affairs, Kiev, Ukraine \\ ORCID ID 0000-0002-1747-1816 ubk2006@ukr.net \\ Pavlovska Nataliia \\ PhD of Juridical Sciences, Associate Professor, Professor of \\ Department of Civil Law and Process of the National Academy of Internal \\ Affairs, Kiev, Ukraine ORCID ID 0000-0003-3311-0364 \\ wwwpav@gmail.com

\section{Svoboda Eugenia} \\ PhD of Juridical Sciences, Associate Professor, Professor of Department of \\ Forensic Support and Forensic Expertise of the National Academy of \\ Internal Affairs, Kiev, Ukraine \\ ORCID ID 0000-0002-8639-8333 jeechka@ukr.net
}

\section{Symchuk Anatolii}

Senior Teacher of Forensic Support and Forensic Expertise of the National Academy of Internal Affairs, Kiev, Ukraine ORCID ID 0000-0002-8663-8210 symchukas@gmail.com

\section{Kofanova Olena}

PhD of Juridical Sciences, Associate Professor of Forensic Support and Forensic Expertise of the National Academy of Internal Affairs,

Kiev, Ukraine

ORCID ID 0000-0002-0919-7570 kofanova_alena@ukr.net

\footnotetext{
Abstract

The Ukrainian state and society, due to historical, socio-political and economic circumstances, are involved in the problems of terrorism so we should seek ways to efficiently counter terrorism, use hands-on experience of the international community, and improve our national legislation in this area.

Having political and economic relations with other states, Ukraine, in addition to the benefits of such cooperation, in some cases acquires problems and is drawn into various kinds of conflicts against its will. Sometimes such conflicts are linked to terrorism.

Rather typical in this regard is the example of attempts in the 1990s to 'bind' Ukraine to the Kurdish problem due to the residence on the territory of Ukraine of about 12 thousand Kurds (as of 1995) [1, p. 50]. In September 2004, similar attempts were made in connection with the migration of Chechens after the events in Beslan.

Keywords: terrorism, legal community but also sociology, political science, social, individual psychology, and other fields of science, historiography.
} 
Introduction At the 50th session of the UN General Assembly (1995), it was noted that with a decrease in the number of terrorist acts, the scale and danger of terrorism increases due to the use of new achievements in science and technology (modern means of communication and transport), world-class sources of financing, good knowledge of explosives and modern weapons, and an increase in transnational actions [2]. The internal restructuring of the state and society in Ukraine, changes in the principles of foreign economic and foreign policy activities, and its greater openness have become the reasons for the penetration of terrorism into the CIS and Ukraine (Commonwealth of Independent States - a regional international organization that includes a number of post-Soviet countries and Ukraine, who terminated participation in the CIS statutory bodies on 19.05.2018 subject to the Presidential Decree by P.Poroshenko. In this regard, numerous political forces in the state represented by various parties and trends to achieve their goals, have intensified the struggle for influence on the public. To this end the entire spectrum of socioeconomic, national, ethno-territorial, interreligious contradictions and other dissensions is used. Due to the socioeconomic polarization of society and increase of the downgraded, marginal strata of society, the struggle between the parties of the democratic bloc and the parties representing the interests of capital has become noticeably more acute. There are ongoing inter-confessional contradictions and conflicts in certain regions of the country.

In 1990s the law enforcement agencies of Ukraine pointed to the attempts of international terrorist groups to expand into the territory of our country. The 'transparency' of borders with the CIS countries, imperfect legislation, which regulated the procedure for foreigners' stay in Ukraine and their expulsion from the country in case of committing illegal actions, was used by members of these organizations to evade responsibility the crimes committed. In 1994-1996, several hundred people were identified and verified, with regard to their involvement in the activities of religious-extremist and terrorist organizations in the Middle East, South-East Asia, and Latin America. The Security Service of Ukraine has exposed several attempts by Middle East terrorist organizations to use Ukraine to prepare and carry out illegal actions against diplomatic missions of foreign states in the CIS and Western Europe, to accumulate arsenals of weapons and explosives. The presence in Ukraine of a significant number of refugees from the former Soviet republics with a complex political criminal situation (Russia, Georgia, Azerbaijan, Armenia, Moldova) had adverse effect on countering terrorism. 
Individuals from these countries committed acts of violence with signs of terrorism in their countries. There are attempts to use the territory of Ukraine by members of the military extreme formations of the CIS countries to hide from prosecution for committing terrorist acts, participation in military conflicts on the territory of their states [1, p. 56 ].

Military conflicts in the CIS countries and the Balkans have led to the expansion of such a negative phenomenon as illegal mercenarism in Ukraine. Specific evidences indicate that the main danger of this phenomenon is that Ukrainian citizens participating in combat operations abroad gain experience in sabotage and terrorist activities and can be used to commit crimes of the terrorist nature. Investigating the issue of terrorism V.Antipenko in his scientific works notes that the dynamics of manifestations of terrorist nature in relation to the authorities in Ukraine in the 1990s comprised more than 200 cases in 1995 (63 of them were threats against parliamentary candidates), about 200 and 100 threats in 1996 and 1997 respectively. In total, over this period, the Security Service detected 165 verbal and 233 written anonymous threats, 126 crimes were committed resulting in the death of 18 individuals and 24 injuries. In cooperation with other law enforcement agencies during this period, more than 200 manifestations of terrorist nature were detected, 31 persons were brought to criminal responsibility, and preventive measures were taken for many of them [1, p. 45]. Political confrontation in the country increases the likelihood of using terrorist methods. Moreover, paramilitary formations of various political forces such as the DSU "VARTA", the Ukrainian branch of the Russian "Red Army", organizations of the "Revolutionary Communist Youth", troops of the "Avdet" party, not excluding extremism in achieving their goals, have been operating in Ukraine for more than a decade.

Particularly dangerous are the integration processes of terrorism and organized crime, which have become so strong that it allows the criminal authorities to carry out actions that may cause socio-economic complications. This was most characteristic in the Autonomous Republic of Crimea, where a notable destabilizing factor was the activity of two criminal clans, "Shoes" and "Sailem" [1, p. 78].

A specific feature that potentially transforms the scale of terrorism in the country is the problem of illegal storage and trafficking of weapons, explosives and other items that can be used for terrorist crimes. The population illegally owns a large number of firearms. In 1995-1998, the police seized 6.5 thousand units, and more than 5.5 thousand units were wanted for. The main ways of acquiring firearms are thefts from storage 
facilities, export from military conflict zones, receipts from abroad, and home-made production. The storage of unregistered weapons by members of illegal paramilitary groups poses great danger. The trend of committing terrorist crimes using improvised explosive devices is becoming more and more threatening. In 1995-1996, more than 560 such crimes were committed in Ukraine resulting in 90 persons killed (15 representatives of government structures), 218 were injured (19 respectively) [1, p. 85]. These crimes are usually committed by criminal elements struggling for the redistribution of spheres of influence to eliminate competitors in illegal business, as well as eliminate or intimidate representatives of local or state authorities.

The issue of nuclear and environmental terrorism remains unresolved for Ukraine. The country features high concentration of nuclear power plants and vast number of environmentally hazardous facilities. Some of them are in a poor technical condition. The volume of telephone terrorism does not decrease. Anonymous calls are received about possible explosions in transport industry, educational institutions, and public places, as well as at nuclear, thermal power plants, and other energy facilities. E.g., officers of the Security Service detained a resident of Slavutych, who in December 1994 via anonymous calls threatened to blow up the Chernobyl Nuclear Power Plant and demanded 2 million US dollars. In 1995 the Security Service of Ukraine, in cooperation with other law enforcement agencies, prevented 5 attempts to illegally acquire, store and export nuclear and radioactive materials abroad [1, p. 97].

In today's conditions, Ukraine cannot adequately counter the growing wave of terrorism. Serious difficulties are revealed on a whole range of issues related to legal, organizational, operational, and other areas of countering various forms of terrorism. The system of social values of the population is distorted: mechanisms of ordering and regulating relations that directly or indirectly affect the foundations of the state and socialpolitical system are not effective enough; new factors have emerged that contribute to criminal acts (social stratification of society, aggravation of political struggle, unemployment and social insecurity, legal nihilism, inter-religious issues).

In Ukraine the issue of terrorism requires careful research not only by representatives of the legal community but also sociology, political science, social, individual psychology, and other fields of science. The lack of scientific and journalistic literature that covering issues of terrorism, the lack of a scientifically-based definition of the state of terrorism and forecasts of its development in Ukraine reduces the severity of 
the issue, narrows down the potential to develop and implement anti-terrorist measures in the legislative, law enforcement, and national spheres. Raising the issue of terrorism prevention in Ukraine as part of the tasks of the law enforcement system, we must first note the need to prevent this crime in the national law. There are acute problems of preventing terrorism in our national legislation. Firstly, there is no dedicated legal act that would solve the problems of terrorism prevention; secondly, there is no special article in the criminal legislation that would provide for responsibility for committing a terrorist act. The dedicated law on counter-terrorism would allow to legislate the organizational and legal basis for combating terrorism, define it as a political and socioeconomic phenomenon, and legislate state law enforcement agencies responsible for preventing and suppressing terrorist attacks.

In order to improve national legislation in this area a draft anti-terrorist law ("On the organizational and legal basis for combating terrorism") has been developed by the team of the Interdepartmental Research Center for Combating Organized Crime. During the transition phase, the version of the draft Law of Ukraine "On strengthening the fight against terrorism", developed by a group of experts, which included representatives of the Security Service of Ukraine, Ministry of Justice, Institute of State and Law of the National Academy of Sciences of Ukraine is acceptable. The draft law provides for amendments and additions to the criminal and criminal procedure legislation, which is especially important, emphasizes terrorism as an independent crime with the definition of a terrorist group and a terrorist organization. Amendments to the "Hostage Taking" Article of the Criminal Code [3]. The draft law defines terrorism as the exercise or threat of an explosion, arson or other act that endangers human life and health, and the threat of grave consequences, if committed with the aim of compelling state bodies, local government or international organizations or their representatives to perform or refrain from performing any act or aimed at provoking war, armed conflict, the emergence of international complications or destabilizing the situation in the country. Since terrorism is a multilevel and large-scale phenomenon, the forms of its manifestation differ both in content characteristics and in the scope of implementation - therefore, the criminal law's phenomenon of terrorism should have a more definitive character and clear boundaries. This is necessary due to a certain formality of law and the obligation to establish sufficient grounds for criminal prosecution. In the criminal law, such a basis is an entirety of corpus delicti, which should clearly and precisely characterize such a phenomenon of life as a 
crime. A positive aspect is the identification of the objective side in the structure of terrorism - threat of committing a crime. The threat of violent extremist actions is highlighted as a new form of terrorism. The need for the inclusion of this form is based on the fact, that, firstly, it is necessary to criminalize cases of 'warning explosions', arson not posing a threat of loss of life or significant material damage by which the perpetrators however, intend to demonstrate the substantiality of their threats; secondly, on the need to strengthen accountability for a dangerous crime such as terrorism by transferring the end of the crime from the practical actions to the previous stage i.e. declaring a serious threat.

The next positive aspect of the draft law is the designation of a special subject of crime, whose age is set at 14 years. One of the qualifying characteristics of a certain type of terrorism is the establishment of a terrorist group and a terrorist organization or participation in it and the establishment or activity of such formations. It provides for the use of an auxiliary means of legal action containing an incentive norm of behavior of the guilty persons. This rule allows a person to voluntarily refuse committing acts of terrorism, without fear of being convicted of a criminal offence.

Given that terrorism has a number of objective and subjective characteristics similar to other types of crimes, it is important to identify, in specific cases, those characteristics that would help distinguish it from other crimes. First, terrorism should be distinguished from attacks on the life of a government official or public figure, and sabotage. These crimes are intended to undermine the constitutional order and security of the state, which is manifested in a different nature and content of the goal than terrorism. While terrorism is the perpetration of explosions, arson, or other actions aimed at intimidating (in the broad sense of the word) of the population, whereas delicta publica are aimed to cause damage to the state as a form of social organization. In the case of sabotage, it is essential to cause material harm rather than physical [4].

This crime differs from attempts on a person in that causing harm to the said objects is a way of committing terrorism and shall be understood as an intermediate, but necessary stage in achieving the ultimate goal. The use of a generally dangerous method is associated not so much with the desire to afflict damage to the protected interests, but with the person's intention to achieve maximum effectiveness of their actions. In addition, in case of a murder, the victims are individually identified, and the perpetrators seek to cause death to such persons, while in the case of destruction or damage to property - to destroy or damage such property, and not the other. In the event of terrorism, the perpetrator is not 
interested in the victim or the nature and ownership of the property; it is important for them to intimidate the population, to induce the authorities to commit, or vice versa not to perform, the actions necessary for the perpetrator [5].

In the national anti-terrorist legislation, it would be wrong not to use such consolidating, public and state institutions, the influence of which is a commonality of approaches to the issue of innocent victims of terrorism. Since terrorism seeks effect of a specific action on the decision-making authorities as well as the relevant segments of the population influencing the decision-making process by their response, in the event of terrorism, there is a gap between the direct victim of violence and the targeted group, the aim of violence. Therefore, the presence of innocent victims, as well as the danger of their occurrence, is a characteristic feature of modern terrorism [6].

To sum it up, it is impossible to neglect positive trends in the adoption of timely legislative acts. The President of Ukraine, Leonid Kuchma, signed a Decree 'On Ukraine's Participation in the Eurasian Group on Combating Money Laundering and Financing of Terrorism' in 2004.

The Decree supports the proposal of the Cabinet of Ministers of Ukraine regarding Ukraine's participation as an observer in the Eurasian Group on Combating Money Laundering and Financing of Terrorism.

According to the document, the State Department for Financial Monitoring is responsible for cooperation with the Eurasian Group on Combating Money Laundering and Financing of Terrorism and representing the interests of Ukraine in this organization [7].

The strategic course of Ukraine towards EU integration and the entry of the national science into the European and global scientific space allowed the Ukrainian legislators, together with scientists, to make a significant step towards the development of counterterrorism and anti-terrorist security legislation.

The provisions of the laws of Ukraine set basic terms, principles and organizational basis of fight against terrorism; range of subjects of fight against terrorism and their powers; regimes, legal basis of anti-terrorism activities; general principles of observance of the rights and legitimate interests of citizens while ensuring anti-terrorism security, and establish responsibility for crimes related to terrorist activity, and outline the general principles of pre-trial investigation.

In order to assess the status and readiness of counter-terrorism actors to perform the 
tasks of preventing, responding to and deterring acts of terrorism and minimizing their consequences, the state of their personnel, financial, logistical and other types of support, as well as the existing capabilities to effectively respond to terrorist threats, Decree No.506 of the President of Ukraine V. Zelensky of July 9, 2019 approved the procedure for conducting an inspection of the national system for combating terrorism. The United Nations' Global Counter-Terrorism Strategy adopted by the UN General Assembly on September 8, 2006, is an international instrument that defines a common strategic approach to combating terrorism on a global scale.

International statutory instruments consented to by the Verkhovna Rada of Ukraine, establish general principles of international cooperation in the field of preventing and countering terrorism, define crimes related to terrorism, and also impose the obligation to promote awareness of the existence, causes, severity of terrorist crimes, and the threat they pose.

At the present stage, the legislation of Ukraine needs further systematization, codification, and improvement, introduction of protective levers aimed at identifying and eliminating the causes and conditions that give rise to terrorism, exposing signs of terrorist manifestations, preventing their transformation into real actions. [8, 9, 10].

Conclusions Further expansion of the scope of research and development of methods, models, techniques for analyzing and assessing the risks of terrorist situations, forecasting their development and prevention will help to improve the efficiency of the counter-terrorism measures.

\section{References}

1. V.Antipenko. Modern Terrorism: State and Prevention Capabilities (Forensic research). - K.: 1998. - p. 50-97.

2. E.Lyakhov. The policy of terrorism is a policy of violence and aggression. International relations, Moscow, 1987. - p. 90.

3. Scientific and practical commentary of the Criminal Code of Ukraine (On the status of legislation and decisions of the Plenum of the Supreme Court of Ukraine on January 1, 1997) - K.: 1997. - p. 235.

4. Scientific and practical commentary of the Criminal Code of Ukraine (On the status of legislation and resolutions of the Plenum of the Supreme Court of Ukraine as of January 1, 1997) - K.: 1997. - p. 240.

5. Scientific and practical commentary of the Criminal Code of Ukraine (On the status of legislation and resolutions of the Plenum of the Supreme Court of Ukraine on January 1, 1997) - K.: 1997. - p. 243. 
6. E. Lyakhov. The policy of terrorism is a policy of violence and aggression. International relations, Moscow, 1987. - p. 45.

7. Decree of the President of Ukraine №1156 / 2004 of 30.09.2004 "On Ukraine's participation in the Eurasian Group on Combating Money Laundering and Terrorist Financing", access mode: https://zakon.rada.gov.ua/laws/show/1156/2004

8. Sergey Kudinov. Ways to improve the legal regulation of anti-terrorist security by the Security Service of Ukraine, 2019, access mode: http://pgpjournal.kiev.ua/archive/2019/2/45.pdf

9. Theoretical and practical aspects of anti-terrorist activity of special unit "SAS". URL: https://doi.org/10.32370/IAJ.2317

10. Specifics of activity of the armed executive body - GENDARMERIE. URL: https://doi.org/10.32370/IAJ.2112 


\title{
UDC 72.013
}

\section{The Notion of Tolerance of the Architectural Form}

\author{
Negai G.A. \\ Candidate of Architecture, Associate Professor \\ Khmelnytskyi National University
}

\begin{abstract}
The article deals with the new features of the architectural form proposed by the author - tolerance and spaces of tolerance: zones of tolerance and fields of tolerance. They allow you to define strictly the size of the architectural form to harmonize the designed objects of architecture, which can be executed automatically in the process of computer design.
\end{abstract}

Keywords: tolerance, fields of tolerance, tolerance ratio, dimensional structure, informativeness, harmonization.

The concept of tolerance, which clarifies the concept of similarity and the related concept of non-recognizability, was introduced in 1970 by mathematician E. Ziman [1]. The concept of "tolerance ratio" has never been used in the theory of architecture. The term "tolerance space" was first introduced by us in 2000. "Tolerance space" is an architectural form - the set of points of any surface, within which, between any two arbitrarily small zones, distinct visual information of one quality is equal to zero "[2]. This mathematical definition of specific forms requires caution. This is important in view of the future of computer aided design, in the process of which the computer will harmonize the dimensional structure of the architectural form with the preset program. For this computer, you need to specify an algorithm for identifying architectural elements that need to be proportionately matched to achieve a visual perception of harmony.

The topicality of such innovation is determined by the widespread use in the design and construction of architectural objects of various construction and decoration materials with different tonal, color-tone and textural characteristics, which significantly affect the visual complexity of the architectural form, make it indefinitely proportional, distort or alter dimensional structure. This leads to the negative consequences of forming a coherent, information-integrated, harmonious architectural environment. Meanwhile, the researchers of proportions, as a rule, took geometrical parameters of the architectural form as a whole its elements and details, and considered them as elements of the dimensional structure, without 
regard to the patterns of visual perception. But in the process of visual perception our visual apparatus is able to differentiate individual elements of the form, or their visual integration, regardless of geometry or structural and tectonic features. For proportioning the researchers adopted dimensional parameters determined only by the structural parts of the form.

It should be noted that in the study of proportionality at all times they meant only structural or tectonic features of the architectural form, not taking into account its tonal or color characteristics. In addition, whether they wanted it or not, the researchers meant sensual, visually-perceived harmony. For example, B.P Mikhailov, quoting Vitruvius, writes: "The response of the regularity, which goes from individual members to the general form of the whole, is achieved most of all by proportionality, i.e. unity of the ratios of parts, due to which the composition of things acquires the greatest clarity and integrity, causing maximum aesthetic satisfaction "[3, p. 137]. That is, in this fragment B.P Mikhailov, definitely speaks about the sensitive estimation of proportionality, which he interpreted as "the proportionality of all parts with everything", "which Polycletes demanded, and which the ancient Greeks called eurythmy, since each part thus received a harmonious response in proportion to all others and the whole in general'[3, p. 171]. Many researchers have the same opinion. However, what determines the parts, no one has formulated. Below we will try to do this.

First, let us define the concepts of "tolerance zone" and "tolerance field". "Tolerance space" is a generally mathematical concept. Tolerance space can be both a "tolerance zone" within which there are no visually perceived differences in a certain quality, and a "tolerance field" as an association of "tolerance zones" that differs significantly from another architectural field forms in terms of aggregate characteristics and certain quality. In this case, the part of the tolerance field where non-recognizability disappears will be called the boundary of the tolerance field. Physical parameters within the field of tolerance will be called elements of the dimensional structure of the architectural form, its parts.

Consider simple examples of graphical interpretation of these concepts. This will allow us to investigate the similarity and non-recognizability of elements of architectural form. We set the similarity to the tone of a number of rectangles with different intensities. There is a tonal difference between adjacent rectangles (eler is one unit of elementary distinction). The tone modeling of this row of rectangles is accomplished in such a way that each subsequent rectangle becomes darker by one unit of elementary distinction. Thus, a number of rectangles 
has been formed, the neighboring ones are different in tone from each other by the value of the threshold of visual sensation (Fig.1).

Fig. 1. A tonal series of rectangles with a tonal difference of one eler.

Now we will create a tone series in which the first two rectangles will be different in tone by the value of the threshold of visual sensation, and the third rectangle will be toned four or more times darker than the first two. In this tone series, the first two rectangles are combined in a field of tolerance, that is, in such a planar formation that differs substantially from the rectangle in terms of aggregate tone, which is several times darker than the first two (Fig. 2).

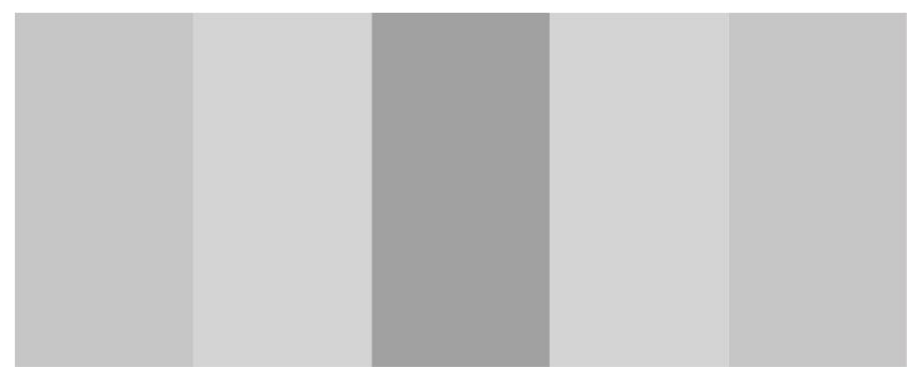

Fig. 2. Tolerance fields.

In this example, you can neglect the tonal difference of two rectangles in one eler compared to a rectangle that is much darker than the first two. It can be claimed that two rectangles with a tonal difference in one eler are in relation to each other's tolerance and are similar in tonality compared to the third rectangle, which is much darker than the first two. In this example, a darker rectangle is antagonistic to the tolerance field of the two lighter rectangles. In practice, a tolerance field can be formed from two or more tolerance zones. Below there are examples of such combinations that determine the visually perceived dimensional structure of an architectural form.

In Fig. 3 and 4 examples of forming tolerance fields with different rectangles are shown. 
In both cases (Fig. 3 and Fig. 4), the formation of a tolerance field occurs on the basis of tonal similarity and non-recognizability, but not uniformity. Equality (equivalence) is a qualitatively different property. It provides for the possibility of replacing one area of the architectural form with another, replacing it, because it repeats all the characteristics of the first: and the tonality, size, and texture, etc. The fact is that the indistinguishable parts of the architectural form are not broken down into separate zones of tolerance, but, on the contrary, are visually combined, forming fields on the principle of similarity or tonal characteristics, or by color, or by some other, for example, similarity in texture, or texture with a consistent tone in tone.

The main task of forming tolerance fields is to determine the parts of the dimensional structure that the designer or the computer working on a given program can include in the process of harmonization, that is, bringing them to a certain system of proportionality with the maximum indicator of the power of information communication [2], taking into account the system of dimension of architectural environment (ensemble) and functional and structural limitations.

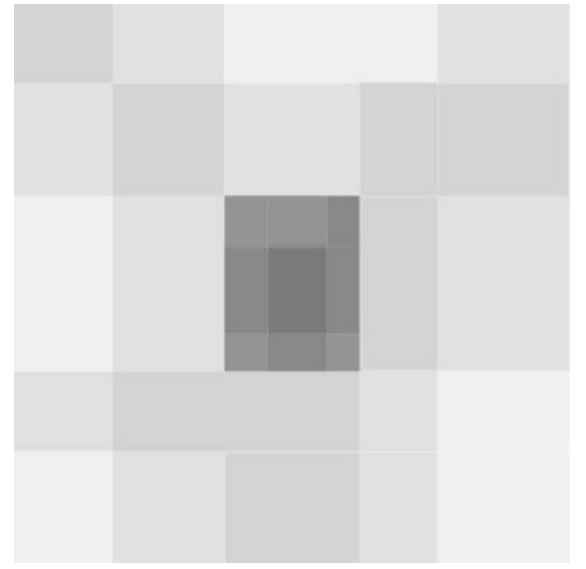

Fig. 3.

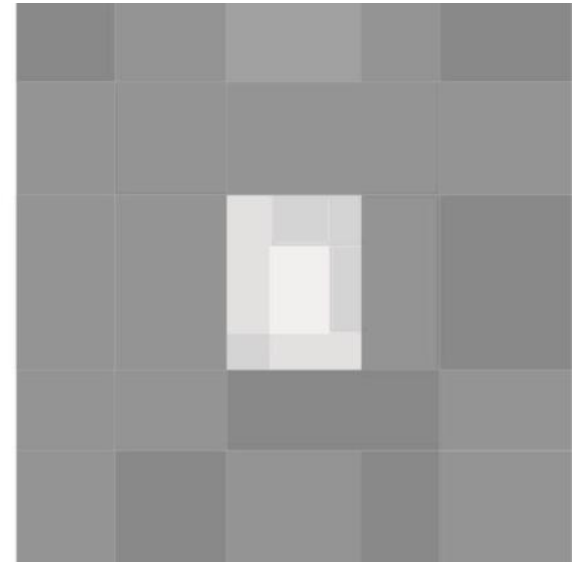

Fig. 4.

Examples of composition formation based on tolerance ratio.

In Fig. 5 depicts a fragment of a facade of a building, which shows that the sheet from the left window to the white pilasters, the pilaster itself and the sheet from the pilasters to the right window are different in tone from each other by the magnitude of the threshold of tonal distinction and are visually combined into a single field of tolerance with respect to a much darker window, both right and left. In turn, windows in different parts have tonal differences 
that can be neglected. Their tolerance zones are combined into a single tolerance field that determines their dimensional structure. In order to analyze the proportionality of the facade, the width of the "wall-pilaster - tolerance field" and the "window" tolerance field width should be taken as elements of the facade structure. Visual information in their ratio will become an informational step of the facade information field, which will be included in the system of determining information modules of the relations of elements of the dimensional structure of the facade and evaluation of the strength of the information (proportional) connection of parts of the architectural form [see. 4]

Another fragment of the facade, shown in Fig. 6, gives us an example of a clearer division into tolerance fields: the window and the shade of the window between the white window frames. Just the size of the windows between the casings and the space between the casings should be taken into account in calculating the proportionality (proportionality) of the parts of this facade. The plinths in this case act as a distributive element. They separate tolerance fields and can be used to adjust their dimensions. And in fig. 7 you can see that the platbands are tonally combined with a tinge of space between them into a single field of tolerance.

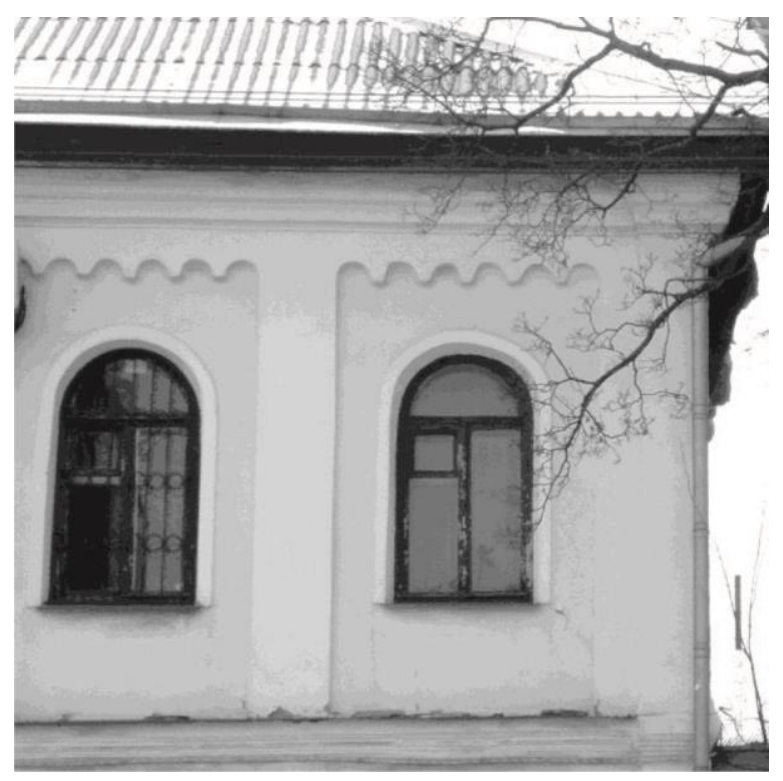

Fig. 5. Depicts a fragment of a facade of a building

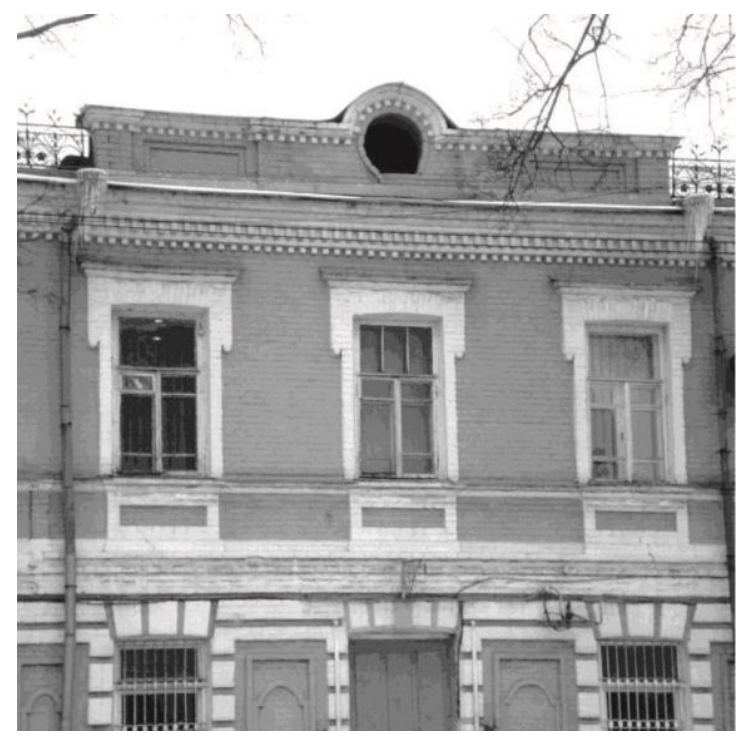

Fig. 6. Fragment of the building facade. Formation of dimensional structure based on tolerance ratio 


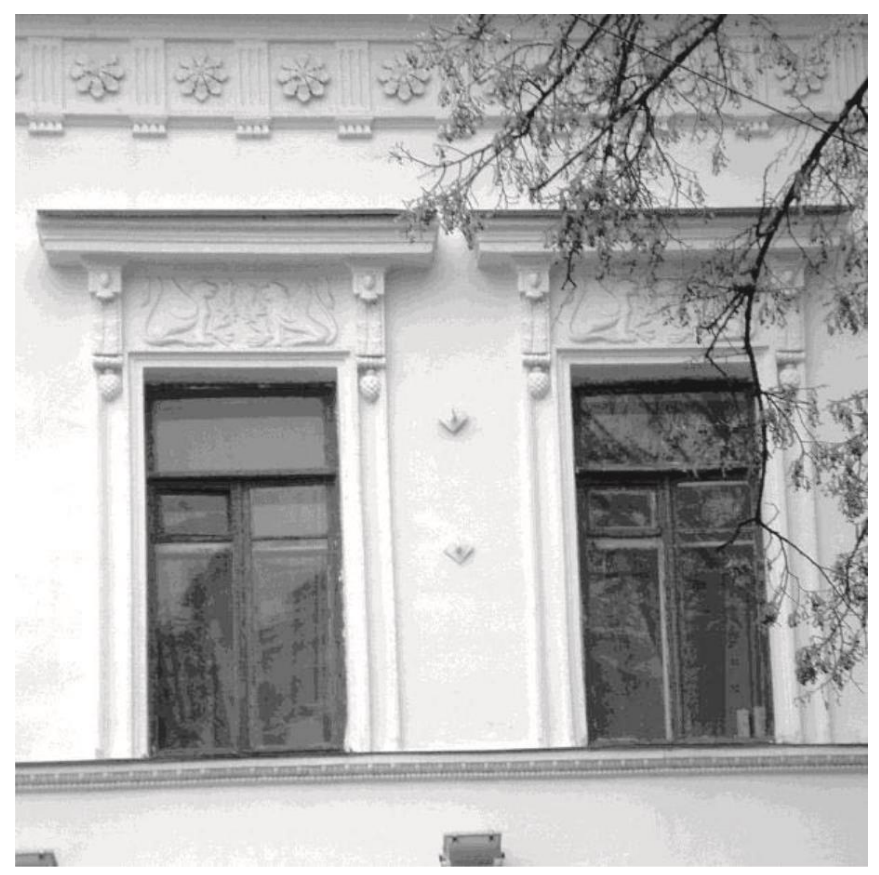

Fig. 7. Fragment of the facade of the building. Façade's tolerance fields.

Conclusion. Based on the concept of tolerance, we can conclude that the parts of the architectural form that should be taken into account when studying the proportionality and harmonization of the architectural form are the fields of tolerance. They determine the visually perceived dimensional structure and form the informative architectural form. The tolerance ratio will make it possible to create an algorithm for computer analysis of the proportionality of the facades of buildings and the harmonization of their dimensional structure. The harmonization of the buildings' facades with regard to the ratio of tolerance will lead to a visual ordering of the architectural form and a significant improvement of their aesthetic quality by increasing the comfort of visual perception.

\section{References}

1. E. Ziman, O. Byuneman. Tolerant spaces and the brain // On the Way to Theoretical Biology. - M.: "World", 1970.

2. G. Negai. Basic provisions of information theory of proportionality // Modern Problems of Architecture and Urban Planning. No. 7. - K.: KNUBA, 2000.

3. B.P. Mikhailov. Vitruvius and Hellas. Fundamentals of the Ancient Theory of Architecture. - M.: 1967.

4. Negai G.A. The information theory of proportionality in architecture // State of modern building science 2006 / IV International Scientific and Practical Internet Conference. Collection of scientific papers. - Poltava, 2006, - p. 225-231. 


\title{
Public Movements in Formation of Rehabilitation Services for Youth and Children with Disability: Advantages and Risks
}

\author{
Ostrolutska Larysa \\ Methodist of Kyiv City Center for Social Services for the Family, \\ Children and Youth (Ukraine, Kyiv)
}

\begin{abstract}
In this paper successful examples of activities of public sector in formation of relevant rehabilitation services for children and youth with disability during the time of Ukraine`s independence are reviewed. Adaptation strategies of parents for children disability are analyzed: "normalization", "altruism", "crusade", "obedience". The criteria of social inclusion are determined. The stages of persons with disability "entering" to the social life: adaptation, socialization, integration, inclusion. As a result of research rehabilitation services of non-governmental organizations were reviewed: Charitable Society for Assistance to People with Disabilities as a result of Intellectual Disorders "Dzherela", Lviv Regional Parental Association for the Protection of Children with Cerebral Palsy "Nadiya", All-Ukrainian Association of Persons with Disabilities "Active Rehabilitation Group", All-Ukrainian Charity Organization "Down Syndrome", Non-Governmental Organization "Feel". Development of rehabilitation services for people with disabilities by public movements has its own advantages and risks. The perspective direction of research could be foreseen combination of studying the processes of society democratization and the role of public associations in services development for children and youth with disabilities.

Key words: rehabilitation services, non-governmental organizations for people with disability, inclusion, children and youth with disability, social pedagogy
\end{abstract}

Актуальність дослідження. На початку 1990-х рр у незалежній Україні почали зароджуватись рухи людей з інвалідністю щодо забезпечення своїх конституційних прав на якісне життя. Умовно ми можемо розділити громадські організації, які об'єднують людей 3 інвалідністю, на три групи: громадські організації (ГО) батьків дітей 3 інвалідністю; молодіжні громадські організації осіб 3 інвалідністю; громадські організації осіб з інвалідністю. Також ці організації можуть функціонувати на різних суспільно-територіальних рівнях, що позначається їхнім статусом, як то: місцеві, всеукраїнські, міжнародні ГО.

Розвиток і вплив громадських рухів осіб з інвалідністю на суспільне і політичне життя вивчалися вітчизняними науковцями, як-от Д. Козел (щодо захисту дітей 3 інвалідністю), Г. Хворовою (роль батьківських організацій в формуванні батьківських компетенцій), В. Мельник (становлення недержавного соціального захисту осіб 3 інвалідністю), М. Заболотною (участь громадських організацій молоді з інвалідністю у формуванні і реалізації державної політики). Натомість науковий аналіз показав, що роль громадських рухів у становленні реабілітаційних послуг для дітей та молоді 3 інвалідністю не отримав достатнього представлення у науковій літературі. Тому, цей 
аспект спонукав нас поставити питання про роль громадської активності добровільних об’єднань людей щодо розвитку та ствердження системи реабілітаційних послуг для осіб 3 інвалідністю.

Метою статі постало оприлюднення результатів пілотажного дослідження щодо ролі громадських рухів осіб з інвалідністю у напрямку розбудови реабілітаційних послуг для дітей та молоді з інвалідністю на різних рівнях соціального функціонування як на місцевому, всеукраїнському так і міжнародному.

Виклад основного матеріалу. У сучасному розумінні інвалідність розглядається як результат взаємодії, яка відбувається між людьми, які мають порушення здоров'я, i відносицькими та середовищними бар'єрами і яка заважає повній та ефективній участі в житті суспільства на рівні з іншими [2]. На час зародження громадського руху осіб 3 інвалідністю (90-ті pp XX ст.), інвалідність розглядалась як індивідуальна медична проблема з причини «недієздатності» особи. Наразі українське суспільство пройшло певну трансформацію з розуміння інвалідності: від медичної до соціальної, із соціальної до правової і біопсихосоціальної моделей, і розглядає інвалідність як різноманіття людського роду, яка потребує додаткових послуг, обладнання або інших ресурсів для задоволення своїх потреб бути членом суспільства і вести самостійне життя [6; 7; 9; 10; 16; 17]. Науковцями визнається, що ситуація інвалідності може привести людину до складних життєвих обставин (далі СЖО), однак сам факт інвалідності не можна тлумачити у категоріях СЖО.

Проведений українським науковцями у 2001 р. аналіз можливості в Україні влаштування дітей-сиріт з функціональними обмеженнями у замінні сім’ї вказав на громадську активність осіб, які зіткнулися із ситуацією потреби дитини з інвалідністю у замінному догляді. Описані ними факти підтримки дітей з інвалідністю вказали на умови, за яких підтримуючі особи могли розвивати свою активність у розбудові реабілітаційних послуг для осіб з інвалідністю [11, с. 56-77]. Із проведеного дослідження можна зробити припущення, що саме життя дитини 3 інвалідністю та іï причетність до іï ситуації інвалідності може виступати критерієм тривалості активності дорослого щодо підтримки осіб з інвалідністю. Наразі питання влаштування дітей з інвалідністю у замінні сім’ї лише частково піднімаються в українських дослідженнях, як і рух щодо їх підтримки, що 
можна розглядати лише як перспективний напрямок розвитку соціальної політики [1, c. 77-96].

У контексті нашої роботи важливим внеском є дослідження американських вчених М. Селігмана та Р. Дарлінга. Вони вивчали рівні адаптації батьків щодо ситуації інвалідності дитини [5, с. 99]. У контексті розробленою ними шкали адаптації розглянемо стратегії батьків і громадських рухів осіб з інвалідністю до вирішення актуальних питань пов’язаних з інвалідністю (табл. 1).

Таблиця 1

Аналіз стратегій у контексті соціальних змін

\begin{tabular}{|l|l|l|}
\hline Стратегії адаптації & \multicolumn{1}{|c|}{ Дії } & \multicolumn{1}{c|}{ Типи залучення } \\
\hline «Нормалізація» & життя в суспільстві & $\begin{array}{l}\text { інклюзія; } \\
\text { інтеграція }\end{array}$ \\
\hline «Хрестовий похід» & $\begin{array}{l}\text { створення послуг; } \\
\text { зміни в суспільстві }\end{array}$ & $\begin{array}{l}\text { створення субкультури } \\
\text { субкультура, як тимчасове явище }\end{array}$ \\
\hline «Альтруїзм» & допомога іншим & $\begin{array}{l}\text { інклюзія } \\
\text { субкультура, як тимчасове явище }\end{array}$ \\
\hline «Покірність» & ізоляція & $\begin{array}{l}\text { задаптація, складні життєві } \\
\text { обставини }\end{array}$ \\
\hline
\end{tabular}

М. Селігман і Р. Дарлінг наголошували, що якісне залучення в суспільне життя досягають стратегії «Нормалізація» і «Альтруїзм». Натомість, стратегії типу «Хрестовий похід» і «Покірність» не можна охарактеризувати таким чином. При тому, що ці стратегії змінюються в залежності від потреб сімей, віку дитини, можливостей, рівня доступу до допомоги. Дослідники наголосили, що зазначена інформація допомагає зрозуміти стиль життя сім’ї, але іiї використання для стереотипізації сімей буде хибним кроком 3 посиленням тенденцій стигматизації та приписування ярликів. Натомість, на сучасному етапі видається доцільним доповнити уже зазначені типи залучення сімей реаліями сьогодення, як-то: інклюзія а також розділити поняття «субкультури», як явища, згідно часу його тривалості - тимчасова (стала).

Слід відмітити, що підхід «Нормалізація», який зародився в соціальній політиці Скандинавських країн у 60-х pp. XX ст. [14, с. 12], наголошує, що 1) у ситуації інвалідності людина може вести звичайний спосіб життя, як і решта людей, що включає: звичайний режим (робота і відпочинок, вільний час), 2) можливість планувати свій день і змінювати графік за бажанням чи потребою, 3) звичайний ритм тижня (робочі і вихідні 
дні); звичайний ритм року (свята і відпустки), 4) можливість переміщатися (жити в одному місці, а працювати в іншому), 5) звичайний розвиток життєвого циклу (дитинство, підлітковий вік, юність, зрілість, старість), 6) повагу і право до самовизначення, 7) стосунки, 8) звичайні для конкретної країни економічні права i можливості, 9) звичайні для конкретної країни вимоги до навколишнього середовища $\mathrm{i}$ житлових стандартів [5, с. 77]. Стратегія «Нормалізація» передбачає прийняття інвалідності всіма членами сім’ї і самою людини з інвалідністю (з врахуванням того, що кожний член сім’ї індивідуально проходить шлях прийняття в сенсовому і часовому вимірах), повернення до звичайного життєвого ритму всіх членів сім’ї (з урахуванням потреб члена сім'ї з інвалідністю), інклюзивне життя в суспільстві особи з інвалідністю.

Ще раз назвемо критерії соціального включення (інклюзіï), визначені Джудіт С. Райкус: 1) бути прийнятим і визнаним в якості особистості, 2) мати особисті взаємини 3 членами родини, друзями, знайомими, 3) бути включеним в дозвілля, відпочинок і інші суспільні заходи, 4) мати належне житло, 5) мати роботу, 6) мати формальну i неформальну підтримку. Зрозуміло, що така стратегія має на увазі створену систему підтримки осіб з інвалідністю і членів їх сімей, розвинуту сферу послуг і реабілітації, доступного середовища тощо. Водночас, на протилежній шкалі стратегії «Нормалізація» є стратегія «Покірність», яка ізолює сім’ю від суспільства, стигматизує інвалідність, знижує пошук підтримки і приводить до дезадаптації. Сім'я може не мати ресурсів підтримки з різних причині: відсутності послуг і організацій, бідність, низький рівень реабілітаційної культури, віддаленого проживання в тому числі. Члени сім’ї не беруть участь в громадських рухах із захисту прав осіб з інвалідністю, не мають спілкування 3 іншими сім'ями, які виховують дітей з інвалідністю. Така сім'я має ризик потрапити до складних життєвих обставин, знизити свій рівень якості життя, жити в стресі.

Стратегія «Хрестовий похід» об’єднує батьків дітей 3 інвалідністю чи осіб 3 інвалідністю для вирішення певних питань, захисту прав і змін у суспільстві пов’язаних 3 інвалідністю: створення послуг, медичне забезпечення, впровадження інклюзивної освіти, створення безбар'єрного середовища тощо. В разі створення необхідної системи підтримки переходять до стратегії «Нормалізація». Наш аналіз показав, що в умовах України ми спостерігаємо тенденцію «Хрестового походу» до вирішення певних питань, 
створення послуг для представників конкретної інвалідності (або вікової групи осіб 3 інвалідністю) і залишатися на цьому рівні не включаючись в життя всього суспільства.

Також було відмічено, що названі тенденції приводять до створення субкультури. Явище субкультури (національні, професійні, демографічні, географічні тощо) притаманне будь-якому суспільству, і є частиною нашої ідентичності, разом з тим і ми є частиною суспільства, а кожна субкультура має інтегруватися і посилювати загальну культуру суспільства. Субкультура може стати проблемою, коли замінює все суспільство і посилюється тенденції ізоляції засобом обмеження спілкування та взаємодії лише серед «своїх». Наше дослідження підтвердило, що субкультуру слід оцінювати як етап розвитку у напрямку інтеграції як один із кроків формування наступної ланки включення людей 3 інвалідністю у загальний соціальний процес. Наприклад, після розпаду Радянського Союзу випускники спеціальних шкіл-інтернатів (для дітей з інвалідністю) залишалися без професійного навчання і працевлаштування. Для вирішення цього питання у 1998 р. Благодійне товариство допомоги особам з інвалідністю внаслідок інтелектуальних порушень «Джерела» (м. Киї) створили програму «Випускник» (1997) для підготовки випускників інтернатних закладів до самостійного життя. 3 часом для них розробили програму «Трамплін» (1998), яка створювала умови для працевлаштування молоді зі зниженим інтелектом. 32000 року програма стала фінансуватись департаментом соціальної політики Київської міської державної адміністрації як спеціалізований центр [4]. Але, на жаль, для більшості відвідувачів центру програма не стала трампліном з працевлаштування, а залишила в цьому центрі до цього часу у якості субкультури, що домінуванням підтримуючої функції над розвивальною для іiі членів. Таким чином, ми спостерігаємо, що вирішення певного соціального питання осіб 3 інвалідністю може допомогти особам 3 інвалідністю адаптуватись через тимчасово створені умови і субкультуру, але може залишити їх в ній ізолюючі від суспільства.

Було встановлено, що стратегія «Альтруїзм» $\epsilon$ найменше розповсюджена в розвинутих країнах як стратегія адаптації сім’ї до ситуації інвалідності: після досягнення мети «Нормалізації», батьки знижують свою активність в діяльності організацій, участь в якій підкреслює стигматизуючий статус в суспільстві. Було встановлено, що розпочату активність продовжують лише ті батьки, які займали ведучі позиції на рівні регіональних і національних організацій. Зберегли свою позицію альтруїстів також і ті батьки, які 
вільно обирали цей тип адаптації для допомоги іншим батькам і ратували за просування змін. На нашу думку, в Україні, цей тип адаптації може мати два напрями: нормалізація/інклюзія/інтеграція або створення субкультури. При цьому створення субкультури може формуватися як етап на обраному шляху (тимчасова) задля підвищення адаптивних можливостей руху осіб з інвалідністю і членів їх сімей, переходу до нормалізації або як тенденція до відмежування та відчуження через створення самоізолюючої субкультури.

Українські дослідники О. Беспалько, І. Зверева, Г. Лактіонова, А. Капська вивчали базові дефініції соціальної педагогіки входження індивіда в суспільне життя, що супроводжується засвоєнням та відтворенням соціального досвіду. 3 урахуванням аналізу сучасної ситуації ми розглянемо етапи «входження» особи з інвалідністю в соціальне життя (табл. 2).

Таблиия 2

Етапи «входження» особи 3 інвалідністю в соціальне життя

\begin{tabular}{|c|c|c|c|c|}
\hline Eтап & Адаптація & Соціалізація & Інтеграція & Інклюзія \\
\hline 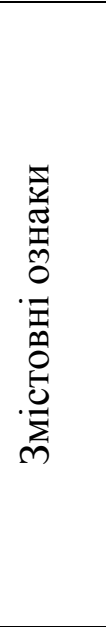 & $\begin{array}{l}\text { - види: } \\
\text { активна, } \\
\text { пасивна; } \\
\text { - етап } \\
\text { прийняття } \\
\text { інвалідності }\end{array}$ & $\begin{array}{l}\text { - види: стихійна, } \\
\text { відносно спрямована, } \\
\text { соціально- } \\
\text { контрольована; } \\
\text { - етапи: первинна, } \\
\text { вторинна; } \\
\text { - фактори: мікро-, мезо-, } \\
\text { мега-, макро-; } \\
\text { - соціально-педагогічні } \\
\text { механізми: традиційні, } \\
\text { інституціональні, } \\
\text { стилізовані, } \\
\text { міжособистісні }\end{array}$ & $\begin{array}{l}\text { - входження } \\
\text { існуючу } \\
\text { систему і } \\
\text { знаходження } \\
\text { свого місця; } \\
\text { - } \\
\text { підлаштування } \\
\text { під існуючі } \\
\text { норми і } \\
\text { цінності }\end{array}$ & $\begin{array}{l}\text { - нормалізація; } \\
\text { - соціальне } \\
\text { залучення; } \\
\text { - створення } \\
\text { власного простору; } \\
\text { - вплив на } \\
\text { суспільство; } \\
\text { - універсальний } \\
\text { дизайн послуг і } \\
\text { середовища }\end{array}$ \\
\hline
\end{tabular}

Таким чином, громадські організації осіб з інвалідністю можуть обрати шляхи для вирішення актуальних питань осіб з інвалідністю і залучення їх до життя в суспільстві через зміну нормативно-правового забезпечення, створення сервісних послуг, усунення соціальних бар'єрів, реалізації прав людей 3 інвалідністю тощо; всебічно сприяти нормалізації, самостійному життю осіб з інвалідністю, підвищенню якості життя, а також можуть створити субкультуру людей з інвалідністю, яка буде складатись із батьківських груп і ініціатив, регіональних громадських організацій, спеціалізованих мас-медія, регіональних і національних асоціацій осіб з інвалідністю [8]. 
Далі наведемо приклади діяльності громадських організацій щодо питань створення реабілітаційних послуг для осіб з інвалідністю.

У травні 1990 р. було створено Львівське обласне батьківське об'єднання захисту дітей з дитячим иеребральним паралічем «Надія», 31992 р. початок співпраці 3 волонтеркою 3 Канади 3. Кушпета, і спільно у 1993 р. створено «Навчальнореабілітащійний иеетр «Джерело». Ініціативу підтримали Львівська міська рада і департамент соціальної політики м. Львова.

Роботу розпочали з двох груп для дошкільнят, у 1994 р. було розпочато будівництво приміщення власного центру. За фінансової підтримки Українськоканадської програми «Партнери у сфері охорони здоров’я» у 1994-1995 рр. було створено навчальну програму підготовки спеціалістів фізичної реабілітації у Львівському державному інституті фізичної культури. В 1996 р. створена перша інклюзивна навчальна програма в поєднанні з реабілітацією в загальноосвітній школі № 82 (м. Львів). Роками пізніше було відкрито приміщення центру (2002) і розпочалась програма раннього втручання. На сьогодні центр надає реабілітаційні, соціальні, освітні послуги у відділеннях: садок-школа для дітей від 3-18 років (з важкими комбінованими формами інвалідності); відділення раннього втручання працює з дітьми від 4 років (має два філіали в дитячих поліклініках міста); відділення розвитку дитини (заняття 3 логопедом, психологом, фахівцем фізичної реабілітації, спеціальним педагогом); майстерні (денні реабілітаційні програми для осіб з інвалідністю старших 18 років). Центр має тренінговий центр і відділ соціальних проектів і розвитку. Щодня центр відвідує 200 вихованців [3].

Всеукраӥнське об’єднання осіб з інвалідністю «Група Активної Реабілітації» (ВГОI «ГАР») створена з метою здійснення заходів активної реабілітації осіб з травмами хребта і ураженням спинного мозку (які користуються кріслом колісним), самостійного життя, включення людей після травми хребта в усі аспекти життя. Організація діє в Україні з 1991 р., офіційно зареєстрована лише в 2002 р. У співпраці Із Шведською неурядовою організацією Рекрітерінгс Группен (Rekryteringsgruppen) українські активісти пройшли навчання методам активної реабілітації за методом «рівний-рівному». Активна реабілітація розглядається як комплекс заходів із застосуванням засобів фізичної культури і спорту, спрямованих на самообслуговування, максимальну незалежність у повсякденному житті і побуті, інтеграцію і громадську активність 
людини, яка перенесла травми або захворювання хребта і спинного мозку, і внаслідок цього пересувається на інвалідному візку. Основними складовими процесу активної реабілітації є фізична, психологічна та соціальна реабілітація. Організація здійснює три головні напрями: 1) проведення щорічних Таборів активної реабілітації, 2) перший контакт, 3) семінари фахівцям. Метою Табору активної реабілітації є досягнення людиною в колясці максимальної незалежності від сторонньої допомоги, і тим самим, поліпшення якості свого життя. Філософія табору грунтується на гаслі: «навчився жити в колясці сам - навчи іншого». Головну роль у процесі навчання грають інструктори в колясках, які мають психоемоційний вплив на учасників табору, оскільки є переконливим прикладом можливості вести повноцінне життя на рівні зі звичайними людьми. Методика проведення таборів активної реабілітації прийнята від Шведської неурядової організації Рекрітерінгс Группен (Rekryteringsgruppen). В Україні табори активної реабілітації проводяться з 1991 р. і реалізуються виключно ВГОІ «ГАР», за підтримки Українського центру «Інваспорт» 32002 р. і окремих благодійників. За роки діяльності табори реабілітували тисячу осіб з інвалідністю. Майже всі українські параолімпійські спортсмени і чемпіони свій спортивний шлях розпочали в таборах активної реабілітації.

Програма «Периий контакт»: створена для людей, які отримали травми спинного мозку і знаходяться в лікарні або реабілітаційному центрі. Перший контакт 3 інструкторами активної реабілітації надає людини після травми всебічної інформаційної підтримки, заохочення його до занять фізичними вправами і активного способу життя, попередження вторинних розладів і порушень. Інструктори першого контакту - це, в більшості випадків, люди, які перенесли такі ж травми хребта і спинного мозку і $є$ прикладом можливостей людей, які живуть в інвалідному візку, вміло ним володіють, самостійні у побуті і несуть теоретичні та практичні знання в сфері проблем і потреб людей після травм. Для розповсюдження досвіду і методу активної реабілітації ВГОІ «ГАР» проводяться семінари для працівників медичних закладів, які працюють 3 особами з травмами хребта (лікарі, реабілітологи, медсестри, інструктори ЛФК), а також з викладачами вищих навчальних закладів, які мають відношення до реабілітації. Мета навчань - показати потреби і можливості людини з травмою хребта і спинного мозку в пост лікарняний період [13]. 
Всеукраӥнська благодійна організаиія «Даун Синдром» заснована батьками дітей у 2004 p., а з 2010 р. є членом Європейської Асоціації Даун Синдром (European Down Syndrome Association). Громадська організація почала проводити активні просвітницькі кампанії з популяризації і розуміння осіб з синдромом Дауна (інформаційна кампанія 3 зірками культури та спорту України «Діти як діти, тільки 3 синдромом Дауна», організовано гастролі голандського Jostiband Orkest музикантів з інтелектуальною інвалідністю, започаткувала відзначання в Україні Дня осіб з синдромом Дауна 21 березня. В 2006 році започаткований проект із Київським департаментом охорони здоров'я Виконавчого органу КМДА та Київським центром соціальних служб для сім'ї, дітей та молоді з консультування породіль при народжені дитини з синдромом Дауна. Цей проект виявив національну прогалину з відсутності клінічного протоколу по синдрому Дауна для медиків, що часто приводило до того, що діти з синдромом Дауна не обстежували профільними фахівцями вчасно і багато проблем «списувалося» на наявність хромосомної аномалії. Сьогодні ВБО «Даун Синдром» реалізує проекти раннього втручання, освіти, працевлаштування дітей і молодих осіб з синдромом Дауна, надає підтримку батькам і сім'ям, має мережу організацій по Україні. Центр раннього розвитку надає професійні консультативно-педагогічні консультації дітям з синдромом Дауна від народження до 8 років. Проект організаиії - «Перспектива 21-3» має на меті створення перспективи для дітей з трисомією 21-ї хромосоми (синдром Дауна) та інших дітей з порушенням розумового розвитку в Україні у XXI столітті у трьох сферах життя: навчання, працевлаштування та самостійне проживання (з супроводом). Спільно зі спеціалізованою школою-інтернатом №26 (м. Київ), під науковим супроводом Національного інституту спеціальної педагогіки було розроблено новітні методики і впроваджені навчальні програми дітей із синдромом Дауна в освітнє середовище з 2011 p. Ці класи носять назву «Радість», в них навчається більше тридцяти учнів 3 різним спектром проблем розвитку від затримки психологічного розвитку до синдрому Дауна. В кожному класі навчається не більше 4х дітей з синдромом Дауна. 32017 р. організація реалізує проект «Підтримане пращевлаштування» 3 працевлаштування молодих осіб 3 синдромом Дауна в мережі магазинів «Ашан» [15].

Громадська організаиія «Відчуй» (м. Київ), заснована в 2011 р. $з$ метою 
адаптації осіб $з$ порушенням слуху, реалізувала 15 всеукраїнських проектів, зарекомендувала себе серед сімей, які виховують дітей з порушенням слуху і спеціалістів різних спеціальностей. Протягом року організація надає реабілітаційні послуги дітям 3 порушенням слуху і підтримку сім'ям, в яких вони виховуються за такими напрямами: «Дитячий центр» (послуги з розвитку і корекції слухо-мовленєвої функції), «Клуб юніор» (психологічна підтримка, розвиток творчих здібностей, розвиток комунікаційних навичок для підлітків 38 до 12 років), «Підлітковий клуб Тееуs» (пошук друзів, підготовка до дорослого життя, клубні зустрічі, охоплює учасників 312 до 20 років) [12].

Висновки. Діяльність громадських організацій осіб з інвалідністю, як вираження потреб громадськості та прояв соціальної активності, є дієвою силою впливу на сучасну ситуацію щодо створення системи реабілітаційних послуг для осіб з інвалідністю впродовж їхнього життя. Встановлено, що критерієм, який може визначати термін включення громадських активістів у громадський рух, часто виступає тривалість життя особи з інвалідністю. Серед ризиків громадського сектору є 1) низький рівень розвитку демократичних процесів у самих організаціях, 2) низька активність осіб з інвалідністю в діяльності громадського сектору, 3) створення сталих субкультур осіб з інвалідністю без включення їх у суспільство, 4) фінансова залежність від грантів чи благодійників. Перевагами громадського сектору в розвитку реабілітаційних послуг $є$ розуміння актуальних потреб осіб з інвалідністю і дефіцитів послуг; створення нових сервісів для осіб з інвалідністю; залучення до співпраці міжнародних партнерів, науковців, державних організацій; довіра людей 3 інвалідністю і членів їх сімей; гнучкість і мобільність в плануванні своєї діяльності; публічне обговорення суспільних проблем.

Перспективним напрямком дослідження можна передбачити поєднання вивчення процесів демократизації суспільства і ролі громадських об'єднань щодо розвитку реабілітаційних послуг для дітей і молоді з інвалідністю.

\section{References}

1. Bevz H.M., Pesha I.V. Dytyna v pryiomni simi: notatky psykholoha [The child in foster care: notes from a psychologist]. Kyiv: Ukrainskyi in-t sotsialnykh doslidzhen, 2001. 101 p.

2. Konventsiia pro prava osib z invalidnistiu [Convention on the Rights of Persons with Disabilities]: Verkhovna Rada Ukrainy. 2006, Hrud. 13. URI: https://zakon.rada.gov.ua/laws/show/995_g71 
3. Istoriia Dzherela / sait Navchalno-reabilitatsiinoho tsentru «Dzherelo». URI : https://dzherelocentre.org.ua/istoriya-dzherela/

4. Istoriia stanovlennia / sait Blahodiinoho tovarystva dopomohy osobam $\mathrm{z}$ invalidnistiu vnaslidok intelektualnykh porushen «Dzherela». URI :

http://www.djerela.org/index.php/uk/pro-nas/istoriya-stvorennya

5. Obychnye semiy, osobye deti [Ordinary families, special children]: [per. s anhl.] / Selihman M., Darlynh R. Izd. 2-e. Moskva: Terevynf, 2009. 368 p.

6. Ostrolutska L.I. Sotsialna robota $z$ ditmy ta moloddiu $z$ invalidnistiu: mifi ta ukrainska realnist [Social work with children and youth with disabilities: myths and Ukrainian reality]. Pedahohichnyi Almanakh. 2012. No.16. P. 242-247.

7. Ostrolutska L I. Sotsialna robota $z$ ditmy ta moloddiu $z$ invalidnistiu: mify ta ukrainska realnist. Chastyna 2. [Social work with children and youth with disabilities: myths and Ukrainian reality. Part 2.]. Visnyk Kyivskoho natsionalnoho un-tu red imeni Tarasa Shevchenka «Sotsialna robota»: zb. nauk. pr. Kyiv. 2017. No. 2 (2). P. 16-19.

8. Ostrolutska L.I. Sotsialno-pedahohichni kompetentsii spetsialistiv sotsialnoi roboty $z$ ditmy ta moloddiu $z$ invalidnistiu ta yikh simiamy. [Social and pedagogical competencies of social work professionals with children and young people with disabilities and their families]. Visnyk Kyivskoho natsionalnoho universytetu imeni Tarasa Shevchenka "Sotsialna robota": zb. nauk. pr. Kyiv. 2017. No. 1 (1). P. 57-63.

9. Pet'ko L.V.English for students with specialization Psychology and Special Education”. Didactic material for practical classes and independent work of students in a foreign language specialties 6.010105 "Special Education", 6.030102 "Psychology", 6.030103 "Practical Psychology" : navch. posibnik dlya studentiv ta vykladachiv VNZ. Kyiv: Talkom, 2015. 160 p.

10. Petko L V. Realizatsiia kontseptsii pidhotovky mahistriv $v$ Ukraini dlia roboty $v$ inkliuzyvnomu osvitnomu prostori [The conception of the preparation masters' in Ukraine Implementation to work in an inclusive educational environment] // Aktualni problemy navchannia ta vykhovannia liudei v intehrovanomu osvitnomu seredovyshchi: Tr. KhI Mizhnar. nauk.-prakt. konf., lystopad 2011 r. Part I. Kyiv: VMURL «Ukraina». 2011. P. 92-94.

11. Pryiomni simi dlia ditei-syrit z funktsionalnymy obmezhenniamy [Foster families with orphans with functional limitations] / O.O.Yaremenko (kerivnyk avt. kol.) N.M. Komarova [ ta in.]. Kyiv : Ukrainskyi in-t sotsialnykh doslidzhen, 2001.120 p.

12. Pro nas / sait hromadskoi orhanizatsii «Vidchui».URI : https://vidchui.org/pro-nas/

13. Pro orhanizatsiiu [About organization] / sait Vseukrainskoho obiednannia osib z invalidnistiu «Hrupa Aktyvnoi Reabilitatsii». URI : https://gar.org.ua/about/

14. Put k rabote: Novyi vzghliad na reabylytatsyiu [The Road to Work: A New Look at Rehabilitation] / Per. so shvedsk. T. Antonchyk, L. Kopochel, O. Sochneva. - Minsk : UP «Tekhnoprynt», 2004. $256 \mathrm{p}$.

15. Tsentr rannoho rozvytku [The center of early development] / sait Vseukrainskoi blahodiinoi orhanizatsii «Daun Syndrom».

URI : http://downsyndrome.org.ua/centr-rannego-razvitiya 
16. Kusol Yevgen. Autism and a Child / Yevgen Kusol, Lyudmila Pet'ko // Materiály X mezinárodní vědecko - praktická konference «Věda a vznik - 2013/2014». - Díl 26. Psychologie a sociologie ; Šéfredaktor: Prof. JUDr Zdenĕk Černák. - Praha : Publishing House «Education and Science» S.r.o, 2014. S. 44-46.

17. Pet'ko Lyudmila. Braille System of Tactile Dots For Blind People / Lyudmila Pet'ko, Repetylo Elisabeth // Intellectual Archive, 2014. Vol. 3. No 2. Toronto : Shiny Word Corp. (Canada). P. 99-104.

Translation of the Title, Abstract and References to the Author's Language

\section{УДК 37.013.42+364.57+364.62}

Остролуцька Лариса. Громадські рухи щодо становлення реабілітаційних послуг для дітей та молоді з інвалідністю: переваги та ризики.

Розглянуто успішні приклади діяльності громадського сектору у створенні актуальних реабілітаційних послуг дітям та молоді 3 інвалідністю в Україні часів незалежності. Проаналізовано стратегії адаптації батьків до інвалідності дитини: «нормалізація», «альтруїзм», «хрестовий похід», «покірність» і визначені критерії соціального включення. Окреслено етапи «входження» особи з інвалідністю в соціальне життя: адаптація, соціалізація, інтеграція, інклюзія. Розглянуто реабілітаційні послуги громадських організацій: Благодійне товариство допомоги особам 3 інвалідністю внаслідок інтелектуальних порушень «Джерела», Львівське обласне батьківське об’єднання захисту дітей з дитячим церебральним паралічем «Надія», Всеукраїнське об’єднання осіб з інвалідністю «Група Активної Реабілітації», Всеукраїнська благодійна організація «Даун Синдром», Громадська організація «Відчуй».

Розбудова реабілітаційних послуг особам з інвалідністю громадськими рухами має свої визначені в статті переваги і ризики. Перспективним напрямком дослідження передбачено поєднання вивчення процесів демократизації суспільства і ролі громадських об’єднань щодо розвитку реабілітаційних послуг для дітей і молоді з інвалідністю.

Ключові слова: реабілітаційні послуги, громадські організації осіб з інвалідністю, інклюзія, діти та молодь з інвалідністю, соиіальна педагогіка.

\section{Остролуцкая Лариса. Общественные движения становления реабилитационных услуг для детей и молодежи с инвалидностью: преимущества и риски.}

Рассмотрены успешные примеры деятельности общественного сектора в создании актуальных реабилитационных услуг детям и молодежи с инвалидностью в Украине времен независимости. Изучены стратегии адаптации родителей к инвалидности ребенка: «нормализация», «альтруизм», «крестовый поход», «покорность» и определены критерии социального включения. Отмечены этапы «вхождения» человека с инвалидностью в социальную жизнь: адаптация, социализация, интеграция, инклюзия.

В результате исследования рассмотрены реабилитационные услуги общественных организаций: Благотворительное общество помощи лицам с инвалидностью вследствие интеллектуальных нарушений «Джерела», Львовское областное родительское объединение защиты детей с детским церебральным параличом «Надежда», Всеукраинское объединение лиц с инвалидностью «Группа активной 
реабилитации», Всеукраинская благотворительная организация «Даун Синдром», Общественная организация «Відчуй».

Развитие реабилитационных услуг лицам с инвалидностью общественными движениями имеет свои определённые в статье преимущества и риски. Перспективным направлением исследования можно предположить сочетание изучения процессов демократизации общества и роли общественных объединений по развитию реабилитационных услуг для детей и молодежи с инвалидностью.

Ключевые слова: реабилитационные услуги, общественные организации лии с инвалидностью, инклюзия, дети и молодежь с инвалидностью, сочиальная педагогика.

\section{Література}

1. Бевз Г. М., Пеша I. В. Дитина в прийомні сім’ї: нотатки психолога. Київ : Український ін-т соціальних досліджень, 2001. 101 с.

2. Конвенція про права осіб з інвалідністю: Верховна Рада України. 2006. Груд. 13. URI : https://zakon.rada.gov.ua/laws/show/995_g71

3. Історія Джерела [Електронний сайт] / сайт Навчально-реабілітаційного центру «Джерело». URI : https://dzherelocentre.org.ua/istoriya-dzherela/

4. Історія становлення / сайт Благодійного товариства допомоги особам 3 інвалідністю внаслідок інтелектуальних порушень «жерела». URI : http://www.djerela.org/index.php/uk/pro-nas/istoriya-stvorennya

5. Обычные семьи, особые дети: [пер. с англ.] / Селігман М., Дарлинг Р. Изд. 2-е. Москва : Теревинф, 2009. 368 с.

6. Остролуцька Л. І. Соціальна робота з дітьми та молоддю з інвалідністю: міфі та украӥнська реальність. Педагогічний Альманах. 2012. № 16. С. 242-247.

7. Остролуцька Л. І. Соціальна робота з дітьми та молоддю з інвалідністю: міфи та українська реальність. Частина 2. Вісник Київського національного ун-ту імені Тараса Шевченка «Сочіальна робота» : зб. наук. пр. 2017. № 2 (2). С. 16-19.

8. Остролуцька Л. І. Соціально-педагогічні компетенції спеціалістів соціальної роботи з дітьми та молоддю з інвалідністю та їх сім’ями. Вісник Київського національного університету імені Тараса Шевченка «Сочіальна робота» : зб. наук. пр. Київ, 2017. № 1 (1). C. 57-63.

9. Петько Л.В. Англійська мова для студентів-психологів та дефектологів. Дидактичний матеріал для практичних занять та самостійної роботи студентів 3 іноземної мови зі спеціальностей: 6.010105 «Корекційна освіта (за нозологіями)», 6.030102 «Психологія», 6.030103 «Практична психологія»: навч. посібник для студентів, магістрантів, аспірантів. Київ: Талком, 2015. 160 с.

10. Петько Л В. Реалізація концепції підготовки магістрів в Україні для роботи в інклюзивному освітньому просторі // Актуальні проблеми навчання та виховання людей в інтегрованому освітньому середовищі: Тр. ХІ Міжнар. наук.-практ. конф., листопад 2011 р. Ч. І. Київ: ВМУРЛ «Україна». 2011. С. 92-94. 
11. Прийомні сім'ї для дітей-сиріт з функціональними обмеженнями / О. О. Яременко (керівник авт. кол.) Н. М. Комарова, Р. Я. Левін та ін. Київ : Український ін-т соціальних досліджень, 2001. 120 с.

12. Про нас / сайт громадської організації «Відчуй» URI : https://vidchui.org/pro-nas/

13. Про організацію / сайт Всеукраїнського об’єднання осіб з інвалідністю «Група Активної Реабілітації». URI : https://gar.org.ua/about/

14. Путь к работе: новый взгляд на реабилитацию / Пер. со шведск. Т. Антончик, Л. Копочель, О. Сочнева. Мінськ : УП «Технопринт», 2004. 256 с., ил.

15. Центр раннього розвитку / сайт Всеукраїнської благодійної організації «Даун Синдром». URI : http://downsyndrome.org.ua/centr-rannego-razvitiya

16. Kusol Yevgen. Autism and a Child / Yevgen Kusol, Lyudmila Pet'ko // Materiály X mezinárodní vědecko - praktická konference «Věda a vznik - 2013/2014». - Díl 26. Psychologie a sociologie ; Š́fredaktor: Prof. JUDr Zdeněk Černák. - Praha : Publishing House «Education and Science» s.r.o, 2014. S. 44-46.

17. Pet'ko Lyudmila. Braille System of Tactile Dots For Blind People / Lyudmila Pet'ko, Repetylo Elisabeth // Intellectual Archive, 2014. Volume 3. Number 2. Toronto : Shiny Word Corp. (Canada). P. 99-104. 


\title{
Organizational and Pedagogical Conditions of Future Social Workers' Professional Training for Social Leadership
}

\author{
Bybyk Daria \\ ORCID ID: $h t t p: / / o r c i d . o r g / 0000-0001-9947-8503$ \\ Postgraduate at the Department of Theory and Technology of Social Work \\ Dragomanov National Pedagogical University (Ukraine, Kyiv)
}

\begin{abstract}
This article is devoted to the study of the need to improve the scientific and methodological support for the professional training of future social workers. Relevance determined the choice of research objectives: to identify the forms and methods of implementing the preparation of future social workers for social leadership.

It was determined that social leadership is the main resource that provides a holistic view of the modern specialist, who should not only be prepared for future professional activity, but also be able to navigate independently in the stream of socio-economic changes, creatively solving professional tasks of social work. Particular attention is concentrated on the features of the use of forms and methods of training social workers. This is noted the prospects of the ideas of social leadership in the development and implementation of the scientific and methodological complex, the success of which is determined by the need to find new ways to improve the quality of theoretical training, the ability to work independently, and professional self-development of students. Non-traditional forms and interactive methods of vocational teaching students provide enhanced training opportunities for social leadership.

Key words: professional training, social worker, social leadership, organisational and pedagogical conditions, non-traditional forms of training, interactive teaching methods.
\end{abstract}

Актуальність дослідження. Сучасна Україна намагається проводити реформи в ситуації постреволюційного суспільства, а також в умовах гібридної війни. Зважаючи, на це, перед професійною підготовкою майбутніх соціальних працівників постає завдання підготувати фахівців здатних до вирішення соціальних проблем, що вимагатиме пошуку шляхів забезпечення максимального прояву особистісного потенціалу та соціального лідерства. Орієнтування на вирішення соціальних проблем та проблем клієнта стає пріоритетним серед різних моделей лідерства, оскільки лідерство узгоджується з цілями і цінностями соціальної робити, які лежать в основі професії «соціальний працівник» [16]. Зокрема, цілі професійної діяльності у соціальній сфері проявляються у змінах, зміщенні, розвитку людини, iï уявлень, розуміння ситуацій, iï практичних уміннях і навичках, набутих у цілеспрямованій діяльності [4; 7; 15; 17].

Об’єктивна соціальна значущість професійної підготовки майбутніх соціальних працівників до соціального лідерства переконливо доводить необхідність пошуку організаційно-педагогічних умов щодо виявлення й удосконалення різних форм і методів 
навчання та виховання, які орієнтовані на особистісний і професійний розвиток, передбачають необхідність актуалізації лідерського потенціалу. Крім того, формування готовності студентів до соціального лідерства має забезпечити реалізацію інноваційних напрямів технологізації професійної діяльності в галузі соціальної роботи.

Професійна підготовка як напрям наукової методології представлено досить поширено у соціально-педагогічних працях та дослідженнях в галузі соціальної роботи (А.Капської, І.Звєрєвої, Л.Міщик, В.Поліщук, С.Харченко, В.Васильєв, Ю.Галагузова, П.Гусак, І.Козубовська, Р.Куличенко, О.Карпенко). Останнім часом форми, методи й технології професійної діяльності у різних осередках соціальної сфери та підготовка майбутніх фахівців до їх застосування розглядалися у дослідженнях І.Дичківської, О.Дубасенюк, С.Коляденко, В.Ковальчук, О.Лісовця, Л.Міщик, Н.Павлік, Р.Петришин, Н.Сейко, Т.Шанскова та ін. Лідерство є темою міжнародних дебатів як в сфері освіти, так і в сфері соціальної роботи. Однак залишаються питання щодо того, які конкретні моделі лідерства слід визначати, і як зміст лідерства повинно бути включено в програму підготовки до соціальної роботи [11].

Загальновідомо, що процес і результат оволодіння цінностями соціальнопедагогічної діяльності, професійно необхідними знаннями, вміннями й навичками, професійно важливими особистісними якостями становлять основу формування готовності до професійної соціально-педагогічної діяльності [9], а процес формування фахівця нового типу, здатного швидко й адекватно реагувати на зміни, що відбуваються в суспільстві сприятиме формуванню компетентності у вирішенні соціальнопедагогічних проблем [5]. Проте, проблема професійної підготовки соціальних працівників до соціального лідерства потребує

спеціального грунтовного вивчення з метою виявлення ефективних форм та методів навчання і виховання майбутніх фахівців.

Виклад основного матеріалу. Стрімкий розвиток фахової підготовки соціальних працівників, зростання значення соціальної роботи щодо подолання суспільних проблем та соціально небезпечних явищ, зумовлює потребу узагальнення тенденцій розвитку як соціальної роботи, так і фахової підготовки соціальних працівників щодо їх впливу на організаційні шляхи реалізації основних напрямів, умов та результатів оновлення змісту, форм та методів навчання [10]. Одним із аспектів, що викликає найбільший інтерес, $є$ 
виявлення, обгрунтування та перевірка умов, які забезпечують успішність здійснюваної діяльності.

Сучасний стан вищої освіти вимагає зосередження уваги на якості професійної підготовки щодо набуття компетенцій майбутніми соціальними працівниками. Тому виникає гостра потреба сформувати лідерів в соціальній сфері, здатних здійснювати професійну діяльність, спрямовану на активізацію особистісного зростання як основи їх життєвого ствердження, реалізації професійного призначення. Оскільки формування готовності майбутніх соціальних працівників до соціального лідерства є динамічним та складним процесом, то його ефективність стає можливою через застосування сукупності організаційно-педагогічних умов професійної підготовки.

3 метою виявлення організаційно-педагогічних умов професійної підготовки майбутніх соціальних працівників було проведено експертне опитування викладачів закладів вищої освіти, які здійснюють професійну підготовку майбутніх соціальних працівників в Україні. Опитування викладачів у якості експертів надало нам можливість визначати важливість та значущість організаційно-педагогічних умов підготовки студентів до соціального лідерства, які були попередньо виділено нами шляхом опрацювання педагогічної та навчально-методичної літератури. Визначення експертами найбільш важливі організаційно - педагогічні умови за п'ятибальною шкалою, забезпечило достатню вірогідність отриманих результатів та надало нам можливість визначити саме ті умови, що мають бути реалізовані в процесі професійної підготовки студентів до соціального лідерства (табл. 1).

Таблиия 1

Визначення значущості організаційно-педагогічних умов підготовки студентів до соціального лідерства

\begin{tabular}{|c|c|c|c|}
\hline \multirow{2}{*}{$\begin{array}{l}\text { № } \\
\text { I/H }\end{array}$} & \multirow{2}{*}{$\begin{array}{l}\text { Організаційно-педагогічні умови } \\
\text { підготовки соціальних працівників }\end{array}$} & \multicolumn{2}{|c|}{ Кількість оцінок } \\
\hline & & абсол. & у $\%$ \\
\hline 1. & $\begin{array}{l}\text { Міжпредметна координація у навчанні професійних } \\
\text { дисциплін та дисциплін загально гуманітарного } \\
\text { циклу }\end{array}$ & 56 & 39,2 \\
\hline 2. & $\begin{array}{l}\text { Формування позитивної навчально-професійної } \\
\begin{array}{l}\text { мотивації через залучення до професійно- } \\
\text { орієнтованої діяльності науково-дослідницької } \\
\text { діяльності }\end{array}\end{array}$ & 61 & 42,7 \\
\hline 3. & $\begin{array}{l}\text { Вдосконалення особистісних і професійних якостей } \\
\text { за допомогою впровадження тренінгової технології }\end{array}$ & 23 & 16,1 \\
\hline
\end{tabular}




\begin{tabular}{|c|c|c|c|}
\hline 4. & $\begin{array}{l}\text { Забезпечення науково-дослідницького змісту } \\
\text { дисциплін фундаментальної, професійної } \\
\text { практичної підготовки соціальних працівників }\end{array}$ & 37 & 25,9 \\
\hline 5. & $\begin{array}{l}\text { Формування мотиваційної основи готовності через } \\
\text { упровадження особистісно орієнтованого навчання }\end{array}$ & 34 & 23,8 \\
\hline 6. & $\begin{array}{l}\text { Імплементація інноваційних } \\
\text { дослідницького, проблемного і саморегульованого) } \\
\text { підходів у освітній процес }\end{array}$ & 21 & 14,7 \\
\hline 7. & $\begin{array}{l}\text { Систематичність, цілеспрямованість, тривалість та } \\
\text { цінність неформального навчання в професійній } \\
\text { підготовці майбутніх фахівців соціальної сфери }\end{array}$ & 56 & 39,2 \\
\hline 8. & 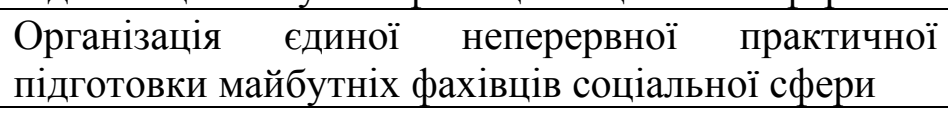 & 5 & 3,5 \\
\hline 9. & 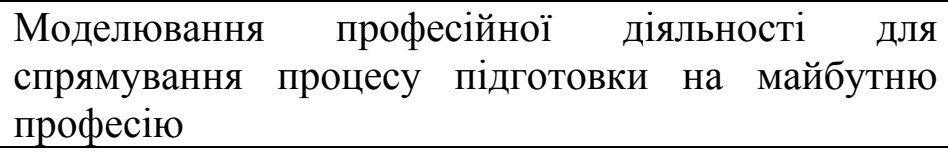 & 9 & 6,3 \\
\hline 10. & $\begin{array}{l}\text { Комплексне використання різних (самостійної, } \\
\text { культурно-дозвіллєвої і волонтерської) видів поза } \\
\text { аудиторної роботи }\end{array}$ & 41 & 28,7 \\
\hline 11. & $\begin{array}{l}\text { Орієнтація на мотиви, інтереси, потреби, установки } \\
\text { учасників неформальної освіти }\end{array}$ & 9 & 6,3 \\
\hline 12. & $\begin{array}{l}\text { Дотримання принципу зв’язку навчання з життям та } \\
\text { практико орієнтованої } \quad \text { місії } \\
\text { навчання }\end{array}$ & 10 & 7 \\
\hline 13. & $\begin{array}{l}\begin{array}{l}\text { Упровадження } \\
\text { технологій }\end{array} \\
\end{array}$ & 53 & 37,1 \\
\hline 14. & $\begin{array}{l}\text { Організація неформальних специфічних структур } \\
\text { середовища підготовки соціальних працівників до } \\
\text { соціального лідерства }\end{array}$ & 87 & 60,9 \\
\hline 15. & $\begin{array}{l}\text { Використання особистісного підходу як базової } \\
\text { ціннісної орієнтації, що визначає стратегію } \\
\text { взаємодії викладача і студента }\end{array}$ & 42 & 29,4 \\
\hline 16. & Розробка навчально-методичного забезпечення & 34 & 23,8 \\
\hline 17. & $\begin{array}{l}\text { Розширення знань } \quad \text { майбутніх соціальних } \\
\text { працівників про сутність соціального лідерства }\end{array}$ & 75 & 52,5 \\
\hline 18. & $\begin{array}{l}\text { Координація методів і технологій формування } \\
\text { професійної комунікативної компетентності }\end{array}$ & 16 & 11,2 \\
\hline 19. & $\begin{array}{l}\text { Систематизація теоретичних знань засобами } \\
\text { інформаційно-комунікативних технологій }\end{array}$ & 8 & 5,6 \\
\hline 20. & 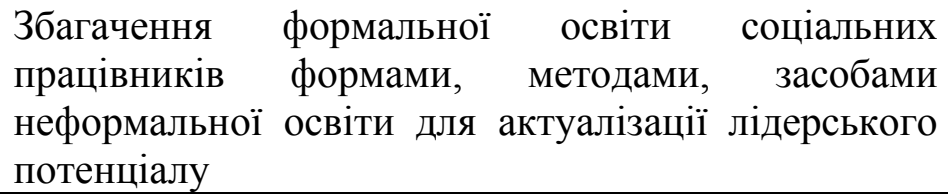 & 82 & 57,4 \\
\hline 21. & $\begin{array}{l}\text { Врахування соціальних } \\
\text { педагогічних папитів } \text { па суходів до вибору змісту, форм і } \\
\text { методів неформальної освіти }\end{array}$ & 12 & 8,4 \\
\hline
\end{tabular}


Спираючись на результати експертного опитування з урахуванням взаємозв'язку сукупності обставин і чинників до організації професійної підготовки майбутніх соціальних працівників було обрано умови, що забезпечать формування готовності студентів до соціального лідерства:

1. Розширення знань майбутніх соціальних працівників про сутність соціального лідерства;

2. Організація неформальних специфічних структур середовища підготовки соціальних працівників до соціального лідерства;

3. Збагачення формальної освіти соціальних працівників формами, методами, засобами неформальної освіти для актуалізації лідерського потенціалу студентів.

Так, дотримання визначених організаційно-педагогічних умов, які розглядаємо враховуючи специфіку формування готовності студентів до соціального лідерства потребує удосконалення форм і методів професійної підготовки майбутніх соціальних працівників.

Першою умовою формування готовності майбутніх соціальних працівників до соціального лідерства є розширення знань про сутність соціального лідерства. Зазначена умова вбирає в себе розробку інтегрованих курсів «Основи лідерства» (90 год. / 3 ЕСТS) та «Соціальне лідерство» (90 год. / 3 ECTS). Розширення знань про сутність соціального лідерства відбувалося завдяки реалізації нетрадиційних форм та методів організації освітнього процесу підготовки (інтерактивні лекції, дискусії, мультимедійні презентації, обговорення, проектний метод, групова робота, тренінгові вправи, аналіз ситуацій, рольові ігри), що сприяли вдосконаленню змісту підготовки соціальних працівників до соціального лідерства. Забезпечення уявлень про лідерство, види та механізми формування й прояву соціального лідерства передбачало активізацію набутого досвіду студентів через зміну поглядів на роль соціального працівника та збагачення його ціннісних та лідерських орієнтирів.

Щодо умови організації неформальних специфічних структур середовища підготовки соціальних працівників до соціального лідерства, то завдяки іï реалізації забезпечується створення та функціонування «Школи social лідерства - Student», яка розширює можливості неформальної освіти студентів та сприяє розвитку їх лідерського 
потенціалу. Адже упровадження системи неформальної освіти в зміст професійної підготовки майбутніх соціальних педагогів дозволить розширити межі їх професійних, громадянських та особистісних компетенцій за рахунок відповідності сучасних організаційних форм і методів різним рівням впливу на особистість майбутнього фахівця [6]. Залучення студентів до освітньо-тренінгової програми Школи, до її волонтерської, проектної та науково-дослідницької роботи $[8 ; 12 ; 13]$ в галузі соціальної роботи забезпечує активізацію саморозвитку, самовдосконалення та самореалізації шляхом створення соціальних проектів, здійснення власних розробок науково-методичних матеріалів, які допоможуть їм набути необхідних знань для професійного зростання лідерства та реалізації лідерського потенціалу, виявити навички та професійно значущі якості для ефективного лідерства майбутнього соціального працівника.

Важливим аспектом організації формальної освіти соціальних працівників стає їі збагачення формами, методами та технологія навчання та розвитку лідерського потенціалу в умовах неформальної освіти (тренінгове навчання, онлайн-навчання, проектний метод, метод практичних ситуацій, метод тимбілдингу, метод сторітелінгу, арт-коучинг, метод фасилітації «світове кафе», квест-змагання). Отже, студентська молодь, будучи залученою до формальної системи вищої освіти, потребує педагогічної підтримки процесів професійної адаптації та навчальної самореалізації, які успішно забезпечуються організацією неформальної освіти як особливого виду соціальнотехнологічної діяльності, спрямованої на зростання соціального досвіду та забезпечення неперервності в освітньому зростанні учасників [5].

Висновки. Спираючись на зазначене вище, можемо дійти висновку, що формування готовності студентів до соціального лідерства вимагає системного застосування організаційно-педагогічних умов підготовки соціальних працівників. Аналіз психолого-педагогічних джерел та експертне оцінювання організаційнопедагогічних умов підготовки соціальних працівників показав їх важливість щодо цілеспрямованого впливу на якість та результат освітнього процесу. У межах нашого дослідження, виділено та обгрунтовано організаційно-педагогічні умови формування готовності студентів до соціального лідерства у професії «соціальний працівник» до яких, на нашу думку, належать: розширення знань майбутніх соціальних працівників про сутність соціального лідерства; організація неформальних специфічних структур 
середовища підготовки соціальних працівників до соціального лідерства; збагачення формальної освіти соціальних працівників формами, методами, засобами неформальної освіти для актуалізації лідерського потенціалу студентів.

Таким чином, кожна $з$ цих умов відповідає за формування певного структурного компоненту готовності до соціального лідерства, а їх сукупність при цілеспрямованій реалізації в професійній підготовці підпорядкована загальній меті, особливостям актуалізації знань, навичок і вмінь та лідерського потенціалу студентів, що дозволяє створити освітнє середовище прояву соціального лідерства майбутніх соціальних працівників.

\section{References}

1. Bondar T.V. Formuvannya zdorovogo sposobu zhyttya molodi [Formation of the healthy lifestyle of youth] : navch.-metod. posib. dlya pracivny`kiv sluzhb dlya sim»yi ditej ta molodi / T.V.Bondar, O.G.Karpenko, D.M. Dykova-Favors`ka [ta in.]. Kyiv: Ukrayinskyj instytut socialnyh doslidzhen, 2005. $116 \mathrm{p}$.

2. Karpenko O.G. Zmist ta struktura profesijnoyi kompetentnosti socialnogo pracivnyka [Content and structure of professional competence of a social worker]. Socialna pedagogika: teoriya ta prakty`ka. 2006. No. 4. P. 54-59.

3. Karpenko O.G. Motyvaciya v strukturi diyalnosti socialnogo pracivnyka [Motivation in the structure of the social worker]. Socialna robota $v$ Ukrayini: teoriya i praktyka: nauk.-metod. zhurnal. 2011. No. 3-4. P. 16-22.

4. Karpenko O.H. Profesiina diialnist sotsialnoho pratsivnyka yak tvorchyi protses [Professional activity of a social worker as a creative process]. Naukovyi chasopys Natsionalnoho pedahohichnoho universytetu imeni M.P. Drahomanova. Seriia 11. Sotsialna robota. Sotsialna pedahohika.- Vypusk 22: zbirnyk naukovykh prats. Kyiv: Vyd-vo NPU imeni M.P. Drahomanova, 2016. P. 139-145.

5. Mishchyk L.I. Sotsialna pedahohika: dosvid ta perspektyvy [Social pedagogy: experience and prospects]. Zaporizhzhia, 1999. 248 p.

6. Pavlyk N. P. Kontseptsiia vprovadzhennia neformalnoi osvity u protses profesiinoi pidhotovky maibutnikh sotsialnykh pedahohiv [The concept of introducing non-formal education in the process of professional training of future social educators.] Innovatsiina pedahohika. 2018. No.8. P. 163-165.

7. Pet`ko L.V., Nikolayenko V.V. Anglijska mova dlya vstupnykiv do magistraturyzi specialnostej: 8.01010601 «Socialna pedagogika», 8.13010201 «Socialna robota» [English for entrants to the master's degree in specialties: 8.01010601 "Social pedagogy", 8.13010201 "Social work"]: navch. posibnyk dlya studentiv, bakalavriv, ta aspirantiv VNZ, 2-ge vyd., dop. i vypr. / za red. O.G.Yaroshenko. Kyiv: «Un-t «Ukrayina», 2011. 152 p.

8. Pet'ko L.V. Zaluchennia studentiv koledzhiv do proektnykh metodyk anhliiskoiu movoiu - odna iz umov neperervnoi osvity [Involving of college students' to project methods in English - one of the conditions for lifelong learning] // Naukova sesiia prysviachena 175-richchiu 
Natsionalnoho ped. un-tu imeni M.P. Drahomanova / upor. L.P.Vovk, O.S.Padalka. Kyiv: Vydvo NPU imeni M.P. Drahomanova, 2010. Knyha 2. P. 383-387.

9. Polishchuk V.A. Profesiina pidhotovka fakhivtsiv sotsialnoi sfery: zarubizhnyi dosvid [Professional training of social specialists: foreign experience] navch. posibnyk. Ternopil: Navchalna knyha - Bohdan, 2003. 184 p.

10. Savelchuk I. B. Pidhotovka sotsialnykh pratsivnykiv za suchasnykh umov: innovatsiini tendentsii [Training of social workers in modern conditions: innovative trends]. Visnyk Zhytomyrskoho derzhavnoho universytetu imeni Ivana Franka . Pedahohichni nauky. 2016. Vol. 1. P. 120-125.

11. Aidyn L. Iachini, Timothy P. Cross \& Darcy A. Freedman. Leadership in Social Work Education and the Social Change Model of Leadership. Journal Social Work Education. 2015. Vol. 34, Issue 6. P. 650-665.

12. Karpenko O.G. Professional functions of social workers as a part of professional competence // Perspective directions of scientific researches: Collection of scientific articles. Agenda Publishing House, Coventry, United Kingdom, 2016. P. 292-294.

13. Karpenko O.G. The formation of professionalism in future social workers in the conditions of higher school // Geopolitical processes in the world today: Collection of scientific articles. - «East West» Association for Advanced Studies and Higher Education. Vienna (Austria). 2016. P. 301-304.

14. Pavlyk N. P. Scientific and methodological instrument for inorgan education in professional preparation of future social pedagoges. Balkan Scientific Review / Balkansko Nauchno Obozrenye, 1, 2018, 64-68. Tsentr, Plovdyv, Blharyia : «Nauchen khronohraf» EOOD.

15. Pet'ko L. Preparing higher school graduates in foreshortening of leader competencies for 2020. Topical questions of contemporary science: Collection of scientific articles. Aspekt Publishing of Budget Printing Center, Taunton, MA 02780, United States of America, 2017. P. 467-472.

16. Sullivan W. Patrick. Leadership in Social Work: Where Are We? Journal of Social Education. 2016. Vol. 52. P. 551-561.

17. Vol'nova Lesya, Zhou Qian. Approaches to upbringing of spiritual culture in Ukrainian and Chinese scientific and educational area. Intellectual Archive. 2016. Volume 5. No. 3 (MayJune). - Toronto : Shiny Word Corp., Canada. PP. 75-85.

Translation of the Title, Abstract and References to the Author's Language

УДК 378: 316.46

Бибик Д. Д. Організаційно-педагогічні умови професійної підготовки майбутніх соціальних працівників до соціального лідерства.

Стаття присвячена дослідженню необхідності вдосконалення науковометодичного забезпечення підготовки майбутніх соціальних працівників. Актуальність визначила вибір цілей дослідження: визначити форми та методи здійснення підготовки майбутніх соціальних працівників до соціального лідерства. Визначено, що соціальне 
лідерство - це ключовий ресурс, який забезпечує цілісний погляд на сучасного фахівця, який повинен не тільки бути готовим до майбутньої професійної діяльності, але й мати можливість самостійно орієнтуватися у потоці соціально-економічних змін, творчо вирішувати професійні завдання соціальної роботи. Особлива увага зосереджена на особливостях використання форм та методів навчання соціальних працівників. Відзначено перспективність ідей соціального лідерства при розробці та впровадженні науково-методичного комплексу, успішність яких визначається необхідністю пошуку нових шляхів підвищення якості теоретичної підготовки, здатності до самостійної творчої роботи, професійному саморозвитку студентів. Розширення можливостей професійної підготовки у соціальному лідерстві забезпечують нетрадиційні форми та інтерактивні методи навчання студентів.

Ключові слова: професійна підготовка, соціальний працівник, соціальне лідерство, організаційно-педагогічні умови, нетрадиційні форми навчання, інтерактивні методи навчання.

Бибик Д. Д. Организационно-педагогические условия профессиональной подготовки будущих социальных работников к социальному лидерству.

Статья посвящена исследованию потребности усовершенствования научнометодического обеспечения профессиональной подготовки будущих социальных работников. Актуальность обусловила выбор целей исследования: обозначить формы и методы реализации подготовки будущих социальных работников к социальному лидерству. Определено, что социальное лидерство выступает тем ключевым ресурсом, который обеспечивает целостное представление о современном специалисте, который должен быть не только подготовленным к будущей профессиональной деятельности, но и уметь самостоятельно ориентироваться в потоке социально-экономических изменений, творчески решая профессиональные задачи социальной работы. Особое внимание сконцентрировано на особенностях использования форм и методов подготовки социальных работников. Отмечено перспективность идей социального лидерства при разработке и внедрении научно-методического комплекса, успешность которых определяется необходимостью поиска новых путей повышения качества теоретической подготовки, способности к самостоятельной творческой работе, профессиональному саморазвитию студентов. Расширение возможностей профессиональной подготовки к социальному лидерству обеспечивают нетрадиционные формы и интерактивные методы обучения студентов.

Ключевые слова. профессиональная подготовка, социальный работник, социальное лидерство, организационно-педагогические условия, нетрадиционные формы обучения, интерактивные методы обучения.

\section{Література}

1. Бондар Т.В. Формування здорового способу життя молоді : навч.-метод. посіб. для працівників служб для сім»ї дітей та молоді / Т.В.Бондар, О.Г.Карпенко, Д.М. Дикова-Фаворська [та ін.]. Київ: Український інститут соціальних досліджень, 2005. $116 \mathrm{c}$.

2. Карпенко О. Зміст та структура професійної компетентності соціального працівника. Соиіальна педагогіка: теорія та практика. 2006. № 4. С. 54-59.

3. Карпенко О.Г. Мотивація в структурі діяльності соціального працівника. 
Соціальна робота в Україні: теорія і практика: наук.-метод. журнал. 2011. № 3-4. C.16-22.

4. Карпенко О.Г. Професійна діяльність соціального працівника як творчий процес. Науковий часопис Національного педагогічного університету імені М.П. Драгоманова. Серія 11. Соціальна робота. Соціальна педагогіка.- Випуск 22: збірник наукових праць. Київ: Вид-во НПУ імені М.П. Драгоманова, 2016. С. 139-145.

5. Міщик Л.І. Соціальна педагогіка: досвід та перспективи. Запоріжжя, 1999. 248с.

6. Павлик, Н.П. Концепція впровадження неформальної освіти у процес професійної підготовки майбутніх соціальних педагогів. Інноваційна педагогіка. 2018. №8. С. 163-165.

7. Петько Л.В., Ніколаєнко В.В. Англійська мова для вступників до магістратури зі спеціальностей: 8.01010601 «Соціальна педагогіка», 8.13010201 «Соціальна робота»: навч. посібник для студентів, бакалаврів, та аспірантів ВНЗ, 2-ге вид., доп. і випр. / за ред. О.Г.Ярошенко. Київ: «Ун-т «Україна», 2011. 152 с.

8. Петько Л.В. Залучення студентів коледжів до проектних методик англійською мовою - одна із умов неперервної освіти // Наукова сесія присвячена 175-річчю Національного педагогічного університету імені М.П. Драгоманова / упор. Л.П.Вовк, О.С.Падалка. Київ: Вид-во НПУ імені М.П. Драгоманова, 2010. Книга 2. С. 383-387.

9. Поліщук В.А. Професійна підготовка фахівців соціальної сфери: зарубіжний досвід: навч. посібник. Тернопіль: Навчальна книга Богдан, 2003. 184 с.

10. Савельчук І.Б. Підготовка соціальних працівників за сучасних умов: інноваційні тенденції. Вісник Житомирського державного університету імені Івана Франка. Педагогічні науки. 2016. Вип. 1. С. 120-125.

11. Aidyn L. Iachini, Timothy P. Cross \& Darcy A. Freedman. Leadership in Social Work Education and the Social Change Model of Leadership. Journal Social Work Education. 2015. Vol. 34, Issue 6. P. 650-665.

12. Karpenko O.G. Professional functions of social workers as a part of professional competence // Perspective directions of scientific researches: Collection of scientific articles. Agenda Publishing House, Coventry, United Kingdom, 2016. P. 292-294.

13. Karpenko O.G. The formation of professionalism in future social workers in the conditions of higher school // Geopolitical processes in the world today: Collection of scientific articles. - «East West» Association for Advanced Studies and Higher Education. Vienna (Austria). 2016. P. 301-304.

14. Pavlyk, N. P. Scientific and methodological instrument for inorgan education in professional preparation of future social pedagoges. Balkan Scientific Review No.1, c. 64-68. Център, Пловдив, България : «Научен хронограф» ЕООД. 2018.

15. Pet'ko L. Preparing higher school graduates in foreshortening of leader competencies for 2020. Topical questions of contemporary science: Collection of scientific articles. Aspekt Publishing of Budget Printing Center, Taunton, MA 02780, United States of America, 2017. P. 467-472.

16. Sullivan W. Patrick. Leadership in Social Work: Where Are We? Journal of Social Education. 2016. Vol. 52. Pp. 551-561. DOI: 10.1080 / 10437797.2016 .1174644

17. Vol'nova Lesya, Zhou Qian. Approaches to upbringing of spiritual culture in Ukrainian and Chinese scientific and educational area. Intellectual Archive. 2016. Volume 5. No. 3 (May-June). - Toronto : Shiny Word Corp., Canada. PP. 75-85. 


\title{
System of Spiritual Values of Modern Youth: the European Dimension
}

\author{
Valerii Budak, Dr.Sc., Prof., \\ Academician of National Academy of Educational Sciences of Ukraine \\ Rector, Mykolaiv V.O. Sukhomlynskyi National University, Mykolaiv, Ukraine \\ e-mail:office@mdu.edu.ua \\ ORCID ID https://orcid.org/0000-0003-2698-6333 \\ Svitlana Zaskaleta, Dr.Sc., Prof. \\ Mykolaiv V.O. Sukhomlynskyi National University, Mykolaiv, Ukraine \\ e-mail: zaskaletas1@gmail.com \\ ORCID ID http://orcid.org/0000-0002-5417-2612
}

Oksana Oleksyuk, Candidate of Pedagogical Sciences, Associate Professor, Associate Professor of Pedagogy and Inclusive Education, the head of Scientific-Research Center of Military and Patriotic Education of

Mykolaiv V.O. Sukhomlynskyi National University, Mykolayiv, Ukraine

ORCID ID https://orcid.org/0000-0002-5527-3861, e-mail: oleksjukoksana@ukr.net

\begin{abstract}
The article deals with the problem of formation of spiritual values of modern youth. It is determined that a new type of personality is formed in the youth environment, which will dominate and develop in the future. The study showed that important components in the formation of the value system of student youth are the formation and development of moral values in a multicultural society, the formation and development of tolerant thinking, understanding and respect for other people's feelings and thoughts, the influence of moral values on the formation and development of tolerant thinking.
\end{abstract}

Keywords: student youth, values, value system, European dimension, European values.

Socio-economic and political transformations taking place in Ukraine actualize the problem of formation of spiritual values of youth. The formation of the spiritual values of the Ukrainian nation requires special attention to the formation of the system of values of modern youth, which is the guarantor of the future of the country and social progress. The problem of educating the spiritual world of student youth is of paramount importance today. After all, the value orientations of the individual are not only the basis of education, but also the key to the implementation of the most important ideas and goals, the implementation of which is the meaning of human and social existence. Unfortunately, due to the decline of the value system 
that has existed for decades, low morals and neglect of culture have become the norm in everyday life. Every day we witness that such universal values as humanism, honor, decency, conscience, empathy, love and friendship, etc., are leveled in society. They are replaced by unjustified resentment, selfishness, indifference to others, contempt for honor and conscience, falling cultural standards. The victims of all these «new changes», first of all, are the souls and hearts of those whose personality is just being formed.

We can not disagree with the opinion of Morozova L.P. that in the conditions of deep crisis of economy, culture, ideology, morality, education and upbringing our youth more and more loses spiritual and world-view targets, does not feel firm ground at formation of life plans, is confused in universal values. The rapid flow of critical and negative information pouring from the pages of newspapers and magazines, from the TV screen, from the radio, the difficult realities of life seriously affect the unstable consciousness of young men and women. Along with the exposure of false ideals, valuable life ideals that are of inalienable significance are also eroded [1].

The process of modernization of Ukrainian education in higher education obviously requires the creation of such a system of values that would serve as a guide in educating the younger generation as patriotic individuals with a globalizing understanding of the current state of society.

Almost two hundred years ago, J. Fichte insisted that any nation or its individual representatives, who are mechanically borrowing other people's spiritual values, types of thinking, lose the ability to create something new both within their native and foreign culture.

I. Franko's views on the factors of universal progress (free labor, freedom as the highest ideal, the highest human value) and the main tasks of the formation of the Ukrainian nation, which can repel the assimilation aspirations of other nations, but at the same time must be inseparable associated with the universal.

In opposition to the new, in particular the negative challenges of our time, we should pay attention to the opinion of Vovchasta N.Ya. and to restructure the system of educational work with student youth, to raise their prestige, to make certain changes in its ideology, content characteristics and specific actions [2]. 
That is why in the State National Program «Education (Ukraine of the XXI century)» the leading values of education of the Ukrainian nation were patriotism, citizenship, humanism, tolerance, conscience, honor, love, friendship, diligence.

Many studies Ukrainian and foreign education scientists devoted to the analysis of the spiritual values of young people. It is necessary to mention the works of V. Andrushchenko, I. Bekh, E. Bondarevskaya, M. Boryshevsky, I. Zyazyun, A. Kapskaya, V. Kirsanov, N. Nychkalo, G. Sagach, O. Sukhomlinskaya, T. Tyurin, J. Zimny, R. Krul, S. Slavinsky, M. Volitsky and others. This problem was also studied in depth by O. Belykh, V. Dolzhenko, B. Nagorny, O. Semashko, D. Chernylevsky, G. Shevchenko, V. Yakovenko and others.

It should be emphasized that the formation of a new educational paradigm is taking place today in accordance with the general philosophical and psychological issues through the prism of both socio-cultural and anthropological dimensions. This allows from new positions to understand the essence of spiritual and worldview consciousness and develop approaches to its formation during the educational process. In affirming the idea of integrity in relation to the understanding of the individual, modern pedagogical science is based on the general philosophical principle of internal interconnection and interdependence of processes and phenomena of the world. Regarding modern philosophical and pedagogical research related to the problem of formation and development of the worldview of the individual, there is a view that spirituality is the core in understanding this phenomenon [3:46].

Value orientations of the individual is one of the main characteristics of the individual, and their development - the main task of the modern education system, as the value system is the foundation of education, the most important ideas and goals, which see the meaning of human existence and society.

During the transformation of modern society, this question acquires special significance, because the formation of value orientations of student youth is influenced by the integral interaction of two integral systems. On the one hand, social life influences the personality of young people, on the other hand, the personality actively assimilates the previous actual experience of society, knowledge, norms, values, traditions, and knowledge. At the same time, young people influence the development of society.

Boryshevsky M.Y. believes that now there is a need to form new value orientations, new value ideals, value worldview of a person who will live and work in the XXI century in 
Ukraine - an independent European state, where target and value orientations will combine creativity, new original ideas with folk traditions and culture. [4].

The student years are a period when the development and upbringing, the formation of the personality, and the professional training of future specialists take place especially intensively, as if at an accelerated pace. This is a period for the development of intelligence, revision and development of the value system, strengthening health and physical strength. Teachers working with students should have a good idea of the features and opportunities of this period in the lives of students, in their professional and civic development, as well as their role in these processes, in particular in solving problems of education.

Students are an integral part of youth, its specific group, characterized by special conditions of life, life and work, social behavior and psychology, a system of value orientations. That is, students should be considered as a social group in the system of higher education, which has its own purpose, its own specific features and which is preparing to perform social roles and functions of the intelligentsia. Students are a mobile group, the purpose of whose existence is organized according to a certain program of preparation for professional and social roles in material and spiritual production. Working together contributes to the development of students' cohesion and collectivism.

The process of learning in a higher education institution involves the inclusion of students in the system of social relations, substitution of positions and the assimilation of social values. An important feature of students is that active interaction with various social formations of society, as well as the specifics of university education create great opportunities for students to communicate. Therefore, a fairly high intensity of communication is a specific feature of students. The student acts as a subject of educational activity, which is primarily determined by two types of motives: achievement motivation and cognitive motivation. Cognitive motivation is the basis of educational and cognitive activity of man, corresponding to the very nature of his mental activity. In teaching, the motivation to achieve is subject to cognitive and professional motivation. Thus, the student as a subject of activity has his own goal, his own motives, his own object, his own ways to achieve the goal, his own opportunities.

The student age has a process of active formation of social maturity. Social maturity involves the ability of each young person to master the necessary set of social roles for society 
(specialist, father, mother, public figure). Students have an increased interest in moral issues (purpose, lifestyle, responsibilities, love, loyalty, etc.). Purposefulness, determination, persistence, independence, individuality, initiative in the process of activity and communication, ability to control oneself increase. It is known that in adolescence, desire and aspiration develops earlier than the will and character.

The attitude of the student as a socially mature person, the bearer of the formed worldview to the future citizens of the country presupposes taking into account that the student has not only a certain system of views on the world, but also on his place in this world. That is, in the organization of educational work it is necessary to develop the student's reflection and awareness that he is the bearer of certain universal values (values), socially significant personality. Based on the above, it can be argued that students are part of youth, its specific group, characterized by special conditions of life, life and work, social behavior and psychology, the system of value orientations. That is, students should be considered as a social group in the system of higher education, which has its own purpose, its own specific features and which is preparing to perform social roles and functions of the intelligentsia.

Education in higher education, in particular in the pedagogical field, should be professionally oriented. The process of its organization is permeated by the idea of training a young specialist of a certain type, a teacher who is needed by society, school, children. The professional orientation of education is expressed primarily in the formation of students' pedagogical orientation and attitude to pedagogical activity as a value. The process of education is associated with the formation of students' views, beliefs, qualities, values, attitudes, abilities. These are the most significant structural components of the personality, which are its affiliation and accompany it everywhere - in learning, activities, communication, behavior. The educational process is not a simple sum of its components, they are interdependent, intertwined in the life of the educational institution, interact, often complement each other. In this process, a holistic personality of the future professional is formed.

Discussions in the UN General Assembly commemorating the tenth anniversary of International Youth Year [5] noted that teaching moral values to youth and responding to their spiritual needs was a key to addressing their current problems.

The following issues were highlighted: 
1) It is imperative to preserve those moral values that provide a spiritual balance for young people and reinforced the family as the fundamental institution of society. It would be well worth it to provide students with an introduction to human rights issues.

2) The world, especially its youth, is suffering from a moral crisis that has been on a huge scale in many societies. To prevent an identity crisis, the international community must meet the spiritual needs of young men and women, as well as their temporary needs.

3) The place of education in preparing young people for their role in society is highlighted. It is noted that the goals of his country's educational programs are to strengthen the sense of belonging of young people and prepare them for citizenship in civil society on the basis of moderation, justice and tolerance.

4) It is emphasized that young people remain on the sidelines of education in some countries, and this is an important source of frustration. This situation was due to a lack of resources, which affected 50 percent of young people, the need to work for others, and the fact that some did not value education.

5) It is noted that education in its various forms should focus on the abolition of technical illiteracy. Rapid technological progress creates problems that must be addressed by the education system so that young people can avoid marginalization.

Exploring the problem of forming the spiritual values of modern youth, it is important to attract attention to the European vector of solving this. According to the Lisbon Strategy for the Development of Education and Training (Europe-2010), the European dimension in education includes: in addition to European knowledge, European language competence, European citizenship, European quality of education, European professionalism, also European identity. The Resolution of the Council and Ministers of Education of the European Community (1988) on the European dimension in education sets out four objectives for the European dimension: strengthening young people's sense of European identity and the value of European civilization, which is important for democracy, social justice and respect to human rights; preparing young people for participation in the economic and social life of the European Community; promoting young people's awareness of the benefits of the Commonwealth, as well as the challenges it faces; strengthening the knowledge of young people about the history, culture and economy of European countries, which will promote the development of cooperation. 
The urgency of the problem of forming the moral values of student youth is confirmed by numerous studies in the countries of the European educational space. Thus, researchers from Estonia, Germany, Latvia and the Czech Republic have covered the impact of moral values on the formation of tolerant thinking [4].

6) The study showed that important components in the formation of the value system of student youth are the formation and development of moral values in a multicultural society, the formation and development of tolerant thinking, understanding and respect for other people's feelings and thoughts, the influence of moral values on the formation and development of tolerant thinking. (The project was supported by the European Community Youth in Action Program).

Ukraine, as a European country, does not stand aside from solving these problems. The value orientations of the youth as the most «dynamic» group of society are more prone to change than others. It is in the youth environment that a new type of personality is formed, which will dominate and develop in the future. Value orientations, spiritual values are the main vectors of social orientations. They determine the orientation of the individual and the degree of its socialization, which change depending on the degree of conformity of individual needs and interests to the needs and interests of society. This causes the problem of forming the value orientations of young people both for today's social policy and for future prospects of social development.

In order to create a system-as orientation of spiritual values, it is necessary to determine the current aspirations, goals, desires of the younger generation.

The prospect of further research is the analysis of the results of psychological research conducted among students «Methods of research of value orientations» in order to determine the respondents' goals that are decisive for them (values-goals) and specific personality traits needed to achieve them (values-means).

\section{References}

1) Morozova L.P. Aspects of the formation of the value world of youth // Scientific notes: special issue. - Kyiv: KM Academy Publishing House, 2003. - Vol.21. - C. 94-102.

2) Vovchasta N.Ya. Spiritual values as an integral part of modern education of students // Proceedings of the scientific-practical Internet conference «Ukrainian science of the XXI century June 25 - 27, 2008». 
3) Podolyak L.G., Yurchenko V.I. Psychology of food schools: Pidruchnik. 2nd view. - K .: Karavela, 2008 .-- 352 p.

4) Boryshevsky M.J. Spiritual values of youth in the formation of the citizen's personality // Pedagogy and Psychology. - № 1, 1997.

5) Influence of the moral values on formation of tolerant thinking https://clubactive.eu/portfolio/influence-of-the-moral-values-on-formation-of-tolerantthinking/

6) MORAL VALUES AND SPIRITUAL NEEDS KEY TO ADDRESSING YOUTH PROBLEMS, SAY SPEAKERS IN GENERAL ASSEMBLY. Press Release GA/8978 https://www.un.org/press/en/1995/19951027.ga8978.html 


\title{
The Use of Local Lore Materials at Lessons of History of Ukraine in Secondary General Education Institutions
}

\author{
Dmytro Nefyodov \\ Doctor of Historical Sciences \\ Provisional Head of the Department of History, \\ Mykolaiv V.O. Sukhomlynskyi National University \\ nefyodovdv@gmail.com
}

\begin{abstract}
The article studies the peculiarities of the use of local lore materials at history lessons. The author concludes that the use of local lore materials at history lessons is one of the means of enhancing students' cognitive activity and encouraging research. Knowledge of local lore studies enriches program material, makes it clearer, more logical and convincing and, of course, helps to improve the quality of knowledge. In the process of study of History of Ukraine, focusing on specific facts, events, processes and phenomena of local lore contributes to students' awareness of the historical basis of the regional-cultural, ethnographic, religious, social and economic diversity of Ukraine within a single national history. Understanding of regional peculiarities (historical-geographical, ethnographic, cultural, religious, mental) as a result of a complex of events, processes and phenomena of the historical development of the Ukrainian territory is a significant factor in shaping the social consciousness of the young generation, which has to understand the state and national unity of Ukraine through regional variety of all manifestations of life of the Ukrainian nation.

Keywords: History of Ukraine, local lore studies, methodology.
\end{abstract}

The modern development of the Ukrainian state, the emergence of civil society, national-cultural revival and the acceleration of the integration processes of Ukraine into the European and world community significantly change the place and role of history as a basic school subject, which is responsible for solving the important tasks of modern education: providing conditions for adaptation and self-realization of young people in the changing modern world, acquisition of important life competencies and guidelines that promote personal development, formation of national consciousness and civic position.

Since Ukraine's independence, historical education has dramatically changed of all school subjects. The current stage of social development requires the study of the national history, particularly through the prism of the peculiarities of regions' history. A person is brought up in a socio-cultural environment that has been formed for centuries. Therefore, the study of local lore is of particular importance in forming a sense of national identity, democracy and tolerance, respect for the historical trajectory of native and other peoples. Today local lore studies is one of the basic elements of historical education, one of the most important branches of history at school, an important means of connecting school with life; 
one of the sources of enriching students with knowledge on the history of their native land, a means of fostering love for it and formation of civic concepts and qualities.

School local lore studies is a component of historical education, which is based on the methodological foundations of the historical and pedagogical scientific fields and has its own methodological specificity. An important condition for the development of local lore studies is, first of all, the contemporary socio-political changes that take place in Ukraine and in the world. The local lore materials, enriched with tradition, allow students to notice the cultural difference of their own environment and at the same time to trace the specifics of individual territories as closed regions or spaces. Therefore, one of the urgent issues of further transformation of the content of school historical education today is the establishment of the optimal correlation between national and regional history, particularly within the subject namely History of Ukraine.

Increasing attention to local lore issues in the classroom gives students the opportunity to be more aware of the history of not only their native land, but also of other regions of Ukraine, to awaken the desire to cooperate with people from other regions, to realize the unity of the country in the conditions of regional differences' existence.

Before using local lore materials in the educational process, it is necessary to determine their importance and place in the historical science. So, when selecting local lore materials, you should first pay attention to whether they:

- have important educational value;

- are closely related to the program of History of Ukraine;

- contribute to a deep understanding of the general patterns of the historical process and features of region's historical development;

- have novelty and relevance;

- reflect the unity of civilizational and cultural approaches in the process of their study;

- take into account the differentiated approach to students.

In addition to teaching at higher educational institution of the IV accreditation level, the author of this article also teaches at the Lyceum, which is an upper secondary education institution. Faculty members of the Department of History of Mykolaiv V.O. Sukhomlynskyi National University, including the author of this article, in 2015 created a unique textbook "History of Native Land: Mykolaiv Oblast" [1] on the pages of which the history of the 
Mykolaiv oblast from ancient times to the present is revealed. The authors, basing on archival documents and materials, demonstrated the emergence of life in the region. In addition to historical events, they also presented such issues as national minorities, the culture of the region, prominent figures and more. The textbook was received by all secondary general education institutions in the Mykolaiv oblast, which in turn made it possible to study the local lore more actively at the lessons of History of Ukraine.

In our teaching activities in the Lyceum at lessons of History of Ukraine, we actively use local lore materials. Thus, using the textbook by O. Hisem and O. Martyniuk [2] in the 9th grade, at the end of each unit, we devote one lesson to the topic "Our land" analyzing the relevant historical period.

In the history of each state we usually consider its components: history of lands, territories, provinces, regions, etc. To link local historical material to general history material we use the following techniques:

- form a comprehensive knowledge of both the history of the region and the history of the country;

- determine the general and special features of events, phenomena of universal and local significance;

- set synchronization of events from the history of the country and the local areas;

- identify important historical events of local importance that are not mentioned in the context of general history for some reason;

- carry out the study of the local history with the general history synchronously or in its context;

- try to focus students' attention on the facts of local history, because they are closer and more real to them.

We defined the following main methodological conditions for successful study of local lore issues in the course of History of Ukraine:

- giving a special attention by a teacher to the development of the content of such concepts as "region" and "native land" with the simultaneous acquisition of the ability to specify the relevant events and processes in time and space;

- teaching local lore materials in the course of national history from the standpoint of multiperspectivity and multiplicity; 
- highlighting appropriate tasks and questions for students aimed at developing their historical competence at the lessons of local lore-oriented educational content;

- providing active participation of students at the lessons of local lore studies by means of interactive teaching methods.

The use of local lore materials at history lessons is one of the means of enhancing students' cognitive activity, encouraging research. Knowledge of local lore studies enriches program material, makes it clearer, more logical and convincing and, of course, helps to improve the quality of knowledge.

Thus, in the process of study of History of Ukraine, focusing on specific facts, events, processes and phenomena of local lore contributes to students' awareness of the historical basis of regional cultural, ethnographic, religious, social, economic diversity of Ukraine within a single national history. Understanding of regional peculiarities (historical-geographical, ethnographic, cultural, religious, mental) as a result of a complex of events, processes and phenomena of the historical development of the Ukrainian territory is a significant factor in shaping the social consciousness of the young generation, which has to understand the national unity of Ukraine through regional variety of manifestations of life of the Ukrainian nation.

The completed research does not exhaust all aspects of the problem, in particular, approaches to the implementation of the content of local lore studies in school textbooks in general in Ukraine and the professional training of history teachers to teaching local lore studies in the course of History of Ukraine require further studies.

\section{References}

1. Istoriia ridnoho kraiu : Mykolaivshchyna : navchalnyi posibnyk [History of Native Land: Mykolaiv Oblast: textbook] / M. M. Shytiuk (ker. avt. kol.), O. O. Bakovetska, N. M. Buhlaitain. - Mykolaiv : Ilion, 2015. - 628 s.

2. Hisem O. V., Martyniuk O. O. Istoriia Ukrainy : pidruchnyk dlia 9 klasu zahalnoosvitnikh navchalnykh zakladiv [History of Ukraine : textbook for the 9th grade students of secondary general education institutions]. - Kharkiv: Ranok, 2017. - 288 s. 


\title{
Future Primary Teacher's Model Preparation for Collaboration with Heterogeneous Groups of Students
}

\author{
Tetiana Tutova \\ Postgraduate student \\ Dragomanov National Pedagogical University (Ukraine, Kyiv)
}

\begin{abstract}
The article discloses the preparation of future modeling of primary school teachers to collaboration with heterogeneous groups of students. Different opinions on the peculiarities of the models of future teachers' professional training have been investigated. The model is viewed as an attempt to improve of preparation of future primary school teachers. Improving the content, forms and methods of professional training of primary school teachers becomes relevant in the context of implementation of inclusive education in the New Ukrainian school.

In the article it is presented the structural-functional future primary school teachers model training which includes: goals, objectives, methodological approaches and principles, structural and functional components, content, forms, methods, pedagogical conditions, results, criteria, indicators and levels of readiness to collaboration with heterogeneous groups of students.
\end{abstract}

Key words: model of training primary future teachers, professional preparation future primary school teachers, designing, heterogeneous groups, inclusive education, primary school teacher's readiness to collaboration with heterogeneous groups of students.

Introduction New Ukrainian School focuses on a personality of a teacher who at every point, in each class has a number of options available to interact with students being tolerant to them, understanding their needs, inspiring them, being ready to generate teacher own rules and guidelines to influence their harmonious development.

Thus, one of the future teacher primary school preparation objectives at the university level is to prepare students to a pedagogical interaction with different school students in the context of NUS reform [7]. Teacher - student interaction is especially important in the era of digital generation, including students with special educational needs . They compose heterogeneous groups a teacher has to be ready to collaborate with. The key objective of teaching students to teach is developing a model "How to work" with heterogeneous groups.

The educational objective of changeable $21^{\text {st }}$ century society is shaping conditions for every person's self - realization taking into consideration his belonging to one or another heterogeneous group because every person is different for his heterogeneity. A successful realization of the objective deals with: 
- Firstly, diagnosis and stocking of individual peculiarities of students ;

- Secondly, organizing conditions for development of those peculiarities ;

- Thirdly, adaptation of all the students despite their different possibilities for social interaction at equal conditions. That is realized according active introduction of inclusive education.

Among the up to date programs the European International Program "Tempus IV"[4] is considered to be a contemporary teacher preparation program that prepares to work with heterogeneous groups. This project stresses a democratic equality of all people. As a result of the program a new branch of pedagogy "Pedagogy of Diversity" is initiated. The problem of heterogeneity has been one of the most complicated in social policy during a few decades. World UNESCO conference 1994, United Nations Congress 2006, All - German UNESCO Commission 2010, United Nations Convention was adopted by European Councils in 2010 prove the actuality of the problem.

The problem of future teachers preparation to pedagogical interaction with heterogeneous groups of school students raises a particular actuality in modern education and needs the following:

- General scientific analysis of the professional preparation of a future teacher;

- Analysis of future primary school teacher readiness to work in the context of our research.

New Ukrainian School Concept is characterized with changes in the structure and the content of education, that causes the necessity to prepare a primary school teacher as a professional and innovator, who is able to spread and enrich an experience of every student, developing his potential, no matter which heterogeneous group he belongs. The reform helps a personality to socialize in contemporary educational conditions.

Having analyzed the issue of heterogeneity according psychological, pedagogical and social aspects as well as documents concerning the inclusion, we came to the conclusion that, a heterogeneous group - is a group of students with special educational needs, that have visible characteristics (age, sex, race) and invisible ones (education, intellectual capability, life experience, well brought up, nationality, beliefs, life and moral principles, sexual orientation, etc.), united by mutual criteria (ethnical and religion belonging, health conditions, psychological and physical peculiarities, social status, intellectual potential, creativity, social 
and emotional characteristics, subculture), are interdependent and need additional support in educational process[11].

The primary school teachers preparation is reflected in a number of official documents at a state level. They regulate the activity of educational establishments and prove that education is a foundation of development of a personality, society, nation and the country that help the development of the future of Ukraine.

The challenge of educational refreshment needs is reflected in works of a number of scholars of Ukraine but their investigations don't reflect the fundamental research of the state of primary school teachers preparation for a pedagogical interaction with heterogeneous groups.

The objective of the article is to analyze contemporary models of future teachers preparation for pedagogical activity and presentation of a structural- component model of future primary school teacher preparation for a pedagogical interaction with heterogeneous groups of students.

Before we analyze models of the future primary school teachers preparation it is important consider the meaning of the notion "a model". In science, a model is a representation of an idea, an object or even a process or a system that is used to describe and explain phenomena that cannot be experienced directly. Models are central to what scientists do, both in their research as well as when communicating their explanations. In time the word developed into the meaning as a theory, a hypothetical description of a complex entity or process.

We consider the object of modeling as a part of the process of primary school teachers preparation when the students are taught to get ready for a pedagogical interaction with heterogeneous groups of students. University students get their readiness for a certain activities they will be able to complete.

Modeling in pedagogics is used to realize such tasks as educational planning improvement, learning material structure development, learning and educational activity guidance. Those components improve the quality of education.

Introducing the conception of a model of future primary school teachers preparation for pedagogical interaction with heterogeneous groups of students we take into consideration the main issue of humanistic (the third force) and humanitarian paradigm of education, professionalism of primary school teachers that meet the social demands, standards of higher education and syllabus of professional preparation of future primary school teachers. All those 
meets the national program "XXI Century Education in Ukraine that considers a human as the greatest social value and the task is to discover his abilities, his educational needs realization, importance of harmonious relationships between people in a society[2;5;8;9;10].

A number of educators have developed different models of professional development of future primary school teachers (O.Matviienko and etc) [6]. They have various components, qualities, characteristics, learning process description of teacher preparation, outline steps and structure of professional development, define tasks, principles and technologies of learning and teaching.

When designing the model, we have set the task to improve primary school teacher preparation for pedagogical interaction with heterogeneous groups. One important issue in this design is introduction to university students the pedagogics of variety, methodology, heterogeneity in education that help them to develop professional qualities, skills and multi dimensional pedagogical thinking to interact with heterogeneous groups.

The structure of the model reflects main elements of the process of primary school teacher preparation for pedagogical interaction with heterogeneous groups of school students. They are:

- Objective module (objective, task, result);

- Methodological module (attitude, principles);

- Organizational and technological module (components of readiness, content, forms and methods);

- Activities and results module (criteria, indicators, levels and pedagogical conditions).

Future primary school teacher preparation for interaction with heterogeneous groups of school students model is a description and theoretical background of modules of this process.

Objective module of the model has to form the readiness of future primary school teacher for pedagogical interaction with heterogeneous groups of students that is based on formation of the fundamental knowledge of heterogeneity, shaping a contemporary type of thinking, developing professional and personal qualities of a future professional under the condition of inclusion. New Ukrainian School reform highlights the importance of the teacher - student collaboration with students with special educational needs and thus heterogeneous groups.

Theoretical and methodological module includes a number of general scientific attitudes (valuable , axiological, systemic humanistic, special- organizational). 
Organizational and technological module realizes the function of the model taking into consideration the steps in future teachers professional formation with the following components content: motivational and valuable, informational and cognitive, communicative and reflective - dynamic.

Activities and results module includes the model of future primary school teachers preparation for pedagogical interaction with heterogeneous groups of students taking into account the levels (high, average and beginners). The effectiveness of the preparation is evaluated with the help of criteria: motivational, informational and cognitive communicative, reflective and methodology of pedagogical appreciation readiness of young teachers to interaction with heterogeneous groups.

There are several levels of pedagogical conditions that form the foundation of primary teacher preparation to interact with heterogeneous groups. The first level is personality characteristics of university students that cause the productivity of educational process. The second level includes the pedagogical conditions in its general meaning: teaching content of students, interpersonal group interaction skills development, teacher - students relationship, adaptation of students to the environment and interaction of the educational establishment with the community. The pedagogical conditions of the second level reflect the system of primary school teacher preparation for pedagogical interaction with heterogeneous groups. The personality characteristics of students have to be taken into consideration when forming pedagogical conditions and developing a strategy of model realization in educational process at higher educational establishment. In conclusion we have to stress that primary school teacher preparation for interaction with heterogeneous groups is effective only under some pedagogical conditions:

- formation of positive motivation for pedagogical activity of students taking into consideration heterogeneous and inclusive educational environment;

- professional development of primary school teachers via subject - subject interaction with improvement of their preparation at the university level;

- activation of student personal and professional qualities for professional activities that meets New Ukrainian School Concept;

- future primary school teachers preparation for practical activity under conditions of heterogeneity of primary school students. 
Our investigations allow us to come to conclusion that the successful function of the model of primary school teachers preparation for interaction with heterogeneous groups is possible under a condition of important criteria mentioned in the article.

Conclusion. The result of the preparation is formation of readiness of future primary school teachers for pedagogical interaction with heterogeneous groups is personality development that promotes high results of teacher collaboration with heterogeneous groups. The development includes professional and moral qualities of a teacher, his values and beliefs, readiness to collaborate with students, professional competency, tolerance, knowledge, skills and habits, experience in organizing of a pedagogical interaction with heterogeneous groups, acceptance of heterogeneity in education, ability to face and overcome difficulties in collaboration with heterogeneous groups of primary school students, predicting and warning them, ability for self - improvement.

The realization of the model opens perspectives of a teacher professional development and readiness to face the educational challenge to collaborate with heterogeneous groups at primary school.

\section{References}

1. N. V. Sankova, A. A. Trejtjak (2016). "Inclusive education from A to Z: a guide for teachers and parents"/- K.,- P. 68.[ in Ukrainian]

2. Decree of the President of Ukraine (2002) № 347. "National doctrine of the development of education in Ukraine in the XXI century". Retrieved from http://zakon5. rada. gov.ua/laws/show/347/2002 [ in Ukrainian]

3. Dubasenyuk O.(2008)."Conceptual models of pedagogical education: scientific research and achievements". Zhytomyr: ZhSU Publishing House. I. Franko.p.8-29[in Ukrainian]

4. Joint European project TEMPUS IV/VI (2013)"Training of teachers and educational managers to work with heterogeneous groups and organizations" 543873-TEMPUS-1-2013-1DE-TEMPUS-JPCR. Retrieved from http://tempus 2013-16.novsu. ru/mod/page. [in Ukrainian]

5. Law on Education in Ukraine (2017). Retrieved from http://zakon.rada. gov.ua/laws/show/2145-19 [in Ukrainian]

6. Matvienko O.(2009) "Training of future teachers for pedagogical coloboration": monograph. NPU named after M. Drahomanov,384 p. [in Ukrainian]

7. Ministry of Education and Science. (2017)"New Ukrainian School”. Retrieved from http:// https://mon.gov.ua/ua/tag/nova-ukrainska-shkola [ in Ukrainian] 
8. State National Program "Education". "Ukraine of the XXI century'. (1994). Kyiv, 61 p.[in Ukrainian]

9. The Cabinet of Ministers of Ukraine. (2002). State program "Teacher". № 379. Retrieved from http://zakon4.rada.gov.ua/laws/show/379-2002-\%D0\%BF [in Ukrainian]

10. The Law on «Higher Education» in Ukraine (2014). Retrieved from http://osvita. ua/legislation/law/2235/list/1/[in Ukrainian]

11. Tutova T. (2019) “Future primary school teacher's readiness to collaboration with heterogeneous groups of students as a component of professional preparation". Scientific journal. Issue 10.T.3 Odessa, p.103-107.[in Ukrainian] 


\title{
Innovative Processes in Modernization of Non-Formal Education: Focus on Creative Self-Expression of Primary Schoolchildren
}

\author{
Boiko Anna \\ ORCID: http://orcid.org/0000-0002-0371-5058 \\ Research Officer of Out-of-School Education Laboratory \\ At Institute of Problems on Education of the National Academy of Educational \\ Sciences of Ukraine (Ukraine, Kyiv)
}

\begin{abstract}
The purpose of the article was to emphasize the importance of problem of modernization of non-formal education in the context of current educational reforms, to identify the main approaches of modernization of nonformal education (out-of-school education), to outline the creative self-expression of personality as a priority of non-formal education and the effective pedagogical conditions of creative self-expression of primary schoolchildren non-formal education.

The obtained data have shown that educational activity of out-of-school education should be modernized according to four scientific approaches: person-oriented, activity, axiological and competence approaches. Based on analysis of modern studies and legislative documents, we define the following pedagogical conditions of creative self-expression of primary schoolchildren non-formal education: motivating primary schoolchildren to express themselves in creative activities, creating a favourable environment in the system "institution of nonformal education - family", developing skills of organization of creative activity, encouraging primary schoolchildren's success in creative activities.

This article provides a good starting point for discussion and further research.

Key words: creativity, creative self-expression, competence, educational process, institutions of nonformal (out-of-school) education, modernization, New Ukrainian School, primary school children, 21st century skills.
\end{abstract}

Relevance of the research. The issue of modernization of non-formal education

in Ukraine is being implemented in the circumstances of the renewal of European and world educational changes. It is associated with the recognition of the importance of knowledge as a driving force of social progress and prosperity.

Nowadays, new Law of Ukraine "On Education" [12] has launched the development of special legislation for improving not only general secondary education, but only non-formal education (out-of-school education). Additionally, within the context of this reform the updated Law of Ukraine "On Out-of-School Education" guarantees comprehensive development of the human being as a personality and as the supreme value of the society, development of its talents, intellectual, creative and physical abilities, formation of values and competences necessary for successful self-realization, raising responsible citizens capable to make a conscious choice and channel their activities for the good of other people and, and enriching the intellectual, 
economic, creative, cultural potential the society and personality [13]. The next important step to modernize education system was the concept of "New Ukrainian School" [4] that has focused on development of competences for life, a value-based education, and a partnership between educators, parents and schoolchildren.

Therefore, the problem of modernization of the system of non-formal education of Ukraine has been actualized and these changes concern the creation of new educational models, revision of the content of educational and didactic materials, forms and methods of teaching and educating the younger generation

The purpose of the research is to emphasize the importance of problem of modernization of non-formal education in the context of current educational reforms, to identify the main approaches of modernization of non-formal education (out-of-school education), to outline the creative self-expression of personality as a priority of non-formal education and the effective pedagogical conditions of creative self-expression of primary schoolchildren nonformal education.

Analysis of recent researches and publications. The study of creative self-expression of the individual is interdisciplinary in nature, as it takes place in philosophical, cultural, sociological, psychological and pedagogical aspects. Consequently, the main foundations to our research were the following scientific points of view on the essence of creative selfexpression that has helped to determine the way how to solve the problem: 1) creative selfexpression is the action that means "to reveal oneself, one's individuality; to express (mainly in artistic creativity, in artistic image) person's thoughts, moods, beliefs [7, p. 1098]; 2) external reaction of individuals' inner feelings, beliefs, guidelines, etc.; "any behaviour that occurs for the pure satisfaction of the person" [14, p. 142]; 3) the desire of the individuals to show their inherent psychological potential of individual uniqueness through the activities, creativity or other form of socially useful behaviour [15, p. 877]; 5) revealing personal thoughts, mood, beliefs by the means of - actions, behaviour, creativity, communication [16, p. 400]; 6) "free expression of personal thoughts, feelings and attitudes through words and actions" [1, p. 379]; 7) free expression of one's own thoughts, feelings, talents and attitudes through such means as communication, poetry, decorative and applied arts, dances and dramatization [3, p. 877].

Research methods. In order to solve the problem of the research, we used a set of following methods: theoretical methods as analysis, comparison, and classification; diagnostic 
methods such as questionnaires and ranking; methods of systematization and generalization obtained findings. The empirical study was carried out among educators and primary schoolchildren in institutions of non-formal education in different cities [6].

Research results. Recently, researchers have shown an increased interest in nonformal education that is an important component of lifelong learning system. Most studies (V. Verbytskyi, A. Korniienko, O. Lytovchenko, O. Lypetskyi, V. Machuskyi, Pustovit, O. Prosina, etc.) have only been carried out in a small number of areas such as content, forms and methods of formation of basic competences and value orientations schoolchildren in institutions of non-formal education $[17 ; 18]$.

However, theoretical analysis of conducted studies does not take account the relevance non-formal education to modern requirements. For that purpose, the survey of educators of nonformal education was conducted, and respondents were asked to evaluate the educational process of out-of-school education and by the set of different indicators [6]. Based on analysis of the survey results, we have identified three most essential indicators, that should into taking into for modernization of non-formal education. The results are presented in table below (Tab.1).

Table 1

\section{Correlation between indicators of modernization of the educational process of non-formal education and educators' answers}

\begin{tabular}{|l|c|}
\hline \multicolumn{1}{|c|}{ Indicators } & $\begin{array}{c}\text { Respondents' } \\
\text { answers, \% }\end{array}$ \\
\hline $\begin{array}{l}\text { regulatory requirements, considering changes in the legislation in } \\
\text { the field of education }\end{array}$ & 41,3 \\
\hline $\begin{array}{l}\text { orientation on psychological and pedagogical approaches } \\
\text { (competence-based, person-oriented, axiological, etc.) and } \\
\text { international achievements }\end{array}$ & 36,9 \\
\hline $\begin{array}{l}\text { requests of children and parents, needs of society, cultural } \\
\text { traditions of the country }\end{array}$ & 21,8 \\
\hline \multicolumn{2}{|c|}{ Total }
\end{tabular}

This research data provided an important opportunity to advance the understanding that a special role belongs to the modern methodology of non-formal education, which should be based on a complex of four scientific approaches: person-oriented, activity, axiological and competence approaches:

1) The person-oriented approach is considered as an educational strategy, the essence of which is a set of interdependent social guidelines for the teacher's attitude to the pupil as a 
self-conscious responsible subject of one's own development and as a subject of educational interaction.

2) The activity approach is defined as the orientation of the educational process on development of the individual's competencies and life skills through application pupil's theoretical knowledge into practice, formation of abilities for self-education and teamwork, successful integration into society and self-realization.

3) The axiological approach is an approach that makes it possible to determine the strategies of their presentation during study of various pedagogical phenomena and processes, development from the standpoint of certain humanistic values.

4) The competency-based approach as a set of general principles for determining the goals of education, selecting the content of education, organizing the educational process and evaluating educational outcomes. Such principles include the following provisions: the meaning of education is to develop students' ability to solve problems in various fields and activities based on the use of social experience, an element of which is students' own experience.

Furthermore, the concept of New Ukrainian School contributes to a competence-based approach in education and to improved values and attitudes of graduates, through more focus on key competences. Key competencies and cross-disciplinary abilities and skills are equally important and interrelated. Children acquire each of them consistently, gradually, and when studying at every stage of education. These competencies have the following skills in common, and the most important for $21^{\text {st }}$ century learning are the following: the ability to logically justify a position taken, critical thinking, leadership, creativity, the ability to modulate emotions in a constructive manner, to apply emotional intelligence, the ability to work together in a team, the ability to resolve problems, estimate risks and make decisions, etc. [4, p. 12].

Due to fact that creativity is in the top of most important skill for $21^{\text {st }}$ century behind complex problem-solving and critical thinking, K. Robinson \& L. Aronica focus their attention on fostering creativity and the necessity to build an educational system that supports rather than undermines creativity. We completely agree to the researchers' idea: "The fact is that given the challenges we face; education doesn't need to be reformed - it needs to be transformed. The key to this transformation is not to standardize education, but to personalize it, to build achievement on discovering the individual talents of each child, to put students in an 
environment where they want to learn and where they can naturally discover their true passions" [5].

Consequently, based on the abovementioned approaches to modernization of nonformal education and considering the developed components (cognitive, emotionally-valuable and behavioural), criteria and indicators, which determine the levels of formation of the creative self-expression of primary schoolchildren in institutions of non-formal education $[2 ; 6 ; 8 ; 9$; $10 ; 11 ; 19 ; 20]$, we have identify the following pedagogical of condition of creative selfexpression of primary schoolchildren in non-formal education (Fig. 1).

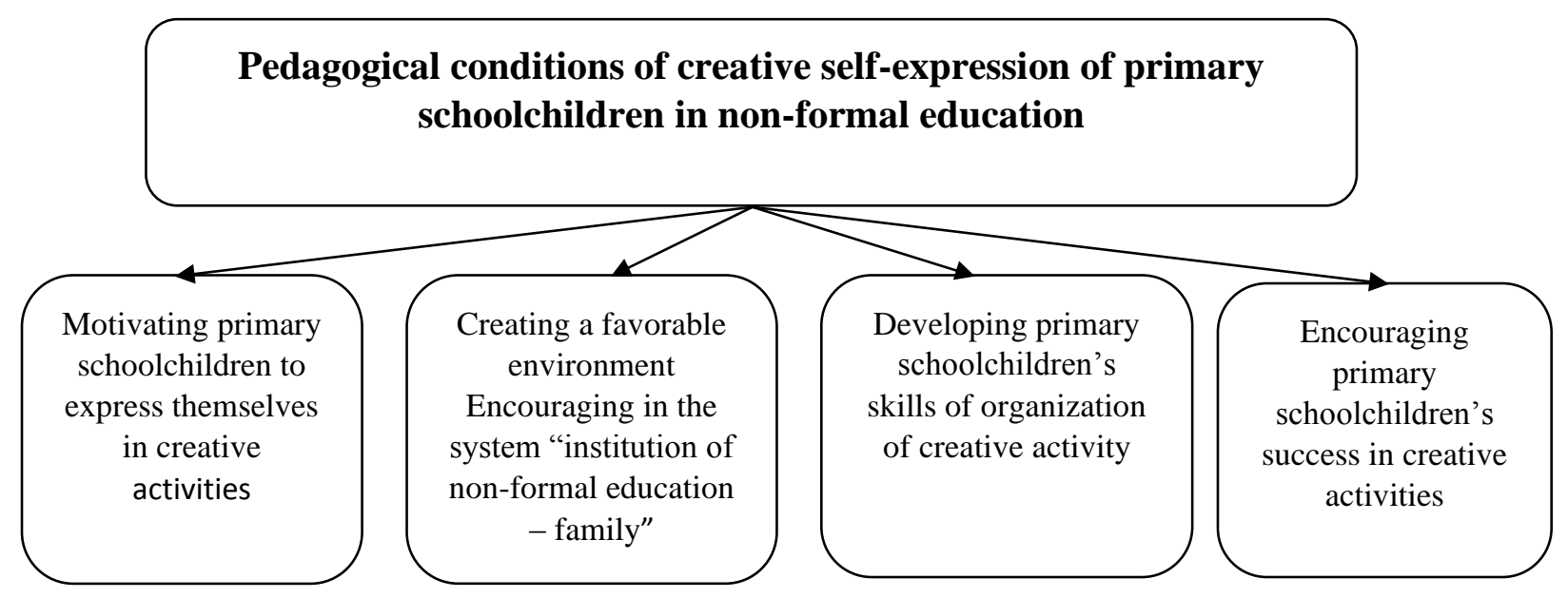

\section{Fig. 1. Pedagogical conditions of creative self-expression of primary schoolchildren} in non-formal education.

We reveal in more detail the essence of the above pedagogical conditions:

The first pedagogical conditions "Motivating primary schoolchildren to express themselves in creative activities" provides for the expansion of their knowledge about themselves, stimulating to realize the need for self-expression in creative activity; creating atmosphere of cocreation as a favourable environment for children to express their self; providing freedom of choice of creative activities.

The second pedagogical conditions "Creating a favourable environment in the system "institution of non-formal education - family" offers comfortable conditions that include interaction with family members through their inclusion in activities of institutions of nonformal education; creating a team of like-minded people (children and parents), taking into account their common interests and needs. 
The third pedagogical conditions "Developing skills of organization of creative activity" supports independence of primary schoolchildren, development of their abilities to interact in a team, ability to set the goals and the expected result of creative activity.

The fourth pedagogical conditions "Encouraging primary schoolchildren's success in creative activities" helps all children with confidence in their abilities, a sense of self-worth, optimism through creative achievements.

Therefore, the technology of ensuring the processes of creative self-expression of primary schoolchildren in non-formal education should include: 1) involvement of various social institutions that can influence the process of creative self-expression of primary schoolchildren; 2) inclusion of adults (parents or close relatives) in the creative activity of primary schoolchildren; 3) creating a situation of success necessary for successful selfexpression; 4) focus both on teamwork and individual work to achieve a quality result.

It is important to note that the technology of ensuring the process of creative selfexpression of primary schoolchildren in non-formal education consists of the following elements: defining the purpose and objectives of the organization of creative activities, developed taking into account the pedagogical conditions of creative self-expression; adequate choice of methods and means of its implementation; creating a diagnostic system that allows educators to assess the effectiveness of technology.

Conclusions of the research and perspectives of further research. We can conclude that the comprehensive modernization of non-formal education is an imperative and main strategic direction of Ukraine's educational policy at the present stage. The extensive system of institutions of non-formal education in terms of content and direction of its activities today is becoming an important educational centre for creative self-expression of children of primary school age.

For achieving this goal in effective way we propose the following pedagogical conditions of creative self-expression of primary schoolchildren non-formal education: motivating primary schoolchildren to express themselves in creative activities, creating a favourable environment in the system "institution of non-formal education - family", developing skills of organization of creative activity, encouraging primary schoolchildren's success in creative activities. 
The study does not cover the whole range of problems of creative self-expression of primary schoolchildren in institutions of non-formal educational requires further study.

\section{References}

1. Basavanna, M. Dictionary of Psychology. New Delhi: Allied Publishers Pvt. Ltd., 2000. $480 \mathrm{p}$.

2. Boiko A.E. Creative self-expression of primary schoolchildren: practice-oriented approaches in the system of out-of-school education. Teoretyko-metodychni problemy vykhovannia ditei ta uchnivskoi molodi. 2017. Vol. 21(1). P. 59-68.

3. Corsini J.R. The Dictionary of Psychology. New York: Brunner-Routledge, 2012. $1156 \mathrm{p}$.

4. New Ukrainian School: Conceptual principles of secondary school reform. 2016. URI : https://mon.gov.ua/storage/app/media/zagalna\%20serednya/Book-ENG.pdf

5. Robinson K., \& Aronica, L. The Element: How Finding Your Passion Changes Everything. London: Penguin, 2009. 300 p.

6. Boiko A.E. Suchasnyi stan problemy tvorchoho samovyrazhennia molodshykh shkoliariv u pozashkilnykh navchalnykh zakladakh [Modern state of the problem of creative self-expression of primary schoolchildren in out-of-school educational institutions]. Pedahohichni nauky: teoriia, istoriia, innovatsiini tekhnolohii. 2012. Vol. 7. Sumy : SumDPU im. A. S. Makarenka. P. 376-385.

7. Velykyi tlumachnyi slovnyk suchasnoi ukrainskoi movy [Large explanatory dictionary of the modern Ukrainian language] / Busel, V. T. (Ed.). Kyiv : VTF Perun, 2001. 1440 p.

8. Kanishevska L.V. Krokuyemo do socialnoyi zrilosti [Towards to social maturity]: nauk.-metod. posib. Kyiv: In-t problem vyhovannya NAPN Ukrayiny, 2011. 175 p.

9. Kanishevska L.V. Formuvannya zhyttyevoyi kompetentnosti pidlitkiv shkil-

internativ [Forming life competence in teenagers of boarding schools]. Novi texnologiyi navchannya. 2006. No. 4. P. 212-220.

10. Kanishevska L.V. Formuvannya cinnostej simejnogo zhyttya starshoklasnykiv zagalnoosvitnix shkil-internativ [Forming family life values in students of boarding schools]. Teoretyko-metodychni problemy vyhovannya ditej ta uchnivskoyi molodi. 2014. No. 1 (18). P. 297-305.

11. Petko L.V. Vitrila tvorchosti [The Sails of Creation]. Direktor shkoli, litseyu, gimnaziyi: vseukr. nauk.-prakt. zhurnal. 2008. No. 6. P. 40-43.

12. Pro osvitu [The Law of Ukraine "On Education"]: zakon Ukrainy. 2017. URI : http://zakon.rada.gov.ua/laws/show/2145-19

13. Pro pozashkilnu osvitu [The Law of Ukraine "On Out-of-School Education"] : zakon Ukrainy. 2017. URI : https://zakon.help/law/1841-III/edition28.09.2017/page1

14. Psykholohichnyi slovnyk [Psykholohichnyi slovnyk] ; za red. Voitko V. I. Kyiv: Vyshcha shkola, 1982. 215 p. 
15. Psykholohichnyi slovnyk [Psykholohichnyi slovnyk]; red. Pobirchenko N.A. Kyiv: Naukovyi svit, 2007. 274 p.

16. Sotsialna pedahohika [Sotsialna pedahohika] ; za red. Alieksieienko T. F. Vinnytsia: Planer, 2009. 542 p.

17. Formuvannia tsinnisnykh oriientyriv navchalno-vykhovnoho protsesu $u$ pozashkilnykh navchalnykh zakladakh [Formation of value orientations of educational process in out-of-school educational institutions] ; za red. Machuskyi V.V. Kyiv: TOV «Vydavnytstvo «Stal», 2017. $330 \mathrm{p}$.

18. Formuvannia $u$ vykhovantsiv pozashkilnykh navchalnykh zakladiv bazovykh kompetentnostei [Formation of pupils of out-of-school educational institutions of basic competences] ; za red. Machuskyi V.V. Kharkiv: Drukarnia Madryd, 2015. 220 p.

19. Pet'ko L.V. Development of students' cognitive activity in foreign language teaching by using analogy method // Actual problems of globalization: Collection of scientific articles. - Midas S.A., Thessaloniki, Greece, 2016. P. 232-237.

20. Pet'ko Lyudmila. Developing students' creativity in conditions of university // Research: tendencies and prospects: Collection of scientific articles. - Editorial Arane, S.A. de C.V., Mexico City, Mexico, 2017. P. 272-276.

\section{Translation of the Title, Abstract and References to the Author's Language}

\section{УДК 37.036:373.3: 374}

Бойко Анна. Інноваційні процеси модернізації позашкільної освіти: орієнтація на творче самовираження молодших школярів.

Стаття присвячена проблемі модернізації позашкільної освіти в умовах сучасних освітніх реформ, акцентується увага на творчому самовираженні особистості в освітньому процесі закладів позашкільної освіти та визначено ефективні педагогічні умови формування творчого самовираження дітей молодшого шкільного віку

На основі аналізу теоретичних досліджень та отриманих емпіричних даних встановлено, важлива роль належить сучасній методиці позашкільної освіти, що має базуватися на застосуванні особистісно орієнтованого, діяльнісного, аксіологічного та компетентнісного підходів. Автор статті представляє педагогічні умови, що сприяють творчому самовираженню молодших школярів в закладах позашкільної освіти: мотивація молодших школярів до самовираження в творчій діяльності, створення сприятливого середовища для реалізації молодшими школярами потреби виразити себе на основі спільної творчої діяльності в системі “заклад позашкільної освіти - сім'я", формування навичок організації творчої діяльності, заохочення успіхів молодших у творчій діяльності.

Ключові слова: творчість, творче самовираження, освітній процес, заклади позашкільної освіти, модернізація, Нова українська школа, молодші школярі, навички 21 століття, педагогічні умови творчого самовираження.

\section{Література} $480 \mathrm{p}$.

1. Basavanna, M. Dictionary of Psychology. New Delhi: Allied Publishers Pvt. Ltd., 2000. 
2. Boiko A.E. Creative self-expression of primary schoolchildren: practice-oriented approaches in the system of out-of-school education. Теоретико-методичні проблеми виховання дітей та учнівської молоді, 2017. Вип. 21(1). С. 59-68.

3. Corsini, Raymond J. The Dictionary of Psychology. New York : Brunner-Routledge 2002. $1156 \mathrm{p}$.

4. New Ukrainian School: Conceptual principles of secondary school reform. 2016. URI : https://mon.gov.ua/storage/app/media/zagalna\%20serednya/Book-ENG.pdf

5. Robinson K, Aronica L. The Element: How Finding Your Passion Changes Everything. London: Penguin, 2009, 300 p.

6. Бойко А.Е. Сучасний стан проблеми творчого самовираження молодших школярів у позашкільних навчальних закладах. Педагогічні науки: теорія, історія, інновачійні технології. Суми: СумДПУ ім. А. С. Макаренка, 2012. № 7. С. 376-385.

7. Великий тлумачний словник сучасної української мови / за ред. В.Т. Бусел. Київ : ВТФ Перун, 2001. 1440 с.

8. Канішевська Л. В. Крокуємо до соціальної зрілості : наук.-метод. посіб. Київ: Ін-т проблем виховання НАПН України, 2011. 175 с.

9. Канішевська Л. В. Формування життєвої компетентності підлітків шкілінтернатів. Нові технології навчання. 2006. № 4. С. 212-220.

10. Канішевська Л. В. Формування цінностей сімейного життя старшокласників загальноосвітніх шкіл-інтернатів. Теоретико-методичні проблеми виховання дітей та учнівської молоді. 2014 № 1 (18). С. 297-305.

11. Петько Л.В. Вітрила творчості. Директор школи, ліщею, гімназї̈: всеукр. наук.практ. журнал / засн. МОНмолодьспорту України, НАПН України, НПУ імені М.П.Драгоманова ; голов. ред. О.І. Виговська. 2008. № 6. С. 40-43.
12. Пр
освіту:
закон
України
№
2145-VIII.
(2017).

URI : http://zakon.rada.gov.ua/laws/show/2145-19

13. Про позашкільну освіту: закон України № 1841-III. (2017). URI : https://zakon.help/law/1841-III/edition28.09.2017/page1

14. Психологічний словник / за ред. В. І. Войтка. Київ : Вища школа, 1982, 215 с.

15. Психологічний словник / за ред. Н. А. Побірченко. Київ : Наук.світ,2007. 274c.

16. Соціальна педагогіка: словник-довідник / за заг. ред. Т.Ф. Алєксєєнко. Вінниця: Планер, 2009. 542 с.

17 Формування у вихованців позашкільних навчальних закладів базових компетентностей / В.В. Вербицький [та ін.] ; за заг. ред. В.В.Мачуського. Харків : «Друкарня Мадрид», 330 с.

18. Формування ціннісних орієнтирів навчально-виховного процесу у позашкільних навчальних закладах / Бойко А. Е. [та ін.] ; за заг. ред. В.В. Мачуського. Київ : ТОВ «Видавництво «Сталь», 2017. 220 с.

19. Pet'ko L.V. Development of students' cognitive activity in foreign language teaching by using analogy method // Actual problems of globalization: Collection of scientific articles. - Midas S.A., Thessaloniki, Greece, 2016. P. 232-237.

20. Pet'ko Lyudmila. Developing students' creativity in conditions of university // Research: tendencies and prospects: Collection of scientific articles. - Editorial Arane, S.A. de C.V., Mexico City, Mexico, 2017. P. 272-276. 


\title{
The Webquest as a Means of Improving the Efficiency of Students' Foreign Language Training of Ukrainian Technical Institutions of Higher Education (Beginning of the 21st Century)
}

\author{
Slyusarenko Nina \\ ORCID ID: https://orcid.org/0000-0002-9215-5936 \\ Kherson State University, Doctor of Pedagogical Sciences, Full Professor, \\ Professor Ye. Petukhov Department of Pedagogy, Psychology and Educational \\ Management of Kherson State University (Kherson, Ukraine)

\section{Soter Mariia} \\ ORCID ID: https://orcid.org/0000-0002-4626-0137 \\ Pervomaisk Branch of Admiral Makarov National University of Shipbuilding, \\ Ph.D. in Pedagogical Sciences, Lecturer, Department of Social and \\ Humanitarian Disciplines (Pervomaisk, Ukraine)
}

\begin{abstract}
The possibilities of WebQuest technology to improve the efficiency of students' foreign language training of Ukrainian technical institutions of higher education at the beginning of the XXI century have been revealed. It has been noted that the opportunity with the help of the WebQuest to involve all kinds of authentic texts (from the text to video material) with professionally-oriented issues helps to increase students' motivation to study and reach educational goals, provides the possibility to activate their cognitive activities and strengthen their desire for selfeducation. The advantages of this technology for improving students' foreign language training have been represented. The results of the questionnaire have been provided, which confirm that WebQuest technology gives an opportunity to expand students' vocabulary on a specific topic, to interest and motivate them to study a particular problem, to intensify the process of studying professional-oriented terminology, to develop students' foreignlanguage, lexical and socio-cultural competence.

Keywords: WebQuest technology, Internet resources, students' foreign language training, Ukrainian technical institutions of higher education.

Introduction. High-quality foreign language training is one of the challenges that sharply face technical institutions of higher education in Ukraine at the beginning of the XXI century. Considering the importance of foreign language training, it should be noted that nowadays such training is the key to full professional realization of a specialist in both domestic and international labour markets. In particular, it is directly related to engineering specialists. However, there are a number of problems that slow this process down and, in some cases, hinder it completely.
\end{abstract}

There are such problems [9, p. 189], for example, as significantly different 
students' level of foreign language training after school (the contingent of technical institutions of higher education in Ukraine, as a rule, covers graduates of rural and urban schools, general and specialized schools with in-depth study of some subjects) and, as a consequence, groups are formed with unequal level of foreign language proficiency, thus, students' level of knowledge usually ranges from the level of foreign language proficiency A 1 (Beginner (Basic), Elementary) to B 2 (Upper Intermediate); insufficient number of credits and, consequently, the number of classroom hours allocated in the technical institution of higher education for foreign language learning by students (it is usually two hours a week (one lesson) for one discipline in the first and second, less often in the upper courses); moreover, quite often such language courses as, for example, "Foreign Language", "English", "English for Specific Purposes" are studied by students of technical majors with a year pause, however, it is deviation from the principle of continuity and consistency in the educational process; insufficient, limited material and technical support of educational classrooms, within which foreign language training is carried out, which complicates the introduction into the educational process of the latest technologies and teaching tools, and many others.

Therefore, the problem of qualitative foreign language training of future specialists of technical majors requires urgent steps to solve it, as the full functioning of specialists both within the state and abroad depends on it. Furthermore, it is also related to the versatility of the language, as foreign language proficiency is a necessity for any specialist, regardless of major, direction or profile. This is especially true for those professionals whose activity is related to the regular professional interaction with colleagues. Such interaction with co-workers can influence not only the equipment integrity, but in some cases, people's lives. For example, language misunderstandings (both in native and foreign languages) can lead to serious damage, accidents and even catastrophes. Thus, it can be established that the level of language training in higher education depends on such important processes as: socialization of the future specialists, their professional self-realization, adaptation to the new challenges of modern society, including: life-long learning, academic and professional international mobility, cooperation in educational, scientific, industrial and other fields with domestic and foreign partners.

Considering all the above-mentioned issues that have been faced with the improvement of students' foreign language training of technical higher education institutions of Ukraine at 
the beginning of the 21 st century, there is an urgent need to find new effective ways to increase its level.

Problem statement. A significant reduction of classroom hours, increase of self-study hours for students of technical majors, as well as the intensification of the usage of Internet resources through various technical devices (for example, computers, laptops, tablets, mobile phones, etc.) have prompted the search of new technologies that combine the creative character, the possibility to implement them during the independent work at any convenient time for students. A WebQuest technology is an example of such educational tool. It was developed by Bernie Dodge together with Tom March (San Diego State University, USA). By B. Dodge's definition, a WebQuest is "an inquiry-oriented activity in which some or all of the information that learners interact with comes from resources on the Internet". The scientist also states that a WebQuest can be "optionally supplemented with videoconferencing" [8].

Thus, the solution of the above-mentioned problems dictates the urgent need to improve the efficiency of students' foreign language training of Ukrainian technical institutions of higher education, in particular through the introduction of a WebQuest technology.

The materials and the results of the research. It should be noted that in Ukraine the study of the experience of integrating the WebQuest technology into the educational process began at the beginning of the 21st century. In the research of Ukrainian scientists, a WebQuest technology is considered as a component of information technologies, multimedia technologies, interactive technologies, project technologies, etc.

O. Hniedkova identifies a WebQuest as a problematic task with elements of a roleplaying game for which information resources of the Internet are used; scenario of organizing students' project activities on any topic using Internet resources [1, p. 142]. While L. Savchenko singles out a WebQuest technology as a set of methods and techniques for organizing research using Internet resources [7, p. 70]. It is necessary to underline that during step-by-step work of completing a WebQuest, there is a constant interactive feedback among all subjects of the educational process (students and educators) at all stages of its completion, which gives an opportunity to ensure full subject-to-subject interaction.

As previously noted, it is not possible to fulfil a WebQuest without the inclusion of Internet resources. As I. Drobit and N. Rak emphasis, involvement in the educational process of information resources of the network gives the possibility to form reading skills, using directly 
authentic materials of different level of complexity; to improve listening comprehension skills with the help of authentic audio or video texts; to improve writing skills; to replenish the vocabulary with words of a modern foreign language; to get acquainted with linguistic and socio-cultural information; to form a stable motivation of students' foreign language activities [2, p. 108]. Thus, we can say that the implementation of information resources with the support and under the guidance of an educator promotes the formation of foreign language competence in listening, reading, writing, lexical competence, socio-cultural and professionally oriented competence, which greatly intensify their language training.

O. Oliinychenko notes that the main advantage of using a WebQuest technology is the focus on autonomy of learning, stimulation of creative thinking, students' involvement in the evaluation of their results and the results of their colleagues [5, p. 893]. V. Krasnopolskyi brings into focus that the involvement of a WebQuest technology in the educational process will give an opportunity to implement both general and methodical principles of learning foreign languages: the principle of interactivity (learning, immersed in communication, which creates conditions for the development of teamwork skills); the principle of autonomy, which is realized in the ability to independently manage their activities; the principle of authenticity, which involves the usage of a variety of authentic information, etc. [4, p. 98]. It should be noted that the opportunity with the help of the WebQuest to involve all kinds of authentic texts (from the text to video material) with professionally-oriented issues helps to increase students' motivation to study and reach educational goals, provides the possibility to activate their cognitive activities and strengthen their desire for self-education.

Bernie Dodge offers such components of a WebQuest as: introduction (the stages of the WebQuest are established and background information on its implementation is provided); representation of the task to be accomplished in the framework of the WebQuest and description of the process to be completed within the WebQuest (the process description should include clearly described steps); providing a set of information sources that are necessary for the task; instructions on the correct organization of the information received; conclusion [8].

Taking in consideration the above mentioned material, it is important to notice that to improve students' level of language training in the educational process of Pervomaisk Branch of Admiral Makarov National University of Shipbuilding during the practical training of fulltime mode of study at the first (bachelor) level of higher education in such educational programs 
as "Thermal Power Engineering", "Engineering Mechanic" and "Internal combustion engines" is used WebQuests.

As an example of using WebQuests we would like to propose the WebQuest "Health and safety", that was designed to organize students' independent work in order to systematize previously learned foreign language material on the topic that was intended future engineers to fulfil a set of tasks. The final aim of the WebQuest was to develop recommendations "Ways to ensure workplace safety for engineers" and represent them. The purpose of this WebQuest was 1) to deepen and broaden students' knowledge concerning the types of risks for engineers in the workplace, protective clothing and equipment and their use by engineers to perform all kinds of work; measures to be taken by engineers to ensure their own safety before, during and after work; 2) to develop foreign language competence in reading, writing, lexical competence, sociocultural and professionally oriented competence; 3 ) to teach respect and tolerance for other people.

The WebQuest combined three interrelated and interdependent stages. The first stage involved the division of students into groups (group A, group B and group C), the task for the first group A was to represent the types of risks for engineers in the workplace through the offered by the educator Internet websites; the task for the second group B was to describe protective clothing and equipment and their use by engineers to perform all kinds of work through the offered by the educator Internet websites; the task for the third group $\mathrm{C}$ was to characterise measures to be taken by engineers to ensure their own safety before, during and after work through the offered by the educator Internet websites. During the second stage, students of groups A, B and C had to organize the selected material and represent it as recommendations. During the third stage, students of groups A, B and C were required to present the material for each group. Before starting work, the educator explained in detail all steps of fulfilment the WebQuest, noted the need for accuracy of written tasks performance (during the development of recommendations "Ways to ensure workplace safety for engineers") and their oral representation, pointed out the indicators that would be evaluated upon completion of the WebQuest, including the quality of information and facts provided in the recommendations, creativity in presenting recommendations to groups, students' interaction in the group and the contribution of each member to achieve the end result. 


\section{Examples of Internet resources for the WebQuest fulfilment}

\begin{tabular}{|c|c|c|}
\hline No & Tasks for groups: & Internet resources for the WebQuest fulfilment \\
\hline $\begin{array}{l}\text { Group } \\
\text { A }\end{array}$ & $\begin{array}{l}\text { to represent the types of } \\
\text { risks for engineers in the } \\
\text { workplace through the } \\
\text { offered by the educator } \\
\text { Internet websites; }\end{array}$ & $\begin{array}{l}\text { How can engineers stay safe in the workplace? - } \\
\text { https://www.nesgt.com/blog/2019/10/how-can-engineers- } \\
\text { stay-safe-in-the-workplace } \\
\text { Safety in Mechanical Engineering by Maureen Malone - } \\
\text { https://work.chron.com/safety-mechanical-engineering- } \\
\text { 27058.html }\end{array}$ \\
\hline $\begin{array}{l}\text { Group } \\
\text { B }\end{array}$ & $\begin{array}{l}\text { to describe protective } \\
\text { clothing and equipment } \\
\text { and their use by } \\
\text { engineers to perform all } \\
\text { kinds of work; }\end{array}$ & $\begin{array}{l}\text { Risk at Work - Personal protective equipment (PPE) } \\
\text { https://www.hse.gov.uk/toolbox/ppe.htm } \\
\text { PPE: Complete guide to Personal Protective Equipment } \\
\text { - https://www.shponline.co.uk/ppe-personal-protective- } \\
\text { equipment/ }\end{array}$ \\
\hline $\begin{array}{l}\text { Group } \\
\text { C }\end{array}$ & $\begin{array}{l}\text { to characterise measures } \\
\text { to be taken by engineers } \\
\text { to ensure their own } \\
\text { safety before, during } \\
\text { and after work; }\end{array}$ & $\begin{array}{l}\text { Seven ways to avoid potential safety hazards - } \\
\text { https://www.plantengineering.com/articles/seven-ways-to- } \\
\text { avoid-potential-safety-hazards/ } \\
\text { Hazard Prevention and Control a } \quad \text { and } \\
\text { https://www.osha.gov/shpguidelines/hazard-prevention.html }\end{array}$ \\
\hline
\end{tabular}

After finishing the WebQuest, the questionnaire was conducted to represent students' self-reflection, which, on the one hand, gave students the opportunity to evaluate the results of their own work on the WebQuest, and, on the other, helped them to determine the effectiveness of its use. The questions of the questionnaire were: 1) Were complicated texts presented on the proposed websites? 2) Was it easy or difficult to fulfil the WebQuest in a team? 3) What details / facts / information have you considered valuable for your future professional activity? 4) What has been learned in the course of the WebQuest? 5) What was interesting / boring during fulfilment of the WebQuest? 6) What has helped / hindered to fulfil the WebQuest? 7) Has this WebQuest improved your English proficiency as a matter of fact? 8) Has the vocabulary expanded in the course of the proposed WebQuest?

The survey results have shown that most students (over 70\%) noted the effectiveness of using a WebQuest technology when studying the topic "Health and safety".

Thus, in response to the question "Were complicated texts presented on the proposed websites?", the majority of respondents (over 59\%) answered that the previously analysed lexical material on the presented problem made it possible to understand almost completely the 
information presented in the WebQuest; $28 \%$ said that they used the dictionary to understand information accurately; $13 \%$ said that the material was difficult to understand.

When answering the question "Was it easy or difficult to fulfil the WebQuest in a team?", $54 \%$ of the respondents said that teamwork made their work easier and allowed them to perform the task better. About $24 \%$ of respondents indicated that they could work effectively both in a group and individually. $22 \%$ answered that they preferred to perform tasks independently.

When answering the question "What details / facts / information have you considered valuable for your future professional activity?", $29 \%$ of respondents said that they could replenish vocabulary with professionally oriented terminology, $46 \%$ said that they learned about a lot of types of hazards in the workplace and about ways to avoid them, expanded knowledge about protective equipment for engineers; $25 \%$

said they would be able to provide their own safety in the real world of production.

In response to the questions "What was interesting / boring during fulfilment of the WebQuest?" and "What has been learned in the course of the WebQuest?", most of the respondents (over 71\%) answered that the WebQuest was interesting and useful, especially with professionally oriented issues of the WebQuest, in particular, professionally oriented lexical material; 24\% said that the WebQuest was quite interesting but overburdened with tasks; $5 \%$ answered that they interested in information about different types of protective equipment.

When answering the question "What has helped / hindered to fulfil the WebQuest?", $58 \%$ of the respondents noted that they used the material they had previously completed while fulfilment the tasks of the WebQuest; $31 \%$ emphasized the opportunity to interact with the students of the group, to assist one another; $11 \%$ indicated that they could use additional materials (electronic dictionaries, textbooks, etc.). In response to the questions "Has this WebQuest improved your English proficiency as a matter of fact?" and "Has the vocabulary expanded in the course of the proposed WebQuest?", more than $80 \%$ of students said they had expanded their vocabulary significantly; $15 \%$ noted that they expanded their vocabulary; $5 \%$ was almost unchanged.

The results of the work on the WebQuest, as well as the questionnaire conducted, made it possible to find out that the WebQuest technology allows to significantly expand students' vocabulary on the topic, to interest and motivate them to study a particular problem, to intensify 
the study of professional terminology, to develop foreign-language lexical, socio-cultural and professionally oriented competences.

Conclusion. The analysis of advanced scientific researches, practical experience of implementing WebQuests in the educational process of Ukrainian technical institutions of higher education, as well as the results of students' questionnaire allowed to highlight the following advantages of this technology: presence of continuous feedback among all subjects of the educational process at all stages of completion of the WebQuest; possibility to use in the WebQuest authentic professionally oriented issues, modern materials and constant updating of the information presented in the WebQuest; increase of students' motivation and interest in studying, intensification of their educational and cognitive activity; development of students' foreign language lexical, socio-cultural and professionally oriented competences; stimulating students to self-education and success in learning activities, to self-improvement; applying a creative approach in the process of finding non-standard solutions to the tasks set in the WebQuest; developing teamwork skills and enabling all team members to feel responsible for their actions and the result of their work as a whole. The prospects for further scientific research include exploring the possibilities of integrating the WebQuest technology with other educational technologies, in particular information and communication, in order to obtain the highest possible result of students' foreign language training of Ukrainian technical institutions of higher education.

\section{References}

1. Hniedkova O. Pedahohichni umovy formuvannia kontroliu fakhovykh znan' maibutnikh uchyteliv inozemnykh mov u protsesi dystantsiinoho navchannia [Pedagogical conditions of formation of control of future foreign language teachers' professional knowledge in the process of distance learning]: dys. ... kand. ped. nauk: 13.00.04. Kherson. derzh. un-t. Kherson, 2017. 294 p.

2. Drobit I., Rak N. Efektyvnist vykorystannia avtentychnykh veb-resursiv u pidhotovtsi perekladachiv [Efficiency of using authentic web resources in translator training]. Informatsiini tekhnolohii i zasoby navchannia. 2013. Vol. 35. No. 3. P. 106-112.

3. Kankovskyi I. Ye. Web-kvest yak zasib aktyvizatsii samostiinoi roboty studentiv [WebQuest as a means of activating students' independent work]. Naukovyi zhurnal "Kompiuterno-intehrovani tekhnolohii: osvita, nauka, vyrobnytstvo". Vol. 11. Lutsk, 2013. P. 199-204.

4. Krasnopolskyi V. Inshomovna pidhotovka studentiv nefilolohichnykh spetsialnostei na osnovi stvorennia $i$ vykorystannia Web-tekhnolohii [Foreign language training for non- 
philological students based on the creation and use of Web-technologies]: dys. ... d-ra ped. nauk: 13.00.01 / Skhidnoukr. nats. un-t im. Volodymyra Dalia. Kyiv, 2019. 438 p.

5. Oliinychenko O. Osoblyvosti vykorystannia veb-kvest tekhnolohii u vykladanni anhliiskoi movy dlia spetsialnykh tsilei [Features of the usage of WebQuest technology for teaching English for specific purposes]. Naukovi zapysky. Seriia: Filolohichni nauky. 2019. Vol. 175. P. 889-893.

6. Pet'ko L.V. Imperativ globalizatsiynyh perspektyv - formuvannya profesiyno spryamovanogo inshomovnogo navchalnogo seredovischa $v$ umovah universitetu [The imperative of globalization perspectives - the forming of the professionally directed foreign language educational environment in the conditions of university]. Pedagogika vyshhoi' ta seredn'oi' shkoly: zb.nauk.prac' ; za red. Z.P.Bakum. Kryvoriz'kyj pedagogichnyj instytut DVNZ «Kryvoriz'kyj nacional'nyj universytet». Vol. 41. Kryvyj Rig : Drukarnja Romana Kozlova, 2014. P. 254-261.

7. Savchenko L. Vykorystannia veb-kvest tekhnolohii u vyshchii shkoli pry pidhotovtsi maibutnikh fakhivtsiv [The use of WebQuest technologies in higher education in the preparation of future specialists]. Pedahohika vyshchoi ta serednoi shkoly. 2017. Vol. 1 (50). P. 67-74.

8. Slyusarenko N., Kulbatska M. (Soter M.). Teoretychni aspekty formuvannia u studentiv umin $i$ navychok mizhkulturnoho spilkuvannia pry vyvchenni inozemnoi movy [Theoretical aspects of formation of students' intercultural communication skills in the process of foreign language studying]. Pedahohichnyi almanakh. Kherson : KVNZ «KhANO», 2015. Vol. 27. P. 109-116.

9. Slyusarenko N., Lipshyts L. Formuvannia sotsiokulturnoi osobystosti maibutnoho sudnovodiia na zasadakh kompetentnisnoho pidkhodu [Formation of the sociocultural personality of future navigators on the basis of competence approach]. Liudynoznavchi studii. Seriia: Pedahohika. 2014. Vol. 1 (29). P. 173-181.

10. Slyusarenko N. V., Soter M. V. Problemy movnoi pidhotovky v tekhnichnykh zakladakh vyshchoi osvity Ukrainy (pochatok XXI stolittia) [Problems of language training in technical institutions of higher education of Ukraine (beginning of the 21st century)]. Teoretykometodolohichni osnovy rozvytku osvity ta upravlinskoi diialnosti: mat. V Vseukr. nauk.-prakt. konf. (12-13 veresnia 2019 r., m. Kherson) Kherson: KVNZ "Khersonska akademiia neperervnoi osvity", 2019. P. 183-186.

11. Bernie Dodge. Some Thoughts About WebQuests. San Diego State University. 2005. URL: https://jotamac.typepad.com/jotamacs_weblog/files/WebQuests.pdf

12. Pet'ko L.V. Development of students' cognitive activity in foreign language teaching by using analogy method // Actual problems of globalization: Collection of scientific articles. Midas S.A., Thessaloniki, Greece, 2016. P. 232-237.

13. Pet'ko L.V. The formation of professionally oriented foreign language teaching environment for Math students in the conditions of university // Prospects for development of education and science: Collection of scientific articles. - Academic Publishing House of the Agricultural University Plovdiv, Bulgaria, 2016. P. 352-356. 
Translation of the Title, Abstract and References to the Author's Language

\section{УДК 378.141}

Слюсаренко Ніна, Сотер Марія. Веб-квест як засіб підвищення ефективності іншомовної підготовки студентів технічних закладів вищої освіти України (початок XXI ст.).

Виявлено можливості технології веб-квест щодо підвищення ефективності іншомовної підготовки студентів технічних закладів вищої освіти України на початку XXI століття. Зазначено, що можливість через веб-квест залучати різного роду автентичні тексти 3 професійно-орієнтованою проблематикою допомагає підвищити мотивацію студентів до навчання та досягнення професійних цілей, дає можливість активізувати їх пізнавальну діяльність та посилити прагнення до самоосвіти. Представлено переваги цієї технології щодо поліпшення іншомовної підготовки студентів. Наведено результати анкетування, які підтверджують, що технологія веб-квест дозволяє розширити словниковий запас студентів із певної теми, зацікавити й вмотивувати їх до вивчення тієї чи іншої проблеми, активізувати процес вивчення професійно-орієнтованої термінології, розвинути іншомовну, лексичну, соціокультурну та професійно орієнтовану компетентності студентів.

Ключові слова: технологія веб-квест, ресурси мережі Інтернет, іншомовна підготовка студентів, технічні заклади вищої освіти України.

\section{Лimepamypa}

1. Гнєдкова О. Педагогічні умови формування контролю фахових знань майбутніх учителів іноземних мов у процесі дистанційного навчання: дис. ... канд. пед. наук: 13.00.04 / Херсон. держ. ун-т. Херсон, 2017. 294 с.

2. Дробіт I., Рак Н. Ефективність використання автентичних веб-ресурсів у підготовці перекладачів. Інформаційні технології $і$ засоби навчання. 2013. Т. 35. № 3. C. $106-112$.

3. Каньковський I. Web-квест як засіб активізації самостійної роботи студентів. Комп'ютерно-інтегровані технологї: освіта, наука, виробництво. 2013. Вип. 11. C. 199-204.

4. Краснопольський В. Е. Іншомовна підготовка студентів нефілологічних спеціальностей на основі створення і використання Web-технологій: дис. ... д-ра пед. наук: 13.00.01 / Східноукр. нац. ун-т ім. Володимира Даля. Київ, 2019. 438 с.

5. Олійниченко О. Особливості використання веб-квест технології у викладанні англійської мови для спеціальних цілей. Наукові записки [Центральноукраӥнського державного педагогічного університету імені В. Винниченка]. Серія: Філологічні науки. 2019. Вип. 175. С. 889-893.

6. Петько Л.В. Імператив глобалізаційних перспектив - формування професійно спрямованого іншомовного навчального середовища в умовах університету. Педагогіка вищої та середньої школи: зб.наук.праць ; за ред. З.П.Бакум. Криворізький пед. інститут ДВНЗ «Криворізький національний університет». Вип. 41. Кривий Ріг : Друкарня Романа Козлова, 2014. С. 254-261.

7 Савченко Л. Використання веб-квест технологій у вищій школі при підготовці майбутніх фахівців. Педагогіка вищзої та середньої школи. 2017. Вип. 1 (50). С. 67-74. 
8. Слюсаренко Н., Кульбацька М. (Сотер М.). Теоретичні аспекти формування у студентів умінь і навичок міжкультурного спілкування при вивченні іноземної мови. Педагогічний альманах. Херсон: КВНЗ «ХАНО», 2015. Вип. 27. С. 109-116.

9. Слюсаренко Н., Ліпшиць Л. Формування соціокультурної особистості майбутнього судноводія на засадах компетентнісного підходу. Людинознавчі студіï. Серія: Педагогіка. Дрогобич: ДДПУ ім. Івана Франка, 2014. Вип. 1 (29). С. 173-181.

10. Слюсаренко Н., Сотер М. Проблеми мовної підготовки в технічних закладах вищої освіти України (початок XXI століття) / Теоретико-методологічні основи розвитку освіти та управлінської діяльності: мат. V Всеукр. наук.-практ. конф. (12-13 вересня 2019 р., м. Херсон) / за ред. Кузьменка В., Слюсаренко Н.: у ІІ ч. Ч. ІІ. Херсон: КВНЗ «Херсонська академія неперервної освіти», 2019. С. 183-186.

11. Bernie Dodge. Some Thoughts About WebQuests. San Diego State University. 2005. URL : https://jotamac.typepad.com/jotamacs_weblog/files/WebQuests.pdf

12. Pet'ko L.V. Development of students' cognitive activity in foreign language teaching by using analogy method // Actual problems of globalization: Collection of scientific articles. Midas S.A., Thessaloniki, Greece, 2016. P. 232-237.

13. Pet'ko L.V. The formation of professionally oriented foreign language teaching environment for Math students in the conditions of university // Prospects for development of education and science: Collection of scientific articles. - Academic Publishing House of the Agricultural University Plovdiv, Bulgaria, 2016. P. 352-356. 


\title{
Content and Structure of Bachelor's Training within the Dual Education System: Ukrainian and German Experience
}

\author{
Dmytro Khrapach \\ Postgraduate Student, Khmelnytskyi National University, \\ (Khmelnitsky, Ukraine) \\ Hanna Krasylnykova \\ Doctor of Science in Pedagogy, Associate Professor \\ Khmelnytskyi National University (Khmelnitsky, Ukraine)
}

\begin{abstract}
The comparative analysis of Ukrainian and foreign experience of creating dual Bachelor's education programs in Automotive Technology has been conducted in the article. The structure and content of the Bachelor's education programs in Automotive Technology provided by the leading Ukrainian higher education institutions have been characterized. The main types of practices have been identified as components of education programs aimed at practical training of the future Bachelors in Automotive Technology. The algorithm of creating educational training programs within the dual education system by mastering a number of special disciplines at higher education institutions has been highlighted. The German experience of creating dual training programs for the Bachelors in Automotive Technology is presented in the article. The implementation of the dual training programs takes place according to two models of dual training: trainingoriented or practical-integrated training. The key features of implementation of dual models are characterized: training-oriented - continuous practical training at the enterprise combined with the theoretical training at the educational institution; practical-integrated training - alternating periods of practical training at the enterprise and training at the educational institution. The advantages of using dual training programs of the future Bachelors in Automotive Technology are identified and the prospects for further development of dual higher education in Ukraine are highlighted.
\end{abstract}


Keywords: higher education, dual form of education, dual program, curriculum structure.

Постановка проблеми. Наріжними проблемами вітчизняної вищої освіти $є$ iii відірваність від потреб ринку праці, незадоволення стейхолдерів змістом та рівнем якості підготовки фахівців відповідно до вимог сучасного виробництва. 3 веденням в дію «Положення про дуальну форму здобуття вищої та фахової передвищої освіти» [1] заклади вищої освіти (3ВО) можуть реорганізувати практичну складову освітнього процесу на основі нових стандартів вищої освіти та освітньо-професійних програм (ОПП), і таким чином, усунути існуючі проблеми. Відтак, у ЗВО виникає нагальна потреба розроблення та створення практико-орієнтованих ОПП, так званих дуальних програм підготовки фахівців різних спеціальностей. При цьому дуальна програма передбачає поєднання навчання осіб у закладах освіти 3 навчанням на робочих місцях на підприємствах, в установах та організаціях для набуття певної кваліфікації на основі договору.

Досвід розроблення дуальних програм у переважній більшості вітчизняних ЗВО практично відсутній, відтак актуальним є вивчення європейських підходів щодо реалізації дуального навчання, зокрема, Німеччини, в якій дуальна освіта реалізується тривалий час, у тому числі у сфері вищої освіти. Впровадження передового міжнародного досвіду щодо організації практичного навчання в умовах реального вітчизняного виробництва дозволить, на нашу думку: модернізувати вищу освіту та привести іiі у відповідність до сучасних вимог ринку праці, підвищити мотивацію здобувачів вищої освіти до навчання шляхом ï залучення до роботи в умовах реального виробництва на етапі їх навчання та подальшого працевлаштування, підвищення якості підготовки фахівців шляхом посилення ролі роботодавців у процесі їх навчання.

Аналіз останніх досліджень і публікацій. Узагальнення зарубіжного та вітчизняного досвіду щодо розроблення ОПП висвітлено в наукових роботах та методичних виданнях педагогів, які є членами Національної ради експертів 3 
реформування вищої освіти України (В. Захарченко, В. Луговий, Ж. Таланова, Л. Гризун, Ю. Рашкевича) [2]. Так, у роботі Ю. Рашкевича [3] розкрито зміст та структуру опису освітньої програми, в контексті нових стандартів вищої освіти. Дослідження Л. Гризун присвячено формуванню змісту вищої професійної освіти [4]. В.Захарченко висвітлює проблему моніторингу освітніх програм вищої освіти з урахуванням міжнародних стандартів з метою забезпечення їх якості. Оцінювання якості вищої освіти в умовах євроінтеграції охарактеризували у своїх аналітичних матеріалах В. Луговий та Ж. Таланова [5].

Отже, аналіз літературних джерел свідчить про привернення уваги вітчизняних науковців до питань розроблення змісту професійно-практичної підготовки фахівців та його представлення у формі ОПП. Водночас, відсутні наукові розвідки в сфері методології, проектування вітчизняних ОПП за дуальною формую навчання, а також практичний досвід їх реалізації для підготовки майбутніх фахівців різних спеціальностей

Формування цілей статті. Полягає в аналізі структури змістового наповнення ОПП підготовки фахівців професійної освіти (на прикладі спеціальності 015.20 «Професійна освіта. Транспорт»), що реалізуються провідними вітчизняними 3ВО, у порівнянні 3 німецькими дуальними програмами навчання за спеціальностями автотранспортного профілю.

Виклад основного матеріалу. В окремих українських 3ВО впроваджуються традиційні ОПП здобуття вищої освіти за окремими спеціальностями 3 елементами дуального навчання, які розробляться відповідно до рекомендацій Міністерство освіти і науки України [6]. Вітчизняна вища освіта має великий досвід поєднання інституційної теоретичної підготовки майбутніх фахівців 3 навчанням на робочих місцях на підприємстві 3 подальшим набуттям певної робітничої кваліфікації, що фактично є прототипом європейської дуальної освіти [7]. Підготовка бакалаврів професійної освіти автотранспортного профілю відбувається за ОПП, що розрахована на 240 кредитів СКТС та термін навчання 4 роки, а з 2019 року - базується на стандарті вищої освіти 015 «Професійна освіта» [8]. Приклади реалізації таких програм знаходимо у багатьох вітчизняних 
університетах, зокрема Національний транспортний університет (НТУ), Хмельницький національний університет (ХНУ) і Чернігівський національно педагогічний університет імені Т.Г. Шевченка (ЧНПУ) та ін.

Структура освітньої-професійної програми містить два компоненти, з яких нормативний визначається стандартом вищої освіти і є базою для створення навчального плану спеціальності 015.20 «Професійна освіта». Обсяг обов’язкової частини навчального плану для підготовки бакалаврів цієї спеціальності може коливатися у межах 50-75\% від загального обсягу ОПП, та спрямовується на забезпечення формування загальних та спеціальних (фахових) компетентностей. Обсяг вибіркових навчальних дисциплін - становить $25 \%$, він спрямований на реалізацію права студента, відповідно до Закону України «Про вищу освіту» [9], щодо вільного вибору частини навчальних дисциплін відповідно до їх власних освітніх потреб та інтересів.

Обов’язкова частина змісту підготовки бакалаврів професійної освіти автотранспортного профілю реалізується в дисциплінах у двох циклах: загальної підготовки та професійної підготовки. До циклу загальної підготовки входять дисципліни гуманітарного, природничо-наукового спрямування та професійноорієнтовані. Водночас, у циклі професійної підготовки є дисципліни, що забезпечують набуття здобувачами вищої освіти низки спеціальних фахових компетентностей, до яких Каньковський I.С. відносить [10]: ергономічну, технологічну, технічну, кваліметричну, діагностичну, статистичну, експертну, рефлексівну. Безумовно, що серед усіх виокремлених, технологічна компетентность є однією із базових для бакалаврів професійної освіти автотранспортного профілю, основною професійною функцією яких є володіння технологіями діагностування та ремонту автотранспортних засобів. Графічне представлення змісту навчальних планів підготовки бакалаврів професійної освіти автотранспортного профілю у вітчизняних ЗВО подано на рисунках 1-3.

Порівняльний аналіз змісту нормативної частини планів вітчизняних ЗВО дозволив встановити, що загальна підготовки гуманітарного спрямування в університетах реалізується через дисципліни: «Іноземна мова» та «Філософія». 


\begin{tabular}{|c|c|c|c|c|c|c|c|c|}
\hline 1 семестр & 2 семестр & 3 семестр & 4 семестр & 5 семестр & 6 семестр & 7 семестр & \multicolumn{2}{|c|}{8 семестр } \\
\hline $\begin{array}{c}\text { Інженерна та } \\
\text { комп ютерна графіка } \\
4 \text { кр. ЄКТС }\end{array}$ & $\begin{array}{c}\text { Інженерна та } \\
\text { комп ютерна графіка } \\
4 \text { кр. ЄКТС }\end{array}$ & $\begin{array}{l}\text { Психологія } \\
4 \text { кр. ЄКТС }\end{array}$ & $\begin{array}{l}\text { Автомобілі } \\
6 \text { кр. ЄКТС }\end{array}$ & $\begin{array}{l}\text { Професійна } \\
\text { педагогіка } \\
6 \text { кр. ЄКТС }\end{array}$ & $\begin{array}{l}\text { Методика професійного } \\
\text { навчання } \\
5 \text { кр. ЄКТС }\end{array}$ & $\begin{array}{l}\text { Методика професійного } \\
\text { навчання } \\
\text { iз курсовоюо роботою } 5 \text { кр. } \\
\text { ЄКТС }\end{array}$ & \multicolumn{2}{|c|}{$\begin{array}{l}\text { Екологія транспорту } \\
4 \text { кр. СКТС }\end{array}$} \\
\hline $\begin{array}{l}\text { Вища математика } \\
6 \text { кр. ЄКТС }\end{array}$ & $\begin{array}{l}\text { Фізика } \\
6 \text { кр. ЄКТС }\end{array}$ & $\begin{array}{l}\text { Автомобілі } \\
6 \text { кр. ЄКТС }\end{array}$ & $\begin{array}{l}\text { Деталі машин } \\
\mathbf{6} \text { кр. ЄКТС }\end{array}$ & $\begin{array}{c}\text { Безпека } \\
\text { життсдіяльності } \\
\mathbf{3} \text { кр. ЄКТС }\end{array}$ & $\begin{array}{l}\text { Ремонт } \\
\text { автомобіля } \\
4 \text { кр. ЄКТС }\end{array}$ & $\begin{array}{l}\text { Ремонт автомобіля } \\
\quad 4 \text { кр. ЄКТС }\end{array}$ & \multicolumn{2}{|c|}{$\begin{array}{l}\text { Транспортна логістика } \\
4 \text { кр. ЄКТС }\end{array}$} \\
\hline $\begin{array}{l}\text { Матеріалознавство } \\
5 \text { кр. ЄКТС }\end{array}$ & $\begin{array}{l}\text { Гідравліка } \\
4 \text { кр. ЄКТС }\end{array}$ & $\begin{array}{c}\text { Технологія } \\
\text { конструктивних } \\
\text { матеріалів } \\
5 \text { кр. ЄКТС }\end{array}$ & $\begin{array}{l}\text { Основи термодинаміка та } \\
\text { теплотехніки } \\
4 \text { кр. ЄКТС }\end{array}$ & $\begin{array}{l}\text { Ремонт автомобіля } \\
3 \text { кр. ЄКТС }\end{array}$ & $\begin{array}{c}\text { Основи електротехніки } \\
\text { 3,5 кр. ЄКТС }\end{array}$ & $\begin{array}{l}\text { Безпека руху } \\
4 \text { кр. ЄКТС }\end{array}$ & \multicolumn{2}{|c|}{$\begin{array}{l}\text { Історія автомобіля } \\
3 \text { кр. ЄКТС }\end{array}$} \\
\hline $\begin{array}{l}\text { Інформатика } \\
3 \text { кр. ЄКТС }\end{array}$ & $\begin{array}{l}\text { Іноземна мова } \\
2,5 \text { кр. ЄКТС }\end{array}$ & $\begin{array}{c}\text { Українське } \\
\text { державотворення } \\
3 \text { кр. ЄКТС }\end{array}$ & $\begin{array}{l}\text { Філософія } \\
3 \text { кр. ЄКТС }\end{array}$ & $\begin{array}{l}\text { Екологічна безпека } \\
3 \text { кр. ЄКТС }\end{array}$ & $\begin{array}{c}\text { Основи надійності та } \\
\text { довговічності машин } \\
4 \text { кр. ЄКТС }\end{array}$ & $\begin{array}{l}\text { Пакети прикладних } \\
\text { програм } \\
4 \text { кр. ЄКТС }\end{array}$ & \multicolumn{2}{|c|}{$\begin{array}{l}\text { Основи проектування } \\
\text { та моделювання } \\
3,5 \text { кр. ЄКТС }\end{array}$} \\
\hline $\begin{array}{l}\text { Іноземна мова } \\
2,5 \text { кр. ЄКТС }\end{array}$ & $\begin{array}{l}\text { Теорія механізмів і } \\
\text { машин } \\
5 \text { кр. ЄКТС }\end{array}$ & $\begin{array}{c}\text { Украӥнська мова (за } \\
\text { профілем } \\
\text { спрямування) } \\
3 \text { кр. ЄКТС }\end{array}$ & $\begin{array}{l}\text { Економічна теорія } \\
3 \text { кр. ЄКТС }\end{array}$ & $\begin{array}{l}\text { Культурологія } \\
3 \text { кр. ЄКТС }\end{array}$ & $\begin{array}{l}\text { Курсова робота } \\
\text { Теорія автомобоіля }\end{array}$ & $\begin{array}{l}\text { Діагностика } \\
\text { автомобіля } \\
3 \text { кр. ЄКТС }\end{array}$ & \multicolumn{2}{|c|}{$\begin{array}{c}\text { Автомобільні } \\
\text { експлуатаційні } \\
\text { матеріали } \\
3 \text { кр. ЄКТС }\end{array}$} \\
\hline $\begin{array}{c}\text { Вступ до } \\
\text { ппеціальності } \\
4 \text { кр. ЄКТС }\end{array}$ & $\begin{array}{l}\text { Теоретична } \\
\text { механіка } \\
6 \text { кр. ЄКТС }\end{array}$ & $\begin{array}{l}\text { Опір матеріалів } \\
5 \text { кр. ЄКТС }\end{array}$ & $\begin{array}{c}\text { Факультатив за фахом 1кр. } \\
\text { ЄКТС } \\
\text { Факультатив Іноземна мова } 2 \\
\text { кр. ЄКТС }\end{array}$ & $\begin{array}{l}\text { Теорія автомобіля } \\
5 \text { кр. ЄКТС }\end{array}$ & $\begin{array}{l}\text { Теорія автомобіля } \\
5 \text { кр. ЄКТС }\end{array}$ & $\begin{array}{l}\text { Теорія спілкування } \\
3 \text { кр. ЄКТС }\end{array}$ & \multicolumn{2}{|c|}{$\begin{array}{l}\text { Діагностика автомобіля } \\
3 \text { кр. ЄКТС }\end{array}$} \\
\hline $\begin{array}{l}\text { Взасмозамінність, } \\
\text { стандартизація i } \\
\text { метрологія } \\
4 \text { кр. ЄКТС }\end{array}$ & $\begin{array}{l}\text { Факультатив за фахом } \\
1 \text { кр. ЄКТС } \\
\text { Факультатив Іноземна } \\
\text { мова } 1 \text { кр. ЄКТС }\end{array}$ & \begin{tabular}{|l} 
Факультатив за фахом \\
1кр. ЄКТС \\
Факультатив Іноземна \\
мова 2 кр. ЄКТС
\end{tabular} & $\begin{array}{c}\text { Виробниче навчання } \\
4 \text { кр. ЄКТС }\end{array}$ & \multicolumn{4}{|c|}{$\begin{array}{c}\text { Факультатив за фахом } 5 \text { кр. ЄКТС } \\
\text { Факультатив Іноземна мова } 8 \text { кр. ЄКТС }\end{array}$} & \multirow{2}{*}{$\begin{array}{c}\text { Атестаційний } \\
\text { екзамен } \\
\mathbf{1 , 5} \\
\text { кр. ЄКТС }\end{array}$} \\
\hline $\begin{array}{c}\text { Факультатив за } \\
\text { фахом } 1 \text { кр. ЄКТС } \\
\text { Факультатив } \\
\text { Іноземна мова } 1 \text { кр. } \\
\text { ЄКТС }\end{array}$ & $\begin{array}{l}\text { Навчально- } \\
\text { технологічна практика } \\
3 \text { кр. ЄКТС }\end{array}$ & $\begin{array}{l}\text { Виробниче навчання } \\
3 \text { кр. ЄКТС }\end{array}$ & $\begin{array}{l}\text { Навчально-виробнича } \\
\text { практика } \\
3 \text { кр. ЄКТС }\end{array}$ & \multicolumn{2}{|c|}{$\begin{array}{c}\text { Виробнича (ремонтна) практика } \\
3+4,5 \text { кр. ЄКТС }\end{array}$} & $\begin{array}{l}\text { Педагогічна практика } \\
9 \text { кр. ЄКТС }\end{array}$ & $\begin{array}{c}\text { Виробинччо } \\
\text { (стажувальна } \\
\text { ) } \\
\text { практика } \\
\text { 6кр. ЄКТС }\end{array}$ & \\
\hline 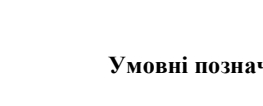 & гення: & & \multirow{4}{*}{$\begin{array}{l}\text { Проекти (курсові, } \\
\text { розрахунковi) } \\
\text { Практики }\end{array}$} & \multicolumn{2}{|c|}{$\begin{array}{c}\text { Навчання на виробництві } \\
\text { (Технічне обслуговування автомобілів } \\
9 \text { кр. ЄКТС }\end{array}$} & & & \\
\hline $\begin{array}{l}\text { Дисцииліни гуманітарног } \\
\text { спрммувания }\end{array}$ & \multicolumn{2}{|c|}{ 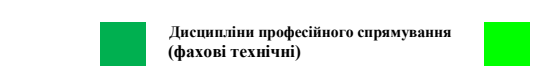 } & & & & & & \\
\hline $\begin{array}{l}\text { Дисципліни природничо-1 } \\
\text { спрямування }\end{array}$ & 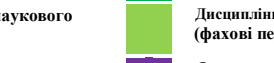 & $\begin{array}{l}\text { и професійного спрямування } \\
\text { дагогічиі) }\end{array}$ & & & & & & \\
\hline Економічні науки & Факульта & тиввні дисципліни & & & & & & \\
\hline
\end{tabular}

Рисунок 1 - Навчальний план підготовки бакалаврів денної форми навчання спеціальності 015.20 (Професійна освіта. Транспорт) Хмельницького національного університету (обов'язкова частина) [6] 


\begin{tabular}{|c|c|c|c|c|c|c|c|}
\hline 1 семестр & 2 семестр & 3 семестр & 4 семестр & 5 семестр & 6 семестр & 7 семестр & 8 семестр \\
\hline $\begin{array}{l}\text { Вступ до спеціальності } \\
3 \text { кр. ЄКТС }\end{array}$ & $\begin{array}{l}\text { Риторика } \\
3 \text { кр. ЄК }\end{array}$ & $\begin{array}{l}\text { Психологія } \\
4,5 \text { кр. ЄКтС }\end{array}$ & $\begin{array}{l}\text { Основи безпеки } \\
\text { людини } \\
4 \text { кр. ЄКтС } \\
\end{array}$ & $\begin{array}{l}\text { Теорія та методика } \\
\text { виховної роботи } \\
\text { 3 кр. ЄКТС } \\
\end{array}$ & $\begin{array}{l}\text { Методика професійного } \\
\text { навчання } \\
5 \text { кр. ЄКТС }\end{array}$ & $\begin{array}{c}\text { Методика професійного } \\
\text { навчання } \\
5 \text { кр. ЄКТС }\end{array}$ & $\begin{array}{c}\text { Комунікативні процеси в } \\
\text { педагогічний діяльності } \\
3 \text { кр. ЄКТС }\end{array}$ \\
\hline $\begin{array}{l}\text { Історія України та укр. } \\
\text { культури } \\
5 \text { кр. ЄКТС }\end{array}$ & $\begin{array}{l}\text { Іноземна мова } \\
3 \text { кр. ЄКТС }\end{array}$ & $\begin{array}{c}\text { Методичні засади } \\
\text { професійної освіти } \\
3 \text { кр. ЄКТС }\end{array}$ & $\begin{array}{l}\text { Tеорія машин та } \\
\text { механізмів } \\
5,5 \text { кр. ЄКТС }\end{array}$ & $\begin{array}{l}\text { Психологія праці } \\
\text { З кр. ЄКТС }\end{array}$ & $\begin{array}{l}\text { Основи надійності та } \\
\text { довговічності машин } \\
4 \text { кр. ЄКТС }\end{array}$ & $\begin{array}{c}\text { Теоретично-планові основи } \\
\text { осіти } \\
4 \text { кр. ЄКТС }\end{array}$ & $\begin{array}{l}\text { Економіка підприємств і } \\
\text { маркетинг } \\
3 \text { кр. ЄКТС }\end{array}$ \\
\hline $\begin{array}{l}\text { Філософія техніки } \\
3 \text { кр. ЄКТС }\end{array}$ & $\begin{array}{c}\text { Українська мова (за } \\
\text { проф. спрямуванням) } \\
3 \text { кр. ЄКТС } \\
\text { TC } \\
\end{array}$ & $\begin{array}{l}\text { Дидактичні основи } \\
\text { професійної освіти } \\
\text { З кр. ЄКТС }\end{array}$ & $\begin{array}{c}\text { Методологія } \\
\text { стандартизація і } \\
\text { управління якістю } \\
3,5 \text { кр. ЄКТС } \\
\end{array}$ & $\begin{array}{l}\text { Електротехніка } \\
3 \text { кр. ЄКТС }\end{array}$ & $\begin{array}{l}\text { Автомобіль двигуни } \\
4 \text { кр. ЄКТС }\end{array}$ & $\begin{array}{c}\text { Ремонт транспортних } \\
\text { машин } \\
\text { б кр. ЄКТС }\end{array}$ & $\begin{array}{l}\text { Основи інженерно- } \\
\text { педагогічної творчості } \\
1,5 \text { кр. ЄКТС }\end{array}$ \\
\hline $\begin{array}{l}\text { Іноземна мова } \\
3 \text { кр. ЄКТС }\end{array}$ & $\begin{array}{c}\text { Інформатика та } \\
\text { обчислювальна техніка } \\
6 \text { кр. ЄКТС }\end{array}$ & $\begin{array}{l}\text { Опір матеріалів } \\
6 \text { кр. СКТС }\end{array}$ & $\begin{array}{l}\text { Гідравліка } \\
3 \text { кр. ЄКТС }\end{array}$ & $\begin{array}{l}\text { Деталі машин та } \\
\text { основи конструкцій } \\
5 \text { кр. ЄКТС }\end{array}$ & $\begin{array}{c}\text { Стратегія сталого } \\
\text { розвитку } \\
4 \text { кр. ЄКТС }\end{array}$ & $\begin{array}{c}\text { Основи сертифікації } \\
\text { автомобіля } \\
4 \text { кр. ЄКТС }\end{array}$ & $\begin{array}{c}\text { Креативні технології } \\
\text { навчання } \\
3,5 \text { кр. ЄКТС }\end{array}$ \\
\hline $\begin{array}{c}\text { Інженерна та } \\
\text { комп ютерна графіка } \\
3 \text { кр. ЄКТС }\end{array}$ & $\begin{array}{c}\text { Інженерна та } \\
\text { комп` ютерна графіка } \\
3 \text { кр. ЄКТС }\end{array}$ & $\begin{array}{l}\text { Матеріалознавство } \\
\text { 3 кр. ЄКТС }\end{array}$ & $\begin{array}{l}\text { Матеріалознавство } \\
3 \text { кр. ЄКТС }\end{array}$ & $\begin{array}{c}\text { Технологія } \\
\text { контруктивних } \\
\text { матеріалів } \\
3 \text { кр. ЄКТС } \\
\end{array}$ & $\begin{array}{c}\text { Технологічні основи } \\
\text { машинобудування } \\
3 \text { кр. ЄКТС }\end{array}$ & $\begin{array}{c}\text { Основи розр. розр і констр } \\
\text { транс машин } \\
4 \text { кр. ЄКТС }\end{array}$ & $\begin{array}{c}\text { Екологія транспорту } \\
4,5 \text { кр. ЄКТС }\end{array}$ \\
\hline $\begin{array}{l}\text { Вища математика } \\
6 \text { кр. ЄКТС }\end{array}$ & $\begin{array}{l}\text { Вища математика } \\
5 \text { кр. ЄКТС }\end{array}$ & $\begin{array}{l}\text { Вища математика } \\
\mathbf{3} \text { кр. ЄКТС }\end{array}$ & $\begin{array}{l}\text { Основи надійності та } \\
\text { довговічності } \\
\text { транспортних машин } \\
4 \text { кр. ЄКТС } \\
\end{array}$ & $\begin{array}{c}\text { Відновлення деталей } \\
\text { машин } \\
4 \text { кр. ЄКТС }\end{array}$ & $\begin{array}{l}\text { Технічне обслуговування } \\
3 \text { кр. ЄКТС }\end{array}$ & $\begin{array}{c}\text { Автоматизація } \\
\text { транспортних машин } \\
\text { 6,5 кр. ЄКТС }\end{array}$ & $\begin{array}{c}\text { Експлуатація транспортних } \\
\text { машин } \\
3 \text { кр. ЄКТС }\end{array}$ \\
\hline $\begin{array}{c}\text { Фізика } \\
4 \text { кр. ЄКТС }\end{array}$ & $\begin{array}{c}\text { Фізика } \\
4 \text { кр. ЄКТС }\end{array}$ & $\begin{array}{c}\text { Теоретична механіка } \\
\text { 4,5 кр. ЄКТС }\end{array}$ & $\begin{array}{c}\text { Осн. розвитку, } \\
\text { розрахунку і констр. } \\
\text { транспорту } \\
3 \text { кр. ЄКТС } \\
\end{array}$ & $\begin{array}{l}\text { Теоретичні основи } \\
\text { теплотехніки } \\
3 \text { кр. ЄКТС }\end{array}$ & $\begin{array}{l}\text { Основи розв. розр і } \\
\text { констр транс машин } \\
3 \text { кр. ЄКТС }\end{array}$ & $\begin{array}{l}\text { Триботехніка } \\
\text { 3 кр. ЄКТС }\end{array}$ & $\begin{array}{l}\text { Основи фірмового } \\
\text { обслуговування } \\
4 \text { кр. ЄКТС }\end{array}$ \\
\hline \multirow[t]{5}{*}{$\begin{array}{c}\text { Хімія } \\
3 \text { кр. СКТС }\end{array}$} & $\begin{array}{l}\text { Екологія } \\
3 \text { кр. ЄКТС }\end{array}$ & $\begin{array}{c}\text { Курсова робота } \\
\text { Матеріалознавство }\end{array}$ & $\begin{array}{c}\text { Курсова робота } \\
\text { Основи надійності та } \\
\text { довговічності } \\
\text { транспортних засобів }\end{array}$ & $\begin{array}{c}\text { Особливості ТО і рем } \\
\text { автомобілів } \\
\text { 3,5 кр. ЄКТС }\end{array}$ & $\begin{array}{l}\text { Зносостійкі матеріали } \\
\text { З кр. ЄКТС }\end{array}$ & $\begin{array}{c}\text { Екеплуатаційні метеріали } \\
3 \text { кр. СКТС }\end{array}$ & $\begin{array}{c}\text { Організація автосервісу } \\
3 \text { кр. ЄКТС }\end{array}$ \\
\hline & & $\begin{array}{l}\text { Розрахунково-графічна } \\
\text { робота опір матеріалів }\end{array}$ & $\begin{array}{c}\text { Навчальна практика } \\
3 \text { кр. ЄКТС }\end{array}$ & $\begin{array}{c}\text { Курсова робота } \\
\text { Деталі машин та } \\
\text { основи } \\
\text { конструювання } \\
\end{array}$ & $\begin{array}{c}\text { Курсова робота } \\
\text { Основи надійності та } \\
\text { довговічності } \\
\text { транспортних засобів }\end{array}$ & $\begin{array}{c}\text { Курсова робота } \\
\text { Ремонт транспортних } \\
\text { машин }\end{array}$ & $\begin{array}{c}\text { Курсова робота } \\
\text { Екологія транспорту }\end{array}$ \\
\hline & & & & $\begin{array}{c}\text { Курсова робота } \\
\text { відновлення деталей }\end{array}$ & $\begin{array}{c}\text { Курсова робота } \\
\text { Автомобільні } \\
\text { двигуни }\end{array}$ & $\begin{array}{c}\text { Розрахунково-графічна } \\
\text { робота } \\
\text { Основи розр. розр і констр } \\
\text { транс машин }\end{array}$ & $\begin{array}{c}\text { Курсовий проект } \\
\text { Експлуатація } \\
\text { транспортних } \\
\text { машин } \\
\end{array}$ \\
\hline & & & & & $\begin{array}{c}\text { Технологічна практика } \\
3 \text { кредата }\end{array}$ & $\begin{array}{c}\text { Курсова робота } \\
\text { Триботехніка }\end{array}$ & Педагогічна практика \\
\hline & & & & & & & Атестаційний екзамен \\
\hline
\end{tabular}

Умовні позначення :

Дисципліни природничонаукового спрямування Дисципліни гуманітарног
Дисципліни професійного спрямування (фахові технічні Дисципліни професійного Проекти (курсові, розрахункові)
Економічна підготовка

Практики

Атестація
Рисунок 2 - Навчальний план підготовки бакалаврів денної форми навчання спеціальності 015.20 (Професійна освіта. Транспорт)

Національного транспортного університету (обов'язкова частина) [12] 


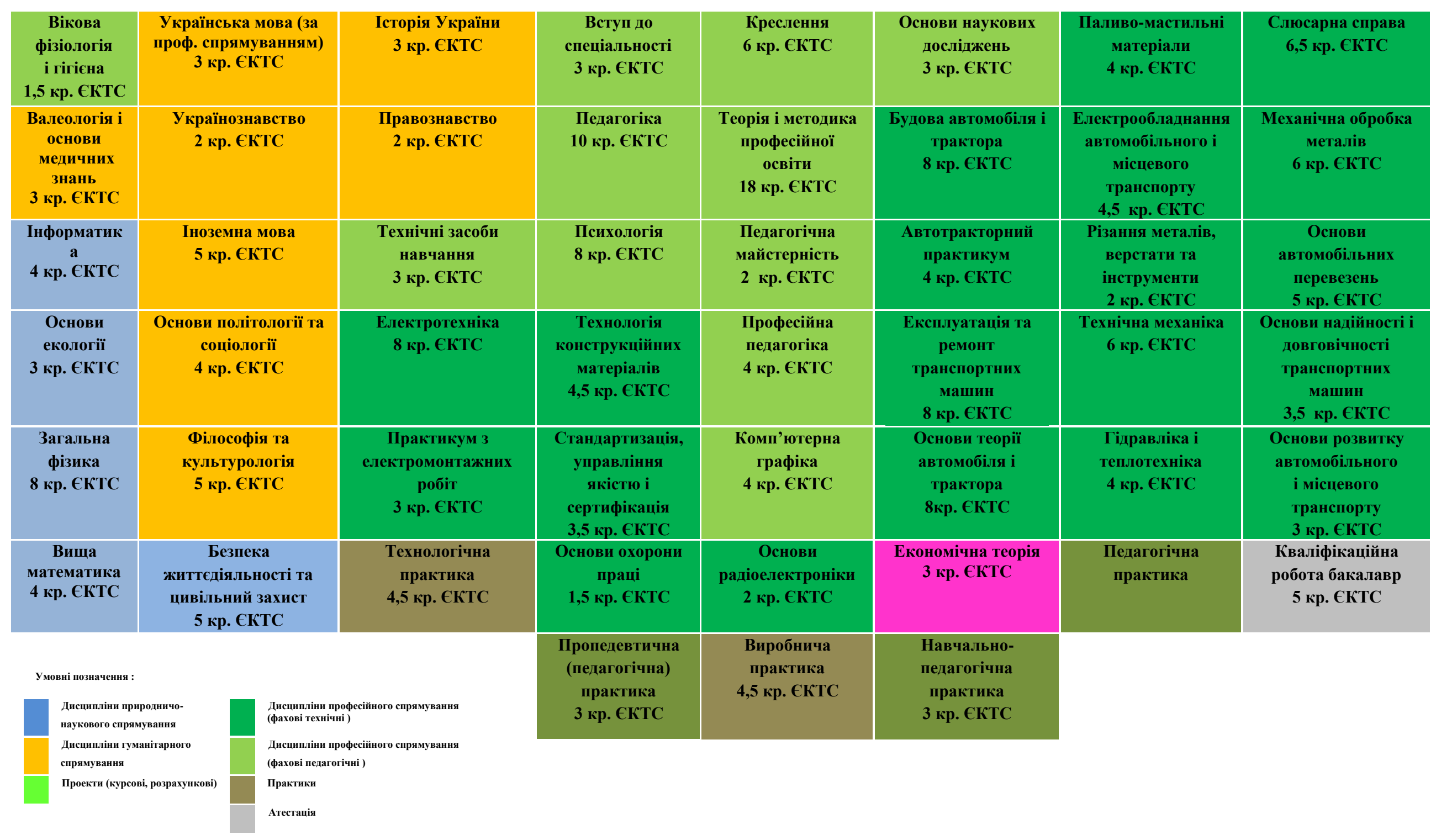

Рисунок 3 - Навчальний план підготовки бакалаврів денної форми навчання спеціальності 015.20 (Професійна освіта. Транспорт) Чернігівського національного педагогічного університету імені Т.Г. Шевченка [11] 
Педагогічна компетентність, як правило, формується в фахових дисциплінах психологічного та педагогічного спрямування, а саме «Вікова фізіологія і гігієна», «Психологія» i «Психологія праці» та педагогічного спрямування «Вступ до спеціальності», «Професійна педагогіка», «Методика професійного навчання». Перелік дисциплін природничо-наукового спрямування, який націлений на формування базових знань та умінь майбутніх фахівців та $є$ підгрунтям успішного засвоєння спеціальної підготовки автомобільного профілю, представлений, у переважній більшості, традиційними дисциплінами: «Вища математика», «Фізика», «Інженерна та комп’ютерна графіка», «Матеріалознавство» тощо. Водночас, кожен навчальний заклад, в межах академічної автономії, доповнює цей цикл власними дисциплінами, як «Безпека життєдіяльності» [6], «Основи екології» [11], «Хімія» [12] тощо.

В той же час, спеціальна компетентність формується при вивченні низки спеціальних дисциплін професійного спрямування: «Теорія машин та механізмів», «Опір матеріалів», «Технологія конструктивних матеріалів», «Гідравліка», «Деталі машин», «Автомобільні експлуатаційні матеріали», «Взаємозамінність, стандартизація і метрологія», «Основи надійності та довговічності машин», «Теоретична механіка», «Експлуатаційні матеріали», «Основи електротехніки», «Ремонт автомобіля», «Екологія транспорту», «Безпека руху» тощо.

Слід зазначити, що навчальні плани кожного ЗВО вирізняються певними особливостями. Так, наприклад, у ХНУ підготовка бакалаврів професійної освіти автотранспортного профілю містить фахову дисципліну «Технічне обслуговування автомобіля», яка передбачає вивчення теоретичного матеріалу курсу у закладі вищої освіти у поєднанні з практичною підготовкою студентів на підприємстві, що відбувається впродовж п’ятого та шостого навчальних семестрів і $\epsilon$, на нашу думку, прикладом започаткування елементів дуальної форми здобуття вищої освіти в українських ЗВО (рисунок 1).

3 метою забезпечення практичної підготовки бакалаврів професійної освіти навчальні плани усіх 3ВО містять різні види практик: навчально- 
технологічна, навчально-виробнича та виробничо-ремонтна (ХНУ), навчальна та технологічна практики (НТУ), технологічна і виробнича практики (ЧНПУ). При цьому, кількість кредитів на різні види практичної підготовки коливається в межах 6-26 (таблиця 1). Більшість проаналізованих ОПП передбачають формою підсумкового контролю за бакалаврською програмою - атестаційний іспит [6, 12], а ЧНТУ - кваліфікаційну роботу [11].

Таблиця 1: Аналіз змісту освітньо-професійних програм підготовки фахівців професійної освіти автотранспортного профілю у вітчизняних ЗВО

\begin{tabular}{|c|c|c|c|}
\hline Назва 3ВО & \multicolumn{3}{|c|}{ Кількість кредитів ЄКТС } \\
\hline Компоненти ОПП & HTУ & ЧНТУ & XHУ \\
\hline 1 & 2 & 3 & 4 \\
\hline $\begin{array}{l}\text { Дисципліни гуманітарного } \\
\text { спрямування }\end{array}$ & 14 & 27 & 20 \\
\hline $\begin{array}{l}\text { Дисципліни природничо- } \\
\text { наукового спрямування }\end{array}$ & 48 & 27 & 31 \\
\hline $\begin{array}{l}\text { Дисципліни професійного } \\
\text { спрямування (фахові технічні) }\end{array}$ & 125 & 94 & 124 \\
\hline $\begin{array}{l}\text { Дисципліни професійного } \\
\text { спрямування (фахові } \\
\text { педагогічні) }\end{array}$ & 39,5 & 61,5 & 23 \\
\hline Економічні науки & 3 & 3 & 3 \\
\hline \multicolumn{4}{|c|}{ Практики та форма атестації випускників } \\
\hline Навчальна & 3 & - & - \\
\hline Навчально-технологічна & 3 & 4,5 & 3 \\
\hline Навчально-педагогічна & - & 6 & - \\
\hline Педагогічна & 3 & 7,5 & 9 \\
\hline Навчально-виробнича & - & - & 3 \\
\hline Виробнича (ремонтна) & - & 4,5 & 7,5 \\
\hline Виробнича (стажувальна) & - & - & 6 \\
\hline Навчання на виробництві & - & - & 9 \\
\hline Атестація & 1,5 & 5 & 1,5 \\
\hline Разом & 240 & 240 & 240 \\
\hline Форми атестації & Атестаційний екзамен & $\begin{array}{c}\text { Кваліфікаційна } \\
\text { робота бакалавра }\end{array}$ & $\begin{array}{c}\text { Атестаційний } \\
\text { екзамен }\end{array}$ \\
\hline Академічна кваліфікація & $\begin{array}{c}\text { Фахівець в галузі } \\
\text { транспорту } \\
\end{array}$ & $\begin{array}{c}\text { Бакалавр в галузі } \\
\text { транспорту }\end{array}$ & $\begin{array}{c}\text { Бакалавр } \\
\text { професійної освіти }\end{array}$ \\
\hline Професійна кваліфікація & $\begin{array}{c}\text { Викладач практичного } \\
\text { навчання в галузі } \\
\text { транспорту }\end{array}$ & - & $\begin{array}{c}\text { Педагог } \\
\text { професійного } \\
\text { навчання. Механік }\end{array}$ \\
\hline
\end{tabular}


Після завершення навчання за освітньо-професійною програмою здобувачі вищої освіти у різних вітчизняних ЗВО можуть отримати одну 3 таких кваліфікацій (таблиця 1): бакалавр професійної освіти [6], бакалавр в галузі транспорту [11], фахівець в галузі транспорту [12]. У доповнення до визначених кваліфікацій ОПП Хмельницького національного університету передбачає здобуття професійної кваліфікації «механік» [6].

Для порівняння розглянемо досвід підготовки фахівців автотранспортного профілю Німеччини (на прикладі програм навчання «Промислова інженерія дуальна енергетична система»). Ця програма передбачає навчання студентів за однією із двох моделей дуального навчання: орієнтована на навчання, або практико-інтегроване навчання (рисунки 4 і 5 відповідно) [13].

Реалізація моделей дуального навчання розрахована на дев'ять семестрів і 210 кредитів СКТС. Зокрема, під час навчання за першою моделлю, орієнтованою на навчання, студенти набувають практичних навиків впродовж восьми навчальних семестрів, з яких перших п'ять - поєднують практичну діяльність на підприємствах галузі з теоретичним навчанням в умовах закладу вищої освіти, а в наступні три - поряд 3 вивченням економічних та фахових дисциплін залучаються до практичного навчання i участі у практичному семінарі. Завершується навчання у дев'ятому семестрі виконанням та захистом бакалаврської роботи.

Особливістю другої практико-інтегрованої моделі дуального навчання є чергування практичного навчання в компанії, що триває впродовж двох перших років, та навчання у закладі вищої освіти. Після дванадцяти місяців практичного навчання студенти здають проміжний іспит, а ще через дев'ять - підсумковий в Ремісничій палаті (die Handwerkskammern, HWK). Завершальний етап навчання за практико-інтегрованою моделлю передбачає виконання та захист дисертації у поєднанні зі здачею колоквіуму. 


\begin{tabular}{|c|c|c|c|c|c|c|c|c|}
\hline 1 Семестр & 2 Семестр & 3 Семестр & 4 Семестр & 5 Семестр & 6 Семестр & 7 Семестр & 8 Семестр** & 9 Семестр** \\
\hline $\begin{array}{c}\text { Математика } 1 \\
6 \text { кр. ЄКТС }\end{array}$ & $\begin{array}{c}\text { Математика } 2 \\
6 \text { кр. ЄКТС }\end{array}$ & $\begin{array}{l}\text { Природннчі } \\
\text { наукн } \\
6 \text { кр. ЄКТС }\end{array}$ & $\begin{array}{l}\text { Управління } \\
\text { проектами } \\
6 \text { кр. ЄКТС }\end{array}$ & $\begin{array}{l}\text { Прнкладна } \\
\text { статистика } \\
6 \text { кр. ЄКТС }\end{array}$ & $\begin{array}{c}\text { Вимірювальний } \\
\text { і технологія } \\
\text { автоматизації } \\
6 \text { кр. ЄКТС }\end{array}$ & $\begin{array}{c}\text { Механіка рідини } \\
\text { (англійська) } \\
6 \text { кр. ЄКТС }\end{array}$ & $\begin{array}{l}\text { Інформація та } \\
\text { комунікаційні } \\
\text { технології } \\
6 \text { кр. ЄКТС }\end{array}$ & $\begin{array}{l}\text { Модуль } 5 \\
6 \text { кр. ЄКТС }\end{array}$ \\
\hline $\begin{array}{l}\text { Енергетичні } \\
\text { системи та } \\
\text { енергія } \\
6 \text { кр. ЄКТС }\end{array}$ & $\begin{array}{l}\text { Електротехнік } \\
6 \text { кр. ЄКТС }\end{array}$ & $\begin{array}{l}\text { Технічна } \\
\text { механіка } \\
6 \text { кр. ЄКТС }\end{array}$ & $\begin{array}{c}\text { Термодннаміка } \\
6 \text { кр. ЄКТС }\end{array}$ & $\begin{array}{c}\text { Технологія } \\
\text { електричної енергії } \\
6 \text { кр. ЄКТС }\end{array}$ & $\begin{array}{c}\text { Економіка } 3 \\
6 \text { кр. ЄКТС }\end{array}$ & $\begin{array}{c}\text { Основи } \\
\text { інформатики } \\
\text { та мови } \\
\text { програмування } \\
6 \text { кр. ЄКТС }\end{array}$ & $\begin{array}{c}\text { Економіка } 4 \\
6 \text { кр. ЄКТС }\end{array}$ & $\begin{array}{c}\text { Модуль } 6 \\
6 \text { кр. ЄКТС }\end{array}$ \\
\hline $\begin{array}{c}\text { Економіка } 1 \\
6 \text { кр. ЄКТС }\end{array}$ & $\begin{array}{c}\text { Господарське } \\
\text { право } 1 \\
6 \text { кр. ЄКТС }\end{array}$ & $\begin{array}{c}\text { Господарське } \\
\text { право } 2 \\
6 \text { кр. ЄКТС }\end{array}$ & $\begin{array}{c}\text { Економіка } 2 \\
6 \text { кр. ЄКТС }\end{array}$ & $\begin{array}{l}\text { Перетворення } \\
\text { енергії } \\
\text { та зберігання } \\
6 \text { кр. ЄКТС }\end{array}$ & $\begin{array}{c}\text { Модуль } 1 \\
6 \text { кр. ЄКТС }\end{array}$ & $\begin{array}{c}\text { Модуль } 3 \\
6 \text { кр. ЄКТС }\end{array}$ & $\begin{array}{c}\text { Модуль } 4 \\
6 \text { кр. ЄКТС }\end{array}$ & $\begin{array}{c}\text { Модуль } 7 \\
6 \text { кр. ЄКТС }\end{array}$ \\
\hline & Практич & діяльність & & & $\begin{array}{l}\text { Модуль } 2 \\
6 \text { кр. ЄКТС }\end{array}$ & \multicolumn{2}{|c|}{$\begin{array}{c}\text { Практнчний семестр } \\
\text { та практичннй семінар } 26+2 \\
\text { кредити }\end{array}$} & $\begin{array}{c}\text { Бакалаврська } \\
\text { робота та } \\
\text { колоквіум } \\
12+2 \text { кр. ЄКТС }\end{array}$ \\
\hline
\end{tabular}

Умовні позначення :

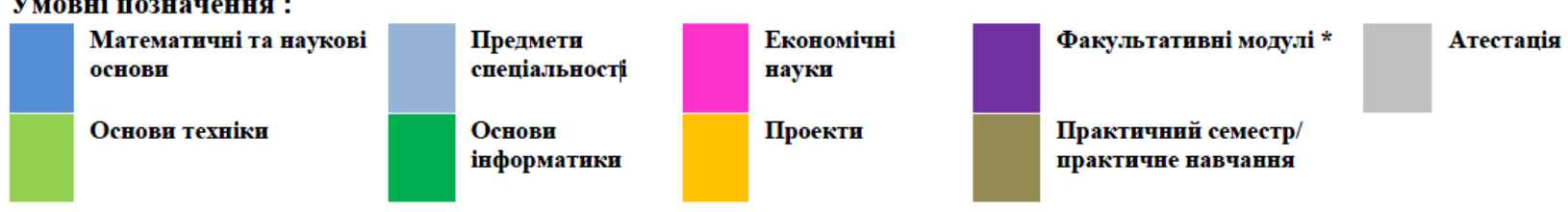

Рисунок 4 - Дипломна програма: промислова інженерія - дуальна енергетична система

(орієнтована на навчання) бакалавра інженерних наук В.Eng. [13] 


\begin{tabular}{|c|c|c|c|c|c|c|c|c|}
\hline 1 Семестр & 2 Семестр & 3 Семестр & 4 Семестр & 5 Семестр & 6 Семестр & 7 Семестр & 8 Семестр** & 9 Семестр** \\
\hline $\begin{array}{l}\text { Математика } 1 \\
6 \text { кр. ЄКТС }\end{array}$ & $\begin{array}{c}\text { Математика } 2 \\
6 \text { кр. ЄКТС }\end{array}$ & $\begin{array}{l}\text { Природничі } \\
\text { науки } \\
6 \text { кр. ЄКТС }\end{array}$ & $\begin{array}{c}\text { Теплодинаміка } \\
6 \text { кр. ЄКТС }\end{array}$ & $\begin{array}{l}\text { Прикладна } \\
\text { статистика } \\
6 \text { кр. ЄКТС }\end{array}$ & $\begin{array}{c}\text { Управління } \\
\text { проектом } \\
6 \text { кр. ЄКТС }\end{array}$ & $\begin{array}{c}\text { Основи } \\
\text { інформатики } \\
\text { та мови } \\
\text { програмування } \\
6 \text { кр. ЄКТС }\end{array}$ & \multirow{2}{*}{\multicolumn{2}{|c|}{$\begin{array}{c}\text { Практичний семестр } \\
\text { та практичний семінар } \\
26+2 \text { кр. ЄКТС }\end{array}$}} \\
\hline $\begin{array}{c}\text { Енергетичні } \\
\text { системи } \\
\text { та енергія } \\
6 \text { кр. ЄКТС }\end{array}$ & $\begin{array}{c}\text { Електротехніка } \\
6 \text { кр. ЄКТС }\end{array}$ & $\begin{array}{l}\text { Природничі } \\
\text { науки } \\
6 \text { кр. ЄКТС }\end{array}$ & $\begin{array}{c}\text { Господарське } \\
\text { право } 1 \\
6 \text { кр. ЄКТС }\end{array}$ & $\begin{array}{c}\text { Механіка рідини } \\
\text { (англійська) } \\
6 \text { кр. ЄКТС }\end{array}$ & $\begin{array}{c}\text { Вимірювальння } \\
\text { і технологія } \\
\text { автоматизації } \\
6 \text { кр. ЄКТС }\end{array}$ & $\begin{array}{c}\text { Модуль } 3 \\
6 \text { кр. ЄКТС }\end{array}$ & & \\
\hline \multirow[t]{3}{*}{$\begin{array}{c}\text { Економіка } 1 \\
6 \text { кр. ЄКТС }\end{array}$} & $\begin{array}{c}\text { Економіка } 2 \\
6 \text { кр. ЄКТС }\end{array}$ & \multirow{3}{*}{\multicolumn{2}{|c|}{$\begin{array}{c}\text { Практичне навчання } \\
\text { в компанії }\end{array}$}} & $\begin{array}{c}\text { Господарське } \\
\text { право } 2 \\
6 \text { кр. ЄКТС }\end{array}$ & $\begin{array}{c}\text { Економіка } 3 \\
6 \text { кр. ЄКТС }\end{array}$ & $\begin{array}{c}\text { Модуль } 4 \\
6 \text { кр. ЄКТС }\end{array}$ & $\begin{array}{c}\text { Основи } \\
\text { інформатики } \\
\text { та мови } \\
\text { програмування } \\
6 \text { кр. ЄКТС }\end{array}$ & \multirow{3}{*}{ 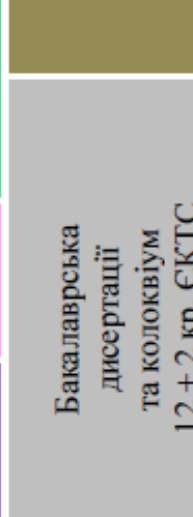 } \\
\hline & \multirow{2}{*}{ Практичне } & & & $\begin{array}{c}\text { Перетворення } \\
\text { енергії } \\
\text { та зберігання } \\
6 \text { кр. ЄКТС }\end{array}$ & $\begin{array}{l}\text { Модуль } 1 \\
6 \text { кр. ЄКТС }\end{array}$ & $\begin{array}{l}\text { Модуљь } 5 \\
6 \text { кр. ЄКТС }\end{array}$ & $\begin{array}{l}\text { Економіка } 3 \\
6 \text { кр. ЄКТС }\end{array}$ & \\
\hline & & & & $\begin{array}{c}\text { Технологія } \\
\text { електричної } \\
\text { енергії } \\
6 \text { кр. ЄКТС }\end{array}$ & $\begin{array}{l}\text { Модуль } 2 \\
6 \text { кр. ЄКТС }\end{array}$ & $\begin{array}{l}\text { Модуль } 6 \\
6 \text { кр. ЄКТС }\end{array}$ & $\begin{array}{l}\text { Модуль } 7 \\
6 \text { кр. ЄКТС }\end{array}$ & \\
\hline
\end{tabular}

Умовні познатення :

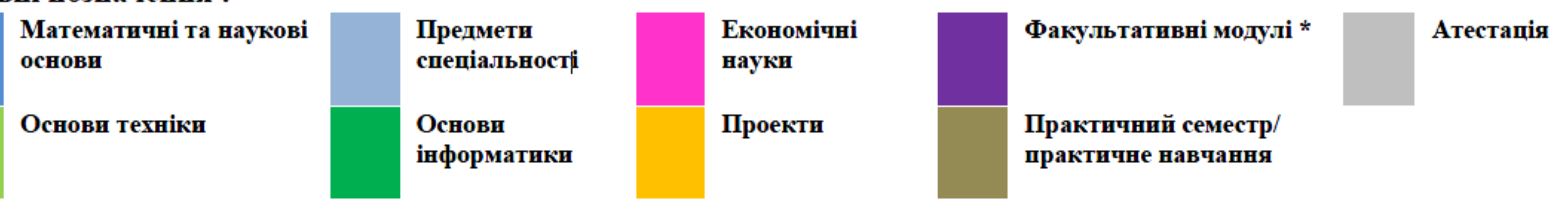

Рисунок 5 - Дипломна програма: промислова інженерія - дуальна енергетична система

(практико-інтегрована) бакалавра інженерних наук B.Eng. [13] 
При цьому, студент, який навчався за моделлю орієнтованою на навчання, отримує ступень бакалавра інженерно-технічних наук та документ про набуття практичних навиків, який видає Торгово-промислова палата Німеччини за умови обов'язкового складання підсумкового іспиту.

Отже, як бачимо обсяги практичної підготовки майбутніх німецьких фахівців автомобільного транспорту суттєво переважають сумарні обсяги практик вітчизняних ОПП. Постійний зв'язок студента з реальним виробництвом сприяє підвищенню їх мотивації до набуття практичних навичок для подальшої роботи; працевлаштуванню випускників, залученню керівників підприємств до практичного навчання майбутніх працівників. Відтак, дуальна форма здобуття освіти відповідає інтересам усіх учасників освітнього процесу та стейхолдерів.

Досвід підготовки бакалаврів автотранспортного профілю Німеччини із використанням дуальної форми здобуття освіти свідчить про існування суттєвих переваг такого навчання. Удосконалення освітнього процесу за рахунок впровадження дуальних програм підготовки бакалаврів дасть можливість: усунути розрив між теоретичним навчанням та практичною складовою підготовки майбутніх фахівців;

Водночас, поєднання теоретичного навчання та практичної роботи за дуальними програмами призводить до: збільшення як фізичного так і психічного навантаження на студента під час навчання, обмежує його в свободі вибору навчальних дисциплін, знижує рівень наукових досліджень серед студентства.

Висновки і перспективи подальших розвідок.

Отже, враховуючи прогресивний досвід Німеччини щодо використання дуальних освітніх програм у вищій освіті, доцільно започаткувати підготовку бакалаврів професійної освіти автотранспортного профілю за дуальною формою здобуття освіти у вітчизняних 3ВО. Така форма здобуття вищої освіти сприятиме набуттю студентами великого практичного досвіду ще під час навчання та гарантованого працевлаштування після його завершення. Дуальна модель навчання сприятиме підвищенню рівня підготовки майбутніх фахівців відповідно 
до вимог сучасного ринку праці та їх успішній адаптації в умовах реального виробництва.

Поєднання теоретичного навчання із практичною підготовкою дозволить модернізувати вищу професійну освіти шляхом підсилення іiі практичної складової. Впровадження передового міжнародного досвіду обумовлює створення освітніх практико-орієнтованих програм нового типу, так званих дуальних програм підготовки фахівців. Перспективними напрямами подальших досліджень вважаємо детальне вивчення закордонного досвіду щодо організації освітнього процесу підготовки бакалаврів за дуальною формую здобуття освіти та особливостей нормативної бази, на якій буде базуватися реалізації дуальних програм.

\section{References}

1. Dualna forma zdobuttia vyshchoi ta fakhovoi pered vyshchoi osvity [Dual Form of Higher Education and Professional Higher Education] [Electronic resource]. Exposure Draft (MSE order from 13.02.2019 № 175) // Ministerstvo osvity i nauky Ukrainy. - Access mode : https://mon.gov.ua/ua/ [in Ukrainian].

2. Kremen, V. H., Zakharchenko, V. M., Luhovyi, V. I., Rashkevych, Yu. M., Talanova Zh. V. (2014) Rozroblennia osvitnikh prohram. Metodychni rekomendatsii [Development of Educational Programs. Guidelines]. Kyiv, Ukraine. [in Ukrainian].

3. Rashkevych, Yu. M. (2018) Metodychni rekomendatsii shchodo opysu osvitnoi prohramy v konteksti novykh standartiv vyshchoi osvity [Guidelines for Describing the Educational Program in the Context of New Higher Education Standards] [Electronic resource]. - Access mode : https://pedpresa.ua. [in Ukrainian].

4. Hryzun, L. E. (2018) Formuvannia zmistu vyshchoi profesiinoi osvity za umov suchasnykh osvitnikh tendentsii [The Content Formation of Higher Professional Education in the Context of Modern Educational Trends] [Electronic resource]. Access mode : https://www.google.com/search?qutf-8\&oe=utf-8\&client=firefox-b. [in Ukrainian].

5. Luhovyi, V. I. (2014) Zabezpechennia yakosti vyshchoi osvity [Higher education quality assurance]. Legal Framework for the Implementation of the Bologna Process in Ukraine. Kyiv, Ukraine. [in Ukrainian].

6. Khmelnytskyi natsionalnyi universytet. Osvitnia prohrama 015 Profesiina osvita. Transport [Khmelnytskyi National University. Educational Program 015 Professional Education. Transport]. [Electronic resource]. - Access mode : https://www.khnu.km.ua/root/page.aspx?l=0\&r=50\&p=1\&f=\%D0\%91. [in Ukrainian]. 
7. Hulai, O. I. (2018) Osoblyvosti stupenevoi pidhotovky maibutnikh inzheneriv [Features of the Future Engineers Degree Training]. Physical and Mathematical Education, Vol. 1 (15). [in Ukrainian].

8. Standart vyshchoi osvity za spetsialnistiu 015 «Profesiina osvita» [Higher Education Standard in Major 015 "Vocational Education”]. [Electronic resource]. Access mode : https://mon.gov.ua. [in Ukrainian].

9. Pro vyshchu osvitu [Higher Education Act 01.07.2014 № 1556-VII]. [Electronic resource]. - Access mode : https://zakon.rada.gov.ua/laws/show/1556-18. [in Ukrainian].

10. Kankovskyi, I. Ie. (2014) Systema profesiinoi pidhotovky inzhenerivpedahohiv avtotransportnoho profiliu [The System of Professional Training of Engineers-Educators of Automotive Profile]. Khmelnytskyi, Ukraine. [in Ukrainian].

11. Chernihivskyi natsionalnyi pedahohichnyi universytet imeni T. H. Shevchenka osvitno-profesiina prohrama 015 Profesiina osvita Transport [Chernihiv National Pedagogical University named after Shevchenko T. G. Educational and Professional Program 015 Professional Education. Transport] [Electronic resource]. - Access mode: https://drive.google.com/file/d/1z- 0lKnydnwCF5qHLIwsi5ql3R24mLRNo/view [in Ukrainian].

12. Natsionalnyi transportnyi universytet robochyi navchalnyi plan studenta spetsialnosti 015 Profesiina osvita. Transport [National University of Transportation. Curriculum for the Major 015 Vocational education. Transport] [Electronic resource]. - Access mode : http://vstup.ntu.edu.ua/navch-plan/FEP-015profosvita.pdf. [in Ukrainian].

13. Bachelor-Abschluss in Wirtschaftsingenieurwesen - Energiesysteme [Bachelor's Degree in Industrial Engineering - Energy Systems] [Electronic resource]. - Access mode : https://www.hochschule-ruhrwest.de/studium/studienangebot/bachelor/wirtschaftsingenieurwesen-energiesysteme/ [in German].

Translation of the Title, Name and References to the Author's Language

\title{
Зміст та структура підготовки бакалаврів за дуальною формою здобуття освіти: український та німецький досвід
}

\author{
Храпач Дмитро \\ Аспірант, Хмельницький національний університет \\ (Хмельницький, Україна) \\ Красильникова Ганна \\ Доктор педагогічних наук, професор \\ Хмельницький національний університет \\ (Хмельницький, Україна)
}




\section{Анотація}

Стаття присвячена компаративному аналізу вітчизняного та зарубіжного досвіду створення дуальних освітніх програм підготовки бакалаврів на прикладі спеціальностей галузі автомобільного транспорту. Схарактеризовані структура та змістове наповнення освітньо-професійних програм підготовки бакалаврів професійної освіти автотранспортного профілю провідних вітчизняних ЗВО. Визначені основні види практик як компоненти освітніх програм, націлені на практичну підготовку майбутніх бакалаврів професійної освіти з автомобільного транспорту. Висвітлена практика створення освітньопрофесійних програм з елементами дуальної освіти окремими вітчизняними закладами шляхом опанування на виробництві низки спеціальних дисциплін. Представлений німецький досвід створення дуальних програм підготовки фахівців автомобільного транспорту, реалізація яких відбувається за однією із двох моделей дуального навчання: орієнтованої на навчання або практикоінтегрованого навчання. Схарактеризовані особливості реалізації дуальних моделей: орієнтованої на навчання - постійна практична підготовка на підприємстві у поєднанні 3 теоретичним навчанням в закладі освіти; практикоінтегрованого навчання - чергування періодів практичного навчання в компанії та навчання у закладі освіти. Визначені переваги використання дуальних програм підготовки фахівців автомобільного транспорту та висвітлені перспективи подальшого розвитку дуальної форми здобуття вищої освіти в Україні.

Ключові слова: вища освіта, дуальна форма здобуття освіти, дуальна програма, структура навчального плану.

\section{Лimepamypa}

1. Дуальну форма здобуття вищої та фахової перед вищої освіти [Електронний ресурс] : Проект положення (наказ МОН від 13.02.2019 № 175) // Офіційний сайт Міністерства освіти і науки України. -Режим доступу: https://mon.gov.ua/ua/ . 
2. Розроблення освітніх програм. Методичні рекомендації / Авт.: В.М. Захарченко, В.І. Луговий, Ю.М. Рашкевич, Ж.В. Таланова / За ред. В.Г. Кременя. - К. : ДП «НВЦ «Пріоритети», 2014. - 120 с.

3. Рашкевич Ю.М. Методичні рекомендації щодо опису освітньої програми в контексті нових стандартів вищої освіти [Електронний ресурс]. Режим доступу: https://pedpresa.ua.

4. $\quad$ Гризун Л. Е. Формування змісту вищої професійної освіти за умов сучасних освітніх тенденцій [Електронний ресурс]. - Режим доступу: https://www.google.com/search?qutf-8\&oe=utf-8\&client=firefox-b.

5. Луговий В.І. Забезпечення якості вищої освіти / В. Луговий // Правові засади реалізації Болонського процесу в Україні: монографія / Колектив авторів: Бугров В., Гожик А., Жданова К., Зарубінська І., Захарченко В., Калашнікова С., Козієвська О., Линьова І., Луговий В., Оржель О., Рашкевич Ю., Таланова Ж., Шитікова С.; за заг. ред. В. Лугового, С. Калашнікової. - К.: ДП «НВЦ «Пріоритети», 2014. - 156 с. - С. 65-95.

6. Хмельницький національний університет освітня програма 015 Професійна освіта. Транспорт [Електронний ресурс] :- Режим доступу: https://www.khnu.km.ua/root/page. aspx $? 1=0 \& \mathrm{r}=50 \& \mathrm{p}=1 \& \mathrm{f}=\% \mathrm{D} 0 \% 91$.

7. Гулай O.I. Особливості ступеневої підготовки майбутніх інженерів. Фізико-математична освіта. 2018. Випуск 1(15). С. 176-180.

8. Стандарт вищої освіти за спеціальністю 015 «Професійна освіта» [Електронний ресурс] : - Режим доступу: https://mon.gov.ua.

9. Про вищу освіту [Електронний ресурс] : Закон України від 01.07.2014 № 1556-VII // Законодавство України / Верхов. Рада України. - Текст. дані. - Київ, 2014. - Режим доступу: https://zakon.rada.gov.ua/laws/show/1556-18.

10. Каньковський I.С. Система професійної підготовки інженерів-педагогів автотранспортного профілю: монографія / Ігор Євгенійович Каньковський; за ред..Н.Г. Ничкало. - Хмельницький: ФОП Цасюк А.А., 2014. 562 с.

11. Чернігівський національний педагогічний університет імені Т.Г. Шевченка освітньо-професійна програма 015 Професійна освіта. Транспорт 
[Електронний ресурс]:- Режим доступу: https://drive.google.com/file/d/1z01KnydnwCF5qHLIwsi5ql3R24mLRNo/view

12. Національний транспортний університет робочий навчальний план студента спеціальності 015 Професійна освіта. Транспорт [Електронний ресурс]:Режим доступу: http://vstup.ntu.edu.ua/navch-plan/FEP-015profosvita.pdf

13. Bachelor-Abschluss in Wirtschaftsingenieurwesen - Energiesysteme [Eine elektronische Ressource]: - Zugriffsmodus: https://www.hochschule-ruhrwest.de/studium/studienangebot/bachelor/wirtschaftsingenieurwesen-energiesysteme/ 


\title{
Learning and Teaching Support Materials for Training Philology Students in Ukrainian Universities from 1850 to 1917
}

\author{
Kan Olena \\ ORCID https://orcid.org/0000-0002-3975-5385 \\ Postgraduate student \\ Prof. Ye. Petukhov Department of Pedagogy, Psychology and Educational \\ Management, Kherson State University (Ukraine, Kherson)
}

\begin{abstract}
The article deals with learning and teaching support materials for training philology students in Ukrainian universities from 1850 to 1917. The author researches main learning and teaching support materials such as syllabus, curriculums, exams requirements, lecture notes, textbooks and guides etc. It is noted that at that period each university created its kit of learning and teaching support material which must be approved by the faculty council. Due to the lack of unified learning and teaching support materials, professors and university lecturers had to prepare their syllabus, curriculums, lectures notes as well as to select the textbook and guides. This reason caused the different level of competence while training philology students as it was completely dependable on the academic staff qualification. The author makes a conclusion that the lack of unified learning and teaching support materials can have as the negative as the positive impact on training philology students in Ukrainian universities. On the one hand, the level of competence mostly depended on academic stuff qualification but, on the other hand, it gave some freedom in the selection of materials that can provide some better results in training philology students.

Key words: learning and teaching support materials, syllabus, curriculums, lecture notes, exam requirements, Ukrainian universities, training philology students.
\end{abstract}

Актуальність дослідження. Питання підготовки майбутніх філологів $€$ актуальним на сучасному етапі розвитку системи освіти України. Методи, форми, прийоми навчання постійно модифікуються і знаходяться в центрі уваги багатьох дослідників, науковців, методистів. Удосконалення системи підготовки студентів філологічного профілю неможливо без вивчення історико-педагогічного досвіду.

Українські та закордонні вчені неодноразово зверталися до вивчення питання щодо підготовки філологів в системі вищої освіти. Проте, їх роботи мають або ознайомлювальний характер, або висвітлюють лише деякі аспекти підготовки філологів, або розглядають окремі дисципліни, які є невід'ємною частиною підготовки фахівців. У попередніх статтях ми дослідили історіографію підготовки майбутніх філологів, відображення проблем підготовки філологів на шпальтах періодичних видань та дисертаційних дослідженнях. У статті «Історіографія підготовки майбутніх філологів в університетах України в II половини XIX - початку XX століття» виділено три 
історіографічні періоди: 1) роботи, опубліковані в період, що досліджуєть (1850-1917 pp.), 2) наукові праці радянського періоду (1918-1990рр.), 3) дослідження на сучасному етапі (1991 - до теперішнього часу) [3, с. 49]. В межах нашої статті особливий інтерес становить перший період.

До робіт першого періоду відносяться в основному публікації, зроблені професорами навчальних закладів, науковцями, громадськими діячами, які опікувалися проблемами освіти, формами, змістом і методами навчання, які переважали в університетах того часу. Ще одним істотним джерелом інформації є огляди викладання по університетам, в яких містяться відомості про організацію навчання, форми, методи, навчально-методичне забезпечення підготовки майбутніх філологів, Всі так звані «класичні університети» мали подібні огляди, які видавалися щорічно. Ці видання містять інформацію щодо професорсько-викладацького складу, кількості предметів і годин на тиждень, стислий зміст курсів, перелік підручників та посібників тощо. Завдяки цим оглядам можна скласти досить цілісну картину щодо організації навчання, форм, методів, навчально-методичного забезпечення підготовки майбутніх філологів, які застосовувалися на історико-філологічних (університет Св. Володимира в Києві, Новоросійський в Одесі і Харківський університети) i філософських (Львівський i Чернівецький університети) факультетах.

«Історія Львівського університету» Л. Фінкеля [19] містить інформацію про всі факультети університету, включаючи філософський факультет, де здійснювалася підготовка майбутніх філологів.

Джерелами матеріалу з підготовки філологів у Чернівецькому університеті можуть служити історичні роботи, в яких оглядається розвиток $\mathrm{i}$ діяльність Чернівецького університету в цілому: «Чернівецький університет за 25 років його існування» $\mathrm{i}$ «Альма Матер Франциска Йосефа» А. Норста [20].

У досліджуваний період видавалися також підручники, посібники, конспекти лекцій для студентів, де міститься інформацію, що стосується викладання окремих предметів: зміст курсів, методику роботи з матеріалом, додаткову літературу для ознайомлення з темою, рекомендації для самостійної роботи студентів, а саме: «Поради студентам щодо читання древніх класичних авторів» В. Данилевича [1], «Лекції 3 
слов'янського мовознавства» Т. Флоринського [18], «Нарис грецьких старожитностей» В. Латишева [6], «Посібник до читання Гомера» I. Срізневського [16] тощо.

Проаналізувавши історико-педагогічні роботи, можна зробити висновок, що нині не існує комплексних і всебічних досліджень, які в повній мірі висвітлюють організацію навчання, форми, методи, навчально-методичне забезпечення підготовки майбутніх філологів в університетах України в 1850-1917 pp., тому дане дослідження $\epsilon$ актуальним. Деякі результати дослідження можуть бути використанні для подальшого вдосконалення підготовки філологів на сучасному етапі.

Виклад основного матеріалу. У II половині XIX - початку XX століття система освіти України перебувала в стані трансформації та розвитку. Університети намагалися впроваджувати нові методи і форми навчання, використовуючи свої власні і зарубіжні моделі.

В усіх університетах основна увага при підготовці філологів приділялася саме класичній філології та вивченню стародавніх мов та літератур. Також існували відділення або окремі кафедри російсько-слов'янської філології, а пізніше й романогерманських мов, хоча викладання так званих новітніх мов у різних варіаціях було присутнє в процесі підготовки майбутніх філологів в усіх університетах [8, с. 9].

В жодному університеті України того часу не було єдиного навчальнометодичного забезпечення. Кожен університет розробляв свої власні навчальні плани, робочі програми та вимоги для складання екзаменів. Так, наприклад, в «Таблицях розподілу навчальних предметів та часу викладання» [17] Харківського імператорського університету було узагальнено кількість годин на кожному факультеті та надавався перелік предметів, які вивчалися на кожному курсі історико-філологічного та інших факультетів. Таблиця містила інформацію щодо назв начальних дисциплін та кількості годин на тиждень на кожне півріччя навчального року кожного курсу.

Вимоги до складання екзаменів містилися в «Програмах напівкурсового випробування студентів» [13]. Програми складалися з трьох частин, а саме: правила щодо заліку за півріччя та напівкурсових випробуваннях, навчальні предмети напівкурсового випробування, програми 3 навчальних дисциплін історикофілологічного факультету. Напівкурсові випробування проводилися за програмою, яка затверджувалася Міністерством Просвіти. Так, наприклад, в Імператорському 
Харківському університету в 1891 році напівкурсові екзамени складалися після 2 та 4 семестрів з наступних дисциплін: класична філологія, староцерковно-слав'янська мова, грецька та римська історія, історія стародавньої філософії, російська історія, логіка, психологія, історія російської мови.

Брак єдиного навчально-методичного забезпечення на державному рівні призводив до того, що кожен професор готував свої власні конспекти та контрольні питання або самостійно обирав підручник (посібник) для занять зі студентами. Тобто рівень викладання цілком залежав від професійних якостей викладача, його обізнаності та якості підготовки з певного предмету. Підручники та посібники були, переважно, видрукувані іншою мовою - німецькою або латиною. Щоб користуватися такими джерелами, студенти мали знати ці мови на досить високому рівні [2, с. 184-185]. Це також спричиняло нестачу підручників, посібників та іншого навчального матеріалу для підготовки фахівців-філологів в університетах України в 1850-1917 рр.

Згідно з інструкціями Міністерства просвіти, викладачі мали надати на розгляд програму своєї дисципліни. Програм обов’язково мала містити пояснювальну записку та перелік рекомендованої літератури. Програма мала бути схвалена радою факультету. Лекції та посібники, які були підготовлені викладачами, також мали отримати позитивний висновок від ради факультету. Усе навчально-методичне забезпечення проходило процес цензури, під час якої вилучалися матеріали антидержавної спрямованості [7, с. 172-173].

Слід зауважити, що вибір форм і прийомів роботи на практичних занять безпосередньо залежав від курсу, що вивчається та навчально-методичного забезпечення, яке вибирається кожним викладачем самостійно - єдиних норм і правил не існувало. Так, наприклад, один із посібників, який використовувався при викладанні дисциплін «Грецька література та старожитності», «Римська література та старожитності» рекомендує студентам виконати низку завдань, яка істотно полегшує засвоєння матеріалу: ознайомитися 3 переліком посібників, які рекомендовані для читання одного із стародавніх авторів, ретельно проаналізувати коментарі до твору, які видавалися окремим виданням, вивчити інформацію про життя і діяльність автора , а також його критичні погляди й переконання. Для повного розуміння прочитаного тексту студент також має розібрати всі незрозумілі йому граматичні моменти, а також 
повністю розуміти переклад твору. Після такої ретельного опрацювання студент повинен оволодіти наступними знаннями, вміннями i навичками: 1) володіти інформацією щодо особи і літературного значення автора; 2) прочитати і перекласти будь-який, обраний викладачем, фрагмент 3 стародавнього тексту; 3) розуміти граматичні конструкції, речення і логічну послідовність думок; 4) вміти пояснити будьякі події твору або розповісти про діючу особу твору; 5) аналізувати твір [5, с. 132-133].

Проаналізувавши архівні документи, можна також знайти інформацію щодо викладання іноземних мов та її навчально-методичного забезпечення. Так, наприклад, у програмі 3 англійської мови за 1852-1853 навчальний рік, яка розроблена Д. Сіпневським та затверджена деканом i ректором Імператорського університету Св. Володимира стверджується, що викладачем у якості основного навчального забезпечення обрано підручник Робертсона. Цей підручник складено таким чином, що студенти можуть швидко і легко опанувати мову. Окрім цього, згаданий підручник був загальновживаним при викладанні англійської мови, як в університетах Російської Імперії, так і закордоном. Підручник Робертсона охоплював 20 тем чи лекцій. Перша частина $\epsilon$ теоретичною та містить граматичні правила англійської мови, які дають студентам навички читання, письма та говоріння. Опрацьовувати теоретичний матеріал рекомендовано наступним чином:

1) читання матеріалу;

2) переклад з англійської на російську чи французьку мови;

3) аналіз слів, їх етимологію та правопис;

4) опитування щодо граматики.

Друга частина є практичною, яка розвиває навички говоріння та перекладу, поповнює лексичний запас. Опрацьовувати практичний матеріал рекомендовано наступним чином:

1) стислий переклад теми з англійської на французьку;

2) бесіда з використанням вивчених слів;

3) вивчення та активізація активної лексики за темою;

4) написання твору чи виконання перекладу коротка робота чи переклад з російської на англійську мову на основі вивченої лексики [12, с. 13]. 
Власні доробки викладачів слугували підручниками для викладання курсів в університетах. Так, наприклад, очільник кафедри «Порівняльної філології слов'янських мов, літератур і мистецтва» Львівського університету А. Каліна видав підручник 3 історії польської мови «Formy gramatyczne јкzyka polskiego do kocca XVIII wieku. Lwyw» (1883 р.), який містив матеріали щодо граматичних форм польської мови кінця XVIII століття. Також його праці містять видання, що стосуються історії мов та інших галузей слов'янської філології: «O lieczebnikach w jzyku staropolskim, jako przycznek do historyji jzyka polskiego», «Ueber die Schreibung der Nasalvocale in den altpolnischen Denkmlern», «Studyja nad historyj jzyka buigarskiego» та інші, які використовувалися ним під час викладання та читання лекцій на філософському факультеті Львівського університету [4, с. 280-285].

Іншими прикладами начальної літератури можуть слугувати власно складені викладачами підручники, посібники, конспекти лекцій, як-от: «Поради студентам відносно читання стародавніх класичних авторів» В. Данилевича (1889р.), «Посібник до читання Гомера» I. Срезневського (1875р.), «Огляд слов’янських літератур» В. Григоровича (1880р.), «Лекції з слов'янського мовознавства» Т. Флоринського (1895р.), «Нарис грецьких старожитностей» В. Латишева (1888 р.), В.І. Шерцель «Санскритська граматика» (1873) тощо.

Висновки. На підставі викладеного вище, можна зробити висновок про те, що в жодному університеті України того часу не було єдиного навчально-методичного забезпечення. Кожен університет розробляв свої власні навчальні плани, робочі програми та вимоги для складання екзаменів. Програми схвалювалися Міністерством просвіти та радою факультету. Підручники та посібники обиралися викладачем, переважно іноземними мовами, що вимагало досить високого рівня володіння мовою від студентів. В університетах України в 1850-1917 pp. брак єдиних навчальних планів і програм, навчально-методичного забезпечення унеможливлював контроль якості знань студентів та спричиняв нестачу навчально-методичного забезпечення підготовки фахівців-філологів. Проте, відсутність єдиних навчальних планів, програм, на нашу думку, можна віднести не лише до негативних, а й до позитивних характеристик навчального процесу, оскільки це надавало викладачам певну свободу дій, спонукало до 
творчості. Якщо педагог був фахівцем своєї справи, мав значний доробок з викладання мов, він міг ефективно використовувати ті чи інші методи та прийоми викладання.

\section{References}

1. Danylevych V. Sovety studentam otnositelno chteniya drevnikh klassicheskikh avtorov [How to read ancient authors: guidelines for students]. Sankt-Peterburg: Typ. V. S Balasheva, 1889. $36 \mathrm{p}$.

2. Yzvestiya o deyatelnosti $i$ sostoyanii nashykh uchebnykh zavedeniy [The bulletin about the operation and conditions of our educational institutions] // Zhurnal Ministerstva narodnogo prosveshcheniya. 1871. No. 2. P. 184-185.

3. Kan O. Iu. Istoriografiya podgotovki budushchikh filologov $v$ universitetakh Ukrainy vo II polovine XIX - nachale XX veka [The historiography of training philology students in Ukrainian universities in the second half of XIX - the beginning of the XX century]. Doklady Kazakhskoi akademii obrazovaniya / redkol. A.K. Kusaiynov (glava) i dr. Astana, 2018. No. 5. P. 48-56.

4. Kan O. Iu. Orhanizatsiia filolohichnoi osvity na filosofskomu fakulteti Lvivskoho universytetu imeni Yana Kazymyra u 1850-1917 rokakh [The organisation of philological education in the philosophical department of Jan Kazimierz Lviv University in 1850-1917]. Pedahohichnyi almanakh : zbirnyk naukovykh prats Kherson : KVNZ «Khersonska akademiia neperervnoi osvity», 2017. Vol. 33.P. 280-285.

5. Kan O. Iu. Formy, metody i priyemy obucheniya filologycheskikh distsyplin $v$ universitetakh Ukrainy vo II polovine XIX - nachala XX veka [Forms, methods and techniques of philological courses teaching in Ukrainian universities in the second half of XIX - the beginning of the XX century]. Sovremennyye problemy gumanytarnykh i sotsyalnykh nauk: materialy mezhdunarodnoi nauchno-prakticheskoy konferentsii / pod obshchey redaktsyiey A.K. Kusaynova (7 dekabrya 2018 goda, g. Astana). Astana: Yevraziskiy gumanytarnyy institut, 2018. P. 130-133.

6. Latyshev V. Ocherk grecheskikh drevnostey. Posobiye dlya gimnazistov starshikh klassov $i$ dlya nachinayushchikh filologov [The outline of Greek ancient studies. The guide for grammar school students and newcomer philology students]. Izdaniye 2-e pererab. $\mathrm{S}$.-Pb. : Tip. V. Bezobrazova i Komp., 1888. 355 p.

7. Levytska N. Naukovo-metodychne zabezpechennia vishchoii humanitarnoii osvity Naddniprianshchyny: druga polovyna XIX - pochatok XX stolittia [The scientific and methodological support for higher humanitarian education in Naddniprianshchyna: the second half of XIX - the beginning of XX century]. Ukraiinoznavstvo. 2012. No. 3. P. 171-176.

8. Obshchiy ustav Imperatorskikh Rossiyskikh Universitetov (18 iyunya 1863) [General statute of Imperial Russian universities (June 18 1863)] // Sbornik postanovleniy po Ministerstvu Narodnogo Prosveshcheniya. SPb, 1855-1864. T. 3. S.1040-1106.

9. Obshchiy Ustav imperatorskikh rossiyskikh universitetov 1884 goda [General statute of Imperial Russian universities of 1884]. Kharkov, 1911. 59 p. 
10. Pet'ko L.V. Inshomovna osvita u konteksti formuvannja novogo vchytelja v umovah universytets'koi' pidgotovky [University foreign language education in the context of the formation of a new teacher]. Pedagogika vyshhoi' ta seredn'oi' shkoly: [zb.nauk.prac']; za red. Z.P.Bakum. - Kryvoriz'kyj pedagogichnyj instytut DVNZ «Kryvoriz'kyj nacional'nyj universytet». Vol. 39. Kryvyj Rig : Drukarnja Romana Kozlova, 2013. P. 232-237.

11. Pet'ko L.V. Osvitnye seredovyshhe universytetu ta inshomovna pidgotovka studentiv [Educational environment of university and foreign language training of students] // Modernizaciya osvitn ogo seredovyshha: problemy ta perspektyvy : Materialy Chetvertoyi Mizhnarodnoyi naukovo-praktychnoyi konferenciyi (m. Uman, 11-12 zhovtnya 2018 r.) / gol. red. Osadchenko I. I. Uman`: VPCz «Vizavi», 2018. 184 p. P. 117-120.

12. Programma po angliyskomu yazyku za 1852-1853 uchebnyy god. Derzhavniy arkhiv m. Kieva (DAK) [The English language curriculum in 1852-1853 academic year]. F. 16. op. 465. spr. 96.53 ark.

13. Programmy polukursovogo ispytaniya studentov istoriko-filologicheskogo fakulteta $v$ Imperatorskom Kharkovskom universitete [Term examinations curriculum for students of historical-philological faculty in Imperial Kharkov University]. Kharkov: Universitetskaya tipografiya, $1891.38 \mathrm{p}$.

14. Sliusarenko N.V., Kokhanovska O.V. Transformatsiia vyshchoi zhinochoi osvity v Ukraini (XIX - pochatok XXI stolittia) [The transformation of higher female educationin Ukraine (XIX - the beginning of the XXI century)]. Visnyk Cherkaskoho universytetu (Seriia Pedahohichni nauky). 2018. Vol. 2. P. 124-130.

15. Sliusarenko N.V. Formy $i$ metody vyhovnoii roboty u vyshchomu navchalnomu zakladi [Forms and methods of extracurricular activites in a higher educational institution]. Tavriiskyi visnyk osvity. 2009. №3 (27). C. 107-116.

16. Sreznevskiy I.I. Posobiye $k$ chteniyu Gomera. Vypusk I. Etimologiya Gomerovskogo dialekta i kommentarii na 1-yu pesn Odissei [The guide to Homer. Issue 1. The etymology of the dialect and comments to the $1^{\text {st }}$ book of Odyssey]. SPb $1875.80 \mathrm{p}$.

17. Tablitsa raspredeleniya uchebnykh predmetov $i$ vremeni prepodavaniya $v$ Imperatorskom Kharkovskom universitete na 1850/51 uchebnyy god [The table of courses and credits in Imperial Kharkov University in 1850/51 academic year]. Kharkov, 1850. 11 p.

18. Florinskiy T. Lektsii po slavyanskomu yazykoznaniyu [Lectures on Slavic linguistics]. Kyiv : Universitet svyatogo Vladimira. 1897. 703 p.

19. Finkel L., Starzycski S. Historya uniwersytetu Lwowskiego [The history of Lviv University]. Lwyw: Drukarnia E. Winiarza, 1894. 351 p.

20. Norst A. Alma Mater Francisco-Josephina, Festschrift zu deren 25-jährigem Bestande. 1900. 146 p.

Translation of title, name of author, abstract and the list of references to the original language

УДК 378.091.2(477)(09)"1850/1917”(043.3) 


\section{Кан Олена. Навчально-методичне забезпечення підготовки філологів в університетах України в 1850-1917 рр.}

Стаття розглядає навчально-методичне забезпечення підготовки філологів в університетах України в 1850-1917 рр. Досліджуються основні навчально-методичні матеріали, такі як навчальні плани, програми, вимоги до іспитів, конспекти лекцій, підручники та посібники тощо. Визначається, що в цей період кожен університет створив свій набір навчальних матеріалів, які повинні бути затверджені радою факультету. Через відсутність уніфікованих навчальних та навчальних матеріалів, професорам та викладачам університету довелося готувати власні програми, конспекти лекцій, а також підбирати підручник та посібники. Автор робить висновок, що відсутність уніфікованого навчально-методичного забезпечення може мати як негативний, так і позитивний вплив на підготовку студентів філології в українських університетах.

Ключові слова: навчально-методичне забезпечення, навчальні плани, навчальні програми, конспекти лекцій, вимоги до іспитів, університети України, студентифілологи.

\section{Лimepamypa}

1. Данилевич В. Советы студентам относительно чтения древних классических авторов. Санкт-Петербург: Тип. В. С Балашѐва, 1889. 36 с.

2. Известия о деятельности и состоянии наших учебных заведений // Журнал Министерства народного просвещения, 1871. №2. С. 184-185.

3. Кан О.Ю. Историография подготовки будущих филологов в университетах Украины во II половине XIX - начале XX века. Докладь Казахской академии образования / редкол. А.К. Кусайынов (глава) и др. Астана, 2018. №5. С. 48-56.

4. Кан О.Ю. Організація філологічної освіти на філософському факультеті Львівського університету імені Яна Казимира у 1850-1917 роках. Педагогічний альманах : збірник наукових праць / редкол. В. В. Кузьменко (голова) та ін. Херсон : КВНЗ «Херсонська академія неперервної освіти», 2017. Вип. 33. С. 280-285.

5. Кан О.Ю. Формы, методы и приемы обучения филологических дисциплин в университетах Украины во II половине XIX - начала XX века. Современные проблемы гуманитарных и социальных наук: материалы международной научно-практической конференции / под общей редакцией А.К. Кусаинова (7 декабря 2018 года, г. Астана). Астана: Евразийский гуманитарный институт, 2018. С. 130-133.

6. Латышев В. Очерк греческих древностей. Пособие для гимназистов старших классов и для начинающих филологов. Издание 2-е перераб.. С.-Пб.: Тип. В. Безобразова и Комп., 1888. 355 с.

7. Левицька Н. Науково-методичне забезпечення вищої гуманітарної освіти Наддніпрянщини: друга половина XIX - початок XX століття. Украӥнознавство. 2012. № 3. С. 171-176.

8. Общий устав Императорских Российских Университетов (18 июня 1863) // Сборник постановлений по Министерству Народного Просвещения. СПб., 1855-1864. T. 3. C.1040-1106. 
9. Общий Устав императорских российских университетов 1884 года. Харьков, $1911.59 \mathrm{c}$.

10. Петько Л.В. Іншомовна освіта у контексті формування нового вчителя в умовах університетської підготовки. Педагогіка вищої та середньої школи: зб.наук.праць ; за ред. З.П.Бакум. Криворізький педагогічний інститут ДВНЗ «Криворізький національний університет». Вип. 39. Кривий Ріг : Друкарня Романа Козлова, 2013. С. 232-237.

11. Петько Л.В. Освітнє середовище університету та іншомовна підготовка студентів // Модернізація освітнього середовища: проблеми та перспективи : Матеріали Четвертої Міжнародної науково-практичної конференції (м. Умань, 11-12 жовтня 2018 р.) / гол. ред. Осадченко І. І. Умань : ВПЦ «Візаві», 2018. 184 с. С. 117-120.

12. Программа по английському языку за 1852-1853 учебный год / Державний архів м. Києва (ДАК). Ф. 16, оп. 465, спр. 96, 53 арк.

13. Программы полукурсового испытания студентов историко-филологического факультета в Императорском Харьковском университете. Харьков: Университетская типография, $1891.38 \mathrm{c}$.

14. Слюсаренко Н. В., Кохановська О. В. Трансформація вищої жіночої освіти в Україні (XIX - початок XXI століття). Вісник Черкаського університету (Серія Педагогічні науки). Випуск 2. 2018. Черкаси: Черкаський національний університет імені Богдана Хмельницького, 2018. С. 124-130.

15. Слюсаренко Н.В. Форми і методи виховної роботи у вищих навчальних закладах. Таврійський вісник освіти. 2009. №3 (27). С. 107-116.

16. Срезневский И. И. Пособие к чтению Гомера. Выпуск І. Етимология Гомеровского диалекта и комментарии на 1-ю песнь Одиссеи. СПб, 1875. 80 с.

17. Таблица распределения учебных предметов и времени преподавания в Императорском Харьковском университете на 1850/51 учебный год. Харьков, 1850. 11с.

18. Флоринский Т. Лекции по славянскому языкознанию. Киев : Ун-т св. Владимира, 1897. 703 с.

19. Finkel L., Starzycski S. Historya uniwersytetu Lwowskiego. Lwyw: Drukarnia E. Winiarza, 1894. 351 p.

20. Norst A. Alma Mater Francisco-Josephina, Festschrift zu deren 25-jährigem Bestande, 1900. $146 \mathrm{p}$. 


\title{
Content of Building Intercultural Competence in Future Specialists of Combat and Operational Support
}

\author{
Liubas Anzhelika \\ ORCID http://orcid.org/0000-0001-6068-6065 \\ Postgraduate Student at the Department of Pedagogical Education \\ Ivan Franko National University of Lviv (Ukraine, Lviv)
}

\begin{abstract}
The article deals with a crucial research issue of acquiring intercultural competence by future specialists of combat and operational support. Following the recent researches intercultural competence of future specialists of combat and operational support is interpreted as an ability to cooperate with professionals - representatives of other cultures with regard for their values, norms, traditions and images and also choose the expedient ways of verbal and nonverbal communication with the aim to solve professional problems. The components of intercultural competence of future specialists of combat and operational support include knowledge (language, speech, multicultural knowledge, knowledge of verbal and nonverbal communicative rules of behavior, cognitive knowledge), skills and abilities (speech skills and abilities, cognitive skills, an ability to control own actions in communication). While studying disciplines "Foreign language", "Foreign language for Specific Purposes" students acquire basic elements of foreign language system, develop and improve speech knowledge, skills and abilities. Introduction into third year students' syllabus the discipline "Intercultural Communication in Professional Cooperation" and organization of learning and field training envisages implementation of intercultural competence while performing professional duties and functions.

Key word: intercultural competence, future specialists of combat and operational support, discipline, syllabus.
\end{abstract}

Актуальність дослідження. У сучасних умовах глобалізації та світової інтеграції, а поруч із тим взаємодопомоги і взаємопідтримки держав у процесі вирішення існуючих військових конфліктів, особливого значення набуває володіння військовослужбовцями, зокрема фахівцями бойового та оперативного забезпечення, міжкультурною компетентністю з метою забезпечення здатності повноцінно виконувати професійні обов'язки та функції у процесі міжнародних спільних навчань та миротворчих операцій.

Проблемі формування міжкультурної компетентності присвячено розвідки таких науковців як М. Байрам, М. Беннет, Л. Гребенюк, О. Зеліковська, З. Корнєва, Л. Петько, А. Садохін та ін., особливості формування і розвитку міжкультурної компетентності майбутніх військовослужбовців досліджували О. Антонова, О. Дубасенюк, Л. Маслак та ін. Здійснений аналіз науково-педагогічної літератури доводить, що на сьогоднішній день не 
існує комплексного дослідження, присвяченого змісту формування міжкультурної компетентності майбутніх фахівців бойового та оперативного забезпечення.

Мета статті - обгрунтувати і сконструювати зміст формування міжкультурної компетентності майбутніх фахівців бойового та оперативного забезпечення.Виклад основного матеріалу. Задля обгрунтування й конструювання змісту формування міжкультурної компетентності майбутніх фахівців бойового та оперативного забезпечення звернемось до сутності поняття «міжкультурна компетентність майбутніх фахівців бойового та оперативного забезпечення» та його структури.

3 урахуванням результатів здійснених досліджень розглядаємо міжкультурну компетентність як здатність особи взаємодіяти з представниками інших культур на основі врахування їхніх цінностей, норм, традицій, уявлень, а також обирати комунікативно доцільні способи невербальної і вербальної поведінки [7, с. 51]. Відповідно, міжкультурну компетентність майбутніх фахівців бойового та оперативного забезпечення трактуємо як здатність иүи фахівців взаємодіяти з професіоналами представниками інших культур на основі врахування їхніх иүінностей, норм, традицій, уявлень, а також обирати комунікативно доцільні способи невербальної $і$ вербальної поведінки з метою вирішення завдань професійного характеру.

До компонентів міжкультурної компетентності майбутніх фахівців бойового оперативного забезпечення відносимо наступні знання, вміння і навички: 1) мовні знання (фонетичні, лексичні, граматичні, орфографічні), вміння і навички; 2) мовленнєві знання, навички та вміння (вести діалог 3 представниками інших культур, аналізувати мовленнєву ситуацію, дотримання норм етикету); 3) полікультурні знання; 4) знання вербальних та невербальних комунікативних правил поведінки; 5) когнітивні знання $i$ навички; 6) здатність контролювати власні дії під час спілкування [3; 4, с. 50-51; 6; 12; $14]$.

На сьогоднішній день зміст професійної підготовки майбутніх фахівців бойового та оперативного забезпечення у закладах вищої освіти України формується на основі: вимог та положень освітньо-кваліфікаційних характеристик, освітньо-професійних програм підготовки військових фахівців, сучасної політики щодо застосування підрозділів і частин у збройних конфліктах, особливостей ведення бойових дій підрозділами збройних сил України у складі сил АТО.Формування і розвиток у майбутніх 
фахівців бойового та оперативного забезпечення знань, умінь і навичок - компонентів міжкультурної компетентності здійснюється у процесі вивчення ними нормативних навчальних дисциплін «Іноземна мова», «Іноземна мова за професійним спрямуванням» та розробленого і запропонованого вибіркового спецкурсу «Міжкультурна комунікація у професійній співпраці». Зміст перелічених дисциплін формується на засадах міжпредметних зв'язків з іншими дисциплінами гуманітарної та соціально-економічної підготовки [5; 6], природничо-наукової підготовки, базової підготовки, загальнопрофесійної підготовки, військово-професійної підготовки та військово-спеціальної підготовки майбутніх фахівців бойового та оперативного забезпечення. Так, аналіз навчальних планів підготовки майбутніх бакалаврів бойового та оперативного забезпечення в українських закладах вищої освіти дозволяє стверджувати, що конструювання змісту навчальних дисциплін «Іноземна мова», «Іноземна мова за професійним спрямуванням» та «Міжкультурна комунікація у професійній співпраці» 3 метою формування у цих фахівців міжкультурної компетентності має здійснюватись на основі міжпредметної координації 3 певними дисциплінами. Перелік навчальних дисциплін відповідних блоків дисциплін, змістове наповнення яких ураховується у процесі конструювання змісту навчальних дисциплін «Іноземна мова», «Іноземна мова за професійним спрямуванням» та «Міжкультурна комунікація у професійній співпраці», представлено у таблиці 1.

Таблиияя 1

Навчальні дисципліни у змісті курсів «Іноземна мова», «Іноземна мова за професійним спрямуванням», «Міжкультурна комунікація у професійній співпраці»

\begin{tabular}{|l|l|}
\hline \multicolumn{1}{|c|}{ Навчальна дисципліна } & \multicolumn{1}{|c|}{ Блок дисциплін } \\
\hline $\begin{array}{l}\text { Основи військового управління (штабні } \\
\text { процедури НАТО) }\end{array}$ & $\begin{array}{l}\text { Блок дисциплін загально професійної } \\
\text { підготовки }\end{array}$ \\
\hline $\begin{array}{l}\text { Правознавство (міжнародне гуманітарне } \\
\text { право) }\end{array}$ & $\begin{array}{l}\text { Блок дисциплін загально професійної } \\
\text { підготовки }\end{array}$ \\
\hline Автомобільна техніка & $\begin{array}{l}\text { Блок дисциплін професійної i } \\
\text { практичної підготовки }\end{array}$ \\
\hline Бойова система виживання воїна & $\begin{array}{l}\text { Блок дисциплін військово-професійної } \\
\text { підготовки }\end{array}$ \\
\hline
\end{tabular}




\begin{tabular}{|l|l|}
\hline Стрілецька зброя та вогнева підготовка & $\begin{array}{l}\text { Блок дисциплін професійної i } \\
\text { практичної підготовки }\end{array}$ \\
\hline Озброєння і стрільба & $\begin{array}{l}\text { Блок дисциплін військово-спеціальної } \\
\text { підготовки }\end{array}$ \\
\hline Розвідувальна підготовка & $\begin{array}{l}\text { Блок дисциплін військово-спеціальної } \\
\text { підготовки }\end{array}$ \\
\hline Основи застосування артилерії & $\begin{array}{l}\text { Блок дисциплін військово-спеціальної } \\
\text { підготовки }\end{array}$ \\
\hline Будова бронетанкової техніки & $\begin{array}{l}\text { Блок дисциплін військово-спеціальної } \\
\text { підготовки }\end{array}$ \\
\hline Експлуатація бронетанкової техніки & $\begin{array}{l}\text { Блок дисциплін військово-спеціальної } \\
\text { підготовки }\end{array}$ \\
\hline
\end{tabular}

3 огляду на особливості майбутньої професійної діяльності й сучасні умови професійної підготовки майбутніх фахівців бойового та оперативного забезпечення, у процесі вивчення навчальних дисциплін «Іноземна мова», «Іноземна мова за професійним спрямуванням» та «Міжкультурна комунікація у професійній співпраці», студенти повинні оволодіти іншомовним лексичним матеріалом щодо основ військового управління у рамках штабних процедур НАТО; міжнародного гуманітарного права; автомобільної техніки, яка застосовується у військовій справі; бронетанкової техніки та іï експлуатації; озброєння і стрільби, зокрема стрілецької зброї та вогневої підготовки; бойової системи виживання воїна; основ застосування артилерії, розвідувальної підготовки. При цьому особливу увагу слід приділяти особливостям міжкультурної взаємодії й міжкультурної комунікації у процесі вирішення професійних завдань.

Програми вивчення нормативних навчальних дисциплін «Іноземна мова» та «Іноземна мова за професійним спрямуванням» укладаються відповідно до освітньопрофесійної програми підготовки освітньо-кваліфікаційного рівня «бакалавр» підготовки військових фахівців у закладах вищої освіти України.

Через що, предметом вивчення навчальних дисциплін «Іноземна мова» та «Іноземна мова за професійним спрямуванням» є оволодіння основними елементами системи іноземної мови, а також формування, розвиток і вдосконалення мовних $\mathrm{i}$ мовленнєвих знань, умінь та навичок, які забезпечують сприйняття інформації, а також спілкування іноземною мовою у професійній сфері в усній та письмовій формах й 
спрямовані на реалізацію міжкультурної комунікації у процесі виконання професійних обов'язків і функцій.

Метою вивчення навчальних дисииплін «Іноземна мова» та «Іноземна мова за професійним спрямуванням» $\epsilon$ підготовка курсантів до майбутнього ефективного спілкування іноземною мовою у їхньому професійному оточенні та формування необхідних офічерських якостей, поглядів на характер сучасного бою, на роль $i$ призначення підрозділів (частин) родів військ, видів збройних сил.

Програми навчальних дисциплін визначають перелік компетентностей, які мають бути сформовані у курсантів у процесі вивчення цих дисциплін. До цього переліку належать: 1) комунікативна компетентність як здатність установлювати та підтримувати контакти з особами; сукупність знань, умінь і навичок, що забезпечують ефективне спілкування [10; 17]; 2) міжкультурна компетентність як здатність успішно будувати міжкультурну взаємодію та вести міжкультурну комунікацію з представниками інших культур; 3) інформаційна компетентність як здатність здобувати, осмислювати, опрацьовувати та використовувати інформацію з різноманітних джерел [2]; 5) соціальна компетентність як здатність виявляти відкритість до світу та відповідальність за навколишнє середовище, вміння працювати у співпраці та приймати діяльність демократичних інститутів суспільства [2]; 6) етична компетентність як здатність толерувати традиції, принципи життя і професійної діяльності, вчинки і якості оточуючих [9].

Тому, в результаті вивчення згаданих дисципліни у курсантів повинні бути сформовані: 1) знання, щзо є компонентами міжкультурної компетентності, а саме: лексичні знання (близько 2000 лексичних одиниць загальновживаної, соціальнопобутової, загальновійськової та вузькоспеціалізованої лексики; словотворчі морфеми $i$ моделі, характерні для сучасної іноземної мови); граматичні знання (граматичні явища в межах відібраного за тематичним принципом навчального матеріалу); орфографічні; мовленнєві знання (ведення бесіди, аудіювання, роботи з автентичною літературою професійного та соціально-побутового характеру; знання вербальних та невербальних комунікативних правил поведінки); полікультурні знання;2) навички і вміння: мовленнєві (сприйняття на слух інформації, повідомлення, що подається в нормальному темпі і має відношення до професійної, загально-побутової та соціально-культурної тематики; 
ведення діалогу з представниками інших культур, викладу думок у зрозумілій для співрозмовника формі; ведення бесіди в межах вивченої тематики і повідомлення іноземною мовою; читання тексту професійного та соціально-побутового характеру 3 різними завданнями: для загального ознайомлення з інформацією, для повного і точного розуміння інформації (з використанням словника), для отримання загального уявлення про зміст тексту, для виокремлення у тексті потрібної інформації; аналізу мовленнєвої ситуації; подолання комунікативних бар'єрів та страху; дотримання норм етикету.

3 метою формування високого рівня міжкультурної компетентності майбутніх фахівців бойового та оперативного забезпечення вважаємо доцільним ввести до навчальних планів підготовки бакалаврів третього року навчання дисципліну «Міжкультурна комунікація у професійній співпраці» та організувати навчальні й виробничі польові практики, а також військові стажування мовою глобального спілкування - англійською.

Володіння студентами англійською мовою по завершенні вивчення ними дисциплін «Іноземна мова», «Іноземна мова за професійним спрямуванням» та «Міжкультурна комунікація у професійній співпраці» 3 метою повноцінної реалізації професійних обов’язків та функцій у процесі подальшої професійної діяльності студенти повинні володіти англійською мовою, у тому числі за професійним спрямуванням на рівні В2 (згідно Загальноєвропейських рекомендацій щодо рівнів володіння мовою [1]).

Програма вивчення запропонованої навчальної дисципліни «Міжкультурна комунікація у професійній співпраці» укладено також відповідно до освітньопрофесійної програми підготовки військових фахівців освітньо-кваліфікаційного рівня «бакалавр» у закладах вищої освіти України.

Предметом вивчення даної навчальної дисципліни є здобуття знань, формування, розвиток і вдосконалення мовленнєвих умінь та навичок, які забезпечують міжкультурну комунікацію у контексті професійної діяльності в усній та письмовій формах.

Метою вивчення навчальної дисципліни «Міжкультурна комунікація у професійній співпраці» є формування у курсантів міжкультурної компетентності як вагомої складової професійної компетентності майбутніх фахівиів бойового оперативного забезпечення. Програма навчальної дисципліни визначає міжкультурну компетентність як ключову, яка формується у курсантів у процесі вивчення згаданої 
дисципліни у тісному взаємозв'язку 3 наступними компетентностями: 1) лінгвокультурною як якістю особистості, що характеризує її обізнаність у професійнокомунікативній сфері знань, відображає готовність та здатність до взаєморозуміння та взаємодії з представниками іншого лінгвокультурного соціуму на основі оволодіння знаннями про іншу лінгвокультуру і особистісного соціального досвіду під час розв'язання професійних завдань на міжнародному рівні; 2) соціокультурною як здатністю до взаємодії у ситуаціях повсякденного життя, підтримки, соціальних контактів, а також ситуаціях професійного характеру; здатністю до взаємодії з іншими та пізнання їх способу життя; 3) дискурсивною як здатністю будувати єдине смислове ціле iз серії висловлювань та сполучати висловлювання у структурований дискурс $[6 ; 8 ; 11$; $12 ; 13 ; 15 ; 16]$.

У результаті вивчення дисципліни у майбутніх фахівців бойового та оперативного забезпечення повинні бути сформовані наступні знання, навички i уміння, що $\epsilon$ компонентами міжкультурної компетентності: 1) лексичні знання (близько 500 вузькоспеціалізованих лексичних одиниць, у тому числі термінів); граматичні знання (граматичних конструкцій в межах відібраного навчального мінімуму, необхідного для ведення дискусії, бесіди, тощо); знання різних типів дискурсів та правил їх побудови; соціокультурні знання (про іншу лінгвокультуру, країнознавчі особливості, розуміння важливих і різнопланових міжнародних соціокультурних проблем), полікультурні знання; 2) мовленнєві навички і уміння (читання та розуміння текстів професійного характеру 3 метою як загального ознайомлення 3 інформацією, так і вилучення конкретної інформації; сприйняття на слух і розуміння мовлення професійного характеру іноземною мовою як при безпосередньому спілкуванні, так і в звукозаписі (що подається в нормальному темпі); усного та письмового перекладу іншомовних текстів професійної тематики, діалогічного та монологічного мовлення (складання діалогів, повідомлень професійного характеру (інформаційні (повідомлення, підтвердження, заперечення інформації); оцінні (похвала, схвалення); етикетні (привітання, прощання, вибачення); імперативні (наказ, розпорядження, заборона, порада), ведення дискусій, бесід, міжнародних військових переговорів 3 партнерами - представниками інших країн) та письма (написання повідомлення, наказу, службового подання, звіту, інструкції у 
письмовому вигляді іноземною мовою); створювати і розуміти професійно орієнтований дискурс з урахуванням особливостей комунікативної ситуації).

Висновки. Як доводять результати здійсненого аналізу, визначене коло знань, навичок і умінь, що формуються у курсантів у процесі вивчення навчальних дисциплін «Іноземна мова», «Іноземна мова за професійним спрямуванням» та «Міжкультурна комунікація у професійній співпраці» забезпечує формування і розвиток усіх визначених i представлених вище структурних компонентів міжкультурної компетентності майбутніх фахівців бойового та оперативного забезпечення.

Перспективи подальших досліджень полягають в експериментальній перевірці ефективності запропонованого спецкурсу «Міжкультурна комунікація у професійній співпраці» у процесі формування у майбутніх фахівців бойового та оперативного забезпечення міжкультурної компетентності.

\section{References}

1. Zagalnoevropeiski Rekomendatsii $z$ movnoi osvitu: vyvchenia, vykladania, otsiniuvania [Common European Framework of Reference for Languages : Learning, Teaching and Assessment]. Kyiv: Lenvit. 2003.

2. Kohut I. Informatsiina kompetentnist yak strukturnyi component profesiinopedagogichnoi komunikatyvnoi kompetentnosti pedagoga v suchasnomu osvitnomu prostori [Information competence as a structural component of professional and pedagogical communicative competence of educator in modern educational environment] Osvitologichnyi dyskurs. 2018. No. 3-4. P. 234-245.

3. Korneva Z.M. Metodika formuvannia mizhkuiturnoi profesiino orientovanoi komunikatyvnoi kompetentnosti studentiv vyshchogo tekhnichnogo navchalnogo zakladu [Teaching methods of building intercultural profesioanlly oriented communicative competence for students of technical school] Visnyk Chernigivskogo natsinalnogo ped. un-tu. Pedagogichni nauky. 2016. No. 141. P. 94-99.

4. Mykytenko N.O. Tekhnologia formuvannia inshomovnoi profesiinoi kompetentnosti maibutnikh fahivtsiv pryrodnychoho profiliu [Technology of forming foreign language professional competence in future specialists of natural profile] : monografiia. Ternopil: TNPU. 2011. $411 \mathrm{p}$.

5. Mykytenko N.O. Chynnyky formuvannia zmistu dystsypliny «Inozemna mova profesiinoho spriamuvannia» [Factors for forming the content of the discipline "Foreign language of professional orientation"]. Visnyk Lvivskoho Natsionalnoho universytetu imeni Ivana Franka. Seria pedahohichna. 2010. Vol. 26. P. 93-103.

6. Pet'ko L.V. Koncepcija sozdanija uchebnyh posobij dlja vstupitel'nogo jekzamena v magistraturu po inostrannomu jazyku professional'noj napravlennosti [Conception of creating of the textbooks for taking an entrance examination in foreign language in professional way to 
magistracy]. Innovacii v obrazovanii. Moskva: Sovremennaja gumanitarnaja akademija, 2014. No. 4. P. 63-74.

7. Pluzhnyk I.L. Formirovanie mezhkulturnoi kompetentsii studentov humanitarnogo profilia $v$ protsese profesionalnoi podgotovki [Building intercultural competence in the students of Humanities in professionally oriented training]. Doctor's thesis. Tuimen. 2003.

8. Popova O.V. (2016) Lingvokulturnyi aspect profesiinoi pidgotovky maibutnikh menedzheriv [Linguo-cultural aspect of professional training of prospective managers] Dukhovnist osobystosti: metodologiia, teoriia i practuka. 2016. No. 1(70). C. 120-126. [

9. Khorunzha L.L. Rozvytok etychnoi kompetentnosti maibutnogo vchytelia yak bagatofaktornyi protses [Development of prospective teacher's ethical competence as multifarious process ] Pedagogika i psykhologiia profesinoi osvity [Pedagogics and psychology of professional education]. 2003. No. 5.

10. Cherezova I.O. Komunikatyvna kompetentnist yak integralna yakist osobystosti [Communicative competence as an integral feature of personality] naukivyi visnyk Khersonskogo derzhavnogo universitetu. Psykhologichni nauky. 2014. 1(1). P. 103-107.

11. Brown H.D. (1987) Principles of Language Learning and Teaching. Eglewood Cliffs:Prentice Hall Regents, 1987. 467 p.

12. Byram M., Zarate G. Investigating Cultural Studies in Foreign Language Teaching. Clevedon, Philadelphia, cop.1991. 219 p.

13. Canale M., Swain M. (1980) Theoretical bases of communicative approaches to second language. 1980.

14. Chen G.M. Foundation of intercultural communication. Boston. 1998. 340 p.

15. Van Ek J. A., Trim J. L. M. Vantage.Cambridge University Press. 2001. 187 p.

16. Pet'ko L. Multicultural upbringing of students and the formation of professionally oriented foreign language teaching environment. Perspectives of research and development : Collection of scientific articles. - SAUL Publishing Ltd, Dublin, Ireland, 2017. Pp. 164-170.

17. Pet'ko L. Preparing higher school graduates in foreshortening of leader competencies for 2020. Topical questions of contemporary science: Collection of scientific articles. Aspekt Publishing of Budget Printing Center, Taunton, MA 02780, United States of America, 2017. Ph. 467-472.

\section{Translation of the Title, Abstract and References to the Author's Languag}

\section{УДК 317-057.86 (477)}

Любас Анжеліка. Зміст формування міжкультурної компететності майбутніх фахівців бойового та оперативного забезпечення.

Стаття присвячена актуальній проблемі оволодіння майбутніми фахівцями бойового та оперативного забезпечення міжкультурною компетентністю. 3 урахуванням результатів сучасних досліджень міжкультурну компетентність майбутніх фахівців бойового та оперативного забезпечення трактуємо як здатність цих фахівців взаємодіяти з професіоналами - представниками інших культур на основі врахування їхніх цінностей, 
норм, традицій, уявлень, а також обирати комунікативно доцільні способи невербальної i вербальної поведінки 3 метою вирішення завдань професійного характеру. До компонентів міжкультурної компетентності майбутніх фахівців бойового оперативного забезпечення відносимо знання (мовні, мовленнєві, полікультурні, вербальних та невербальних комунікативних правил поведінки, когнітивні), вміння та навички (мовленнєві навички та вміння, когнітивні навички, здатність контролювати власні дії під час спілкування). У процесі вивчення навчальних дисциплін «Іноземна мова», «Іноземна мова за професійним спрямуванням» студенти оволодівають основними елементами системи іноземної мови, розвивають та вдосконалюють мовленнєві знання, уміння та навички, які забезпечують спілкування іноземною мовою у професійній сфері. Введення до навчальних планів підготовки бакалаврів третього року навчання дисципліни «Міжкультурна комунікація у професійній співпраці» та організація навчальних й виробничих польових практик англійською мовою передбачає реалізацію міжкультурної комунікації у процесі виконання професійних обов'язків і функцій.

Ключові слова: міжкультурна компетентність, майбутні фахівці бойового оперативного забезпечення, навчальна дисципліна, навчальні плани.

\section{Лimepamypa}

1. Загальноєвропейські Рекомендації з мовної освіти: вивчення, викладання, оцінювання / наук. ред. укр. вид. С. Ніколаєва. Київ : Ленвіт, 2003. 273 с.

2. Когут I. Інформаційна компетентність як структурний компонент професійнопедагогічної комунікативної компетентності педагога в сучасному освітньому просторі. Освітологічний дискурс. 2018. № 3-4. С. 234-245.

3. Корнєва 3. М. Методика формування міжкультурної професійно орієнтованої комунікативної компетентності студентів вищого технічного навчального закладу. Вісник Чернігівського національного педагогічного університету. Серія : Педагогічні науки. 2016. Вип. 141. С. 94-99.

4. Микитенко Н.О. Технологія формування іншомовної професійної компетентності майбутніх фахівців природничого профілю : монографія. Тернопіль : ТНПУ, 2011. $411 \mathrm{c}$.

5. Микитенко Н.О. Чинники формування змісту дисципліни «Іноземна мова професійного спрямування». Вісник Львів. нац. ун-ту. ім. I. Франка. Серія педагогічна. 2010. Вип. 26. С. 93-103.

6. Петько Л.В. Концепция создания учебных пособий для вступительного экзамена в магистратуру по иностранному языку профессиональной направленности. Инновации в образовании : научно-метод. журнал / учред. Современная гуманитарная академия ; гл. ред. И.В.Сыромятников. Москва: Современная гуманитарная академия, 2014. № 4. С. 63-74.

7. Плужник И.Л. Формирование межкультурной коммуникативной компетенции студентов гуманитарного профиля в процессе профессиональной подготовки: дис... д-ра пед. наук: 13.00.01. Тюмень, 2003. 335 с.

8. Попова О.В. Лінгвокультурний аспект професійної підготовки майбутніх менеджерів. Духовність особистості: методологія, теорія і практика. Сєвєродонецьк, 2016. Вип. 1 (70). С.120-126. 
9. Хоружа Л.Л. Розвиток етичної компетентності майбутнього вчителя як багатофакторний процес. Педагогіка і психологія професійної освіти. 2003. № 5. С. $42-44$.

10. Черезова I. О. Комунікативна компетентність як інтегральна якість особистості. Науковий вісник Херсонського державного університету. Серія: Психологічні науки. 2014. Вип. 1(1). С. 103-107.

11. Brown H. D. Principles of Language Learning and Teaching. Eglewood Cliffs:Prentice Hall Regents, 1987. 467 p.

12. Byram M., Zarate G. Investigating Cultural Studies in Foreign Language Teaching. Clevedon, Philadelphia, cop., 1991. 219 p.

13. Canale M., Swain M.. Theoretical bases of communicative approaches to second language teaching and testing. Applied Linguistics, 1980. P.1-47.

14. Chen G. M. Foundation of intercultural communication. Boston, 1998. 340 p.

15. Van Ek J. A., Trim J. L. M. Vantage.Cambridge University Press, 2001. 187 p.

16. Pet'ko L. Multicultural upbringing of students and the formation of professionally oriented foreign language teaching environment. Perspectives of research and development : Collection of scientific articles. - SAUL Publishing Ltd, Dublin, Ireland, 2017. Pp. 164-170.

17. Pet'ko L. Preparing higher school graduates in foreshortening of leader competencies for 2020. Topical questions of contemporary science: Collection of scientific articles. Aspekt Publishing of Budget Printing Center, Taunton, MA 02780, United States of America, 2017. Ph. 467-472. 


\title{
Content Transformation of Improvement of Qualification of the Teachers of Philological Disciplines in the Kherson Region (1944-1958)
}

\author{
Kuzmenko Vasily \\ ORCID http://orcid.org/0000-0002-5424-8234 \\ Kherson Academy of Continuing Education Municipal Higher Education \\ Institution, Doctor of Pedagogical Sciences, Professor (Ukraine, Kherson)
}

\author{
Chukh Ganna \\ ORCID http://orcid.org/0000-0002-6831-4204 \\ Applicant at the Department of Department of Pedagogy and Education \\ Management, Kherson Academy of Continuing Education Municipal Higher \\ Education Institution
}

\begin{abstract}
The article on the basis of archival materials reveals the peculiarities of the formation of the system of advanced teacher's training of philological disciplines of the South of Ukraine in 1944-1958, in particular in the Kherson region. It is established that in the studied historical period the determining factor of this educational branch was the focus on updating the content of education, based on veiled russification, ideologization of language and literature education in the region without taking into account the polyethnic composition of the population. Analysis of archival data reflecting the results of the system in this period, gave an opportunity to determine the specific features of this period, potential, results and existing contradictions, made it possible to identify positive trends that are relevant for extrapolating the experience of postgraduate education of teachers of philological disciplines in southern Ukraine, in particular in the Kherson region, in the modern educational space.
\end{abstract}

Key words: postgraduate education, philological disciplines, system of advanced training, teachers, the South of Ukraine.

Актуальність дослідження. У контексті нашого дослідження ми відстежимо трансформацію змісту системи підвищення кваліфікації вчителів філологічних дисциплін на Півдні України, зокрема в Херсонській області, у 1944-1958 рр. через призму архівних документів, що відображають діяльність цієї освітньої галузі. Основу джерельної бази становлять архівні матеріали Державного архіву Херсонської області, деякі з них залучені до наукового обігу вперше.

Виклад основного матеріалу. Певні аспекти досліджуваної проблеми можна віднайти в працях українських науковців. Нами здійснено аналіз історико-педагогічних пошуків Крисюка С. В. [4], Кузьмінського А. І. [6], Слюсаренко Н. В. [13; 14] та ін. У цих дослідженнях розкрито основні тенденції розвитку й функціювання означеної 
освітньої галузі в різні періоди, у тому числі й у 1944-1958 рр., однак недослідженим залишається відстеження змін у процесі формування змісту підвищення кваліфікації вчителів філологічних дисциплін на Півдні України на прикладі діяльності конкретного закладу підвищення кваліфікації педагогів означеного періоду - Херсонського обласного інституту удосконалення вчителів (ОІУВ). Саме в цьому й полягає наукова новизна публікації.

За архівними даними, починаючи з 1944 року, в ОІУВ УРСР, зокрема в такий освітній заклад у Херсоні, було надіслано збірник керівних матеріалів про школу, виданих Народним комісаріатом РРФСР. Очевидно, що за таких підходів ідея врахування регіональних особливостей функціювання цієї освітньої галузі навіть не обговорювалася: цей процес відображав загальнодержавні й всеукраїнські тенденції змісту післядипломної освіти. Зокрема, рекомендованими для пропагування серед педагогів були постанова Ради народних комісарів РРФСР № 671 від 23.07.1943 р. «Про введення роздільного навчання хлопчиків і дівчаток у неповних середніх і середніх школах обласних, крайових міст, столичних центрів автономних республік і великих промислових міст» [2, арк. 3], наказ Наркому освіти РРФСР №162 від 16.09.1943 року «Про покращення контролю за роботою шкіл і вчителів і організацією обліку знань учнів», який передбачав «розроблення системи заходів 3 підвищення педагогічної кваліфікації...» [там само, арк. 11] тощо.

На нашу думку, показовим є той факт, що хронологічне відстеження архівних документів Херсонського ОІУВ підтверджує: уже через рік після зазначеного вище транслювання для вчителів ідей Наркому освіти РРФСР у 1944-1945 роках у заклад надходять інструктивні матеріали за підписом народного комісара освіти (чи його заступника) УРСР. Зокрема, для вчителів філологічних дисциплін у 1944 р. - це «Вказівки про святкування в школах УРСР сторіччя з дня смерті великого російського байкаря І. А Крилова» [1]. Інструкції та вказівки орієнтували цю категорію педагогів на вивчення творів російської літератури, нівелюючи твори світової літературної класики, на вивченні творчості українських письменників не наголошувалося в нормативних документах галузі народної шкільної освіти.

3 січня 1945 р. почав виходити науково-педагогічний журнал «Радянська школа». У вказівці Наркому освіти УРСР для педагогів, у тому числі й для херсонських 
вчителів, відзначено, що це видання містить статті на актуальні теми теорії, історії педагогіки, психології та методики викладання окремих дисциплін і всієї практичної методичної роботи [10]. Використання цієї грунтовної та всебічної інформації про концептуальні засади розвитку освітньої галузі стало поштовхом для створення вже працівниками Херсонського ОІУВ методичних рекомендацій для вчителів філологічних дисциплін. Зокрема, такі вказівки «Повторення пройденого з української мови в 7-10 класах» мали практичне спрямування й містили зразки пов'язування повторення орфографічного матеріалу з викладом нових тем, рекомендації щодо використання вивченого в початковій школі [3].

Отже, цитовані документи дають можливість відстежити трансформацію змісту підвищення кваліфікації вчителів філологічних дисциплін в Херсонській області: від буквального виконання постанов і наказів Ради народних комісарів і Міністерства просвіти РРСФСР до використання в роботі вказівок Народного комісара освіти УРСР та матеріалів всеукраїнського видання для освітян, і далі - до формування змісту означеної освітньої галузі з урахуванням регіональних запитів педагогів, хоч ці заклади у своїй роботі відображали загальнодержавні й всеукраїнські тенденції змісту післядипломної освіти. Цю думку підтверджено й подальшим хронологічним переліком архівних справ, що фіксують діяльність Херсонського ОІУВ та методичних служб області: річний і піврічний звіти райпедкабінетів за 1948-1949 н.р. [12], річний звіт Херсонського ОІУВ за 1953 р. [11], плани роботи ради інституту і звіти завкабінетами і методистів про наукові відрядження 1954-1955 н.р [7] тощо. Окрім того, 31946 р. розпочався новий наступ на національну школу. Стан українізації шкільної освіти пішов у зворотному напрямку: кількість шкіл із російською мовою навчання починає збільшуватися, а кількість шкіл з українською мовою навчання зменшується [5, c. 250$]$.

У документах, що містять аналіз діяльності цих складових підвищення кваліфікації вчителів, чітко визначено напрацювання і недоліки в мовно-літературній освіті Херсонської області цього періоду. Зокрема, відзначено, що для вчителів російської мови «забезпечено подальше підвищення ідейно-політичного рівня, надана методична допомога, особливо молодим учителям-початківцям» [11]. Ця цитата дослівно дублює Положення про ОІУВ, що ще раз підтверджує тезу про те, що подібні 
освітні заклади у своїй роботі відображали загальнодержавні й всеукраїнські тенденції змісту підвищення кваліфікації педагогів. 3-поміж іншого, відзначено, що для цієї категорії вчителів проведено 9 семінарів, працівниками ОІУВ відвідано 128 уроків російської мови, надано 200 консультацій, розроблено методичні рекомендації щодо впровадження передового педагогічного досвіду, роботи 3 молодими вчителями; здійснено аналіз підручників «Російська мова» Фінкеля і Баженова для шкіл 3 українською мовою навчання (I i II частини), аналіз навчальних програм; надано рецензії на статті з методики викладання російської мови в журналі «Радянська школа» за 1952 рік [там само, арк. 25].

Цей же документ фіксує зростання професійності цієї категорії вчителів: вони вже «не допускають зловживання історичними екскурсами в минуле, що завдавало збитків міцному засвоєнню граматики сучасної російської мови» [11, арк. 34]. Серед зазначених недоліків - той факт, що «частина вчителів нашої області, особливо ті, які не мають відповідної підготовки, не завжди правильно науково викладають шкільний граматичний матеріал. Ці вчителі мало готуються до уроків, не цікавляться методичною літературою [там само, арк. 36]. Зазначені недоліки пояснюють такими причинами: фахівці «не відповідають тим вимогам, що тепер визначені для словесників; вони не мають в достатній кількості методичної літератури; райони не мають у достатній кількості кваліфікованих учительських кадрів словесників, у низці районів викладають російську мову вчителі, які не мають спеціальної освіти» [там само, арк. 47].

Значно меншим за обсягом є звіт Херсонського ОІУВ щодо аналізу фахової майстерності й напрямів підвищення кваліфікації вчителів української мови, іноземної мови. Зокрема, з-поміж іншого, зазначено, що складено й розіслано «примірний план роботи методичного об'єднання вчителів української мови». 3 недоліків указано на «формалізм у низки викладачів: вони не прагнуть виховувати марксистський світогляд на уроках мови» [11, арк. 83]. Звіт про роботу підвищення кваліфікації вчителів іноземної мови вкрай заідеологізований. До речі, про викладання англійської мови в школах в документі згадується лише принагідно, у переліку іноземних мов, які викладаються в школах області. Натомість є інформація про «перебудову викладання німецької мови у світлі вчення тов. Сталіна про мову»; у пропонованому плані роботи методичного об’єднання вчителів німецької мови - доповідь «Учення Сталіна про 
граматичну будову мови і роль граматики в системі викладання іноземної мови» [там само, арк. 95].

Висновки. Таким чином, зміни в процесі формування змісту підвищення кваліфікації вчителів філологічних дисциплін на Півдні України на прикладі діяльності Херсонського ОІУВ спрямовані на пошук оптимальної моделі, яка відображала загальнодержавні й всеукраїнські тенденції змісту післядипломної освіти. Для підвищення результативності цього процесу застосовувалися всі наявні ресурси цієї освітньої галузі, хоч уся їхня діяльність підпорядковувалася ОІУВ. Крім цього, іiі діяльність була спрямована на оновлення змісту освіти, що грунтувалося на завуальованій росіянізації, ідеологізації мовно-літературної освіти регіону в досліджуваний період.

\section{References}

1. Vkazivki pro svyatkuvannya $v$ shkolah URSR storichchya $z$ dnya smerti velikogo rosijskogo bajkarya I.A.Krylova. [Instructions on the celebration in the schools in URSR the centenary of the death of the best-known Russian fabulist I. A Krylov] // Derzhavnij arhiv Hersonskoyi oblasti (DAHO). F.R. 2419. Op. 1. Spr.9. 3 p.

2. Metodicheskie razrabotki Ministerstva prosveshchenija [Methodological materials of the Ministry of Education] // DAKhO. F.R. 2419. Op. 1. Spr.3. 165 p.

3. Metodichni rekomendaciyi «Povtorennya projdenogo z ukrayinskoyi movi v 7-10 klasah» Hersonskogo OIUV. [Methodological recommendations "Repetition of passed in the Ukrainian language in grades 7-10" of Kherson OIUV] // DAKhO. F.R. 2419. Op. 1. Spr. $15 \mathrm{p}$.

4. Krisyuk S.V. Rozvitok pislyadiplomnoyi osviti pedagogichnih kadriv v Ukrayini (1944-1995 rr.): monografiya [Development of postgraduate education of pedagogical staff in Ukraine (1944-1995): monograph]/ L'viv, 1997. 206 p.

5. Kuzmenko V.V. Formuvannya naukovoyi kartyny svitu uchniv: vid vytokiv do sogodennya: monografiya [The formation of a scientific picture of the world of students: from beginnings to the present]. Tretye vy`dannya pereroblene i dopovnene/ V.V Kuz menko. Kherson, $679 \mathrm{p}$.

6. Kuz'minskij A. I. Teoretiko-metodologichni zasadi pislyadiplomnoyi pedagogichnoyi osviti v Ukrajini (1944-1995rr.) [Theoretical and methodological tasks of postgraduate pedagogical education in Ukraine (1944-1995)]: dis. ... d-ra ped.nauk: 13.00.04. Kyiv, 2003. $481 \mathrm{p}$.

7. Pet`ko L.V. Na shlyachu perebudovy [On the way of rebuilding]. Rad. shkola. 1987. No. 11. P. 60-65.

8. Pet'ko L.V. Realizacija neperervnoi' movnoi' osvity $u$ VNZ Ukrai'ny [Implementation of lifelong language learning in high school of Ukraine] // S'omi jurydychni 
chytannja «Kul'tura i pravo na pochatku HHI stolittja»: mat. mizhnar. nauk. konf. Kyiv: Vydvo NPU im. M. P. Dragomanova, 2011. C. 436-438.

9. Plani roboti radi institutu $i$ zviti zavkabinetami $i$ metodistiv pro naukovi vidryadzhennya 1954-1955 n.r. [Work plans of the institute council and reports of heads of offices and methodologists on scientific business trips 1954-1955] // DAKhO. F.R. 2419. Op. 1. Spr. 71.238 p.

10. Pro vikoristannya zhurnalu «Radyans'ka shkola» [About using the magazine «Soviet school»] // DAKhO. F.R. 2419. Op. 1. Spr. 14. 3 p.

11. Richnij zvit Hersons'kogo OIUV za 1953 r. [Annual report of Kherson OIUV for 1953] // DAKhO. F.R. 2419. Op. 1. Spr. 58. 158 p.

12. Richnij i pivrichnij zviti rajpedkabinetiv za 1948-1949 n.r. [Annual and semiannual report of district pedagogical offices for 1948-1949] // DAKhO. F.R. 2419. Op. 1. Spr. 24. $158 \mathrm{p}$.

13. Sliusarenko N. V. Formy I metody vyhovnoii roboty u vyshchomu navchalnomu zakladi [Forms and methods of extracurricular activites in a higher educational institution]. Tavriiskyi visnyk osvity. No 3 (27). 2009. P. 107-116.

14. Sliusarenko N. V., Kokhanovska O. V. Transformatsiia vyshchoi zhinochoi osvity v Ukraini (XIX - pochatok XXI stolittia) [The transformation of higher female educationin Ukraine (XIX - the beginning of the XXI century)]. Visnyk Cherkaskoho universytetu (Seriia Pedahohichni nauky). 2018. Issue 2. P. 124-130.

\section{Translation of the Title, Abstract and References to the Author's Language}

УДК 378.046-021.68:80 (477.7)

Кузьменко Василь, Чух Ганна. Трансформація змісту підвищення кваліфікації вчителів філологічних дисциплін у Херсонській області в період 19441958 pp.

У статті на основі регіональних архівних матеріалів розкрито особливості становлення системи підвищення кваліфікації вчителів філологічних дисциплін Півдня України в 1944-1958 pp. - період становлення радянської системи підвищення кваліфікації педагогів, зокрема в Херсонській області. Установлено, що в досліджуваний історичний період визначальним чинником діяльності означеної освітньої галузі була спрямованість на оновлення змісту освіти, що грунтувалося на завуальованій росіянізації, ідеологізації мовно-літературної освіти регіону. Аналіз нормативних галузевих документів і практичних результатів функціювання закладу, що зібрані в Державному архіві Херсонської області, дав можливість визначити специфічні риси цього періоду, потенціал, результати і наявні суперечності та позитивні тенденції, що $є$ актуальним для екстраполяції досвіду в сучасний освітній простір.

Ключові слова: післядипломна освіта, філологічні дисципліни, система підвищення кваліфікації, вчителі, Південь України. 


\section{Jimepamypa}

1. Вказівки про святкування в школах УРСР сторіччя 3 дня смерті великого російського байкаря I. А Крилова // Державний архів Херсонської області (ДАХО). Ф.Р. 2419. Оп. 1. Спр.9. - 3 арк.

2. Методические разработки Министерства просвещения // ДАХО. Ф.Р. 2419. Оп. 1. Спр.3. 165 арк.

3. Методичні рекомендації «Повторення пройденого з української мови в 7-10 класах» Херсонського ОІУВ // ДАХО. Ф.Р. 2419. Оп. 1. Спр. 15. 7 арк.

4. Крисюк С. В. Розвиток післядипломної освіти педагогічних кадрів в Україні (1944-1995 рр.): монографія. Львів, 1997. 206 с.

5. Кузьменко В. В. Формування наукової картини світу учнів: від витоків до сьогодення: монографія. 3-є вид., перереб. і доп. Херсон, 2020. 679 с.

6. Кузьмінський А. І. Теоретико-методологічні засади післядипломної педагогічної освіти в Україні (1944-1995 рр.): дис. ... д-ра пед.наук: 13.00.04. Київ, 2003. 481 с.

7. Плани роботи ради інституту і звіти зав кабінетами і методистів про наукові відрядження 1954-1955 н.р. // ДАХО. Ф.Р. 2419. Оп. 1. Спр. 71. 238 арк.

8. Петько Л. В. На шляху перебудови. Рад.школа. 1987. № 11. С. 60-65.

9. Петько Л.В. Реалізація неперервної мовної освіти у ВНЗ України // Сьомі юридичні читання «Культура і право на початку XXI століття»: мат. міжнар. наук. конф. Київ: Вид-во НПУ ім. М. П. Драгоманова, 2011. С. 436-438.

10. Про використання журналу «Радянська школа» // ДАХО. Ф.Р. 2419. Оп. 1. Спр. 14. 3 арк. 158 арк.

11. Річний звіт Херсонського ОІУВ за 1953 р. // ДАХО. Ф.Р. 2419. Оп. 1. Спр. 58.

12. Річний і піврічний звіти райпедкабінетів за 1948-1949 н.р. // ДАХО. Ф.Р. 2419. Оп. 1. Спр. 24. 158 арк.

13. Слюсаренко Н. В. Форми і методи виховної роботи у вищих навчальних закладах. Таврійський вісник освіти. 2009. №3(27). С. 107-116.

14. Слюсаренко Н. В., Кохановська О. В. Трансформація вищої жіночої освіти в Україні (XIX - початок XXI століття). Вісник Черкаського університету (Серія Педагогічні науки). 2018. Вип. 2. С. 124-130. 


\title{
The Methods on Forming the Worldview Culture of Future Music Teachers in the Process of Piano Learning
}

\author{
Zhang Jiangan \\ ORCID: 0000-0003-0735-6360 \\ Postgraduate student (China) \\ Dragomanov National Pedagogical University (Kyiv, Ukraine)
}

\begin{abstract}
The article highlights the peculiarities of the introduction of methods of forming the worldview culture of students of arts faculties of pedagogical universities in the conditions of piano education. The leading directions of methodical providing of piano preparation of students are allocated, namely: activation of cognitive-performing interests and needs of students, enrichment of their musical-theoretical knowledge on the basis of performing repertoire; development of performing skills to create emotional and figurative representations in the process of learning to play the piano. Methodical measures for the formation of worldview culture on the basis of the developed criteria and indicators of certain components are presented. The efficiency of the offered technique in the conditions of piano training at all stages of educational process is proved.
\end{abstract}

Key words: worldview culture, music art teacher, piano teaching, methods of worldview culture formation.

Актуальною проблемою сьогодення стає впровадження у теорію і практику підготовки майбутніх учителів музичного мистецтва методики, спрямованої на формування світоглядної культури як важливого чинника їх фахової компетентності. Така методика має спирається на теоретико-методологічні положення щодо функцій та існуючих протиріч у цій галузі знання, а також на вивчення стану музично-педагогічної освіти. Адже в умовах переоцінки та змін усталених цінностей надзвичайно важливою стає посилена увага до підготовки вчителя, здатного долучати учнів до загальнолюдських ідеалів, втілених у творах мистецтва, та керувати їх гармонійним розвитком. Сьогодні суспільству потрібен вчитель, який не тільки виступає активним суб'єктом педагогічного процесу, а й готовий працювати у нових, постійно змінювальних обставинах.

Основні концептуальні засади формування світоглядної культури представлені у естетико-філософських (Р.Арцишевський, М.Ашманис, В.Іванов, В.Кобылянський, В.Тугарінов, В.Черноволенко, В.Шинкарук, Т.Шуртакова) і психолого-педагогічних (А.Бєлих, С.Гессен, І.Лернер, Б.Ліхачев, В.Сластьонін, М.Фіцула) дослідженнях. Педагогічні аспекти світоглядної культури майбутніх вчителів в галузі мистецтва висвітлені у дослідженнях В.Бутенко, О.Рудницької, С.Соломахи, Б Целковникова, О.Щолокової та ін. 
Метою статті $є$ розкриття особливостей формування світоглядної культури майбутніх учителів музичного мистецтва у процесі фортепіанного навчання i обгрунтування методичних заходів щодо формування на основі визначених критеріїв та показників усіх компонентів світоглядної культури майбутніх учителів музичного мистецтва.

Виклад основного матеріалу. У нашому дослідженні розроблена методика втілює ідею, згідно якої у формуванні світоглядної культури студентів виокремлюються дві основні функції: естетична (емоційна реакція на художній твір) та конструктивна (уміння оперувати музичним матеріалом, знаходити подібне і відмінне, встановлювати зв’язки між різними видами мистецтва і робити необхідні висновки). Разом 3 тим зауважимо, що усвідомлюючи важливість формування світоглядної культури для фахового становлення майбутнього вчителя музичного мистецтва, вважаємо, що вона має стати його міцним підгрунтям, тобто своєрідною «надбудовою» музичної фахової підготовки. Вона ні в якому разі не повинна замінювати фахове музичне навчання, а тільки його поглиблювати, розширюючи світоглядні межі, практичні уміння майбутнього вчителя музики. У такий спосіб світоглядну культуру доцільно розглядати як підгрунтя для удосконалення фахових знань в галузі музичного мистецтва.

Під час проведення формувального експерименту ми керувалися такими теоретичними положеннями: 1) удосконалення світоглядних уявлень майбутніх учителів на факультетах мистецтва потребує для використання збільшення кількості творчих методів, а також спеціального комплексу художно-інтерпретаційних умінь і навичок. Це стосується як теоретичної так і практичної складових фахової підготовки студентів, в якій поєднуються когнітивний, естетико-емоційний, операційний і самоорганізаційний компоненти. 2) ефективність формування світоглядної культури майбутніх учителів музичного мистецтва забезпечується відповідною спрямованістю інструментальновиконавського навчання, його безперервністю та наступністю. 3) формування світоглядної культури студентів у процесі фортепіанного навчання має керуватися такими основними принципами: фундаменталізації світоглядних уявлень; історизму у класифікації світоглядної культури; системності та послідовності у набутті світоглядних знань; естетичної спрямованості навчальної діяльності; спонукання до творчого самовираження; діалогізації. 
Завдання формувального етапу експерименту включали: перевірку ефективності запропонованої методики в умовах фортепіанного навчання студентів факультетів мистецтва на всіх етапах навчального процесу; обгрунтування динаміки світоглядних уявлень у виконавській діяльності; інтерпретацію отриманих результатів та остаточних висновків.

3 урахуванням існуючих теоретико-методологічних напрацювань в галузі педагогіки мистецтва було визначено провідні напрямки методичного забезпечення фортепіанного навчання студентів, а саме: активізація пізнавально-виконавських інтересів і потреб студентів, збагачення їх музично-теоретичних знань на основі виконавського репертуару, розвиток виконавських умінь i навичок для створення емоційно-образних уявлень у процесі навчання гри на фортепіано.

Для підвищення ефективності у своїй роботі ми намагалися дотримуватися наступних методичних положень: постійно змінювати форми і методи роботи; розвивати емоційно-образне сприйняття студентів.

3 урахуванням визначених на діагностувальному етапі дослідження недоліків, зафіксованих у відповідних показниках, був проведений перший (мотиваційностимулювальний) етап дослідно-експериментальної роботи. Він підпорядковувався такої педагогічної умови: педагогічно доцільного забезпечення досвіду художньосвітоглядних знань майбутнього вчителя музичного мистецтва і на цій основі корекції мотивації студентів до виконавської діяльності.

Оскільки одним із головних мотивів навчання є пізнавальний інтерес (особлива вибіркова спрямованість особистості на процес пізнання, виражений у тій чи іншій предметній галузі знань), для визначення когнітивно-мотиваційного ставлення студентів у сфері світоглядної культури було застосовано декілька завдань пошуково-творчого характеру. Наприклад, студентам під час індивідуальних занять пропонувалося створити портфоліо для фіксації власних досягнень під час набуття культурологічних знань $\mathrm{i}$ світоглядних уявлень, де вони збирали матеріали про творчість митців у різних галузях мистецтва, цікаві висловлення про їх творчість [6; 7; 10; 11;12; 13].

Інший блок портфоліо розкривав особистість студента, де розміщувалися репертуарні списки музичних творів, з якими вони познайомились, фото або відео 
матеріали з фестивалів і конкурсів, в яких студенти брали участь. Таке завдання дозволило студентам оцінити свої досягнення в навчальному процесі, виявити резерви для покращення їх результатів. Воно викликало інтерес у всіх респондентів і допомогло замислитись над причинам своїх проблем, збагатитися необхідним теоретичним i практичним досвідом.

Для формування когнітивних знань світоглядного спрямування на заняттях 3 дисципліни «Основний музичний інструмент» студенти виконували спеціальні завдання, зокрема такі: цілісно проаналізувати музичні твори і порівняти художні образи у різних видах мистецтва, дотримуючись наступних елементів: враховувати відомості про творчість композитора, а також тих суспільно-історичних умов, за яких твір був написаний; визначити жанр музичного твору; розкрити засоби художньої виразності та ïx роль у створенні художнього образу; проаналізувати авторські позначки, які розкривають особливості музичного образу і впливають на характер виконання; за можливістю, зіставити образи цього твору з образами інших творів цього композитора. Основною вимогою у виконанні даного завдання було: під час аналізу музичного твору спиратися на його безпосереднє сприйняття з додаванням методичних вказівок, які існують у роботах відомих педагогів-методистів.

Друге завдання вимагало зробити аналіз власного виконання музичного твору і оцінити його з точки зору художньої довершеності. Для цього використовувався метод відеозапису 3 подальшим прослуховуванням отриманого матеріалу. Наступним завданням студентам пропонувалося прослухати незнайомий твір і надати йому емоційну характеристику. У процесі ознайомлення з кожним твором потрібно було визначити його характер та підібрати відповідні епітети, які розкривають емоційний спектр його образів. Після цього студенти знайомились 3 назвою твору i з'ясовували, наскільки їх характеристики відповідають назві твору, наданої композитором. Для прослуховування використовувались твори К. Дебюссі «Місячне сяйво», І. Шамо «Літній вечір», Е. Гріг «У печері гірського короля». У процесі роботи над цими творами особлива увага спрямовувалась на виявлення характеру музики, на яскраві мелодійні звороти, модуляції, темброві співставлення й кольори, тобто усе, що надає процесу виконання емоційного та естетичного задоволення. 
Згідно визначених у нашому дослідженні критеріїв важливо було встановити, які зміни відбулись у когнітивно-мотиваційній сфері майбутніх учителів музичного мистецтва після проведеної роботи. Для цього було проаналізовано динаміку рівнів сформованості мотивації до виконавської діяльності, усвідомлення значущості світоглядних уявлень як важливої складової фахової компетентності сучасного вчителя музичного мистецтва, а також ставлення до музично-творчої діяльності як умови професійного самовдосконалення.

Розвиток художнього мислення у такому напрямку став необхідною передумовою для оцінювання усіх критеріїв світоглядної культури і забезпечив поступовий перехід до наступного (виконавсько-розвивального) етапу дослідно-експериментальної роботи, який був спрямований на детальне опрацювання

кожного компонента світоглядної культури.

На цьому етапі особливого значення набуло використання на заняттях фортепіано знань, отриманих на інших фахових дисциплінах; Для цього використовувалися проблемні методи, які включалися у вирішення художньо-естетичних завдань i стимулювали асоціативне мислення студентів.

Так, для виконання завдання "Порівняй інтерпретащуію", студентам пропонувалося зробити аналіз виконання музичних творів своїх товаришів. При цьому схвалювалися спроби охарактеризувати використані засоби музичної виразності, зіставити їх з еталонним звучанням. Виконання цього завдання показало, що студенти, які раніше майже не проявляли інтерес до якості виконання, показали власне розуміння художніх образів та значимості засобів музичної виразності для їх відтворення. Відповідно їх власне виконання музичних творів стало більш виразним і осмисленим.

Працюючи у цьому напрямі, студентам пропонувалося знайти для музичних творів репродукції картин, які відповідають їх настрою. Тобто потрібно було виявити спільні або відмінні риси у настроях знайдених творів мистецтва, показати, які засоби виразності використовують митці для їх передачі. Прикладами стали: твори Ф. Ліста «Заручини» і «Мислитель», написані під враженням картин Рафаеля, а також К. Дебюссі «Місячне сяйво», «Затонулий собор», «Пагоди», «Вечір в Гренаді», «Сади під дощем». Ці завдання виконувалися у формі підготовки студентів 3 короткими виступами в естетико-оцінювальному аспекті. Так, порівнюючи твори Ф. Ліста і Рафаеля «Заручини» 
і «Мислитель», студенти звернули увагу на таку споріднену їх якість як гармонічність, яка проявляється у композиційних, колористичних і скульптурних зображень цих митців. Ліст - засобами свого мистецтва - намагається передати «споглядальність» образів, а Рафаель - засобами образотворчого мистецтва - їх музикальність. Обговорюючи i аналізуючи твір К. Дебюссі «Місячне сяйво», студенти пригадали картину А. Куїнджі «Місячна ніч на Дніпрі», а твір «Вечір в Гренаді» викликав у них асоціації з картиною Ф. Гойї «Махи на балконі», тоді як «Сади під дощем» - з українською народною піснею «Дощик».

Зазначимо, що деякі студенти обрали згадані твори для свого навчального репертуару, під час роботи над якими основна увага приділялася осмисленому виконанню засобів музичної виразності. Студенти з'ясовували, що різні інтонаційні варіанти надають виконанню свіжості, збагачують його особливими відтінками. Відтак, завдання у фортепіанному класі спрямовувались на цілісне сприйняття твору за рахунок усвідомлення основних принципів викладення музичного матеріалу, а саме: форми, виражальних елементів музичної мови (інтонація, метроритм, динаміка, тембр), осягнення загальної драматургії твору. На основі таких вражень у респондентів формувалися навички, які ставали засобом осмислення естетико-емоційної сутності музичного твору.

Також ефективною формою роботи на цьому етапі стало проведення бесідконцертів для учнів різних вікових категорій. Їх метою було: поглиблення знань студентів про музичне мистецтво та його зв'язок з іншими видами мистецтва; створення ситуацій успіху як у виконанні музичних творів, такі і у їх вербальній презентації. При цьому широко використовувалися метод встановлення асоціативних зв'язків між творами, які розглядаються, і метод тематичного моделювання. Їх застосування розвивало у студентів мотивацію до підвищення своєї ерудиції та розширення світогляду. Використання даних методів створювало важливу педагогічну ситуацію, в якій студент був вимушений постійно займатися самоосвітою. Наприклад, студентами було підготовлено та проведено ряд бесід-концертів: «Відгомін століть», «Осінній вернісаж», «Універсальність творчості Леонардо да Вінчі», «Чарівний світ мелодії та кольору М.Чурльоніса», «Образ Демона у мистецтві», «Романтична фантазія Р.Шумана «Метелики» та ін. Готуючи проєкти таких бесід, учасники експерименту презентували 
цікаві факти з життя і творчості видатних митців, намагалися визначити характерні особливості їх творчості. Під час підготовки до цих заходів студенти аналізували твори за обраними темами, добирали відповідні репродукції з поетичних, живописних, скульптурних або архітектурних творів, підкріплювали свої думки уривками 3 літературних джерел. Для обмінну враженнями і думками після зазначених заходів відбувались дискусії, у яких майбутні вчителі аргументовано висловлювали свої думки.

Опрацювання різних музичних творів допомогло студентам систематизувати свої знання, познайомитися 3 новими для себе творами, визначити характерні риси композиторських знахідок для втілення конкретних музичних образів. Така робота показала, що вони можуть цілеспрямовано йти до своєї мети, здатні до аналізу і рефлексії, що певною мірою відбилося й на характері виконання обраних музичних творів, яке ставало більш осмисленим і виразним.

Домінантою третього (інтерпретаційно-діяльнісного) етапу стала корекція і реалізація набутих знань та світоглядних переконань у процесі фортепіанного навчання, що передбачало вирішення наступних завдань: забезпечення цілісності інтерпретаційноаналітичних уявлень студентів, їх спрямованість на виконавський саморозвиток та самореалізацію; виховання емоційної чутливості та вольової активності у власній інтерпретаторській діяльності; спрямованість студентів на музичне пізнання і творчу ініціативу.

На цьому етапі найбільше застосовувалися методи, необхідні для залучення студентів до практичного втілення художньо-творчих ідей та моделювання різноманітних емоційних ситуацій, а саме: створення цілісного художнього образу і моделювання різноманітних ситуацій творчого процесу, метод самостійного підбору музичного репертуару. Саме вони, на нашу думку, допомагають студентам позбавитися зайвої скутості рухів, більш комфортно почувати себе за інструментом на концертній естраді.

Студенти вчилися самостійно добирати необхідні виконавські прийоми, коригувати своє звучання, оцінювати власні виконавські дії. При цьому їх увага зверталася на формування якостей, необхідних для успішної виконавської діяльності: вільне володіння виконавськими прийомами; одухотворене виконання; бажання та вміння впевнено передати свою інтерпретацію слухачам. Для надання більшої самостійності 
студентам пропонувалося підібрати музичний репертуар 3 урахуванням власних уподобань і задач піаністичного розвитку, оскільки кожний самостійно обраний музичний твір надає можливість розкрити свої яскраві риси, збагатити духовний світ, розширити музичні обрії. Підбір репертуару відбувався за такими вимогами: музичні твори мають бути різними за жанрами та стилями; вони мають подобатися і викликати певні емоції, відповідати технічним можливостям студента i, разом 3 тим, сприяти подальшому художньо-естетичному розвитку. У такий спосіб у студентів розвивалася сконцентрованість зусиль на осмислення та усвідомлення творів мистецтва, які вони намагалися долучити до своєї виконавської діяльності; уміння мобілізувати свою волю для досягнення складних творчих завдань; розвиненість потреби в удосконаленні виконавських навичок, міра сформованості виконавської мобільності.

Важливою формою роботи на цьому етапі стало створення творчих проєктів. Орієнтиром для вибору їх тематики було використання творів, підібраних за власним бажанням. Тобто студенти могли вільно їх обирати та інтерпретувати згідно власних уявлень. Паралельно з розробкою тематики проєктів перед студентами ставилося завдання враховувати вікову та мистецьку підготовку аудиторії. Серед різноманіття представлених проєктів найбільш оригінальними виявилися «Вальси Шопена мовою танцю» і «Палітра засобів виразності у мистецтві». Розробляючи їх, студенти підібрали виразні твори для виконання і яскраві репродукції для ілюстрації своїх думок. Подібні проєкти розроблялися протягом всього етапу навчання, що дозволило значно підвищити рівні світоглядних уявлень майбутніх вчителів музики за всіма компонентами.

У площині світоглядної спрямованості навчання увага приділялася розвитку умінь оцінювати твори мистецтва, які виконують функцію не тільки контролю знань, а й мотивування саморозвитку у поліхудожньому спрямуванні, зокрема у музичновиконавської діяльності. Завдяки методу колективного обговорення, який сприяв аргументованому оцінюванню музичних творів i активізував розумову діяльність, студенти вчилися оцінювати виконання на музичному інструменті з різних позицій: педагога, автора твору, музичного критика тощо, що забезпечувало позицію активних суб’єктів рефлексивно-оцінювальної діяльності, сприяло посиленню самостійності та критичності мислення. 
Спостереження показали, що студенти прагнули творчо підходити до вирішення виконавських завдань. Перш за все, вони намагалися підібрати для себе репертуар, який відповідав їх смакам і викликав зацікавленість своїм звучанням. Вивчаючи кожний власноруч підібраний твір, вони намагалися прослухати його у виконанні різних піаністів i зробити його виконавський аналіз, що допомогло відтворити його найбільш яскраво і емоційно. Тобто вони не тільки опановували нотний текст, не тільки думали про його технічність, а й намагалися відтворити його художню образність. При цьому було помічено, що у цих студентів під час опрацювання твору значно зменшилась кількість помилок у нотному тексті. Була також відзначена відповідність піаністичних рухів характеру музичного твору, що свідчило про розвинутий слуховий самоконтроль.

Виконання цих творів у концертному варіанті довело, що запропоновані методи допомогли значній кількості студентів компенсувати недостатній рівень довузівської музичної підготовки і забезпечити виконання навчальної програми на високому рівні.

Отже, проведена експериментальна робота підтвердила наше припущення, що ефективність фортепіанної підготовки майбутніх учителів музичного мистецтва підвищиться, якщо забезпечити сформованість світоглядних уявлень студентів через упровадження науково обгрунтованої методики навчання, яка передбачає: 1) усвідомлення майбутніми вчителями значущості світоглядної культури для ефективної музично-педагогічної та виконавської діяльності, 2) стимулювання всіх компонентів світоглядної культури в контексті фахової підготовки студентів, 3) активне залучення майбутніх учителів музичного мистецтва до виконання навчальних завдань творчого характеру в різних формах фахової підготовки, які проводяться на мотиваційностимулювальному, виконавсько-розвивальному та інтерпретаційно-діяльнісному етапах. Через що, розроблена нами методика органічно вписується у навчальний процес навчання вищих музично-педагогічних закладів і дозволяє реалізувати потенційні можливості кожного студента за рахунок збагачення його світоглядних уявлень.

\section{References}

1. Artsyshevs'kyy R.A., Bondaruk S.O., Voznyak S.S. Lyudyna v suchasnomu sviti [Man in the modern world]. Kyiv: VTF «Perun», 1997. $221 \mathrm{p}$.

2. Bekh I. Vykhovannya osobystosti : Skhodzhennya do dukhovnosti [Education of personality: Ascent to spirituality]. Kyiv: Lybid', 2006. 272 p. 
3. Hessen S. Y. Osnovy pedahohyky. Vvedenye $v$ prykladnuyu fylosofyyu [Fundamentals of pedagogy. Introduction to applied philosophy]. Moskva, «ShkolaPress», 1995. 448 p.

4. Hrytsenko YU. Mystetstvo v rozvytku khudozhn'o-estetychnoho svitohlyadu osobystosti: retrospektyvnyy analiz [Arts in the development of artistic and aesthetic worldview of the individual: a retrospective analysis]. Estetyka $i$ etyka pedahohichnoyi diyi. 2015. Issue 9. P. 131-139.

5. Zys' A. YA. Fylosofskoe myshlenye y khudozhestvennoe tvorchestvo [Philosophical thinking and artistic creativity]. - Moskva: Iskusstvo, 1987. 255 p.

6. Pet ko L.V. Lingvosociokulturnyj pidhid u vyvchenni anglomovnoyi novorichnoyi pisni «Jingle Bells» [Lingvosociocultural Approach to Teaching American New Year's Song «Jingle Bells»] // Topical issues of redagogy : Collective monograph. - Edizioni Magi, Roma, Italy, 2019. P. 31-57.

7. Pet'ko L.V. Shljahy formuvannja inshomovnoi' sociokul'turnoi' kompetencii' studentiv mystec'kyh special'nostej VNZ u procesi fahovoi' pidgotovky [The Ways of Formation of Foreign Language Socio-Cultural Competence of Students of Music-Pedagogical Specialties in Higher School in the Process of Professional Teaching]. Problemy pidgotovky suchasnogo vchytelja. 2012. Vol. 6. Part 3. Pp. 57-62.

8. Tselkovnykov B.M. Myrovozzrenye pedahoha-muzykanta $v$ poyskakh smysla. Yssledovanye [The worldview of a music teacher in search of meaning.] / Otv. red É. Abdullyn. Moskva, 1999.

9. Shevchenko G. P. Khudozhestvenno-esteticheskaya vospitannost' i obrazovannost' lichnosti kak neobkhodimoye usloviye formirovaniya yeye kul'tury [Artistic and aesthetic upbringing and education of the individual as a necessary condition for the formation of its culture.]. Science and Education a New Dimension: Pedagogy and Psychology. Vol. 9. 2013. Pp. 149-155.

10. Shcholokova O.P. Svitohlyadna spryamovanist' fakhovoyi pidhotovky vchytelya mystets'kykh dystsyplin [Worldview orientation of professional training of teachers of art disciplines]. Teoriya i metodyka mystets'koyi osvity. Naukovyi Chasopys NPU imeni M.P. Drahomanova. 2017. No. 22(27), Part 1. Pp. 3-8.

11. Shholokova O.P. Kompetentnisnyj pidhid u prosvitnyczkij diyalnosti vchytelya muzyky`. Naukovyj chasopy`s Nacionalnogo pedagogichnogo universy`tetu imeni M.P.Dragomanova. Seriya 14 : Teoriya i metodyka mysteczkoyi osvity : zb. nauk. pracz. 2011. Issue 11 (16). Pp. 15-19.

12. Pet'ko L.V. Development of students' cognitive activity in foreign language teaching by using analogy method // Actual problems of globalization: Collection of scientific articles. Midas S.A., Thessaloniki, Greece, 2016. P. 232-237.

13. Shcholokova Olga, Ding Yun. Pedagogical Principles of Young Pupils' Music Culture Formation in Piano Teaching Process. Intellectual Archive. 2015. Volume 4. No. 6 (November). Toronto : Shiny Word Corp., 2015. Pp. 160-169. 
Translation of the Title, Abstract and References to the Author's Language УДК: 378.016:780.616.432

Чжан Цзянань. Методика формування світоглядної культури майбутніх учителів музичного мистецтва у процесі фортепіанного навчання.

У статті висвітлено особливості впровадження методики формування світоглядної культури студентів факультетів мистецтва педагогічних університетів в умовах фортепіанного навчання. Виокремлено провідні напрямки методичного забезпечення фортепіанної підготовки студентів, а саме: активізація пізнавально-виконавських інтересів і потреб студентів, збагачення їх музично-теоретичних знань на основі виконавського репертуару; розвиток виконавських умінь і навичок для створення емоційно-образних уявлень у процесі навчання гри на фортепіано. Представлено методичні заходи щодо формування світоглядної культури на основі розроблених критеріїв та показників визначених компонентів. Обгрунтована ефективність запропонованої методики в умовах фортепіанного навчання на всіх етапах навчального процесу.

Ключові слова: світоглядна культура, вчитель музичного мистецтва, фортепіанне навчання, методика формування світоглядної культури.

\section{Лimepamypa}

1. Арцишевський Р.А., Бондарук С.О., Возняк С.С. Людина в сучасному світі. Київ : ВТФ «Перун», 1997. 221 с.

2. Бех І. Виховання особистості : Сходження до духовності : [наук. видання] Київ: Либідь, 2006. 272 с.

3. Гессен С.И. Основы педагогики. Введение в прикладную философию. Москва : «Школа-Пресс», 1995. 448 с.

4. Гриценко Ю. Мистецтво в розвитку художньо-естетичного світогляду особистості: ретроспективний аналіз. Естетика і етика педагогічної дії. 2015. Вип. 9. С. 131-139.

5. Зись А.Я. Философское мышление и художественное творчество. Москва : Искусство, 1987. 255 с.

6. Петько Л.В. Лінгвосоціокультурний підхід у вивченні англомовної новорічної пісні «Jingle Bells» // Topical issues of redagogy : Collective monograph. - Edizioni Magi, Roma, Italy, 2019. P. 31-57.

7. Петько Л.В. Шляхи формування іншомовної соціокультурної компетенції студентів мистецьких спеціальностей ВНЗ у процесі фахової підготовки. Проблеми підготовки сучасного вчителя: зб. наук. пр. Уманського держ. пед. ун-ту імені Павла Тичини. Умань : ПП Жовтий О.О., 2012. Випуск 6. Ч. 3. С. 57-62.

8. Целковников Б.М. Мировоззрение педагога-музыканта в поисках смысла. Исследование / отв. ред Э. Абдуллин. Москва, 1999.

9. Шевченко Г.П. Художественно-эстетическая воспитанность и образованность личности как необходимое условие формирования ее культуры. Science and Education a New Dimension: Pedagogy and Psychology. 2013. Vol. 9. P. 149-155. 
10. Щолокова О.П. Світоглядна спрямованість фахової підготовки вчителя мистецьких дисциплін. Теорія і методика мистещькоӥ освіти. Науковий часопис НПУ імені М.П. Драгоманова. 2017. Вип. № 22(27). Ч.1. С. 3-8.

11. Щолокова О.П. Компетентнісний підхід у просвітницькій діяльності вчителя музики. Науковий часопис Національного педагогічного університету імені М. П. Драгоманова. Серія 14 : Теорія і методика мистецької освіти : зб. наук. праць. Київ : Видво НПУ імені М. П. Драгоманова, 2011. Вип. 11 (16). С. 15-19.

12. Pet'ko L.V. Development of students' cognitive activity in foreign language teaching by using analogy method // Actual problems of globalization: Collection of scientific articles. Midas S.A., Thessaloniki, Greece, 2016. P. 232-237.

13. Shcholokova Olga, Ding Yun. Pedagogical Principles of Young Pupils' Music Culture Formation in Piano Teaching Process. Intellectual Archive. 2015. Volume 4. No. 6 (November). Toronto : Shiny Word Corp., 2015. Pp. 160-169. 


\title{
Commissioning of Sole Micropiles with Foundation Slabs into Compatible Construction During the Foundation Strengthening of an Existing Building
}

\author{
Demchyna Bohdan, \\ Doctor of Engineering, Professor. National University «Lviv Polytechnic» \\ ORCID:0000-0002-3498-1519 (Lviv, Ukraine) \\ Kunanets Iurii \\ Postgraduate. National University «Lviv Polytechnic» \\ orcid.org/0000-0003-3171-5394 (Lviv, Ukraine)
}

\begin{abstract}
.
Strengthening the foundation is one of the fundamental stages of reconstruction or restoration of a building. Deformation of structures, in particular foundations, occurring in the process of long-term operation of buildings and structures. The main processes affecting the destruction, deformation and shrinkage of the foundations and foundations of buildings are the increase of load, destruction of masonry, reduction of waterproofing properties, deterioration of the stability of foundations or soils in their base, the increased deformability of soils, unacceptable movement of structures. For example, superstructure with the increase of loads on the foundations is accompanied by the restoration of the process of subsidence of the building. Many houses are superstructed, time repeatedly. To a large extent, the deformability of foundations is affected by the physical impact, i.e. construction activities that take place in the city - the development of subways, tramways, trails, engineering systems that provide the dynamic impact on the foundation from the outside.

To solve these problems, foundations are often strengthened using multi-section indentation piles and a monolithic reinforced concrete slab, which is connected to the foundations of the building. This method is quite common, especially when there are difficult conditions and limited access.

Strengthening of foundations of the existing building of the Faculty of Law of Ivan Franko National University of Lviv on 14 Sechenov Streltsov Street in Lviv was carried out using indentation piles. To improve the efficiency of new foundations, piles were included in the work.

The difficulty lies in the fact that the reinforced foundations and the existing foundations work in different conditions and it is necessary that their settlement in the process of operation was the same. Immediately after the performance of strengthening, the piles should be included in the joint work with the reinforced concrete foundation slab to work the building together with the foundations foundation soil, rather than after several years of independent settlement of the structure and loading of the strengthening piles with it.

This article also describes a technique of the additional inclusion of tubular-concrete micropiles in joint work with the foundation slab, which allowed to considerably reduce the development of the building trichenouts and settlements after putting it into operation.
\end{abstract}

Key words. reinforcement; micropiles; indentations; reconstruction; foundations.

Актуальність дослідження. На сьогоднішній день у Львові та в інших містах 3 історичною забудовою є значна кількість споруд, які потребують підсилення. Як правило ці споруди вимагають в першу чергу підсилення фундаментів. Процес реконструкції цих будинків ускладнюють такі фактори, як щільна забудова [1], складні геологічні умови, обмежений простір в підвальних приміщеннях та ін.. Враховуючи ці фактори, на сьогодні досить активно застосовують метод підсилення фундаментів із використанням трубобетонних багатосекційних паль [2,3], які вдавлюються через отвори-вікна у залізобетонній фундаментній плиті, після чого 
оголовки паль об'єднують з плитою. Особливістю даного методу є необхідність додаткового включення в сумісну роботу палевих фундаментів із існуючою спорудою.

Тому $є$ необхідність в розробці методики включення паль в сумісну роботу 3 фундаментною плитою заведеною у фундаменти існуючої споруди. Цьому питанню присвячена дана робота.

Аналіз останніх досліджень і публікацій. Дослідженнями несучої здатності багатосекційних вдавлюваних мікропаль невеликого діаметру присвячені роботи [4-7]. Вагомим вкладом у дослідження роботи цих ропаль є також робота [8] у якій була розроблена та досліджена раціональна конструкція наконечника палі, встановлено величину максимального зусилля вдавлювання, а також виявлено, що несуча здатність вдавлених паль по грунту збільшується із часом їх відпочинку, а саме через 5років до 17\%. Ефективність застосування вдавлюваних мікропаль при реконструкції підтверджено в роботі [9].

Мета і задачі дослідження. Метою дослідження є розробити методику включення паль в сумісну роботу із залізобетонною плитою, яка заведена у фундаментні стіни підвалів будівлі.

Виклад основного матеріалу. Включення паль в сумісну роботу із залізобетонною фундаментною плитою необхідно виконати для спільної роботи будівлі із грунтом основи одразу після виконання підсилення фундаментів, а не через декілька років самостійного осідання споруди та привантаження нею паль підсилення. Необхідність такого додаткового включення паль в сумісну роботу з підсилюваною будівлею була доказана під час підсилення будівлі юридичного факультету ЛНУ ім. Ів.Франка по вул. Січових Стрільців, 14 у м.Львові.

До початку виконання включення паль в сумісну роботу з будівлею були виконані наступні роботи: забетонована залізобетонна фундаментна плита (1), яка виконувала роль ростверкової плити (рис. 1,2.) зі спеціальними отворами-вікнами (2) та анкерами для кріплення установки, якою в подальшому вдавлювалися палі (3). Всього на об'єкті було вдавлено 315 трубобетонних мікропаль, діаметром металевих труб 159 мм, на глибину до 4,5 ..5,5 м, секціями довжиною по 0,5 .. 1 м. Після вдавлювання в середину труб встановлювався арматурний каркас та велося бетонування внутрішньої частини труби. Металеві труби вдавлювалися спеціальною установкою, яка кріпилася до 
анкерів монолітної плити. При цьому, окремі секції труб зварювалися в процесі вдавлювання між собою. Мікропалі вдавлювалися контрольованим зусиллям $300 \mathrm{kH}$. Очікувана несуча здатність палі $\mathrm{F}=300 / 1.4=214$ kН. Статичне випробування палі згідно стандартної методики, [10] показало її несучу здатність 270/1.2=225kH >214kH.

Готові палі витримувалися не менше 1-го місяця, після чого виконували включення паль в сумісну роботу із залізобетонною плитою згідно розробленої методики.

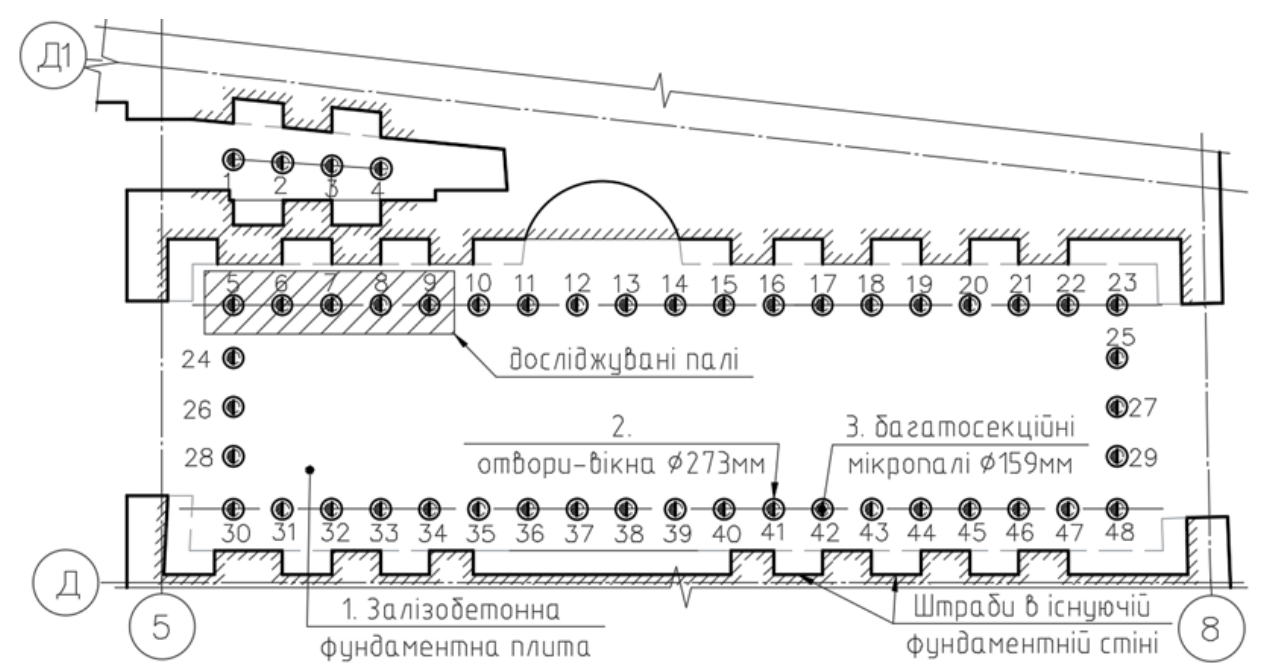

Рис. 1. Фрагмент план-схеми розташування паль

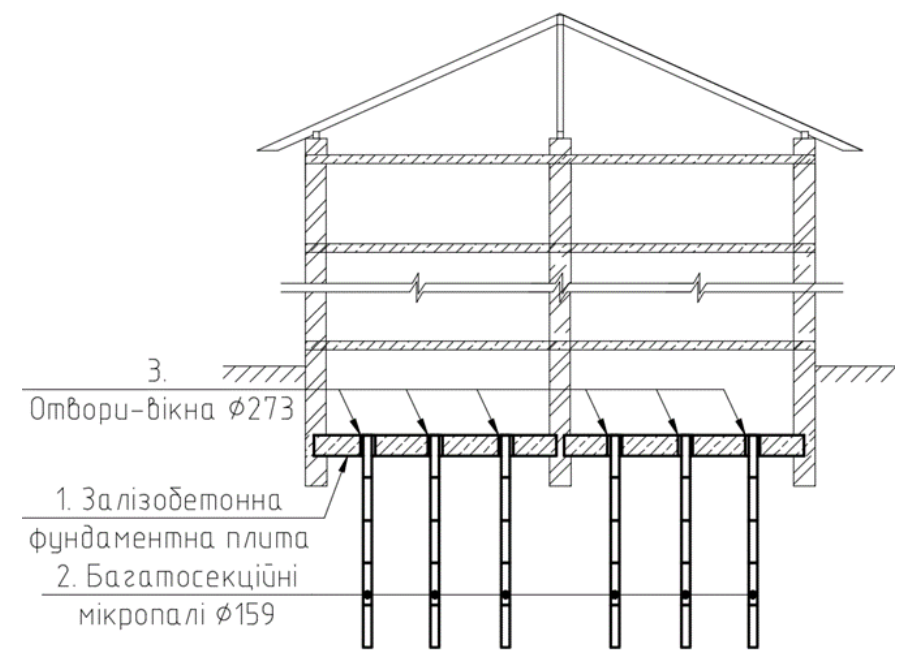

Рис. 2. Схематичний розріз будівлі

Методика проведення випробувань. Основною метою випробувань було дослідити роботу паль під час їхнього додавлювання. Виконувався контроль зусиль, додаткового вдавлювання 
та додаткових осадок паль по всьому палевому полю. Включення в спільну роботу із залізобетонною плитою відбувалося від осі Д1, де була найбільша осадка споруди, в напрямку осі А, де осадка споруди була найменшою (рис. 3,4).

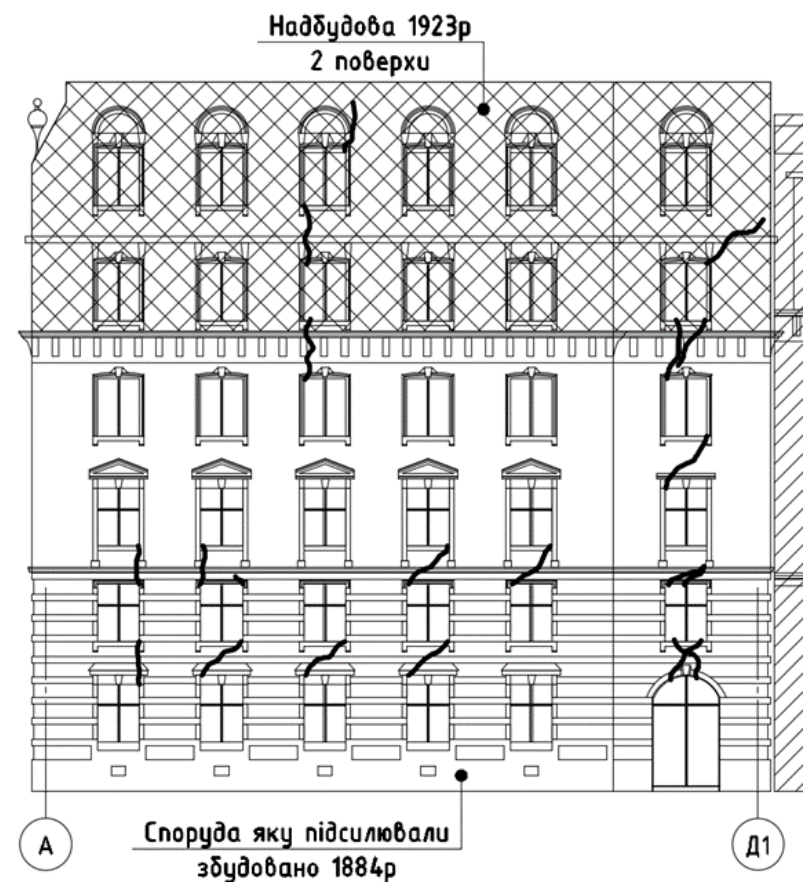

Рис. 3. Схема розташування тріщин в зовнішній стіні на фасаді в осях А-Д1

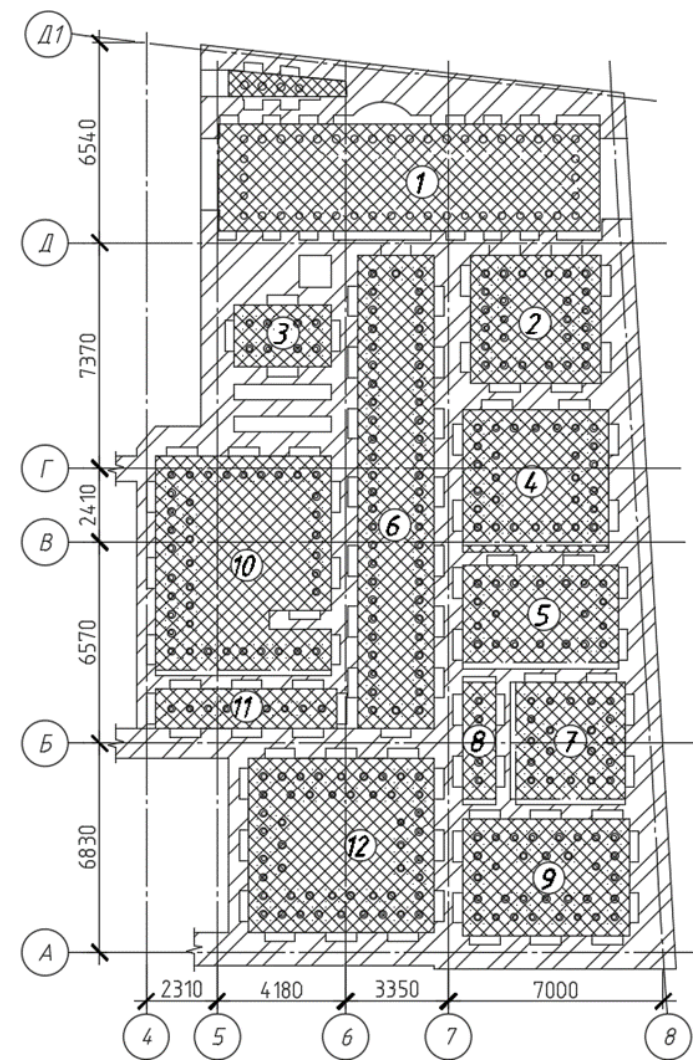

Рис. 4 План-схема груп паль 3 нумерацією по черзі виконання додавлювання

На рис. 5 представлено силовий стенд, який використовувався для додавлювання паль. Додаткове навантаження паль здійснювалось методом термічного нагрівання анкерів (1) в процесі їх охолодження, зусилля передавалось через систему траверс та наставки (2) на палі.

Нагрівання-охолодження анкерів відбувалося в два етапи: на першому етапі температура нагріву склала до $350{ }^{\circ} \mathrm{C}$, на другому етапі до $400{ }^{0} \mathrm{C}$. Температуру нагріву анкерів контролювали за допомогою пірометра. Контроль зусилля, яке діяло на палю визначали за допомогою кільцевого динамометра (3). Осадку палі визначали за допомогою двох прогиномірів Аістова (4). Після другого етапу нагрівання анкерів, палю приварювали через металеві пластини до стінок отворів-вікон (5), які були виконані з металевих труб діаметром 273мм. 


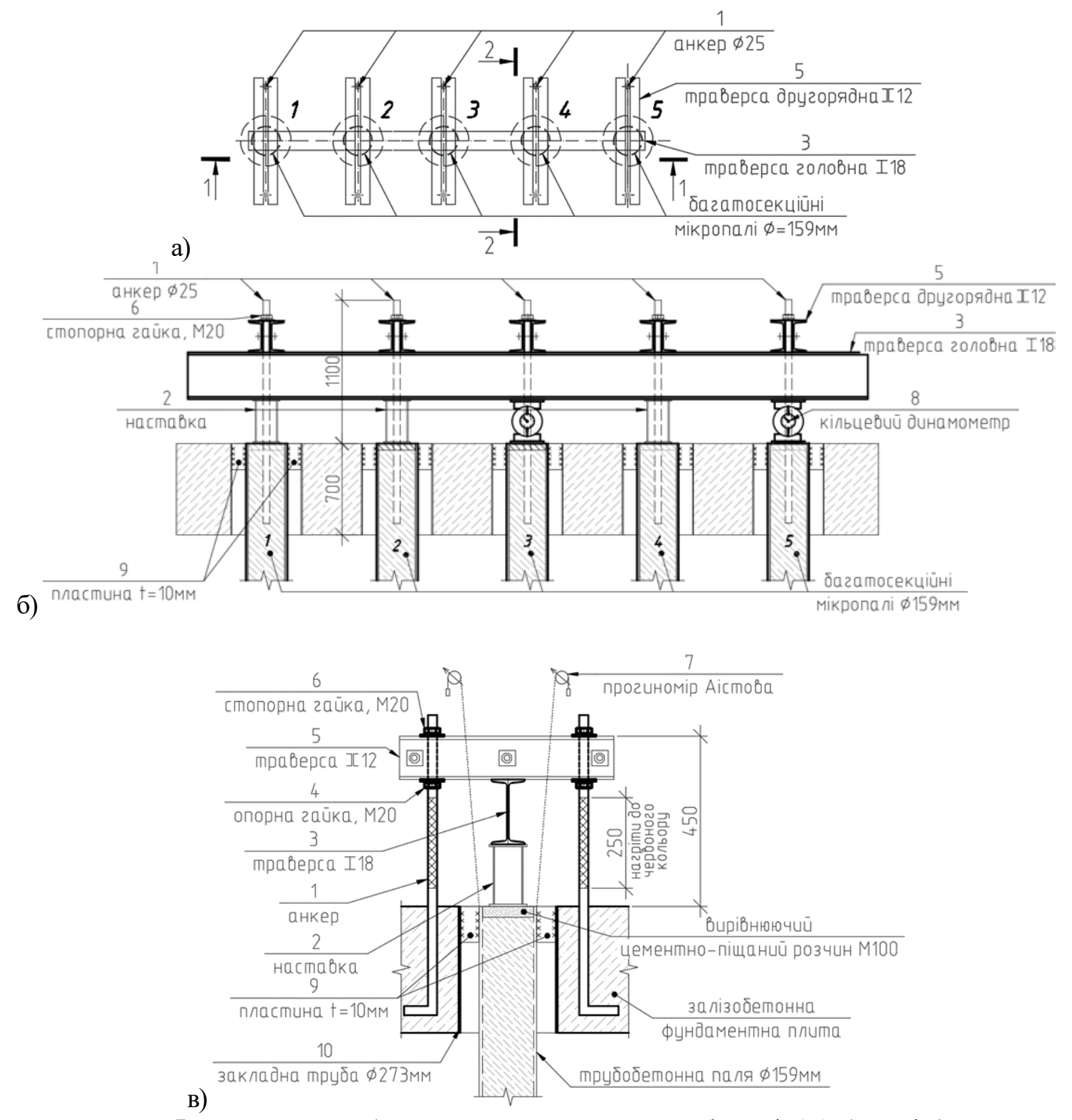

Рис .5 Силовий стенд: а) План-схема силового стенду, б) Розріз 1-1, в) Розріз 2-2.

Методика включення паль в сумісну роботу з фундаментною ростверковою плитою, а через неї з будівлею проводилась за наступною послідовністю:

1. Вирівнювалися оголовки паль за допомогою цементно-піщаного розчину марки М100.

2. Встановлювалася система траверс $(3,5)$, наставки (2) та кільцеві динамометри (8).

3. Підтягувалися стопорні гайки (6) на анкерах (1).

4. Встановлювалися прогиноміри Аістова (7).

5. Відпускалися опорні гайки (4). 
6. Нагрівали почергово анкери (1), до червоного кольору, на довжину до 250мм, в два послідовних етапи з одночасним підкручуванням стопорних гайок(6).

7. Після охолодження анкерів (1) приварювались металеві пластини (9) до стінок закладних гільз (10). (пластини розмістили навколо палі навхрест - по чотири пластини на одну палю).

8. Після зварювання всіх паль з гільзами було знято стопорні гайки, демонтовано силовий стенд та забетоновано простір між палею та гільзою.

Загальний вигляд силового стенду для дослідження паль в процесі їх додавлювання представлено на рис.6.

a)

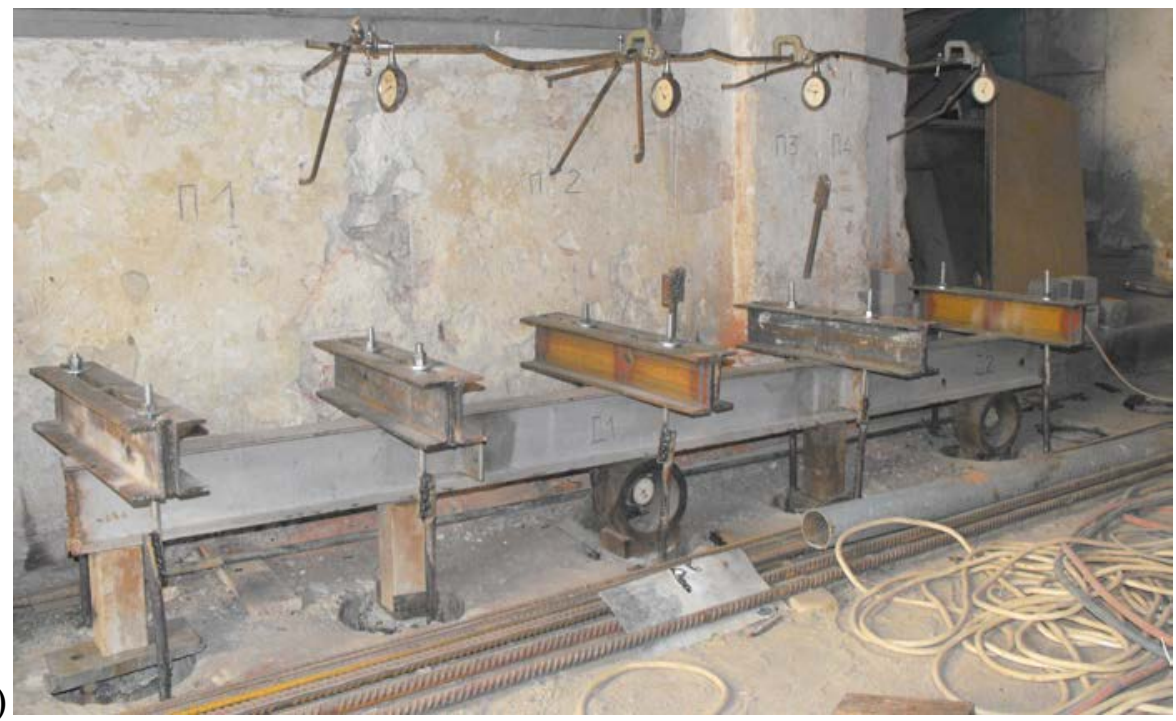

б)

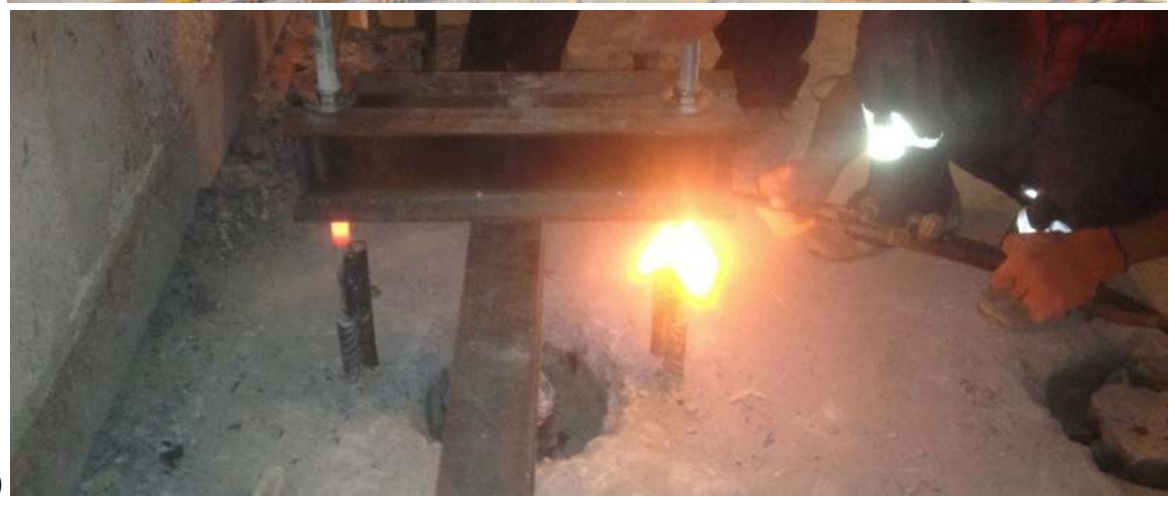

Рис .6 Вигляд силового стенду для дослідження паль в процесі їх додавлювання:

а) загальний вигляд; б) нагрівання анкерів газовим пальником.

Результати випробувань представлені у вигляді графіків залежності «навантаження осідання» для груп дослідних паль. На графіках відображено усереднені значення по дослідних 
палях у кожної групи, рис. 7. Кожен графік складається з двох прямих, які відображають осідання паль під час двох етапів нагрівання анкерів.

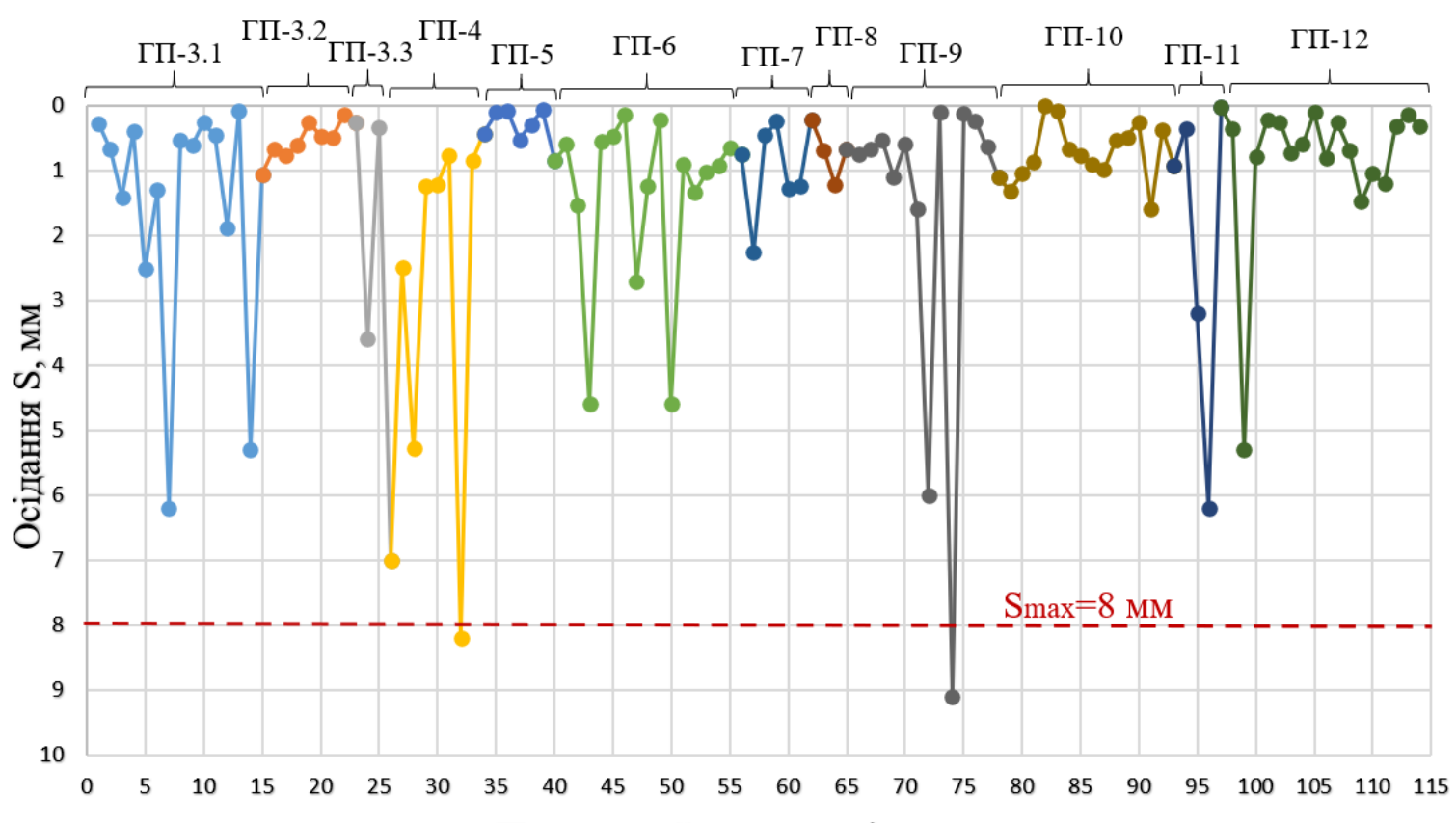

Порядковий номер палі

Рис .7 6 Діаграма осідань дослідних паль.

Результати подані на графіках показують, що додаткове усереднене осідання паль склало від 0,5 до 2,0 мм, проте в 8\% паль спостерігались граничні значення від 5 до 9.1 мм при зусиллях додавлювання 40...70 кН, що складали до 40\% від розрахункової несучої здатності паль рівній 179 кН, та до 32\% від експериментальної несучої здатності паль рівній 225 кН. Такі результати підтверджують необхідність додавлювання паль перед їх закріпленням до фундаментної ростверкової плити.

\section{Висновки:}

1. В результаті виконаного додавлювання трубобетонних мікропаль після їхнього «відпочинку» більше 1-го місяця у вказаних інженерно-геологічних умовах встановлено, що після прикладання до паль зусилля, яке складали 18..36\% від розрахункового навантаження на палю, додаткові середні осідання були в межах від 0,5мм до 5.3мм, проте у 8\% паль спостерігались осадки близькі до граничних від 5,5 до 9.1 мм.

2. -Виконані дослідження підтвердили необхідність виконання додаткового додавлювання паль після їх «відпочинку» перед їх включенням в сумісну роботу з посилюваною будівлею через монолітну залізобетонну ростверкову плиту, що більш рівномірно включить ростверк в 
роботу і суттєво зменшить можливість утворення додаткових тріщин в будівлі зразу після іï введення в експлуатацію.

\section{References}

1. $\quad$ DBN B.1.2-12-2008. Budivnictvo v umovah ushilnenoyi zabudovi. K.: Minregionbud Ukrayiny, 2008. 44 p.

2. VBN V.2.1-36-2-2002. Pidsylennia fundamentiv budivel ta sporud bahatosektsiinymy vdavliuvanymy paliamy. ZAT "Ukrhidrospetsbudproekt". Kyiv: Ukrmontazhspetsbud, 2003. 38 p.

3. Micropile Design and Construction. Report No. FHWA-NHI-05-039, United States Department of Transportation, 2005

4. Lebeda O.F., Korniienko M.V., Movchan V.O., Voroniuk O.A. Doslidzhennia nesuchoi zdatnosti bahatosektsiinoi vdavliuvanoi pali nevelykoho diametru $\mathrm{v}$ gruntovykh umovakh kyivskoho lesovoho plato. Osnovy i fundamenty. Kyiv. 2008. Vyp. 31. pp. 47-57.

5. Lebeda O.F., Korniienko M.V., Litnarovych Ye.V., Movchan V.O. Osoblyvosti pidsylennia fundamentiv pamiatky arkhitektury - kontory tsukrozavodchyka Kharytonenka v m.Sumy. Svit heotekhniky. Zaporizhzhia. 2016. Vyp. 31. pp. 30-33.

6. Demchyna B.H., Morklianyk B.V., Bazylevych Ya.O., Pelekh T.B. Pidsylennia fundamentiv budynkiv pid chas yikh rekonstruktsii u m. Lvovi. Arkhitekturnyi visnyk. Lviv. 2001. Vyp. 1. pp. 34-35.

7. Onyskiv B.M., Demchyna B.H., Soroka Ya.V., Kaniuk V.M. Pidsylennia fundamentiv zalizobetonnymy buronabyvnymy mikropaliamy pid chas rekonstruktsii budynkiv v umovakh sutsilnoi zabudovy. Teoriia i praktyka budivnytstva. Lviv. 2004. Vyp. 520. pp. 209-213.

8. Morklianyk B.V. Pidsylennia fundamentiv isnuiuchykh budynkiv na slabkykh gruntakh metodom vdavliuvannia pal: dys. ... kand. tekhn. nauk: 05.23.02. Naukovo-doslidnyi instytut budivelnykh konstruktsii. Kyiv. 2005. 140 p.

9 Demchyna B.H., Kunanets Y.M. Surmai M.I. Application of pressed pipe-concrete piles, at reconstruction of the engineering and laboratory case PAT "Khmelnytskoblenergo". Building Structures. Theory and Practice. Kyiv. 2020. Issue 6. C.64-71.

10. DSTU B V.2.1-1-95. Hrunty. Metody polovykh vyprobuvan paliamy. - K.: Derzhkommistobuduvannia Ukrainy, 1996. 63 p.

\section{Translation of the Title, Abstract and References to the Author's Language}

\section{УДК 624.154 \\ Демчина Б., Кунанець Ю. Включення трубобетонних мікропаль в сумісну роботу з фундаментною плитою при підсиленні існуючої споруди}

Анотація. Зміцнення фундаменту є одним з основоположних етапів реконструкції або реставрації будівлі. Деформації конструкцій, зокрема фундаменту, відбуваються в процесі тривалої експлуатації будівель і споруд. Основними процесами, що впливають на руйнування, деформацію і усадку основ і фундаментів будівель, є збільшення навантаження, руйнування кладки, зниження гідроізолюючих властивостей, погіршення умов стійкості фундаментів або грунтів у їх основі, збільшення деформативності грунтів, неприпустиме переміщення конструкцій. Наприклад, надбудова 3 збільшенням навантажень на фундаменти супроводжується відновленням процесу осідання будівлі. Безліч будинків надбудовують, часом неодноразово. В значній мірі на деформативність фундаменту впливає фізичний вплив, тобто будівельні роботи, які проводяться в місті - розвиток метрополітену, трамвайних шляхів, трас, інженерних систем, які надають динамічний вплив на фундамент ззовні.

Для вирішення цих проблем часто застосовують метод підсилення фундаментів 3 допомогою багатосекційних вдавлюваних паль та монолітної залізобетонної плити, яка з'єднюється з фундаментами споруди. Даний метод $є$ досить поширеним, особливо коли $є$ складні умови та обмежений доступ. 
Було виконано підсилення фундаментів існуючої будівлі юридичного факультету ЛНУ ім. Ів.Франка по вул. Січових Стрільців, 14 у м.Львові з використанням вдавлюваних паль. Для підвищення ефективності нових фундаментів, палі включали в роботу.

Складність полягає в тому, що підсилені та існуючі фундаменти працюють в різних умовах i потрібно щоб їх осадки в процесі експлуатації були однаковими. Одразу після виконання підсилення, палі необхідно включити в сумісну роботу із залізобетонною фундаментною плитою для спільної роботи будівлі із грунтом основи фундаментів, а не через декілька років самостійного осідання споруди та привантаження нею паль підсилення.

В даній статті описано спосіб та методику виконання додаткового включення трубобетонних мікропаль в спільну роботу із ростверковою фундаментною плитою, що дало змогу суттєво зменшити розвиток тріщиноутворень та осідань будівлі після введення їі в експлуатацію.

Ключові слова. підсилення; мікропалі; вдавлювання; реконструкція; фундаменти.

Лimepamypa
1. ДБН В.1.2-12-2008. Будівництво в умовах ущільненої забудови. К.: Мінрегіонбуд України, 2008. 44 с.

2. ВБН В.2.1-36-2-2002. Підсилення фундаментів будівель та споруд багатосекційними вдавлюваними палями. ЗАТ "Укргідроспецбудпроект". Київ: Укрмонтажспецбуд, 2003. 38 с.

3. Micropile Design and Construction. Report No. FHWA-NHI-05-039, United States Department of Transportation, 2005

4. Лебеда О.Ф., Корнієнко М.В., Мовчан В.О., Воронюк О.А. Дослідження несучої здатності багатосекційної вдавлюваної палі невеликого діаметру в грунтових умовах київського лесового плато. Основи і фундаменти. Київ. 2008. Вип. 31. C. 47-57.

5. Лебеда О.Ф., Корнієнко М.В., Літнарович Є.В., Мовчан В.О. Особливості підсилення фундаментів пам'ятки архітектури - контори цукрозаводчика Харитоненка в м. Суми. Світ геотехніки. Запоріжжя. 2016. Вип. 31. С. 30-33.

6. Демчина Б.Г., Моркляник Б.В., Базилевич Я.О., Пелех Т.Б. Підсилення фундаментів будинків під час їх реконструкції у м. Львові. Архітектурний вісник. Львів. 2001. Вип. 1. С.34-35.

7. Ониськів Б.М., Демчина Б.Г., Сорока Я.В., Канюк В.М. Підсилення фундаментів залізобетонними буронабивними мікропалями під час реконструкції будинків в умовах суцільної забудови. Теорія і практика будівництва. Львів. 2004. Вип. 520. С.209-213.

8. Моркляник Б.В. Підсилення фундаментів існуючих будинків на слабких грунтах методом вдавлювання паль: дис. ... канд. техн. наук: 05.23.02 / Науководослідний інститут будівельних конструкцій. Київ, 2005. 140 с.

9 Демчина Б.Г., Кунанець Ю.М., Сурмай М.І. Застосування вдавлюваних трубобетонних паль, при реконструкції інженерно-лабораторного корпусу ПАТ «Хмельницькобленерго». Будівельні конструкції. Теорія і практика. Київ. 2020. Вип.6. С.64-71.

10. ДСТУ Б В.2.1-1-95. Грунти. Методи польових випробувань палями. - К.: Держкоммістобудування України, 1996. 63с. 


\section{Manuscript Guidelines}

1. All submitted papers must contain the Title, Name of author(s), Affiliation (if any), Abstract and List of References (Literature) written in English. The Abstract must count not less than 100 and not more than 300 words and must be the good representation of your article. Optionally paper may also contain this information duplicated in another language.

2. Font faces. Arial, Times, Times New Roman, Courier New and Helvetica.

3. Language. You may use any language for your paper text, however English is MUCH preferable.

4. Title. Font size - 16, bold. Position - central alignment.

5. The author's name. Font size - 14, bold. Position - central alignment.

6. The affiliation (your University etc). Font size - 14, regular (not bold). Position - left alignment.

7. The word "Abstract". Font size - 12, bold-italics. Position - central alignment.

8. The text of the abstract. Font size - 10, regular (not bold).

9. The word "Keywords" (if any). Font size - 10, bold. Position - left alignment.

10. The text of keywords (if any). Font size - 10, regular (not bold). Position - left alignment.

11. Text of article. Font size - 14. Position - left alignment or fully justified. Line spacing - 1.5 lines.

12. The word "References" (if any). Font size - 12, bold-italics. Position - central alignment.

13. The text of References (if any). Font size - 12, regular (not bold).

In all other cases please use your own good judgment or contact our Editorial Board.

\section{Where to find us}

The "IntellectualArchive" is distributed to major libraries across Canada and the US, including

Library of Congress, USA (http://lccn.loc.gov/cn2013300046 ) ,

Library and Archives Canada

(http://collectionscanada.gc.ca/ourl/res.php?url_ver=Z39.88-2004\&url_tim=2012-09-

05T01\%3A46\%3A54Z\&url_ctx_fmt=info\%3Aofi\%2Ffmt\%3Akev\%3Amtx\%3Actx\&rft_dat=40904933\&r

fr_id=info\%3Asid\%2Fcollectionscanada.gc.ca\%3Aamicus\&lang=eng) and others.

The references to articles published in the "IntellectualArchive" are available in the

Google Scholar, (http://scholar.google.ca/scholar?q=\%22IntellectualArchive\%22 ),

Arxiv.org (http://search.arxiv.org:8081/?query=\%22Intellectual\%20Archive\%22\&in= ),

WorldCat.org (https://www.worldcat.org/search?q=n2\%3A1929-4700\&qt=advanced \&dblist=638 ) ,

Academia.edu

(http://www.academia.edu/15503799/Light_diffraction_experiments_that_confirm_the_STOE_model_and

_reject_all_other_models )

The National Research Council (Italy) (http://data.cnr.it/data/cnr/individuo/rivista/ID658222 )

Наукова бібліотека of the University named after Dragomanov, Ukraine

(http://enpuir.npu.edu.ua/handle/123456789/7974?mode=full )

Google.com (https://www.google.ca/\#q=site:IntellectualArchive.com ) thousands of links etc. 